\title{
Advanced Diesel Engine Component Development Program Final Report - Tasks 4-14
}

Detroit Diesel Corporation

Tony S. Kaushal

Karen E. Weber

November 1994

Prepared for

NATIONAL AERONAUTICS AND SPACE ADMINISTRATION

Lewis Research Center

Under Contract DEN 3-329

for

U.S. DEPARTMENT OF ENERGY Office of Transportation Technologies 


\section{DISCLAIMER}

This report was prepared as an account of work sponsored by an agency of the United States Government. Neither the United States Government nor any agency thereof, nor any of their employees, makes any warranty, expressed or implied, or assumes any legal liability or responsibility for the accuracy, completeness, or usefulness of any information, apparatus, product or process disclosed, or represents that its use would not infringe privately owned rights. Reference herein to any specific commercial product, process, or service by trade name, trademark, manufacturer, or otherwise, does not necessarily constitute or imply its endorsement, recommendation, or favoring by the United States Government or any agency thereof. The views and opinions of authors expressed herein do not necessarily state or reflect those of the United States Government of any agency thereof.

Printed in the United States of America

Available from

National Technical Information Service

U.S. Department of Commerce

5285 Port Royal Road

Springfield, VA 22161

NTIS price codes

Printed copy: A09

Microfiche copy: A01 


\section{DISCLAIMER}

\section{Portions of this document may be illegible in electronic image products. Images are produced from the best available original document.}




\section{FOREWORD}

The authors and DDC are grateful to Mr. John Fairbanks of the Department of Energy for supporting this work, and to Messrs. Richard Barrows and James Wood of the NASA Lewis Research Center for providing technical direction. The authors would also like to thank a number of individuals at DDC for their contributions to this program and in the assembly of this document. This includes Theo Freiheit, Mark Groeneweg, Al Warner, Rich Winsor, Leland Haines and Jim Hoelzer. 


\section{SUMMARY}

Diesel engine propulsion consumes over $25 \%$ of the U.S. transportation energy and dominates the heavy-duty transport sector because of its low fuel consumption and high reliability and durability. The application of new technology in cost-effective, evolutionary steps has increased fuel economy of diesel engines by over $25 \%$ in the past ten years.

The overall objective of the Advanced Diesel Engine Component Development (ADECD) Program is to develop and demonstrate critical technology needed to advance the heavy-duty low heat rejection (LHR) engine concept. The advanced diesel engine has potential for improved thermal efficiency, lighter weight, simpler design, and longer life. Major development activities reported are the design, analysis and fabrication of monolithic ceramic components, vapor phase and solid film lubrication, electro-hydraulic valve actuation and high pressure common rail injection.

The ADECD has been a highly successful program at Detroit Diesel Corporation (DDC). Evidence of this is provided by the fact that many of the advanced technologies developed (structural ceramic components, design methodologies and high pressure injection systems with electronic controls) were conceptually incorporated in production DDC Series 50 bus and Series 60 truck, bus, genset, construction and industrial engines.

An advanced single cylinder test bed (SCTB) was fabricated by DDC. This test bed is a laboratory tool in studying the many advanced technologies of the ADECD program, as well as other technologies necessary to meet the overall Heavy Duty Transport Technology (HDTT) program goals. The SCTB simulates the reciprocator for a system having no cooling system, turbo compounding, Rankine bottoming cycle, variable area turbocharger, common rail injection, and variable valve actuation to achieve fuel consumption of 160 $\mathrm{g} / \mathrm{kW}-\mathrm{hr}(.26 \mathrm{lb} / \mathrm{hp}-\mathrm{hr})$.

The advanced concepts were successfully integrated into the SCTB after proof of concept demonstration in laboratory tests. The confidence gained in ceramic components through these efforts led to the subsequent introduction of production ceramic components (cam roller follower and turbocharger rotor) in DDC multi-cylinder engines. In addition, emissions reduction was approached by the analysis and testing of engine components known to have factors which influence the particulate/NOx emissions trade-off. Modified components, including camshafts, injectors and ring packs, were designed, fabricated, and tested on a DDC Series 60 to quantify their influence on emissions. As a result, 1994 emission level requirements were first demonstrated during the ADECD program with production feasible hardware.

It should be noted that all ceramic components provided by suppliers met or exceeded their strength and reliability requirements. The ADECD program included one cermet and several monolithic ceramic components. A cermet piston ring was the lone monolithic cermet component. The firedeck, cast-in-place ports, valves, valve guides, piston cap, and 
piston ring were made from silicon nitride. All components were subjected to preliminary proof of concept testing, followed by successful integration into the SCTB.

Numerous breakthroughs were required to implement a "ceramic" engine. Some of these are the fabrication of air-gap cylinder heads, elimination of compression gaskets, machining of ceramic valve seats within the ceramic firedeck, fabrication of cast-in-place ceramic port liners, implementation of vapor phase lubrication, and elimination of the engine coolant system for LHR. In addition, design, analysis and proof-testing methodologies were developed for implementation of ceramic engine components. Specific technology related issues are discussed in this final report.

Silicon nitride valves were successfully developed, exceeding the design and durability criteria and meeting several production abuse test requirements using a DDC Series 60 valve train test fixture. These were then incorporated into the SCTB along with a ceramic valve guide and solid film lubrication. The ADECD cylinder head design also incorporated four (two intake and two exhaust) cast-in-place ceramic port shields to increase insulating effectiveness and exhaust energy recovery. The uncooled operating conditions of the engine imposed high thermal loads on these port shields. Fabrication and testing of the cylinder head ceramic components were major program successes.

The combustion chamber of the engine included the firedeck and piston cap, both of which were fabricated from monolithic silicon nitride. The tribological challenge posed by top piston ring reversal temperatures of $550^{\circ} \mathrm{C}$ was met through the development of vapor phase lubrication. A special lubricant, tricresyl phosphate, was investigated on a tribology test fixture and then applied to the critical ring-liner interface on the test engine. An electronic in-cylinder lubricant injection system was developed to inject precise quantities of tricresyl phosphate.

A solenoid-controlled, variable valve actuation system that eliminated the conventional camshaft was demonstrated on the SCTB. This system has the potential to revolutionize valve train design of heavy-duty engines, while improving fuel economy and emissions. High pressure fuel injection via a common rail system was also successfully demonstrated. The benefits of high injection pressures in reducing particulate emissions was verified on a DDC multi-cylinder Series 60 engine. Electronic unit injectors that develop over $200 \mathrm{MPa}$ peak injection pressure are now in production at DDC.

A number of engineering design, analysis and test methodologies for ceramic components and vapor phase lubrication are included in the report appendices for their interest to the critical reader. Based on the test results, this report recommends future development activities in the areas of advanced engine systems, advanced materials applications and NOx emissions reduction for heavy-duty engines. Technology infusion into the diesel industry is needed to improve fuel economy, reduce U.S. dependence on imported petroleum, and in reducing emissions for a cleaner environment. 


\section{LIST OF ACRONYMS}

\begin{tabular}{|l|l|}
\hline ADECD & Advanced Diesel Engine Component Development \\
\hline ADRE & Advanced Diesel Reference Engine \\
\hline BDC/BC & Bottom Dead Center/Bottom Center \\
\hline BOE & Beginning of Event \\
\hline BOI & Beginning of Injection \\
\hline BOL & Beginning of Lift \\
\hline BRR & Bottom Ring Reversal \\
\hline BSFC & Brake Specific Fuel Consumption \\
\hline BSNOx & Brake Specific NOx \\
\hline BSP & Brake Specific Particulates \\
\hline BTC & Before Top Center \\
\hline CKTTF & Cylinder Kit Tribology Test Fixture \\
\hline CRI & Common Rail Injection \\
\hline DDC & Detroit Diesel Corporation \\
\hline DDEC & DDC Electronic Engine Control \\
\hline DDPP & Diphenyl Ditertibutyl Phenyl Phosphate \\
\hline DOE & Department of Energy \\
\hline ECM & Electronic Control Module \\
\hline EDAX & Electron Dispersive X-ray Analysis \\
\hline EHVA & Electro-hydraulic Valve Actuation \\
\hline EOC & End of Combustion \\
\hline EOE & End of Event \\
\hline EUI & Electronic Unit Injector \\
\hline EVO & Exhaust Valve Open \\
\hline FEA & Finite Element Analysis \\
\hline FS & Fill/Spill \\
\hline GMC & General Motors Corporation \\
\hline HDTT & Heavy Duty Transport Technology \\
\hline HIP & Hot Isostatic Press \\
\hline IMEP & Indicated Mean Effective Pressure \\
\hline ISFC & Indicated Specific Fuel Consumption \\
\hline L/D & Length to Diameter Ratio \\
\hline LHR & Low Heat Rejection \\
\hline PO & Nitrous Oxides \\
\hline & Proof of Concept \\
\hline & Probability of Survival \\
\hline ulse Width \\
\hline
\end{tabular}




\section{LIST OF ACRONYMS}

\begin{tabular}{|l|l|}
\hline PWM & Pulse Width Modulation \\
\hline R & Ramp \\
\hline SAFE & Initial SCTB Valve Event \\
\hline SAFEX & Valve Event with $30^{\circ}$ Angular Clearance Between Valves \& Piston \\
\hline SAFEY & Valve Event with $10^{\circ}$ Angular Clearance Between Valves \& Piston \\
\hline SCTB & Single Cylinder Test Bed \\
\hline SEM & Scanning Electron Microscope \\
\hline SF & Solid Film \\
\hline SFC & Specific Fuel Consumption \\
\hline SLA & Surface Layer Activation \\
\hline SRB & Separated Ring Belt \\
\hline TBP & Tributyl Phosphate \\
\hline TC & Top Center \\
\hline TCP & Tricresyl Phosphate \\
\hline TDC/TC & Top Dead Center \\
\hline TEM & Transmission Electron Microscope \\
\hline TRR & Top Ring Reversal \\
\hline TRS & Timing Reference Sensor \\
\hline VAIF & Valve Actuator, Injector Fixture \\
\hline VCO & Valve Covered Orifice \\
\hline VOP & Valve Opening Pressure \\
\hline VP & Vapor Phase \\
\hline VPL & Vapor Phase Lubrication \\
\hline
\end{tabular}


SECTION I - INTRODUCTION

1.1 BACKGROUND.

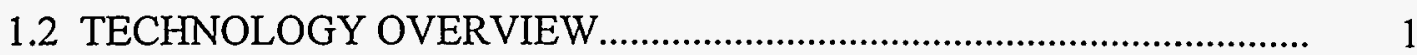

1.3 COMPONENT FABRICATION ............................................................

SECTION II - ADVANCED IN-CYLINDER COMPONENTS

2.1 CERAMIC FIREDECK AND CYLINDER HEAD ASSEMBLY .............. 5

2.2 PISTON CAP .............................................................................

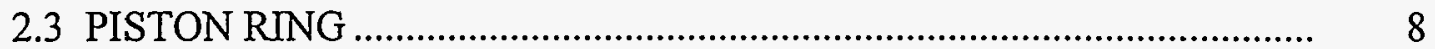

2.4 PISTON RING WEAR …………………………................................

2.5 DISTORTION MODELING OF IN-CYLINDER COMPONENTS.......... 14

2.6 L-SECTION RING DESIGN ……………………................................... 17

\section{SECTION III - ADVANCED CYLINDER HEAD COMPONENTS}

3.1 CERAMIC VALVE DEVELOPMENT .................................................... 22

3.2 CERAMIC VALVE GUIDE .............................................................. 23

3.3 CERAMIC CAST-IN-PLACE PORT .......................................................... 23

\section{SECTION IV - TRIBOLOGY}

4.1 SOLID FILM LUBRICATION.............................................................. 27

4.2 VAPOR PHASE LUBRICATION....................................................... 30

4.3 FIXTURE TESTING OF VAPOR PHASE LUBRICATION …………...... 31

4.4 ENGINE VAPOR PHASE DELIVERY SYSTEMS ................................. 34

4.5 IN-CYLINDER LUBRICANT INJECTION SYSTEM DESIGN.............. 39

4.6 PERFORMANCE COMPARISON OF LUBRICATION SYSTEMS........ 45

\section{SECTION V - ADVANCED ENGINE VALVE ACTUATION SYSTEM}

5.1 VARIABLE VALVE ACTUATION ....................................................... 53

5.2 METHOD OF OPERATION …….................................................... 54

5.3 FIXTURE DEVELOPMENT ................................................................ 56

5.4 ELECTRO-HYDRAULIC VALVE ACTUATION..................................... 62 


\section{TABLE OF CONTENTS}

\section{SECTION VI - ADVANCED ENGINE INJECTION SYSTEM}

6.1 COMMON RAIL INJECTION SYSTEM BENEFITS................................ 66

Injection Pressure Control ................................................................... 66

Lubrication System.......................................................................... 66

Injection System Efficiency .................................................................. 66

6.2 COMMON RAIL INJECTION SYSTEM RESULTS.................................. 67

\section{SECTION VII - SINGLE CYLINDER TEST BED}

7.1 SINGLE CYLINDER ENGINE \& TESTING .......................................... 72

7.2 BUILD \#1 ….......................................................................

7.3 BUILD \#2 2............................................................................

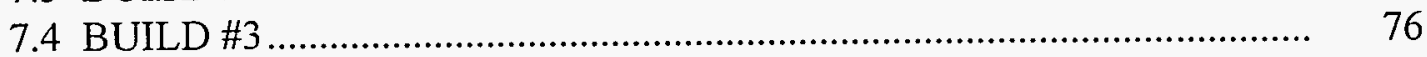

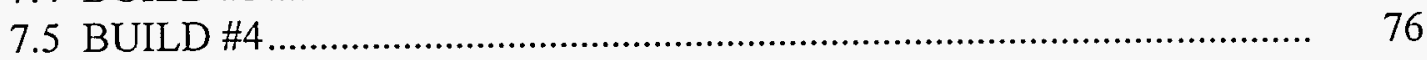

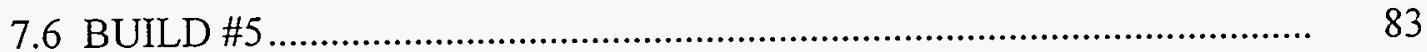

7.7 BUILD \#6 ............................................................................... 86

7.8 BUILD \#7 ............................................................................. 86

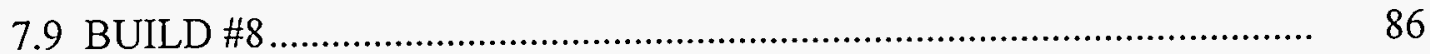

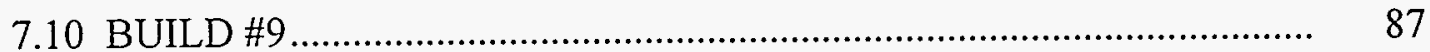

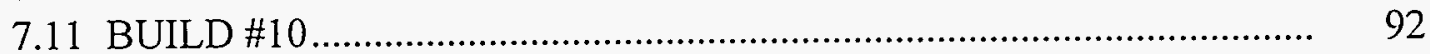

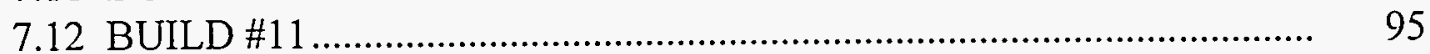

7.13 BUILD \#12 ............................................................................. 96

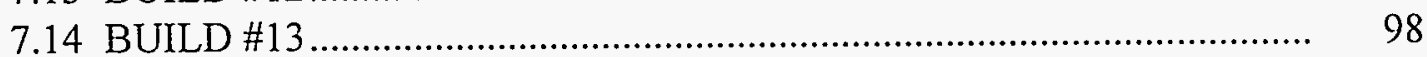

\section{SECTION VIII - ADVANCED EMISSIONS PARAMETRIC STUDIES}

8.1 VERY HIGH INJECTION PRESSURES .................................................. 100

8.2 INJECTOR COMPONENT PARAMETERS ............................................. 101

Injector Valve Opening Pressure ......................................................... 105

Low Sac versus Valve Covered Orifice Spray Tip Style ...................... 105

Tip Spray Hole Location ..................................................................... 106

Spray Tip Hole Length ..................................................................... 106

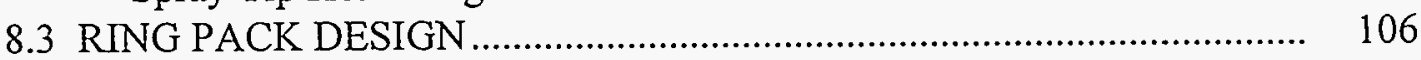

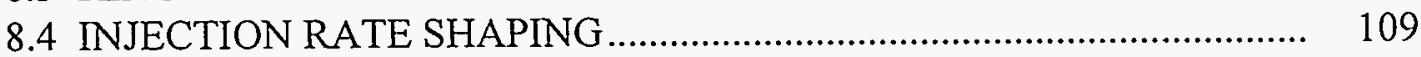

Dual Lift-Velocity Camshaft.................................................................. 109

Pressure Limiting Injector ................................................................... 112

Dual Spring Needle Valve Injector .................................................. 112 
TABLE OF CONTENTS

SECTION IX - RECOMMENDATIONS FOR FUTURE WORK

9.1 EMISSION REDUCTION

113

9.2 ADVANCED MATERIALS

113

9.3 ADVANCED ENGINE SYSTEMS.

APPENDIX A - ADECD GASKETLESS COMBUSTION SEAL STUDY ........... 115

Analysis ..................................................................................................... 115

Experimental Investigation of Cylinder Head ................................................ 122

APPENDIX B - CERAMIC VALVE DEVELOPMENT ......................................... 135

Initial Valve Geometry ............................................................................... 135

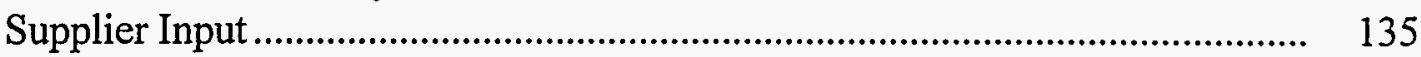

Material Selection...................................................................................... 135

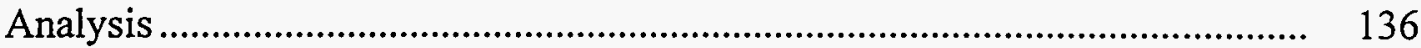

Supplier Selection and Procurement............................................................. 141

Proof of Concept Testing.................................................................................... 141

Engine Testing .................................................................................................. 144

APPENDIX C - FINITE ELEMENT ANALYSIS OF PORT SHIELD.................. 145

Recommendations ........................................................................................ 163

APPENDIX D - CYLINDER KIT TRIBOLOGY TEST FIXTURE RESULTS.... 165

Test Results ................................................................................................... 165

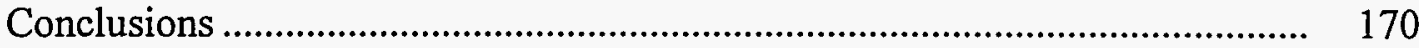




\section{LIST OF FIGURES}

Figure

Page

1 Advanced Technologies Integrated in the ADECD Single Cylinder

Test Bed....................................................................................... 2

2 Build \#6 Firedeck Temperature Distribution, $1600 \mathrm{r} / \mathrm{min} \& 30 \mathrm{~N}-\mathrm{m} . \ldots \ldots \ldots . . .6 \quad 6$

3 Build \#6 Cylinder Head Temperature Distribution, $1600 \mathrm{r} / \mathrm{min} \& 30 \mathrm{~N}-\mathrm{m}$. 6

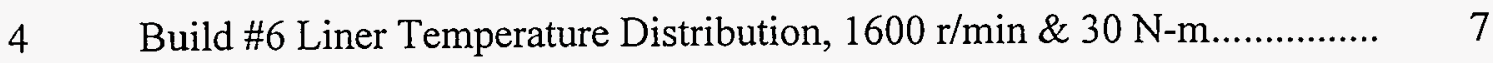

5 EDAX Analysis of Sample \#1 (TRR of the Liner) ..................................... 9

6 EDAX Analysis of Sample \#2 (BRR of the Liner) ..................................... 9

$7 \quad$ EDAX Analysis of Sample \#3 (Piston Ring) .............................................. 10

$8 \quad$ EDAX Analysis of Sample \#4 (Piston Cap) ................................................. 10

$9 \quad$ EDAX Analysis of Sample \#5 (Piston Body) ............................................. 11

10 Cermet Ring Wear vs. Time ( 0.1 Mole Percent Durad 125)..................... 11

11 Condition of Cermet Piston Ring, at End of Build \#9 Test......................... 13

12 Build \#9, Initial Failure Region of Cermet Headland Piston Ring............... 15

13 Liner Temperatures and Blowby (Build \# 11)........................................... 16

14 Effect of Temperature Gradient and Pressure Balance on Blowby .............. 18

$15 \quad$ Segmented L-Section Ring.............................................................. 19

$16 \quad$ Modified L-Section Ring Profile Comparison ............................................. 20

$17 \quad$ ADECD Cylinder Head Design............................................................ 24

18 Two-Band Cast-in-Place Port Shield............................................................ 25

19 SF Lubrication Test Results Nitralloy on Silicon Nitride (performed by Pennwalt) ....................................................................................... 28

20 SF Lubrication Test Results, Silicon Nitride on Silicon Nitride, (performed by Pennwalt) ......................................................................... 29

21 Cross-section of a Chamber of the CKTTF Test Fixture ............................. 32

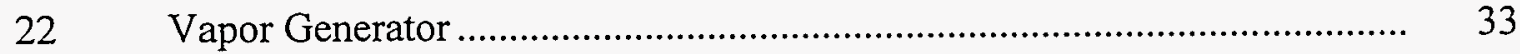

23 Original VPL System Schematic for the ADECD SCTB............................ 35

24 Typical Piston Ring Profile Traces (Various Low Load Engine Operation, 0.1 mole percent TCP VP Lubrication) ................................ 36

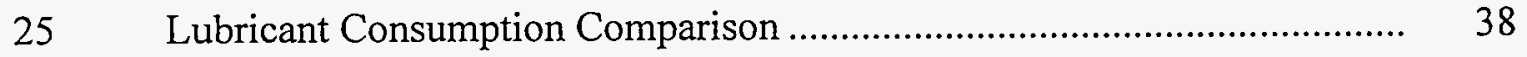

26 Electronically Controlled In-cylinder Lubricant Injector ............................. 40

27 Conceptual Schematic: Integration of an Electronically Controlled In-cylinder Lubricant Injector into a DDC Series 60 Engine.................. 41

28 In-cylinder Lubricant Rig ...................................................................... 


\section{LIST OF FIGURES}

Figure

Page

29 In-cylinder Lubricant Injector Data Injected Volume vs. Cavity Pressure ..

30 In-cylinder Lubricant Injector Data Number of Skipped Cycles

vs. Injected Volume

Ring Wear Comparison, Ring Mass Change.

Ring Wear Comparison, Radial Thickness Change

VPL Lubrication Concentration \& Wear.

VPL Lubrication Concentration \& Wear.

Liner Wear Comparison, Second Ring - Top Ring Reversal Wear Step.....

Liner Wear Comparison, Top Ring - Top Ring Reversal Wear Step.

Common Rail Injector and Valve Actuator, Injector Fixture.

A Typical Valve Event Produced by the Electro-hydraulic

Valve Actuator..

Rate of Injection Characteristic for the High Pressure Common

Rail System (delivering $167 \mathrm{~mm}$ at $1800 \mathrm{r} / \mathrm{min}$ ).

Blowby Comparison, Build \#5 vs. Build \#4.

Build \#10 Injection Event

Motoring Friction Power vs. Speed $\left(183 \mathrm{~mm}^{3}\right.$ fuel, SAFE valve event)....

Liner Temperature Profiles at $1500 \mathrm{r} / \mathrm{min}$, No Load,

Fully Configured SCTB

P-t and Valve Event Data $1500 \mathrm{r} / \mathrm{min}$, No Load, Fully Configured SCTB..

SAFEX vs. SAFE Valve Events.

Build \#10 Valve Event 


\section{LIST OF FIGURES}

57 In-Cylinder Temperatures \& Blowby Baseline Carrier Gas Run................ 97

58 In-Cylinder Temperatures \& Blowby Lubricant Injector Test Run ............ 99

59 Very High Injection Pressures - Transient Emissions .............................. 102

60 Very High Injection Pressures - Steady-State Low Power.......................... 103

61 Very High Injection Pressures - Steady-State High Power ......................... 104

$62 \quad$ Injector Spray Tip Style Comparison ................................................. 107

63 Lift-Velocity Comparison - Constant and Dual Velocity Cam .................. 110

64 Dual Velocity Cam - Transient Emissions Test Results........................... 111

65 ADECD Gasketless Combustion Seal Study Finite Element Model Geometries

66 Liner/Insert Joint Sealing Stress 4 Bolt Cylinder Head Configuration $14 \mathrm{~mm}$ Grade 10.9 Cylinder Head Bolts Bolt Up Only......................... 118

67 Liner/Insert Joint Sealing Stress 4 Bolt Cylinder Head Configuration $14 \mathrm{~mm}$ Grade 10.9 Cylinder Head Bolts Bolt Up +16.2 $\mathrm{MPa}$ Comb. Pressure

68 Liner/Insert Joint Sealing Stress 8 Bolt Cylinder Head Configuration 14mm Grade 10.9 Cylinder Head Bolts, Bolt Up Only........................ 120

69 Liner/Insert Joint Sealing Stress 8 Bolt Cylinder Head Configuration $14 \mathrm{~mm}$ Grade 10.9 Cylinder Head Bolts, Bolt Up +16.2 $\mathrm{MPa}$ Comb. Pressure

70 Liner/Insert Joint Sealing Stress 8 Bolt Cylinder Head Configuration $14 \mathrm{~mm}$ Grade 10.9 Cylinder Head Bolts $14 \mathrm{~mm}$ Grade 12.9 "Shared" Cylinder Head Bolts Bolt Up + 16.2 Comb. Pressure.

71 Liner/Insert Joint Sealing Stress

8 Bolt Cylinder Head Configuration

$14 \mathrm{~mm}$ Grade 10.9 Cylinder Head Bolts

$16 \mathrm{~mm}$ Grade 10.9 "Shared" Cylinder Head Bolts

Bolt Up + 16.2 MPa Comb. Pressure

$\begin{array}{lll}72 & \text { Cylinder Head - Top View, Strain Gage Locations Also Shown .................. } & 126 \\ 73 & \text { Cylinder Head - Section Thru Port................................................................ } & 127\end{array}$

$74 \quad$ Fixture Assembly.......................................................................... 128

$75 \quad$ Fixture Test - Mapping Leakage Pressure Versus Clamp Load ................. 130

76 Coulomb-Mohr Static Failure Criteria and Resulting Safety

Factors ADECD Cylinder Head 


\section{LIST OF FIGURES}

Figure

Page

77 Mean Alternating Stress Diagram - GM-13M Cast Iron........................... 134

78 Thermal Boundary Conditions for ADECD Silicon Nitride Ceramic Valves' Valve Head Transfer Analysis................................................. 137

79 ADECD Monolithic Silicon Nitride Valves ("Starting Point" vs.

Finalized Designs)

80 ADECD Monolithic Silicon Nitride Valve Stresses Due to

In-cylinder Loading

ADECD Monolithic Silicon Nitride Valve Stresses Due to Valve Closing.

140

82

Proof of Concept Testing Matrix for ADECD Ceramic Valve

ADECD Port Shield Finite Element Model

ADECD Port Shield Analysis - Casting Shrink Load Boundary

Conditions

ADECD Port Shield Analysis - Thermal Boundary Conditions

Silicon Nitride Port Shield Temperature Distribution (4mm Wall -

Two Band Design - $42 \mathrm{MPa}$ Mesh) Peak Torque

Conditions $\left({ }^{\circ} \mathrm{C}\right)$

Silicon Nitride Port Shield Temperature Distribution.(4mm Wall -

Two Band Design - $42 \mathrm{MPa}$ Mesh) Casting Shrink +

Thermal Load - Max. Principle Stress Outer Surface.

Silicon Nitride Port Shield Temperature Distribution (4mm Wall -

Two Band Design - 42 MPa Mesh) Casting Shrink +

Thermal Load - Max. Principle Stress Inner Surface.

89 Silicon Nitride Port Shield Temperature Distribution (4mm Wall -

Two Band Design - $42 \mathrm{MPa}$ Mesh) Casting Shrink +

Thermal Load - Min. Principle Stress Outer Surface.

90 Silicon Nitride Port Shield Temperature Distribution (4mm Wall -

Two Band Design - 42 MPa Mesh) Casting Shrink +

Thermal Load - Min. Principle Stress Inner Surface.

Ceramic Port Designs

92 Vapor Phase Lubrication CKTTF Phase 1 Ring Wear Results.

93 CKTTF Vapor Phase Lubrication Ring Wear Summary.

94 VP Lubrication Evaluation Results 


\section{LIST OF TABLES}

Table

Page

$1 \quad$ ADECD Advanced Concept Hardware ………........................................ 4

$2 \quad$ Ring and Liner Wear Comparison............................................................ 12

3 Engine Performance Comparison of Ring Pack Designs ............................. 21

$4 \quad$ Lubrication System Engine Performance Comparison................................... 47

$5 \quad$ Valve Actuator Response Data................................................................. 61

6 Comparison of Actual Common Rail Injection Parameters vs. Target Values ............................................................................. 67

$7 \quad$ Integration of Concepts into SCTB …………...................................... 72

$8 \quad$ ADECD SCTB Activity ………....................................................... 73

$9 \quad$ In Situ Ring Wear Measurements, Build \#4 ............................................. 79

10 ADECD SCTB Build \#5 Results........................................................... 85

11 BUILD \#9 Test Sequence...................................................................... 87

12 SCTB BUILD \#9 Performance Data $1800 \mathrm{r} / \mathrm{min}, 23$ Brake N-m, $-15^{\circ} \mathrm{BOI}$

13 SCTB BUILD \#9 Emissions Data $1800 \mathrm{r} / \mathrm{min}, 23$ Brake $\mathrm{N}-\mathrm{m}$, $-15^{\circ} \mathrm{BOI}$

14 SCTB- Build \#10, Performance and Emissions Data At 50\% Power Point

Cam Lift-Velocity and Injection Pressure

101

Injection Component Parameters - Transient Emissions.

105

Ring Pack Design for Oil Control - Transient Emissions

108

Injection Rate Shaping - Transient Emissions.

109

ADECD Gasketless Combustion Seal Study Finite Element Model Component Properties

ADECD Liner/Head Joint Sealing Stress Summary ...

122

Clamp Load vs. Leakage

ADECD Cylinder Head Calculated Stress Levels and Safety

Factors Under Clamp and Clamp Plus Pressure Load.

Test Cycle to Demonstrate Design Criteria................................................ 143

Test Cycle to Establish the Ceramic Valve Durability. 


\section{LIST OF TABLES}

Table

Page

26 ADECD Silicon Nitride Port Shield Analysis Effect of Mesh Stiffness on Port Stress-Casting Shrink Load (3mm Wall).............................. 152

27 ADECD Silicon Nitride Port Shield Analysis (4mm Wall-Two Band Design-42 MPa mesh) ................................................................. 152

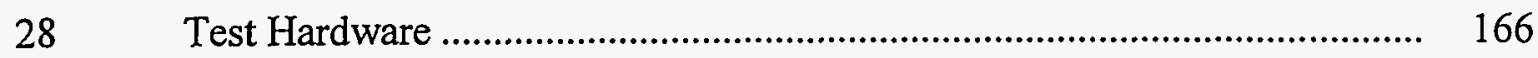

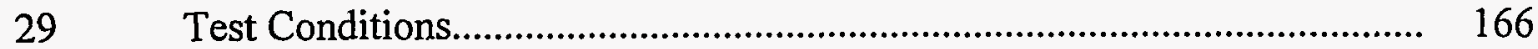




\section{SECTION I}

\section{INTRODUCTION}

\subsection{BACKGROUND}

The Advanced Diesel Engine Component Development (ADECD) Program is a multi-year, multi-phase effort to develop and demonstrate the critical technology needed to advance the heavy-duty low heat rejection (LHR) engine concept for the long-haul, heavy-duty truck market. The ADECD Program has been partitioned into two phases. The first phase, Phase I, was completed in 1986, resulting in definition of the Advanced Diesel Reference Engine (ADRE)[1]. The second phase, Phase II/III, examines the feasibility of the ADRE concepts for application to the on-highway diesel engine. Phase II/TII is currently underway.

This project is sponsored by the U.S. Department of Energy, Office of Transportation Technologies. The work has been performed by the Detroit Diesel Corporation (DDC) under Contract DEN3-329 with the NASA Lewis Research Center, who provide project management and technical direction.

\subsection{TECHNOLOGY OVERVIEW}

An advanced diesel engine has the potential for improved thermal efficiency, lighter weight, simpler design, and longer life. Significant structural, material, and tribological problems must first be overcome to bring this technology to the marketplace.

This report summarizes program efforts in the 1986-92 time period. Specifically, the following Phase II/III activities: fabrication of several advanced concepts, preliminary proof of concept evaluation, and single cylinder engine testing will be reported. Major development activities reported are the design, analysis, fabrication and testing of monolithic ceramic components (Sections II and III), tribology (Section IV), electrohydraulic valve actuation (EHVA, Section V) and high pressure common rail injection (CRI, Section VI).

An advanced single cylinder test bed (SCTB) was fabricated for this investigation. This laboratory test bed is based on a conventionally lubricated engine with special features such as the extended piston incorporated to study vapor phase lubrication and ceramic components in a high temperature environment. Each of the advanced concepts that are reported in Sections II through VI was successfully integrated into the SCTB after proof of concept demonstration in laboratory tests. See Figure 1 - ADECD SCTB Schematic. The evaluation of the integrated advanced technology concepts is reported in Section VII in the form of consecutive SCTB Build numbers 1 through 13. Section VIII covers developments related to the reduction of particulate emissions including the development of very high pressure fuel injectors. This concept has been successfully implemented by DDC in production engines that meet 1994 emission standards. 


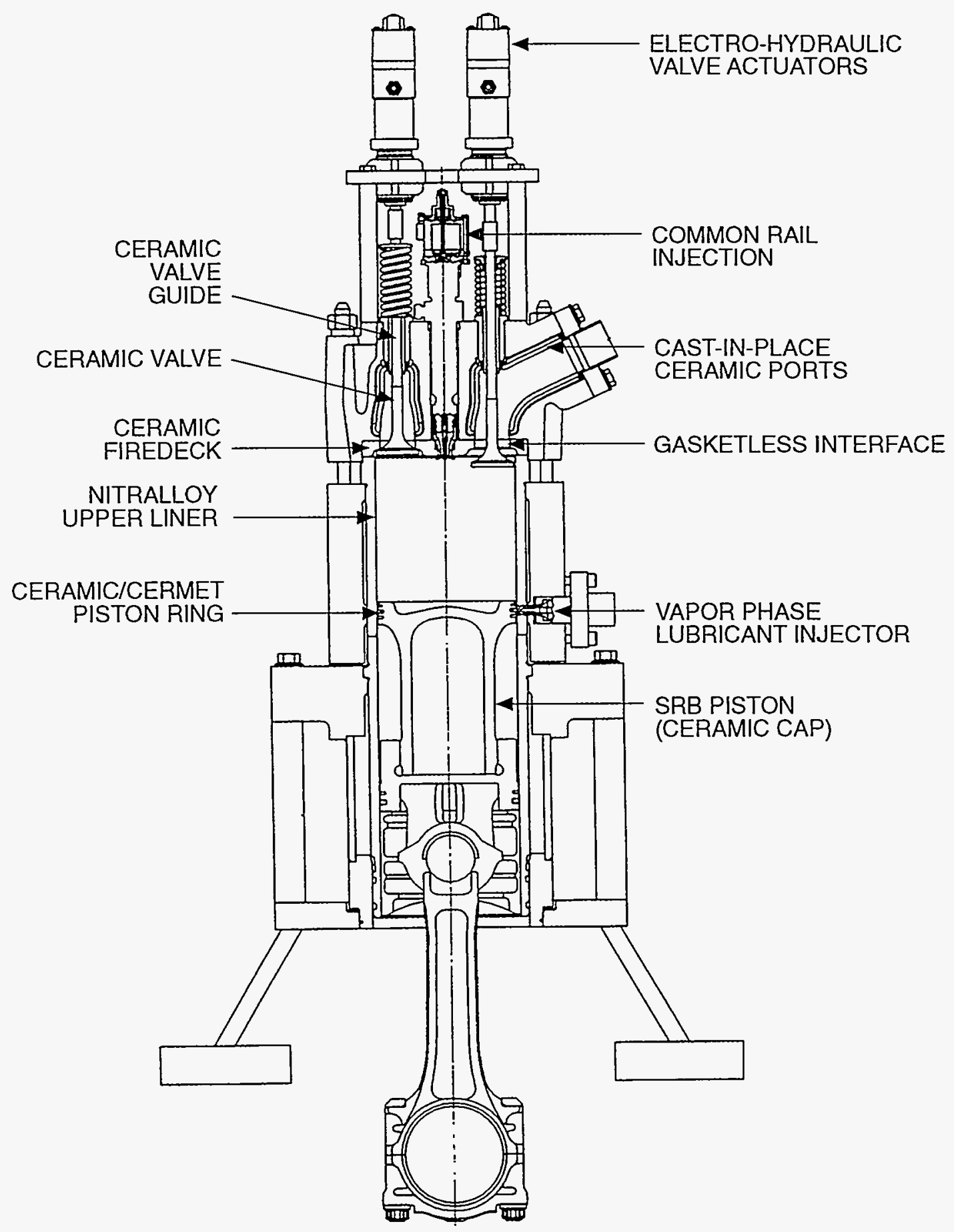

Figure 1: Advanced Technologies Integrated in the ADECD Single Cylinder Test Bed 
Significant progress was made during Phase II/III in the areas of conceptualization, analysis, design, fabrication and testing of these advanced technologies. The SCTB accumulated over 275 hours under various operating conditions with these advanced technology concepts.

The ceramic components utilized in this program include: silicon nitride cast-in-place port liners, firedeck, piston cap, piston ring, valves and valve guides. Both silicon nitride and cermet piston rings were developed. In-cylinder component development (firedeck, piston cap and piston ring) is covered in Section II and ceramic cylinder head components (valves, valve guide and cast-in-place port liner) are reported in Section III.

Numerous breakthroughs were required to implement a "ceramic" engine. Some of these are the fabrication of air-gap cylinder heads, elimination of compression gaskets, machining of ceramic valve seats within the ceramic firedeck, fabrication of cast-in-place ceramic port liners, implementation of vapor phase lubrication and elimination of the engine coolant system. In addition, design, analysis and proof testing methodologies were developed for implementation of ceramic engine components. The specific technology related issues are discussed in Sections II through VI, and the SCTB results are given in Section VII.

While some of the aforementioned advanced technologies are still in their infancy, the ADECD program, especially the SCTB operation, has produced some promising results. The performance, emissions and critical tribological attributes of an advanced "ceramic" engine have been quantified. Vapor phase and solid film lubrication concepts have been investigated. A tribotester has been successfully used to link basic research laboratory testing of the vapor phase concept to the advanced diesel engine ring-liner interface. Vapor generation and delivery technology have been evaluated; demonstrating the viability of the vapor phase concept. The integration of vapor phase lubrication into the hot section of the research engine was done in conjunction with a separated ring belt piston advanced cylinder kit concept. Additionally, the advanced vapor phase lubrication concept has been successfully demonstrated on the SCTB at low load operation.

Increasing the power level to $50 \%$ or higher resulted in high engine blowby due to increased susceptibility of the ring pack to frictional heat deformation. This resulted in additional efforts to develop advanced tribological systems for improved lubrication at the higher temperatures encountered in a ceramic engine. An electronically controlled inter-ring lubricant injector was developed to directly lubricate the most critical cylinder kit area, the ring pack, while minimizing the volume into which the lubricant must be vaporized. Blowby reduction in the SCTB was approached by modeling bore and ring distortion to produce recommendations for the redesign of the piston ring pack.

The confidence gained in ceramic components through these efforts on the ADECD program led to the subsequent introduction of production ceramic components in the DDC multicylinder Series 60 engine. In addition, emissions characterization was approached by the analysis and testing of engine components known to have factors which influence the particulate/NOx emissions trade-off. Modified DDC Series 60 engine components, including camshafts, injectors and ring packs, were designed, fabricated, and tested on a 
DDC Series 60 to quantify their influence on emissions. As a result, 1994 emission level requirements were demonstrated during the ADECD program with production-feasible hardware under laboratory test conditions.

\subsection{COMPONENT FABRICATION}

All advanced concept hardware required to meet the ADECD program objectives was fabricated or procured. Table 1 summarizes this activity along with the corresponding suppliers and quantities procured. The ADECD program included several monolithic ceramic components. The firedeck, cast-in-place ports, valves, valve guides, piston cap, and piston ring were made from silicon nitride. A second piston ring material, cermet (titanium carbide/titanium nitride/nickel) was also selected. It should be noted that all monolithic ceramic components received met or exceeded their as-published strengths and Weibull characteristics. The ceramic components are denoted with an asterisk $\left[{ }^{*}\right]$ and the cermet with a double asterisk [**].

TABLE 1

ADECD ADVANCED CONCEPT HARDWARE

\begin{tabular}{|l|l|c|}
\hline \multicolumn{1}{|c|}{ Component } & \multicolumn{1}{c|}{ Supplier } & Qty. \\
\hline Piston Cap * & Kyocera & 4 \\
\hline Head Land Piston Ring ** & Kyocera & 8 \\
\hline Head Land Piston Ring * & GTE Lab. & 2 \\
\hline Nitralloy Upper Liner & DDC Shop & 6 \\
\hline Firedeck * & Kyocera & 4 \\
\hline Port * & Kyocera & 16 \\
\hline Valve Guide * & AC-GMC & 12 \\
\hline Valve Guide * & GTE Lab & 6 \\
\hline Cylinder Head & CFD-GMC & 4 \\
\hline Valve * & GTE Lab & 8 \\
\hline Valve * & Kyocera & 8 \\
\hline Valve Actuator & DDC Shop & 4 \\
\hline Common Rail Injector & DTC & 3 \\
\hline Vapor Lubrication System & DDC Shop & 2 \\
\hline
\end{tabular}

All components were subjected to preliminary proof of concept testing, thus demonstrating their feasibility.

\section{REFERENCES}

1. Hakim, N.: "Adiabatic Diesel Engine Component Development Program - Phase 1 Interim Report, Reference Engine for On-Highway Applications", 1986 


\section{SECTION II}

\section{ADVANCED IN-CYLINDER COMPONENTS}

This section addresses the design, analysis, fabrication and test results associated with the silicon nitride piston cap, the silicon nitride firedeck and the piston rings developed for the ADECD program. Different materials, including silicon nitride and a cermet, were tested for the piston ring. Ring pack modeling and modifications to address blow-by are discussed.

\subsection{CERAMIC FIREDECK AND CYLINDER HEAD ASSEMBLY}

Four silicon nitride firedecks were made by Kyocera (SN-220M) and mated directly to the cylinder liner without a gasket. The gasketless design was analyzed extensively through finite element modeling and experimentally validated. All four of these firedecks were statically tested to $20.7 \mathrm{MPa}$ without failure or leakage during the proof testing, thereby meeting the design goal. Dynamically, these firedecks have sustained peak cylinder pressures of 9.4 MPa without failure or leakage.

The firedeck, cylinder head, and liner temperatures were monitored throughout this test work. Temperature distributions for these components at the $1600 \mathrm{r} / \mathrm{min}$ and $30 \mathrm{~N}-\mathrm{m}$ brake torque point are shown in Figures 2,3 and 4 respectively. Steady-state top ring reversal (TRR) temperatures, as measured $2.0 \mathrm{~mm}$ below the liner surface, varied between 340 and $440^{\circ} \mathrm{C}$, depending on the engine load.

The cylinder head for the single cylinder ADECD engine incorporates many unique features. Four identical ceramic port shields are cast directly into the cast iron head structure. The port shields were made of sintered silicon nitride and were wrapped externally with a compliant material to mechanically and thermally isolate them from the iron during the casting process. Port shields without the compliant outer surface failed during the casting process, proving the usefulness of the design feature. A monolithic silicon nitride firedeck and valve guides are retained in the finished cylinder head by interference fits. Eight equally spaced studs clamp the cylinder head onto the top of the liner flange with no intervening head gasket. Effective sealing of the combustion gas pressure was achieved through control of the geometry, clamp load and material properties of the cylinder liner and ceramic firedeck. It should also be noted that the firedeck when shrunk fit into the cylinder head was designed to operate with an air gap.

The combustion gas sealing capability of a gasketless cylinder liner-to-fire deck insert joint was evaluated and optimized using finite element modeling. See Appendix A.

\subsection{PISTON CAP}

Four silicon nitride piston caps, each weighing $7.0 \mathrm{~kg}$, were procured from Kyocera (SN-220M). The four caps were thermally assembled into the piston with an interference 


\section{Temperature vs. Location ( Backside of Firedeck )}

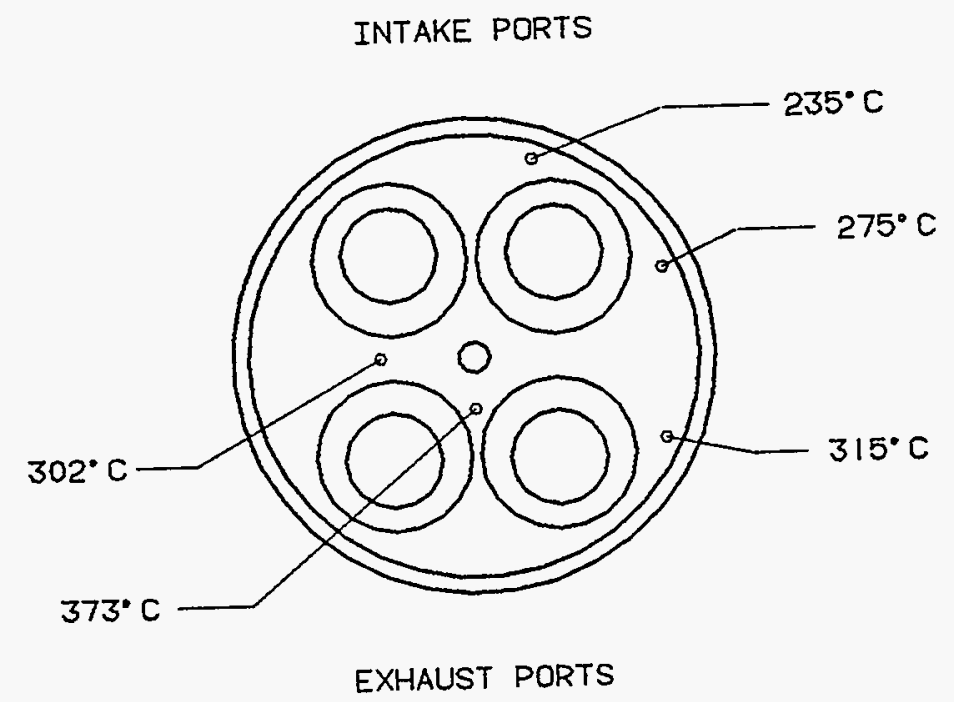

Figure 2: Build \#6 Firedeck Temperature Distribution, $1600 \mathrm{r} / \mathrm{min} \& 30 \mathrm{~N}-\mathrm{m}$

\section{Temperature vs. Location ( Cylinder Head)}

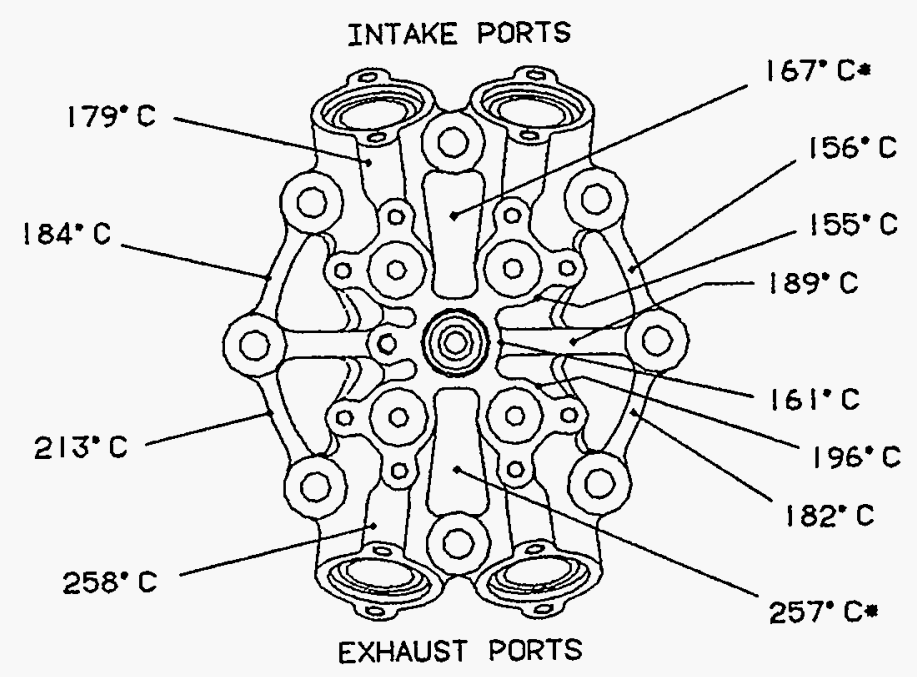

* INTERNAL IRON TEMPERATURE
BETWEEN PORTS, 2 LOCATIONS

Figure 3: Build \#6 Cylinder Head Temperature Distribution, $1600 \mathrm{r} / \mathrm{min} \& 30 \mathrm{~N}-\mathrm{m}$ 
Temperature vs. Location

(Along Axial Length of Liner, from TRR )

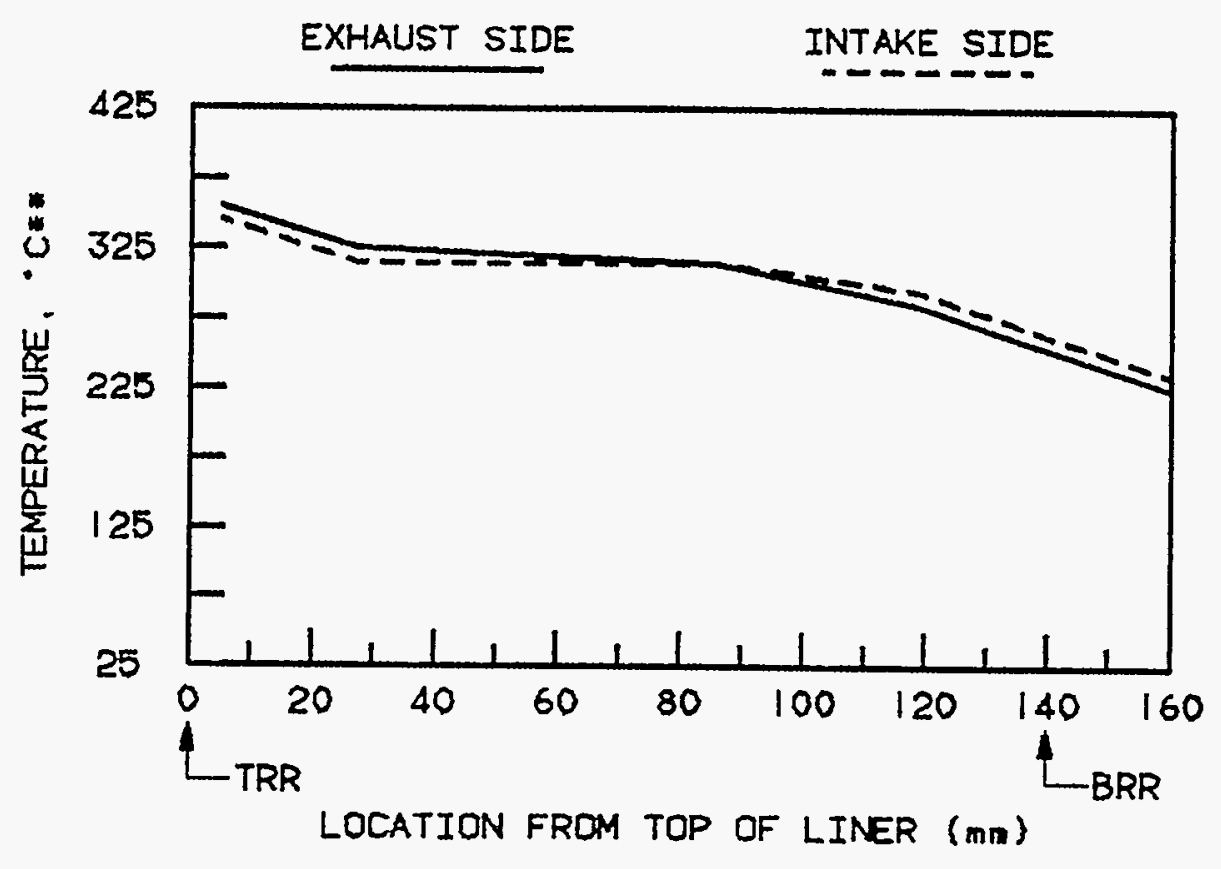

* meAsured $2 \mathrm{~mm}$ Below surface

Figure 4: Build \#6 Liner Temperature Distribution, $1600 \mathrm{r} / \mathrm{min} \& 30 \mathrm{~N}-\mathrm{m}$ 
fit. Two of the caps had a single ring groove and two were designed and fabricated with dual groove geometry. The separated ring belt (SRB) piston, consisting of a ceramic cap retained in an iron body by a shrink fit, was designed to separate the extremely hot upper cylinder liner area from the conventionally lubricated crankcase and piston skirt area. The SRB piston geometry was combined with a diametral shrink fit specification of .209 to .260 $\mathrm{mm}$ to result in a probability of survival of 0.99999 and a safety factor of between 3.0 and 5.6 under assembly and steady peak torque loading conditions. During the program, it was discovered that a thin copper coating was required on the $\mathrm{OD}$ of the piston cap bottom ledge to uniformly distribute the load due to interference assembly.

Preliminary proof of concept demonstration was performed on the single cylinder test bed with one of the piston caps. This piston accumulated 8.7 hours of successful engine motoring, including 65 minutes at $2000 \mathrm{rpm}$ without separation or incident. No problems were encountered during firing operation or in subsequent engine testing (see Section VII).

\subsection{PISTON RING}

Both cermet and silicon nitride piston rings were fabricated and tested. Eight cermet piston rings were procured from Kyocera (TC35). Five of five rings were successfully proof tested. The proof test consisted of expanding the end gap $24.0 \mathrm{~mm}$ to $26.0 \mathrm{~mm}$ (nominal end gap is $2.0 \mathrm{~mm}$ ). These cermet rings were used in initial engine testing without incident. Additionally, two silicon nitride rings were procured from GTE (hot isostatic pressed [HIP] AY6). The proof testing of these rings consisted of installing the rings on the pistons and removing the rings from the pistons numerous times without incident.

A post-test inspection of the Build \#5 hardware (see Section VII) was conducted. Visual inspection of the piston ring and liner surface revealed no scuffing or scoring. Wear debris samples were collected from five locations: TRR of the liner, bottom ring reversal [BRR] of the liner, the piston ring, the piston cap, and the piston body. These samples were sent to the Pennsylvania State University for analysis. The electron dispersive X-ray analysis (EDAX) for each of these samples are shown in Figures 5 through 9. This evaluation confirmed the presence of Durad 125 and its reaction products in the upper section of the cylinder liner. Additionally, the amounts of phosphorous and iron found in this analysis were similar to those found in previous samples taken from the Cylinder Kit Tribology Test Fixture (CKTTF) and Build \#3 [1].

\subsection{PISTON RING WEAR}

Upon disassembly of the SCTB following the Build \#6 test sequence, no scuffing was evident. The ring's weight, gap, thickness and profile were measured. The wear measurements are shown in Figure 10. The two methods of measurement show good agreement. The ring wear rate was very consistent, averaging 2.84 microns/hour. 
EDAX of Build \#5 Debris

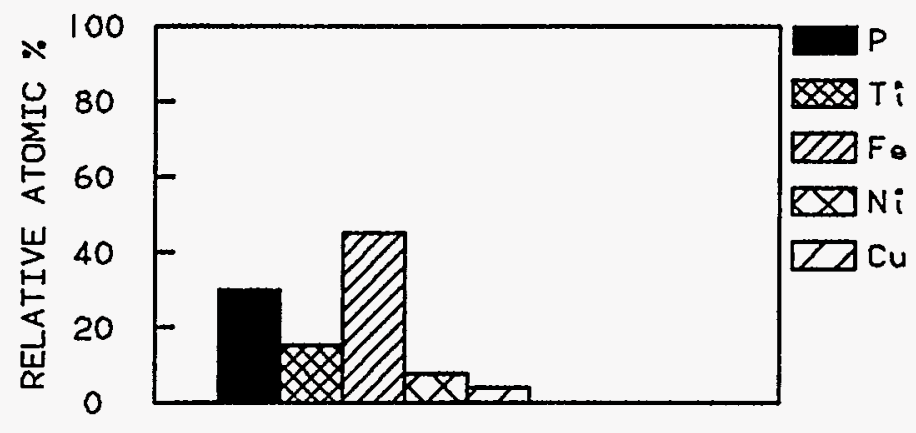

Figure 5: EDAX Analysis of Sample \#1 (TRR of the Liner)

EDAX of Build \#5 Debris

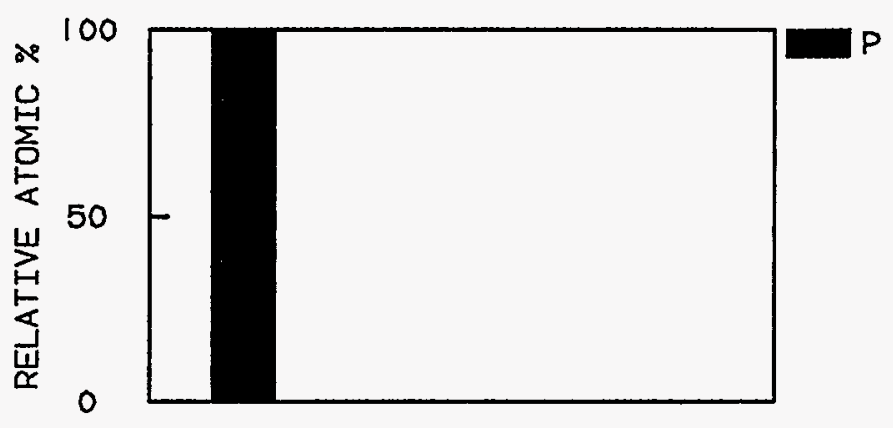

Figure 6: EDAX Analysis of Sample \#2 (BRR of the Liner) 


\section{EDAX of Build \#5 Debris}

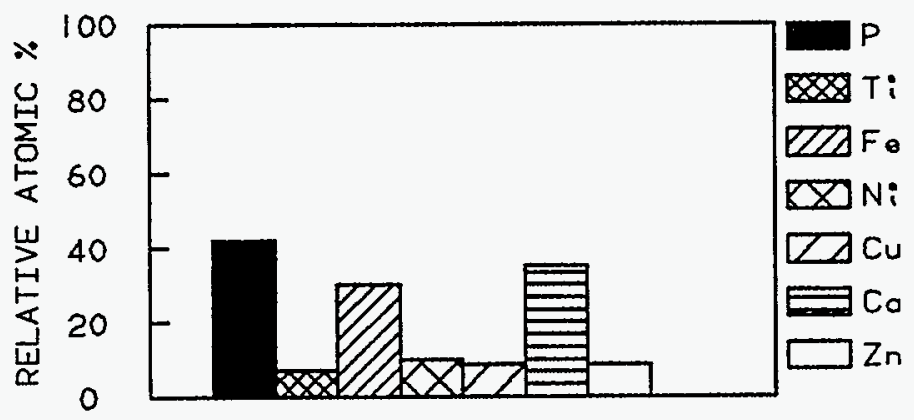

Figure 7: EDAX Analysis of Sample \#3 (Piston Ring)

EDAX of Build \#5 Debris

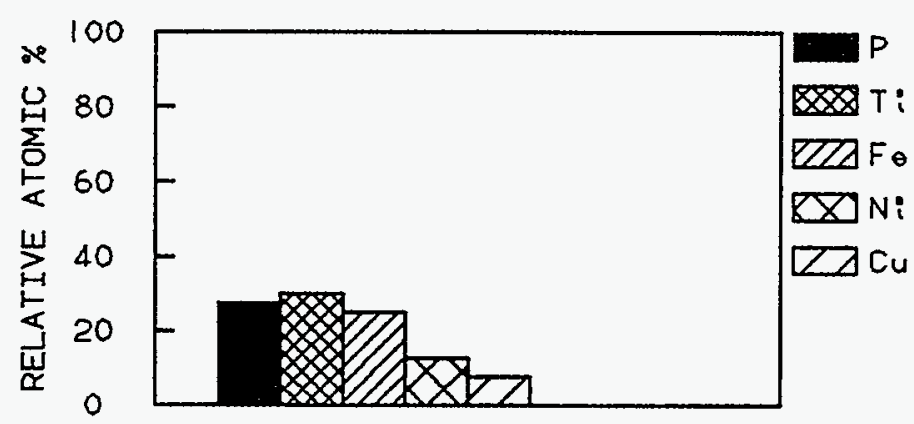

Figure 8: EDAX Analysis of Sample \#4 (Piston Cap) 


\section{EDAX of Build \#5 Debris}

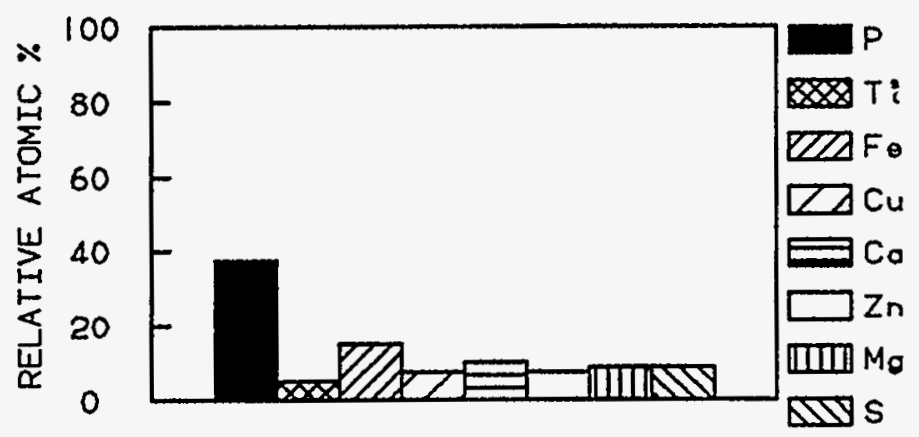

Figure 9: EDAX Analysis of Sample \#5 (Piston Body)

\section{Build \#6 Ring Wear Rate}

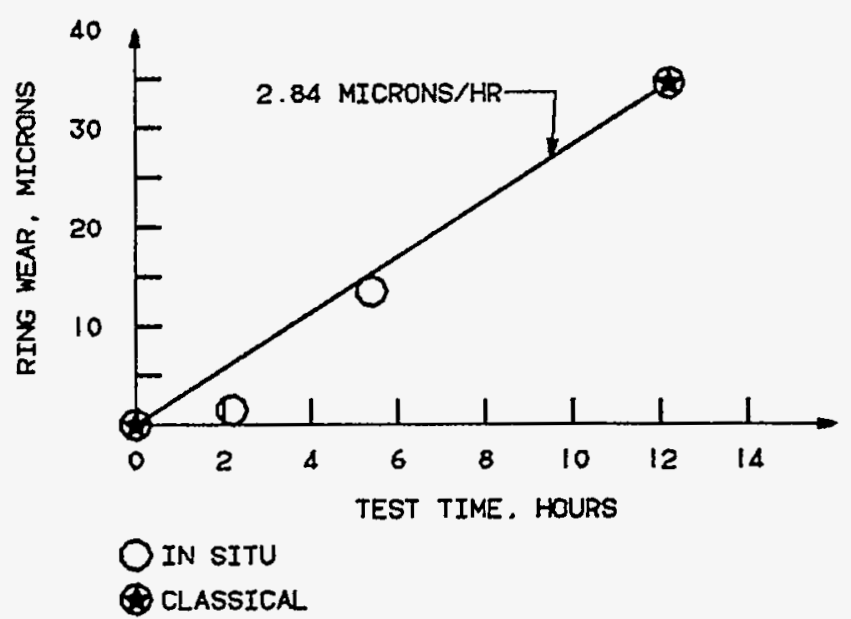

Figure 10: Cermet Ring Wear vs. Time ( 0.1 Mole Percent Durad 125) 
Even though the ring wear rate shown in Figure 10 (Build \# 6, see Section 7.7 for build description) is at least 10 times greater than the goal, the results were considered promising. A TRR temperature of $340^{\circ} \mathrm{C}$ was sustained, and no attempt at optimizing in-cylinder component materials, geometries, or lubricant delivery parameters had been made.

Upon disassembly of the SCTB following Build \# 8, the cermet piston ring was found to be broken. The failure occurred approximately $145^{\circ}$ from the gap.

Upon completion of Part II of the Build \#9 test sequence, the SCTB was disassembled for an in-cylinder component inspection. During this inspection, the cermet piston ring was found to be fractured and excessively worn. The piston ring fractured approximately $145^{\circ}$ from the gap, as shown in Figure 11. No other damage was evident. The ring and liner wear rates from Build \#9 were measured, converted to wear coefficients, and compared to Build \#6 results. These results are summarized in Table 2.

TABLE 2

RING AND LINER WEAR COMPARISON

Wear Coefficient, $\mathrm{K}$

\begin{tabular}{|ccc|}
\hline & Ring & Liner \\
Build \#6 & $4.5 \times 10^{-6}$ & $2.6 \times 10^{-7}$ \\
& & \\
Build \#9 & $6.0 \times 10^{-6}$ & $5.9 \times 10^{-7}$ \\
\hline
\end{tabular}

$$
\mathrm{K}=\frac{\text { Wear Volume } \times \text { Hardness }}{\text { Avg. IMEP } \times \text { Sliding Distance }}
$$

See Sections 7.7 and 7.10 for build descriptions

As shown in Table 2, significantly more wear occurred in the no intentional lubrication run (Build \#9) than in the Build \#6 run which was lubricated with 0.1 mole percent concentration of vapor phase Durad 125 lubricant. The unlubricated Build \#9 ring wore $33 \%$ more than the vapor phase lubricated ring. Similarly, the unlubricated Build \#9 liner wore $127 \%$ more than the vapor phase lubricated Build \#6 liner. Based on these results, it is concluded that vapor phase lubrication is superior to no intentionally delivered lubricant. Section IV discusses further the development of vapor phase lubriction through testing on the CKTTF and SCTB. 


$$
0
$$


Subsequently, a failure analysis of the Build \#9 piston ring was conducted. As shown in Figure 12, the fracture was determined to be a typical fatigue failure, initiating at the top OD chamfered corner. Since the fractured surface was determined to be free of defects, it has been concluded that the failure was simply due to exceeding the strength of the base material while running in the unlubricated mode.

The cermet ring fracture was repeated in Build \#10 when $50 \%$ power operation was attempted. Disassembly revealed localized fractures in the ceramic piston cap on its thrust and anti-thrust surfaces. The ceramic coating on the second compression ring was severely chipped.

Build \#11 initially achieved a stable blowby at $1800 \mathrm{r} / \mathrm{min}$ under motoring and low power levels using a stainless steel ring. However, at higher power levels, blowby increased radically after the operating point was held for a period of time. The blowby stability of the stainless steel ring was better than the cermet ring, giving a longer time of blowby stability at any given load point. A maximum of $28 \mathrm{~N}$-m torque at $1800 \mathrm{r} / \mathrm{min}$ and a peak firing pressure of $11.1 \mathrm{MPa}$ was achieved, but a radical increase in blowby resulted in the test run being terminated after 4.8 hours were accumulated, 0.7 of which were firing. See Figure 13 for temperature and blowby results of this test run.

\subsection{DISTORTION MODELING OF IN-CYLINDER COMPONENTS}

The approach used to determine possible causes of the excessive blowby included computer modeling of the ADECD in-cylinder components and conditions to examine the influence of factors related to bore and ring distortion on blowby. A finite element model of the SCTB cylinder liner, block, and head was developed to assess the sensitivity of bore distortion to axial and circumferential temperature variation and peak cylinder pressure.

Modeling of the symmetrical, single cylinder test bed liner showed bore distortion was determined to be reasonable, albeit non-trivial, and its influence on blowby could be controlled through ring design. Of various factors examined, the largest contribution to bore distortion resulted from axial temperature variation. The modeling also indicated that the bore distortion could not have caused the sudden increase in blowby observed in the engine testing. The bore distortion would have been more gradual with time, resulting in a more linear increase in blowby. 


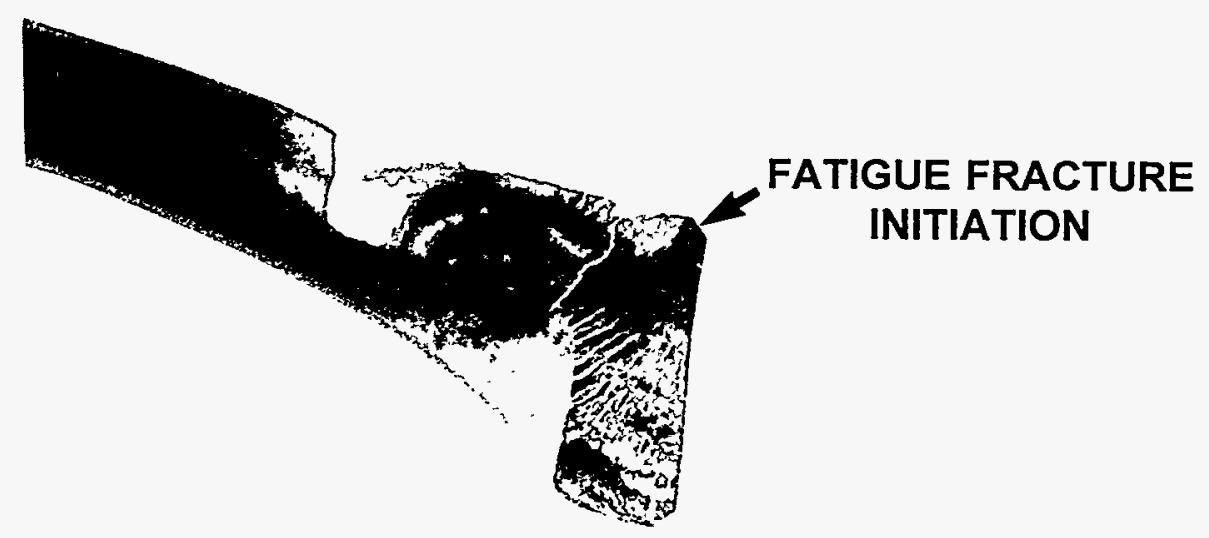

Figure 12: Build \#9, Initial Failure Region of Cermet Headland Piston Ring 


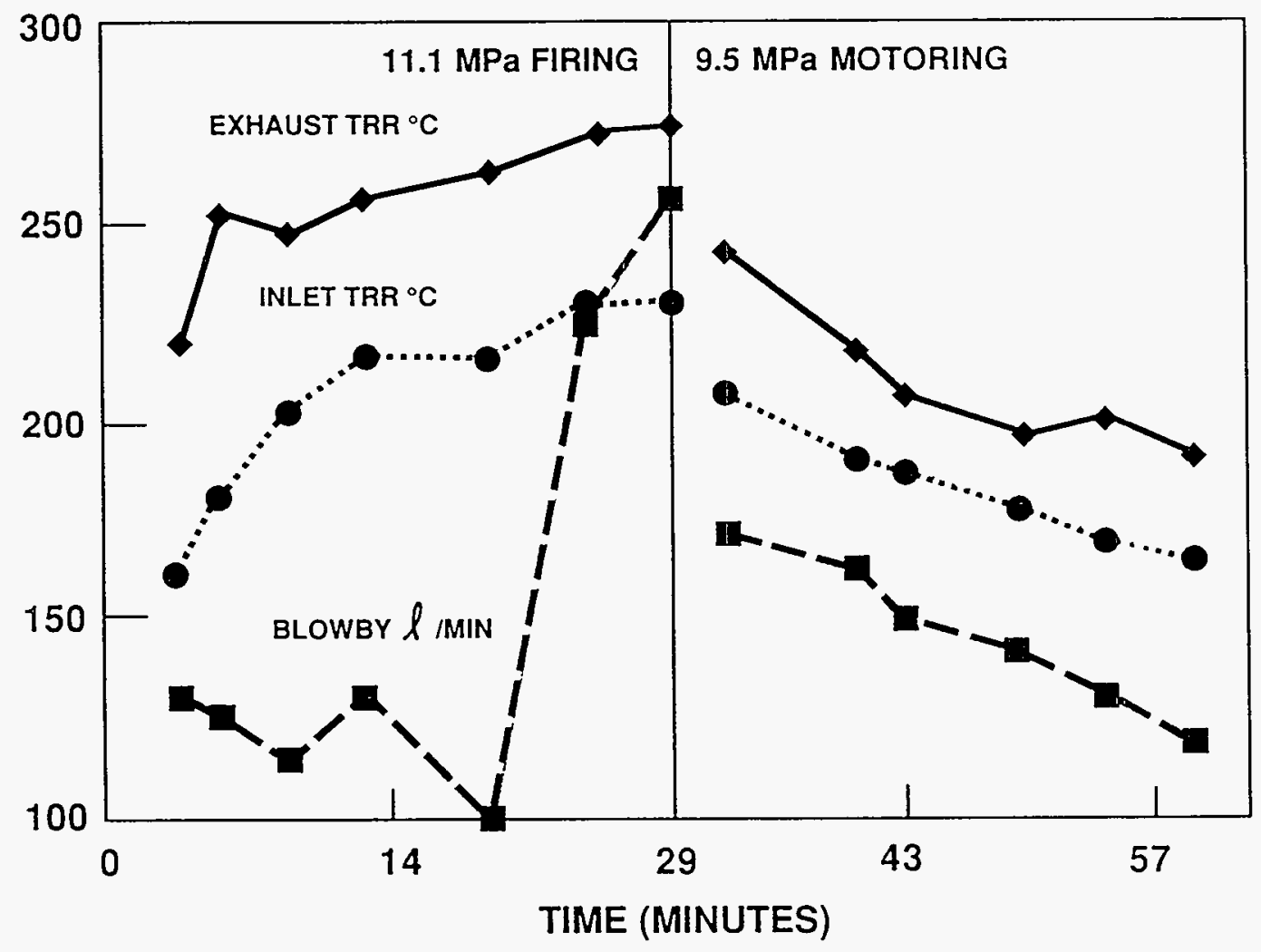

Figure 13 Liner Temperatures and Blowby (Build \# 11) 
Ring distortion modeling included an assessment of the sensitivity of the existing L-section ring design to radial ring temperature gradients (a significant factor in ring distortion and twist) and the conformability of the ring to the liner. The ring radial temperature gradient factors examined were frictional heat input and temperature boundary conditions due to combustion gases and heat fluxes through the piston and liner. Ring conformability modeling assumed the worst case bore distortion and examined the influence of ring profiles on ring distortion and twist and their influence on blowby.

The most sensitive factor affecting the radial temperature gradient was found to be frictional heat input. Figure 14 shows results typical of the ring distortion modeling, demonstrating the effect of ring temperature gradient and ring geometry on blowby. Three levels of pressure balance (the ratio of ring face area to the ring rear area exposed to the cylinder pressure) under different levels of radial ring temperature gradient are shown.

\subsection{L-SECTION RING DESIGN}

Using the above ring distortion blowby modeling, three ring design recommendations were selected as possible solutions to the excessive blowby: a segmented ring design, a modified L-section ring design, and an angled step-gap second ring design.

The segmented ring design, shown in Figure 15, is a set of L-section ring segments held together with a wire spring expander. By segmenting the ring, better conformity of the ring to the bore is achieved through the isolation of each ring segment from the thermal distortion of the adjacent segments due to uneven ring heating. However, this design is difficult to manufacture and durability of the wire spring expander exposed to the hot combustion gases is a concern.

The modified L-section ring design, shown in Figure 16, is a modification of the L-section cermet ring design used in the tenth and earlier builds. This design specifies a stainless steel material for more flexibility than the cermet material used in the existing ring design. It has a smaller radial width, reducing the effect of thermal ring twist. A smaller face width is also provided to improve the pressure balance of the ring when subjected to thermal distortion. This is accomplished by maintaining a seal surface between the ring and the liner at a higher point on the ring face. The gas pressure balance between the front and rear of the ring is not significantly different with this smaller face, but the larger chamfer on the top edge improves the uniformity of the gas induced load on the ring against the liner, helping to reduce the frictional heat input to the ring.

Computer blowby modeling of this modified L-section ring, together with a conventional design angled step-gap second ring was found to provide acceptable levels of blowby, based on the worst case bore distortion and ring boundary conditions determined by the modeling. 

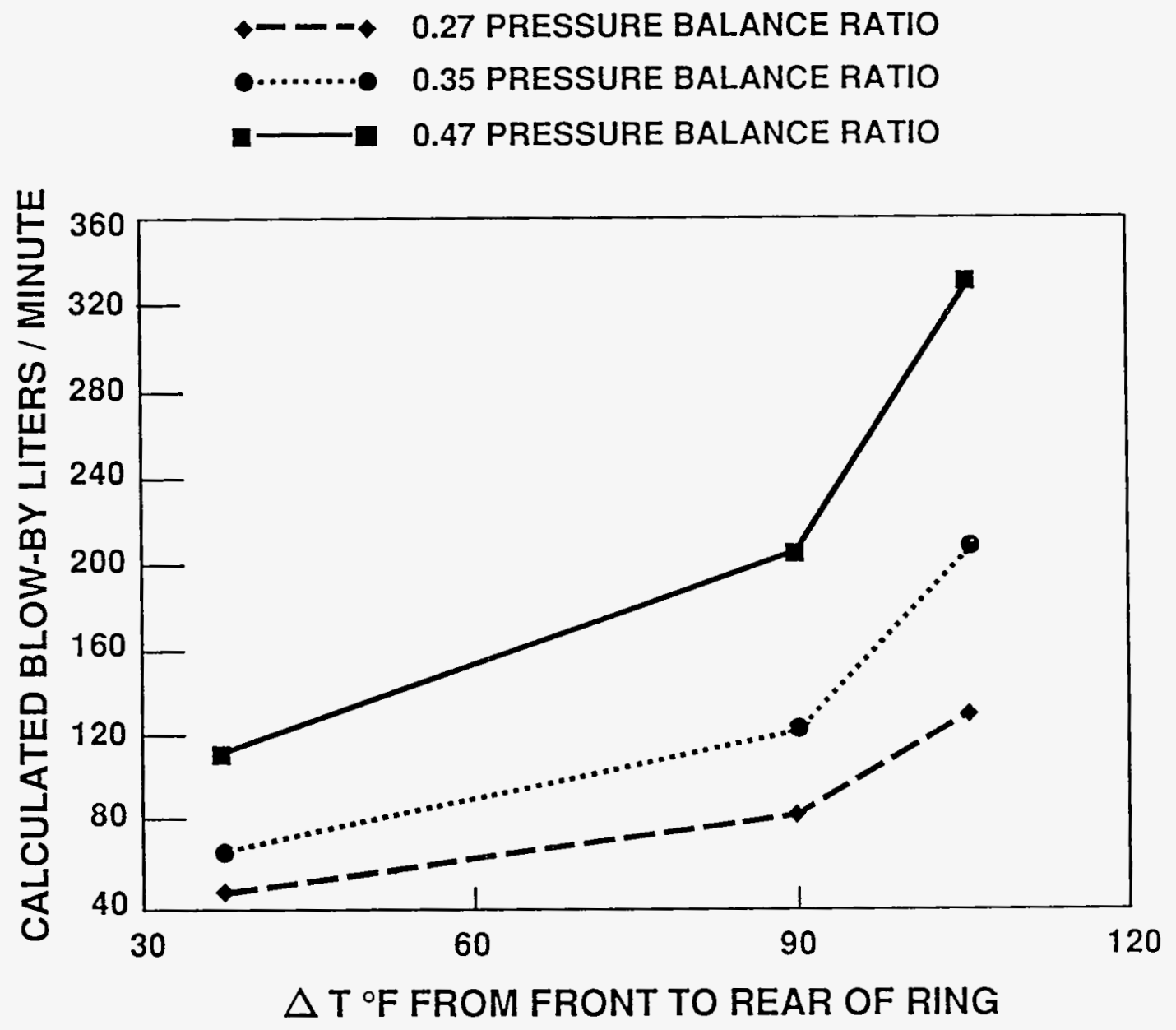

Figure 14: Effect of Temperature Gradient and Pressure Balance on Blowby 

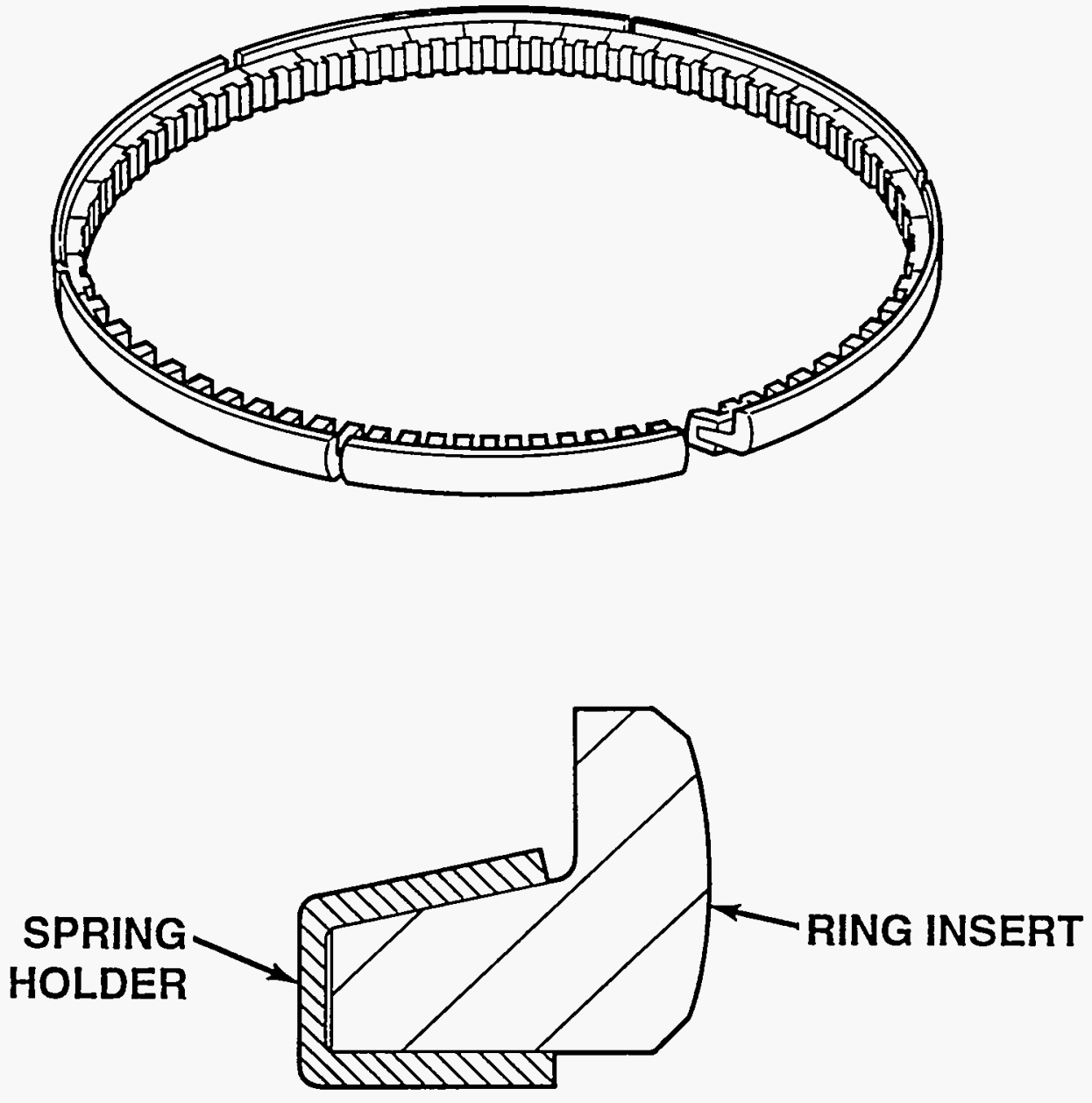

SECTIONAL VIEW

Figure 15: Segmented L-Section Ring 


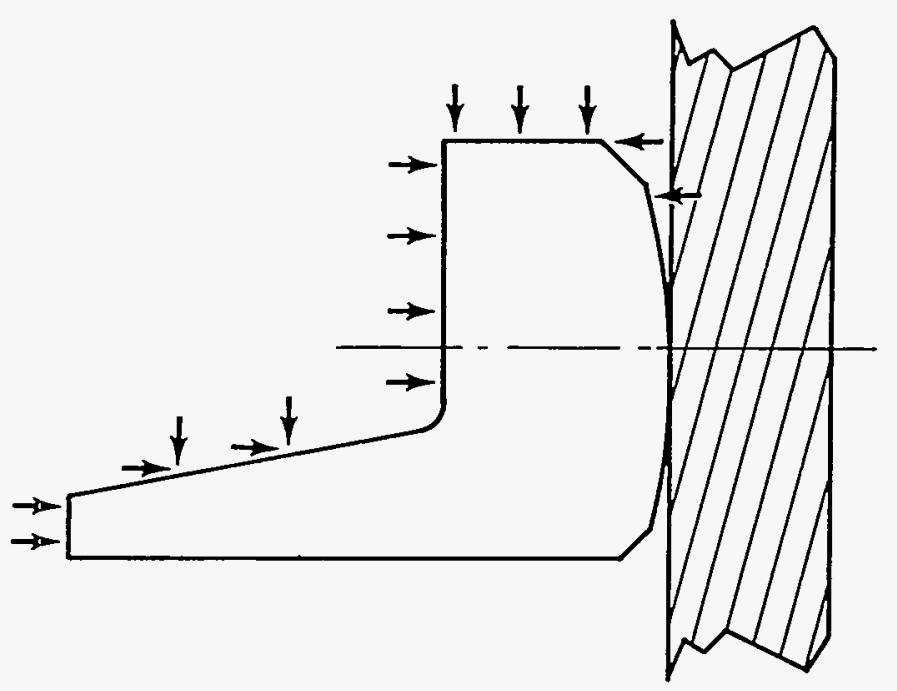

CURRENT L-SECTION FACE PROFILE

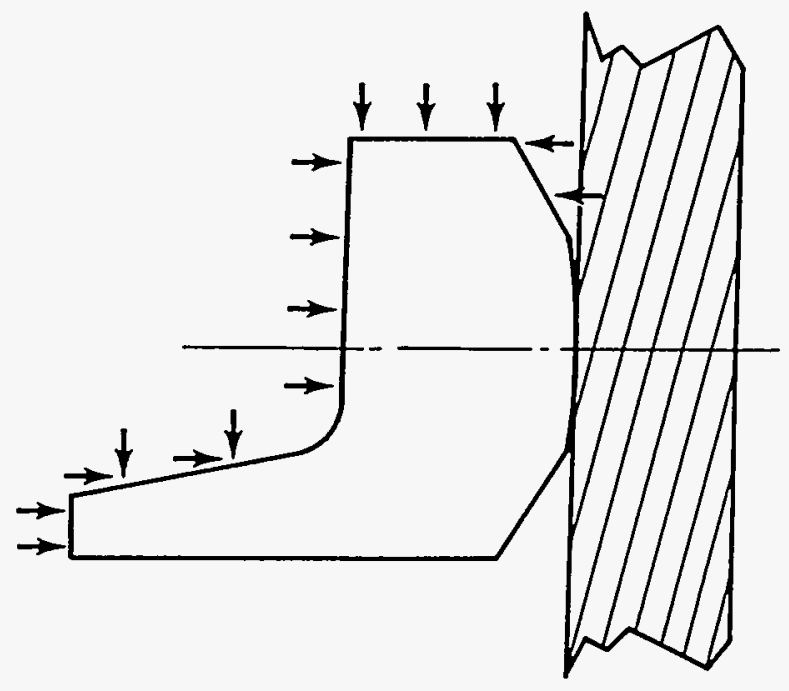

MODIFIED L-SECTION

FACE PROFILE

Figure 16: Modified L-Section Ring Profile Comparison 
The resulting ring pack design consisted of an L-section top ring, modified in cross-section from the cermet ring, and an angled step gap second ring. The modified rings were made of tool steel, faced with a moly-chrome-cobalt wear coating and plated with a friction reducing silver coating. The goal of this ring pack design was to reduce the blowby to the 35 liters/minute level considered acceptable for good lubricant injector performance.

The new ring pack was tested utilizing the lubricant injector cylinder kit hardware (liner with injector port and piston with lubricant pocket). Engine performance, Table 3, was generally consistent with earlier cermet ring pack runs, with comparable indicated power. However, pumping losses, maximum cylinder pressure, frictional power losses and fueling levels were reduced for the same generated torque. This indicates that the rings produced a better seal and lower friction. Although blowby was much higher than the design target, it was stable, which allowed single cylinder testing of the lubricant injector system to continue. The issues pertaining to lubrication are discussed in more detail in Section IV (Tribology). Details of the SCTB sequence of builds are described in Section VII.

TABLE 3

ENGINE PERFORMANCE COMPARISON OF RING PACK DESIGNS

\begin{tabular}{|c|c|c|c|}
\hline \multicolumn{2}{|c|}{\begin{tabular}{c}
$1800 \mathrm{r} / \mathrm{min}$ \\
$\mathbf{1 1 0} \mathbf{3 0} \mathrm{N} \cdot \mathbf{m}$ \\
\multicolumn{2}{|c|}{$\mathbf{k P a}$ Intake/Exhaust } \\
Restriction
\end{tabular}} & $\begin{array}{c}\text { Baseline } \\
\text { Cermet }\end{array}$ & $\begin{array}{c}\text { New Ring } \\
\text { Pack }\end{array}$ \\
\hline Indicated Power & $\mathrm{kW}$ & 16.65 & 16.70 \\
\hline Pumping Loss & $\mathrm{kW}$ & -2.45 & -2.35 \\
\hline $\begin{array}{c}\text { Max. Cylinder } \\
\text { Pressure }\end{array}$ & $\mathrm{MPa}$ & 11.1 & 10.4 \\
\hline ISFC & $\mathrm{g} / \mathrm{kW}-\mathrm{hr}$ & 190 & 182 \\
\hline Fuel Rate & $\mathrm{kg} / \mathrm{min}$ & .0529 & .0508 \\
\hline Blowby & liters/min & $\begin{array}{c}200+ \\
\text { Unstable }\end{array}$ & 184 \\
\hline
\end{tabular}

\section{CONCLUSIONS}

1. The SRB piston and gasketless firedeck-liner interface represented innovative approaches for assembly of the ceramic components in an advanced diesel engine. These concepts helped in the successful design, analysis and test of the silicon nitride firedeck and piston cap on the SCTB.

2. Valuable design, analysis and test experience was gained with ceramic and cermet piston rings. Further improvements in the top compression ring are required for advanced engines. 


\section{SECTION III}

\section{ADVANCED CYLINDER HEAD COMPONENTS}

This section addresses the design, analysis, fabrication and significant test results for the advanced cylinder head ceramic components - the intake and exhaust valves, the valve guides and the port liners. These components were all fabricated from monolithic silicon nitride.

\subsection{CERAMIC VALVE DEVELOPMENT}

This section describes the development of a silicon nitride valve from the initial design state to actual engine testing. Supplier involvement, finite element analysis, and preliminary proof of concept demonstration testing played a significant role in this project's success.

Benefits associated with the ceramic valve were identified that tended to offset the high risk aspect of pursuing monolithic ceramic valves for heavy-duty diesel engines[1]. Specifically, a 40 to $60 \%$ reduction in valve mass lowers inertial forces, reduces fuel consumption, and allows a means to increase power density. Further, surfaces at the valve's interfaces could wear significantly less and have lower coefficient of friction $[2,3]$.

The objective of this effort was to design and demonstrate operation of monolithic ceramic valves in a heavy-duty diesel engine. In order to achieve this objective, successful operation at $1800 \mathrm{r} / \mathrm{min}$ under extreme LHR conditions and without traditional liquid lubrication was required. At this operating condition, it is felt that the ceramic valve should have at least a 99.9\% probability of survival (POS) determined by probabilistic finite element modeling. Also, it was felt that the relative transverse and rotational motion needed to be minimal, due to the lack of traditional lubrication. Valve stems were coated with trithioxymolybdate, a solid film lubricant.

The methodology used to demonstrate that monolithic ceramic valves can be successfully operated in heavy-duty diesel engines consisted of three main activities. The first included five interacting efforts: preliminary concept and design generation; ADECD Program considerations; cylinder head compatibility; supplier input; and finite element and Weibull based probabilistic life analyses. It should be noted that the potential suppliers' inputs and finite element/life analyses were thought to be critically important in defining a $211 \mathrm{~mm}$ long ceramic valve.

The second activity included material and supplier selection, design finalization, and component fabrication. The third activity involved: proof of concept demonstration on a laboratory rig and engine operation. Each of these activities is discussed in greater detail in Appendix B. 
Based on the finite element analysis, the proof of concept testing and the engine evaluation performed, the following conclusions can be made:

1. The monolithic silicon nitride valves specially designed for the ADECD program meet the design objective, i.e. two hours of successful operation at $1800 \mathrm{r} / \mathrm{min}$ engine speed.

2. Seating velocities of $0.5 \mathrm{~m} / \mathrm{s}$ can be tolerated by this valve design.

3. When extremely overstressed (running $3600 \mathrm{r} / \mathrm{min}$ equivalent engine speed), the silicon nitride valves failed at the valve stem locking radius, as predicted by the finite element model. After failure, the ceramic valve is retained by the locks, preventing secondary incylinder damage.

Material expenditures were minimized by using as many off-the-shelf production components as possible. It should be noted that spring caps were selected, rather than rotators, to minimize the rotation between the valve tip-to-bridge counter-bore and the valve stem-to-guide interfaces.

\subsection{CERAMIC VALVE GUIDE}

Eighteen silicon nitride valve guides were procured, twelve from AC Spark Plug (SN-90) and six from GTE (HIPed AY6). All of these guides were thermally assembled via shrink fit within sleeves for final installation into the cylinder head without incident. Depletion of the solid film lubrication at the guide-to-valve interface during engine tests remains a problem to be resolved in future work.

\subsection{CERAMIC CAST-IN-PLACE PORT}

The cylinder head included cast-in-place ceramic valve port shields to increase insulating effectiveness. The shields are subject to loading from the shrinkage of the molten cylinder head metal as it cools. In addition, the uncooled operating conditions of the ADECD engine could be expected to impose high thermal loads on the exhaust port shields.

The ADECD cylinder head design shown in Figure 17 incorporates four (two exhaust and two intake) identical cast-in-place ceramic port shields. The "two band design" port shield, Figure 18, is wrapped in an insulating ceramic blanket except for two bands of wire mesh (nominally $4.5 \mathrm{~mm}$ thick) located at each end of the port. During the casting process, only the wire mesh comes in contact with the molten metal. The ceramic insulating blanket protects the ceramic from thermal shock and forms a low conductivity annulus about the shield for added insulating effectiveness during engine operation. 


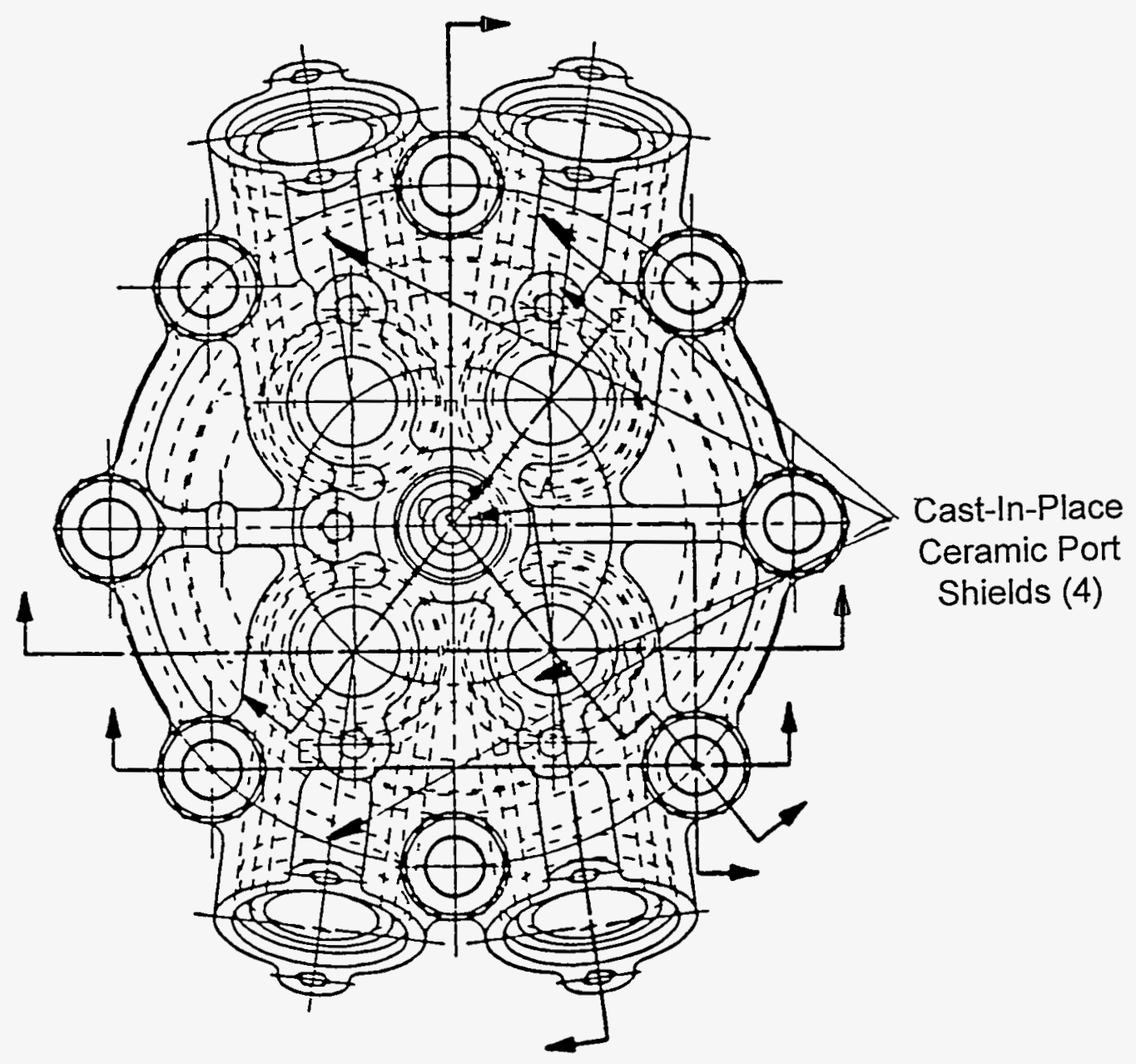

Figure 17: ADECD Cylinder Head Design 


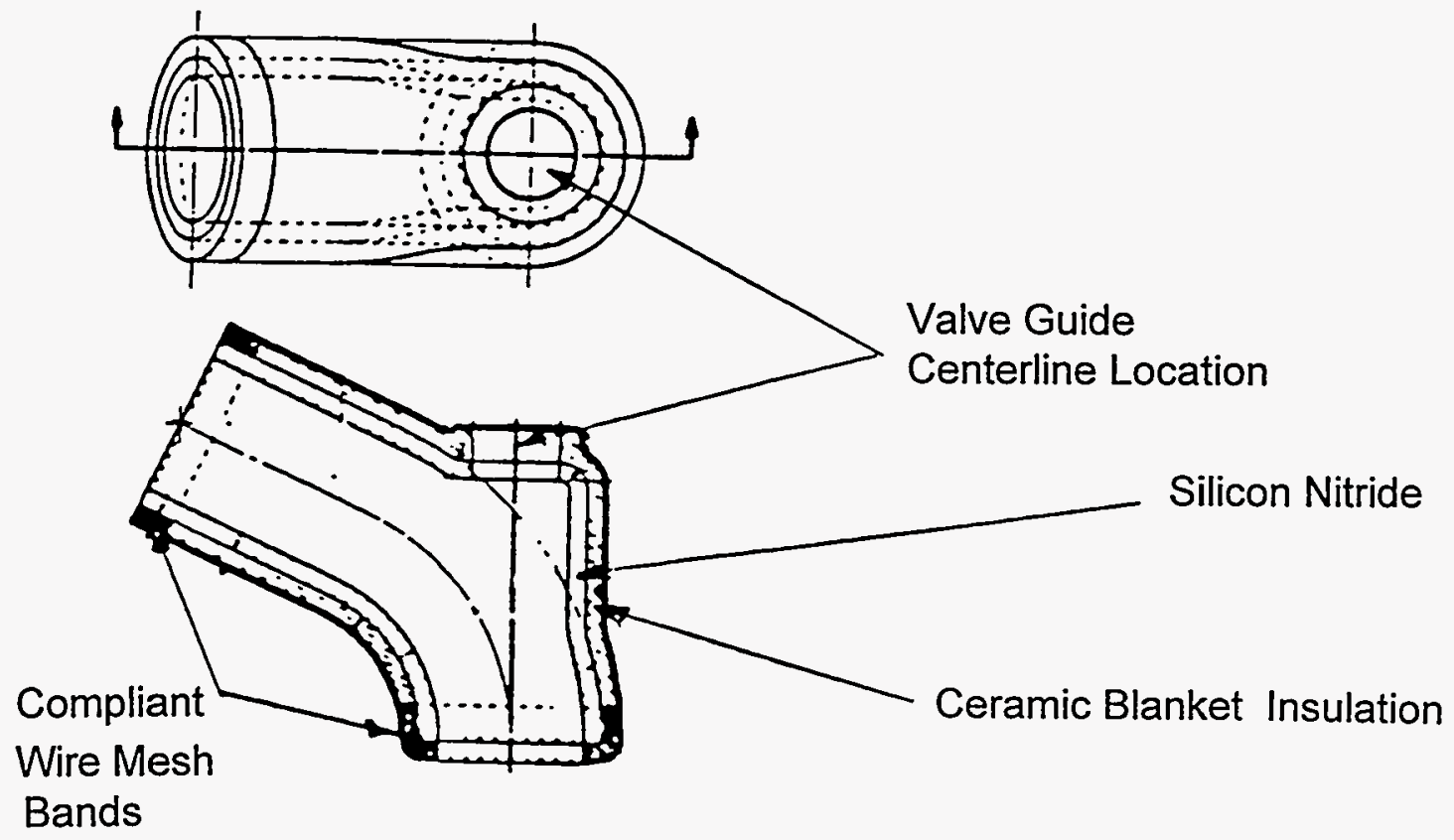

Figure 18: Two-Band Cast-in-Place Port Shield 
Viability of the ceramic cast-in-place port shield concept under casting shrink and thermal loading was examined via finite element analysis. See Appendix $C$ for details of the analysis. The following is a summary of the FEA (Finite Element Analysis):

1. Compliant bands are critical to the viability of the cast-in-place concept. A low (42 $\mathrm{MPa}$ ) elastic modulus wire mesh must be used for the load carrying bands surrounding the ceramic port shield.

2. The ADECD silicon nitride cast-in-place port shield with a $4 \mathrm{~mm}$ nominal wall and two $42 \mathrm{MPa}$ modulus wire mesh bands was predicted to have a probability of survival of nearly 1.000 when subjected to simulated casting shrink and peak torque thermal loads.

Two designs were proposed as a result of FEA. The first design was a silicon nitride port covered with a compliant layer of alumina fiber, a single wire mesh band on both ends and a $1.0 \mathrm{~mm}$ thick alumina barrier coating. The second design was a silicon nitride port completely covered with a compliant layer of wire mesh and a $1.0 \mathrm{~mm}$ thick alumina barrier coating. Eight shields of each design were fabricated by Kyocera. Twelve of sixteen silicon nitride ports were successfully cast into cast iron cylinder heads: four of the Design \#1 type and eight of the Design \#2 type. See Appendix C, Figure 91.

Based on nondestructive CATSCAN X-ray of the four unsuccessfully cast ports, it was determined that their cracking was due to molten iron penetration through the alumina barrier. The most likely cause of penetration was improper handling of the ports, prior to casting, which can generate cracking of the alumina barrier. Further, DDC concluded that either design type is castable, as long as the alumina barrier is not penetrated.

\section{CONCLUSIONS}

1. Ceramic valves and guides met all design criteria and were successful in the SCTB tests.

2. The viability of cast-in-place ceramic port liners was established through successful engine testing. A compliant layer is necessary for successful casting of silicon nitride ports.

\section{REFERENCES:}

1. Saviwala, M.S. and Hakim, N.S., "Statistically Optimized Performance Predictions of Low Heat Rejection Engines with Exhaust Energy Recovery," SAE Transaction 860315, 1986.

2. Updike, S.H. and Nagle, P.D., "Ceramic Valve Train Components," SAE Transaction $880441,1988$.

3. Asnani, M. and Kuonen, F.L., "Ceramic Valve and Seat Insert Performance in a Diesel Engine," SAE Transaction 850358, 1985. 


\section{SECTION IV}

\section{TRIBOLOGY}

Accelerated wear at the piston ring-cylinder liner interface poses one of the greatest challenges to LHR diesel engine technology. Advanced LHR diesel engines are predicted to experience top piston ring reversal temperatures of up to $550^{\circ} \mathrm{C}$. This is beyond the operating temperature range for conventional liquid lubrication.

Residency time at such high temperature interfaces promotes the formation of excess amounts of deposits resulting from lubricant decomposition and oxidation. These deposits trap debris, accelerate wear, and cause ring sticking. The resulting increase in lubricant consumption and blowby can cause premature engine overhaul or engine failure. The solution of the high temperature ring-liner tribology problem appears to be a prerequisite for further development of the commercial LHR engine.

The strategy for the tribological activity called for parallel pursuit of two advanced lubrication concepts for the hot section of the cylinder liner: vapor phase [VP] and solid film [SF] lubrication. These concepts have been investigated. Liquid lubricants were used for the lower section of the cylinder liner.

\subsection{SOLID FILM LUBRICATION}

The SF lubrication technology was evaluated through basic laboratory testing and development. The testing matrix for the development of SF lubrication included: three ring materials (cermet, sialon, and silicon nitride), three liner materials (nitralloy, Clevite, and divitrium), and three SF lubricants (intercalated graphite, metal fluorides, and cesium trithioxymolybdate) at three temperature levels $\left(25,300\right.$, and $\left.650^{\circ} \mathrm{C}\right)$. Both friction and wear were measured and compared to the unlubricated condition. The results from the nitralloy and silicon nitride pairs with cesium trioxymolybdate are shown in Figure 19. Due to the poor quality of the sialon test samples, this ring material was eliminated from the test matrix.

The best results were obtained when a SF coating of cesium trithioxymolybdate was used with the nitralloy and silicon nitride pair, where the nitralloy plate simulates the liner and the silicon nitride ball simulates the piston ring. This combination was subsequently recommended as the backup to vapor phase lubrication of a cermet ring and nitralloy liner.

The results from the silicon nitride on silicon nitride testing at $316^{\circ} \mathrm{C}$ are shown in Figure 20. Based on these results, a SF coating of cesium trithioxymolybdate was recommended for the valve-guide interface. 


\section{Friction and Wear of the Nitralloy/Silicon Nitride Pairs $650^{\circ} \mathrm{C}$}

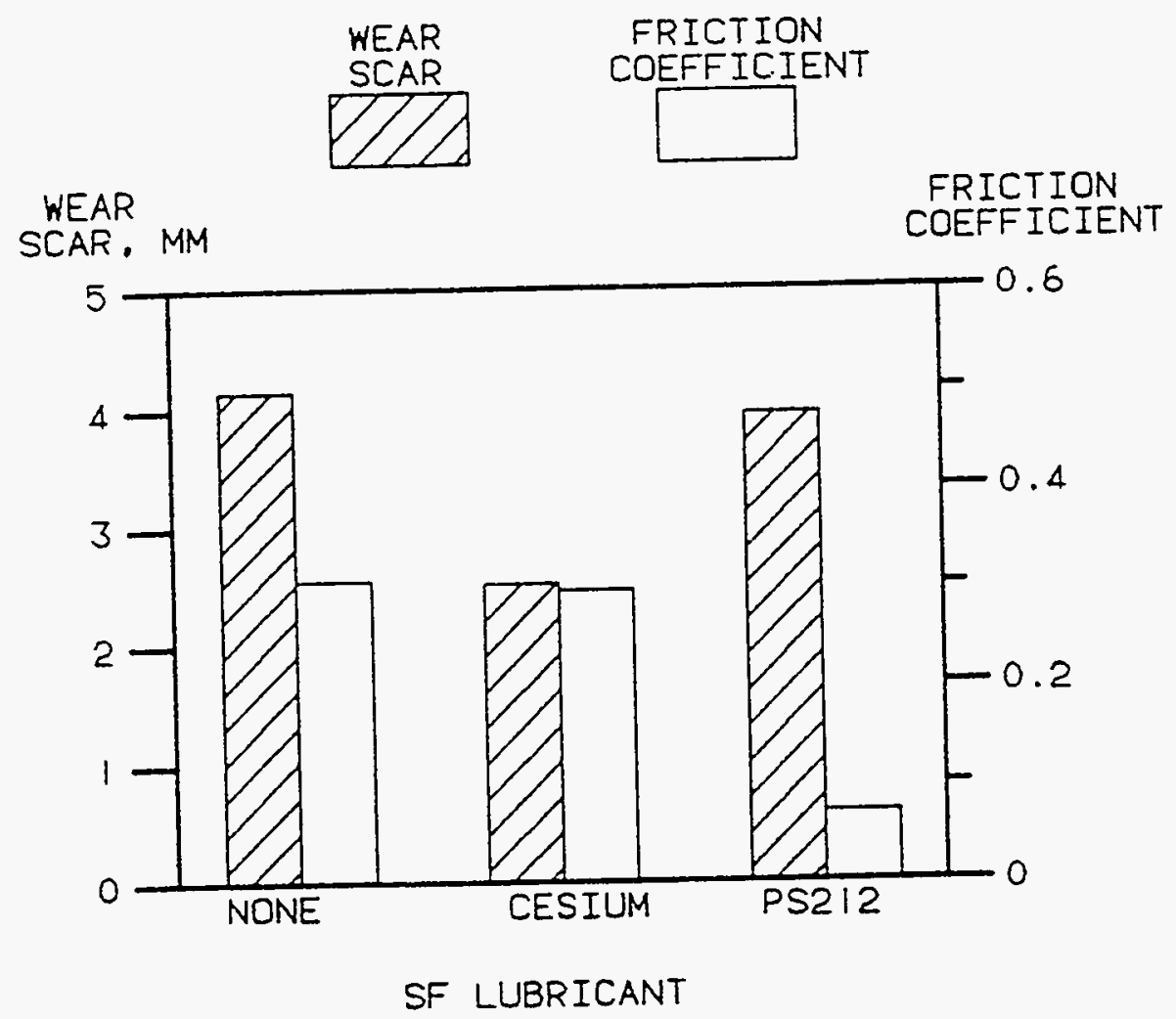

Figure 19: SF Lubrication Test Results Nitralloy on Silicon Nitride (performed by Pennwalt) 


\section{Friction and Wear of the Silicon Nitride/Silicon Nitride Pairs \\ $316^{\circ} \mathrm{C}$}

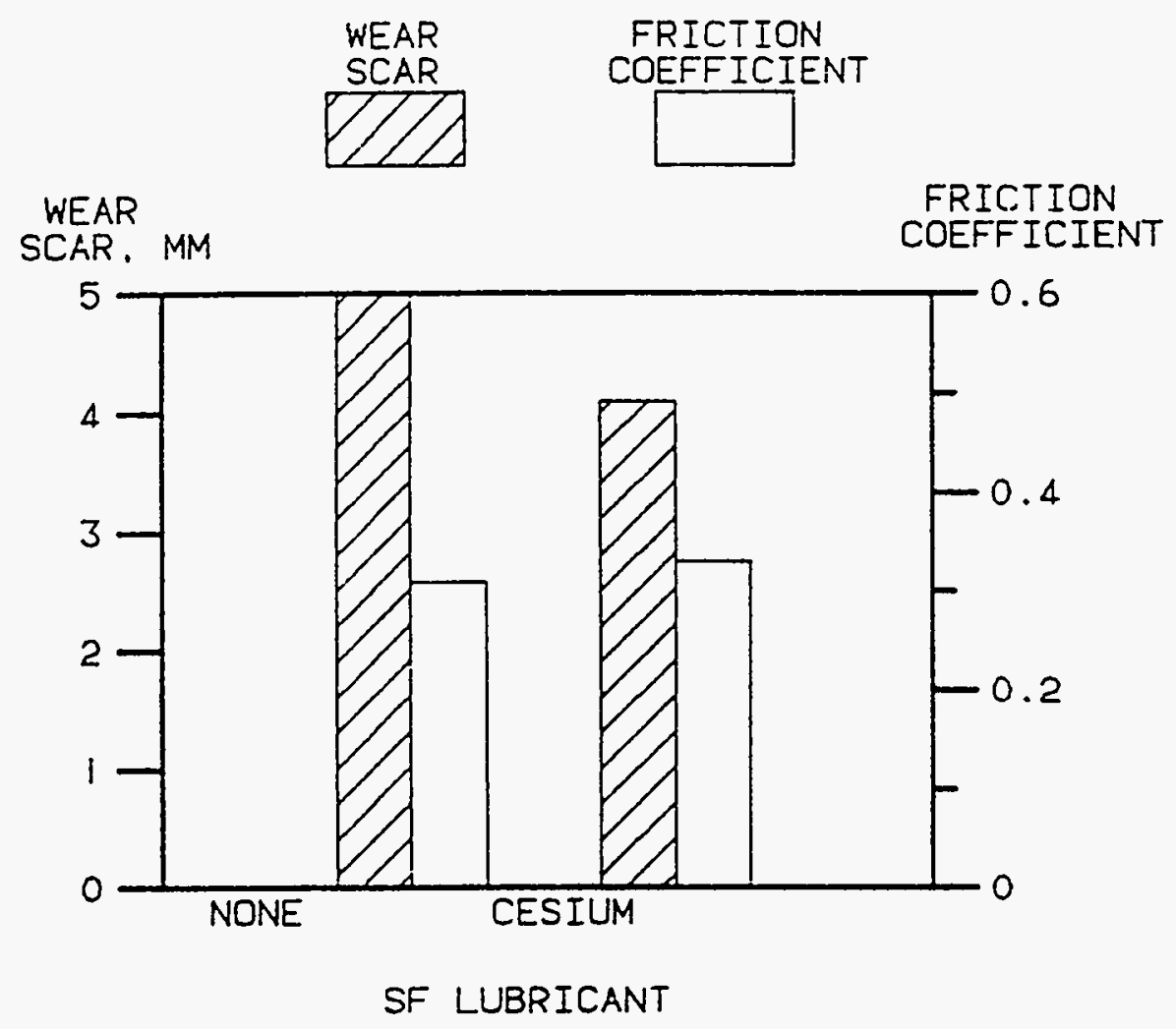

Figure 20: SF Lubrication Test Results, Silicon Nitride on Silicon Nitride, (performed by Pennwalt) 


\subsection{VAPOR PHASE LUBRICATION}

A promising approach for lubrication of the ring-liner interface in the LHR engine is the VP lubrication concept. Vapor delivered lubricant at the piston ring-cylinder liner interface promises expanded operating range and other potential advantages. Vaporized phosphate esters in small concentrations have been used to lubricate diesel engine piston rings in a cylinder kit tribology simulator at $350^{\circ} \mathrm{C}$. Ring wear coefficients and surface topography for several vaporized lubricants and concentrations were measured. The lubrication chemistry correlates well with that observed in vapor lubricated four-ball wear tests.

VP lubrication refers to the deposition of lubricating films directly from an atmosphere of vaporized lubricant. The vaporized lubricant is delivered in a carrier gas to the hot bearing surface where it reacts chemically to form an easily sheared surface layer or a lubricant film. A key advantage of the concept over conventional liquid lubrication, including drop or mist applications, is that it provides a method for continuously delivering only the amount of lubricant necessary for effective lubrication. Thus the degradation of excess lubricant and the buildup of wear accelerating deposits can be reduced. VP lubrication can utilize relatively inexpensive lubricants such as phosphate esters, unlike current high temperature liquid lubricants which are exotic and expensive. Another potential advantage of VP lubrication is in the area of particulate emissions. By delivering a metered amount of vapor, the lubricant consumption of heavy duty diesel engines could be dramatically reduced. Hence, the contribution of engine oil to the particulate emissions can be minimized.

VP lubrication was evaluated in cooperation with Pennsylvania State University. Various concentration levels of three lubricants - tricresyl phosphate [TCP], tributyl phosphate [TBP], and Durad 220 B (diphenyl ditertibutyl phenyl phosphate [DDPP]) - were evaluated.

The formation of vapor deposited lubricant films has been extensively investigated in laboratory tests[1]. Four-ball wear data using vaporized TCP to lubricate M50 tool steel balls at $370^{\circ} \mathrm{C}$ has shown that the VP concept can provide the same level of wear as that obtained from fully flooded liquid lubrication using a formulated API/SF $10 \mathrm{~W}-30$ automotive lubricant. These studies indicate that the deposition rate, and the resulting effectiveness of the VP deposited lubricant film, can be controlled by varying the lubricant concentration in the carrier gas or the elemental composition of the bearing surfaces. Laboratory friction measurements of VP lubricated interfaces [2] have shown that friction coefficients of about 0.15 can be expected. Based on laboratory data, the VP lubrication concept was proposed for the hot section of uncooled LHR diesel engines[3].

The objective of this study was to extend the VP concept to the lubrication of diesel engine piston rings and cylinder liners. Vapor lubricated ring wear was investigated on a cylinder kit simulation rig using ceramic coated piston rings and hardened cast iron liners operating at $350^{\circ} \mathrm{C}$. The performance of three phosphate ester lubricants, supplied at concentrations between 0.0 and 0.17 mole percent in the vapor was evaluated. The morphology and chemical composition of wear debris taken from the simulation rig tests were also examined. 


\subsection{FIXTURE TESTING OF VAPOR PHASE LUBRICATION}

The initial investigations of the VP lubrication concepts of diesel engine components were conducted on a cylinder kit simulation rig. The tests utilized a Cylinder Kit Tribology Test Fixture (CKTTF). This fixture is designed to investigate wear and friction of diesel engine piston rings and cylinder liners under controlled and measurable conditions. The configuration of one of the CKTFF test chambers and its internal details is displayed in Figure 21. The fixture is a dual test chamber, opposed piston arrangement (note that Figure 21 only shows one-half of the CKTTF - the second half is a mirror image of the first half) which reciprocates piston rings on shortened sections of actual cylinder liners. The stroke of the CKTTF is $10 \mathrm{~mm}$ which allows simulation of the critical low speed, boundary lubricated, ring reversal conditions encountered in an engine. Each test chamber contains dual piston rings for more efficient data generation. Piston ring normal force can be controlled by mechanical ring expanders or gas actuation. Heaters on the O.D. of the liner and I.D. of the piston allow testing at engine temperatures.

To accommodate VP lubrication, a vapor generator was added to the CKTTF (Figure 22). The vapor generator consists of a carrier gas heater, a hypodermic needle for lubricant introduction, and a quartz vaporization chamber packed with glass rings. In operation, a nitrogen carrier gas is heated to $260^{\circ} \mathrm{C}$ in a heater. The lubricant is supplied by a syringe pump and delivered to the packed bed of glass rings where it vaporizes. The vapor is carried to the CKTTF test chamber by the continuous flow of the nitrogen carrier and is introduced into the space between the piston rings. The nitrogen and vapor is forced around the rings, through the ring gap, and exhausts to a water trap where any surplus lubricant is recovered.

Two sets of VP lubrication tests were conducted on the CKTTF. The details of these tests (hardware, procedure, wear results) and resulting analysis of ring profiles and wear debris from the CKTTF are discussed in Appendix D. The VP lubrication evaluation on the Tribotester can be summarized as follows:

- Chemical deposits taken from the Tribotester match those taken from Penn State's Laboratory testing.

- TCP provided the most robust ring lubrication for concentrations between 0.06 and 0.17 mole percent and was selected for subsequent engine development.

- TBP increased ring wear at comparative concentration levels. The condition most adversely affecting the TBP lubrication process is elevated temperature (above $350^{\circ} \mathrm{C}$ ).

- Durad 220 B appears to offer excellent lubrication at 0.1 mole percent and warrants further investigation. 


\section{Vapor Inlet}

High

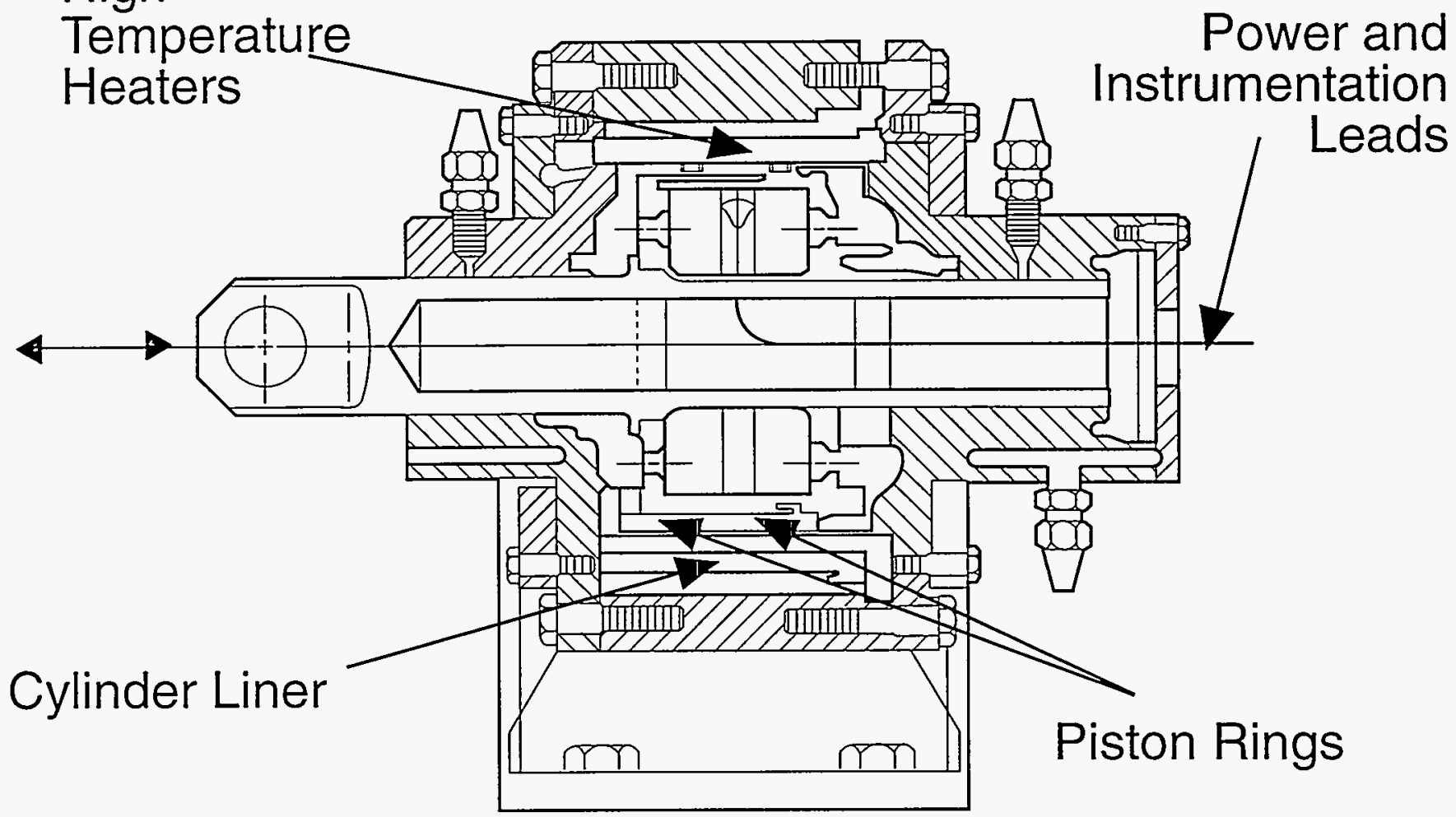

Figure 21: Cross-section of a Chamber of the CKTTF Test Fixture 


\section{Carrier Gas Flow}

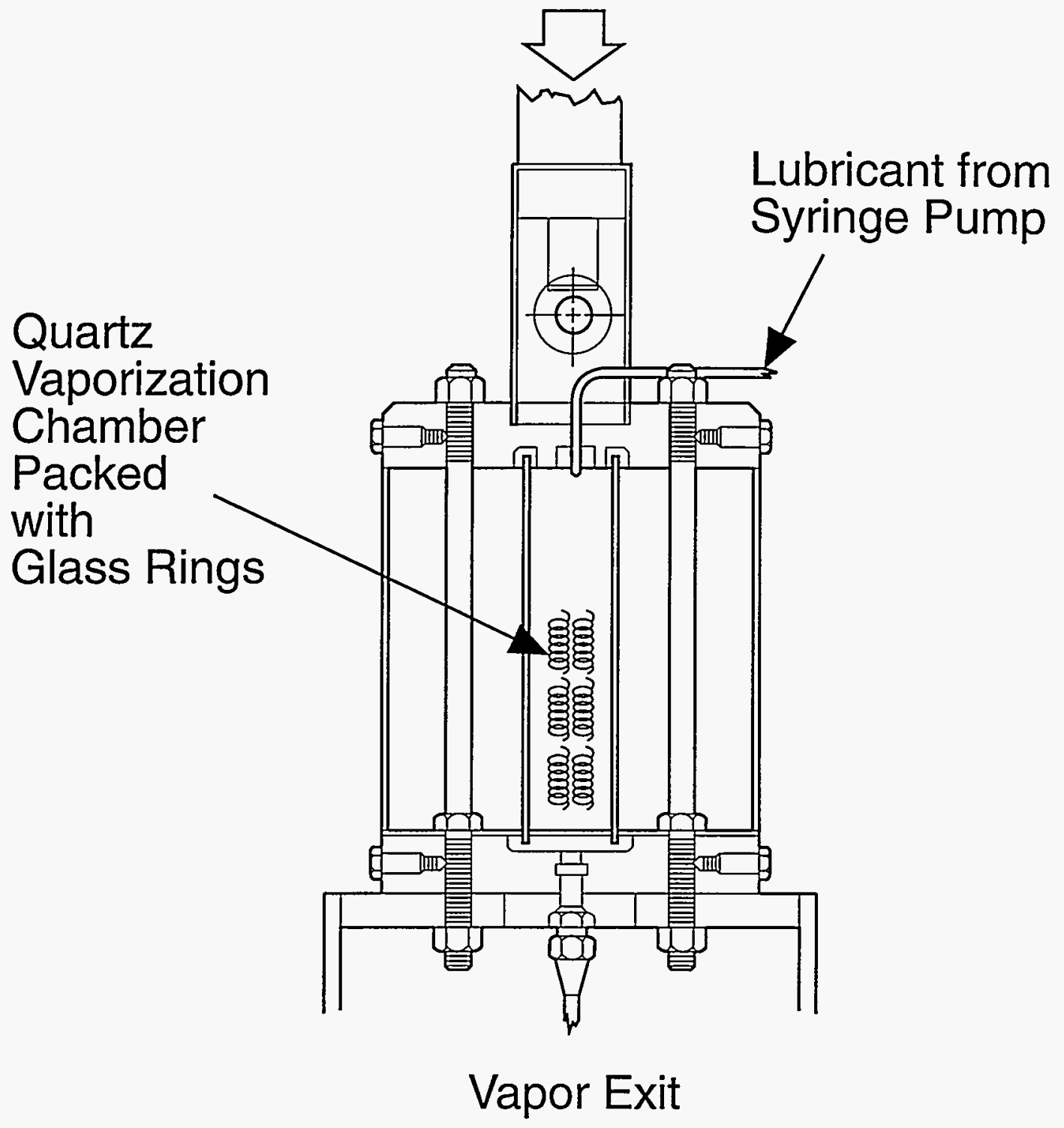

Figure 22: Vapor Generator 


\subsection{ENGINE VAPOR PHASE DELIVERY SYSTEMS}

The successful preliminary proof of concept testing of the VP lubrication concept was followed by integrating the system into the hot section of a SCTB cylinder liner in conjunction with the SRB concept. Initial SCTB activities were accomplished with the vapor phase lubrication [VPL] system shown in Figure 23. With this system, a lubricant is vaporized and delivered into a separated ring belt [SRB] piston cavity by means of a carrier gas, nitrogen. Although complex, this system served to demonstrate the ability to lubricate the critical in-cylinder components with VPL.

The piston ring was lubricated with 0.1 mole percent TCP for 45 hours. TRR temperatures exceeded $475^{\circ} \mathrm{C}$. Real time, in situ wear measurements, via surface layer activation [SLA] were used to monitor the progression of this ongoing activity. These SLA results compared very well to the post-test ring wear measurements. Average ring wear rate varied between 1.29 and 2.01 microns/hr. A typical piston ring profile trace is shown in Figure 24. Posttest inspection also revealed no scuffing or seizure of the VP lubricated SCTB cylinder kit.

Chemical deposits taken from the cylinder liner matched those taken from the CKTTF. This supported use of the tribotester to simulate engine operation toward developing the VP lubrication concept for subsequent LHR application at the critical ring-liner interface. Alternate methods were considered for delivering VPL to the in-cylinder components using electronic control to achieve optimal performance and reduce lubrication contribution to emissions. Five metered lubricant delivery methods were identified and assessed.

- Crankcase Lubrication

- Intake Port Injection

- Lubricant/Fuel Mixture Injection

- Between-the-ring Injection (from within the piston)

- Between-the-ring Injection (from within the cylinder wall)

A crankcase metering approach presents electronic control problems and would require significant improvement over today's oil control technology to meet future emission goals. Even if this could be overcome, lubricant concentration and residency time at top ring reversal [TRR] would be sacrificed, resulting in reduced in-cylinder lubrication and component life. Hence this approach was eliminated from further consideration.

Intake port injection of vaporized and/or liquid lubricant into the cylinder can be electronically controlled and the lubricant's residency time at TRR would seem sufficient. However, the large amount of lubricant required and consumed to maintain the desired concentration level, due to large air flow rates, makes this approach impractical. Additionally, with this approach, the lubricant would be exposed to the combustion process, increasing the likelihood of exhausted emissions. Hence this approach was eliminated from further consideration. 


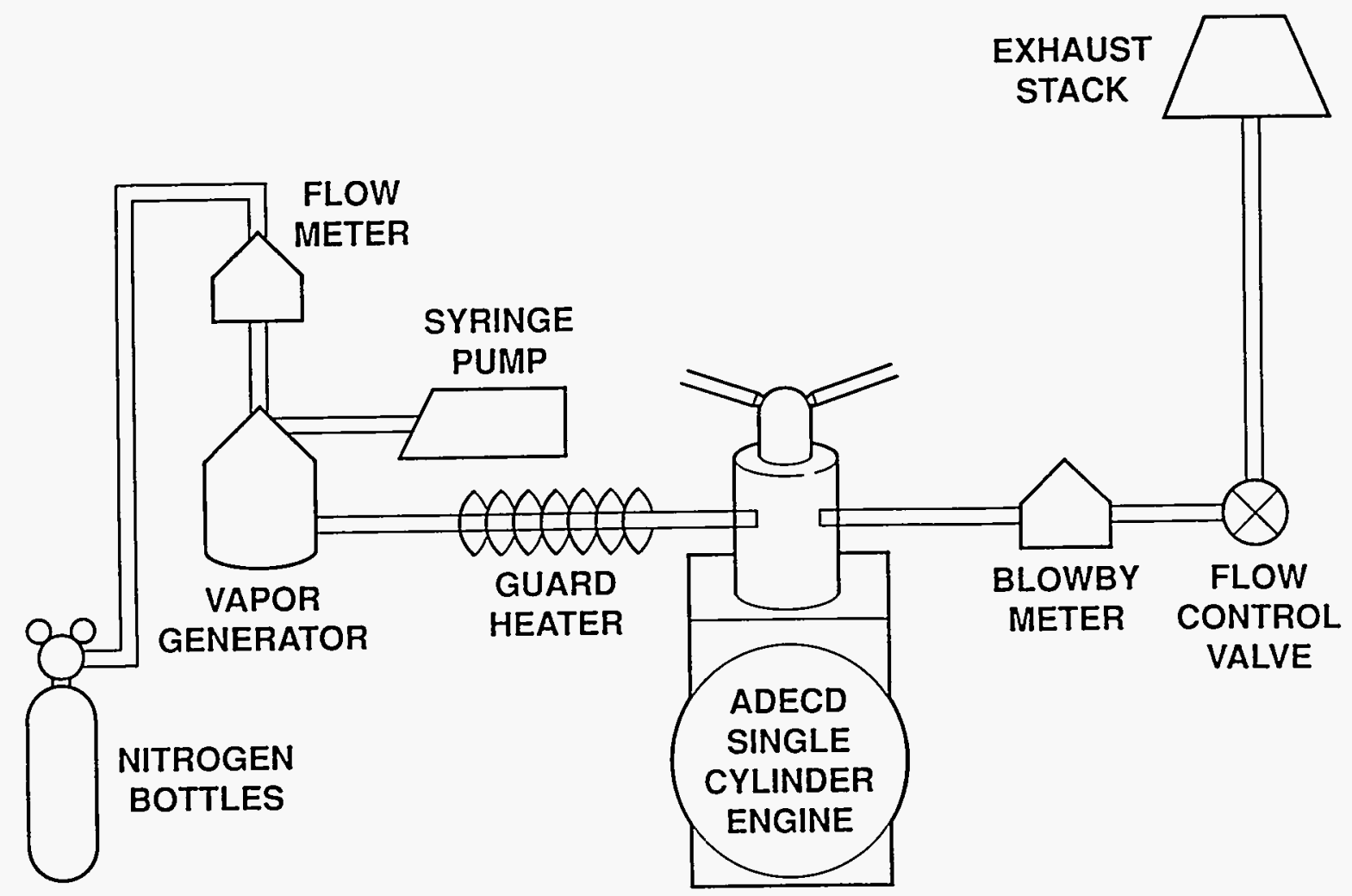

Figure 23: Original VPL System Schematic for the ADECD SCTB 
Piston Ring Profile (Wear vs. Time)

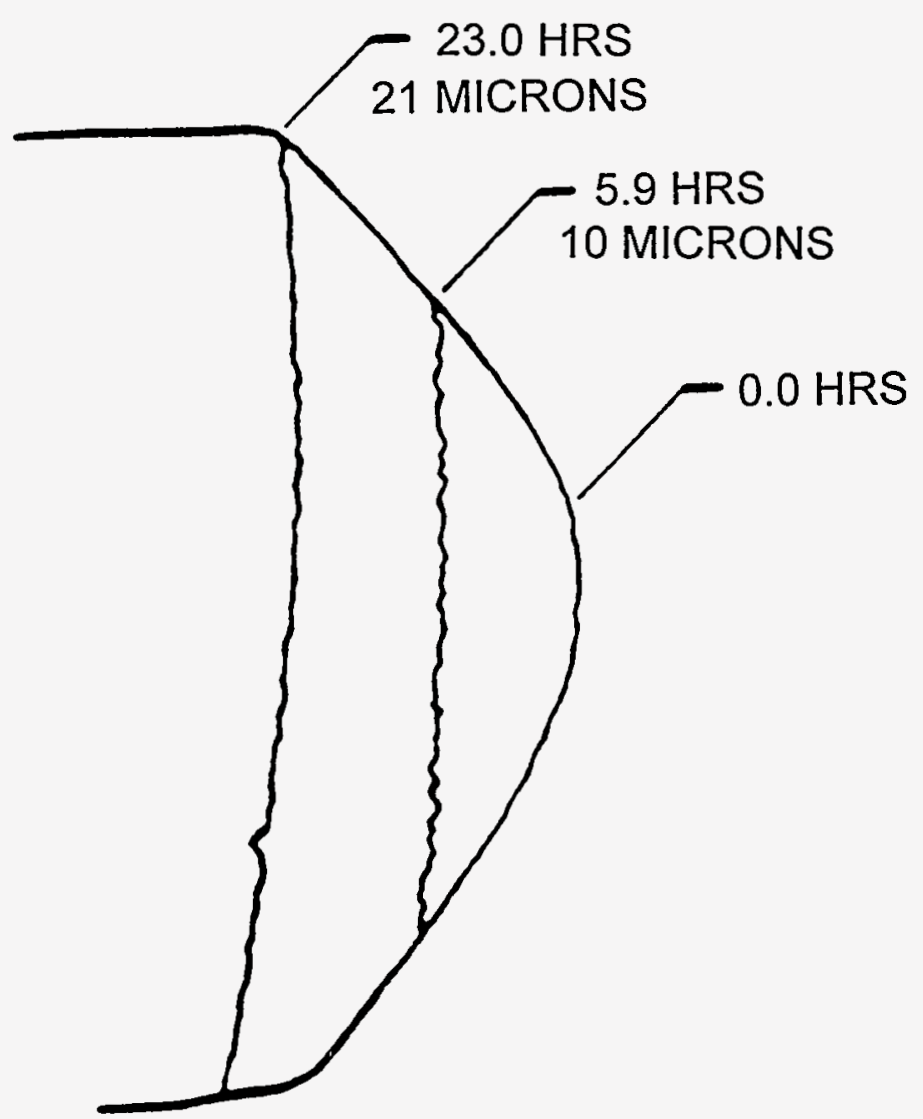

Figure 24: Typical Piston Ring Profile Traces (Various Low Load Engine Operation, 0.1 mole percent TCP VP Lubrication) 
A lubricant/fuel injection mixture system can be electronically controlled and integrated into an engine that already has a unit fuel injector, but the amount of lubricant required and consumed to maintain the desired concentration level would be too large and the potential for durability problems of the injector increases, due to its added complexity. As with the intake port injection system, this approach would expose the lubricant to the combustion process, increasing the likelihood of exhausted emissions. Hence this approach was eliminated from further consideration.

Between-the-ring lubricant delivery through the piston would eliminate the need for a lubricant injector, but it would require a very complex and expensive passageway for lubricant to travel to the desired location of injection. Additionally, the heat of the piston could decompose the lubricant and clog the passageway.

To avoid these problems lubricant routing previously referred to as the between-the-ring (through the liner) approach was chosen for further consideration for the following reasons:

- The ring cavity would facilitate delivery of lubricant to the ring/cylinder interface on a continuous basis.

- The amount of lubricant consumed and exhausted can be controlled, since less lubricant will be required to maintain the necessary volumetric concentration of lubricant within the small between-the-ring cavity.

- The lubricant will not be exposed to the combustion process, avoiding unnecessary exhaust emissions.

- The lubricant parameters can be optimized through electronic control utilization.

- The system is adaptable to engines fitted with electronic engine control.

Consequently, the method of in-cylinder vapor phase lubrication was significantly simplified, as compared to the initial system which required delivery of a vaporized lubricant into a SRB design approach. The simplified system makes it easily adaptable to electronically controlled diesel engines, as well as being directly integrable into the SCTB. An electronically controlled unit injector was designed, fabricated, and calibrated to deliver minute quantities of liquid lubricant directly into the ring/liner interface. Since delivery of the lubricant can be achieved with a conventional fuel injector, high reliability would result.

Calculations were completed to determine the magnitude of lubricant required for this system, as well as how it compares to the current and anticipated state-of-the-art consumption levels. A similar calculation was performed on the previous recirculating SRB system. As shown in Figure 25, the initial recirculating SRB system was expected to match the anticipated state-of-the-art goal of $32 \mathrm{ml} / \mathrm{hr}$. With the alternate delivery system, more than two orders of magnitude reduction in lubricant consumption could be achieved as compared to the anticipated levels. 


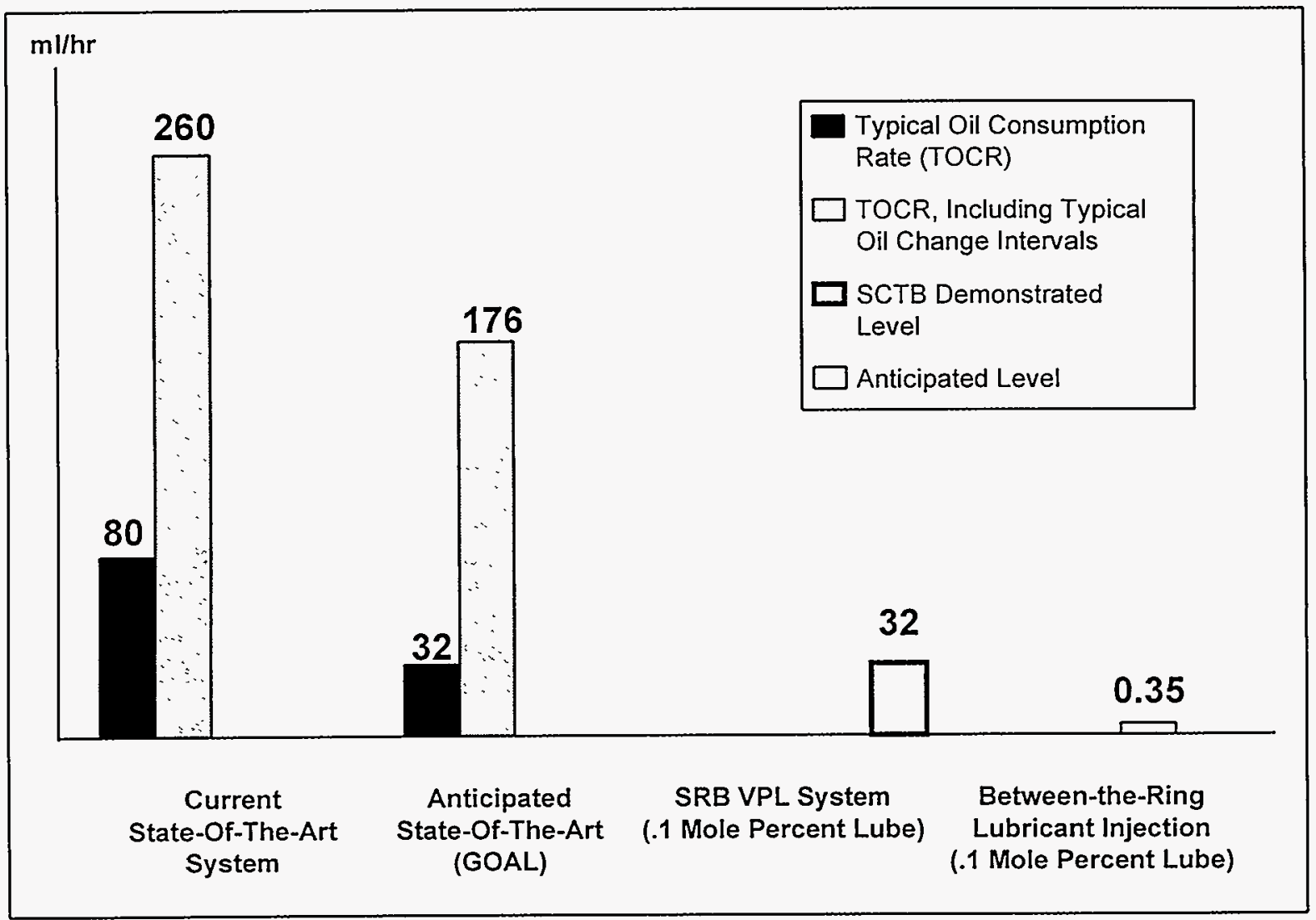

Figure 25: Lubricant Consumption Comparison 


\subsection{IN-CYLINDER LUBRICANT INJECTION SYSTEM DESIGN}

In order to take advantage of the previously mentioned benefits, the in-cylinder lubricant injector shown in Figure 26 was designed. As shown in Figure 26, the proposed in-cylinder lubricant injector consists of 14 pieces and is very similar to an electronic fuel injector. Some of the components in this lubricant injector design are also used in DDC's production fuel injectors.

To assist in the VPL process, an inter-ring insert was designed to increase surface area while filling $20 \%$ of the cavity's volume. This insert had been determined to provide the optimal surface area to facilitate vaporization in previous laboratory testing[1,2]. A nickel-based material was selected for this insert because of its high temperature characteristics and low propensity to attract phosphate. Manufacturing considerations, space available within the current ceramic piston caps, and finite element analysis determined the final geometry. The ability of this insert to minimize the lubricant purge effect of blowby was recognized.

The DDC electronic engine control (DDEC) system was selected to control the in-cylinder lubricant delivery parameters. In addition to controlling the timing and duration of liquid lubricant injection, the DDEC software can be programmed to select regular lubricant injection or a skip cycle option. Use of skipped cycles would tend to increase life and reliability of the in-cylinder lubricant injector beyond the already acceptable level of electronically controlled production fuel injectors. Applicability of this system to production engines is illustrated by the proposed in-cylinder lubricant injection system integration into a DDC Series 60 production engine shown in Figure 27.

Two in-cylinder lubricant injectors were assembled for evaluation in a special rig designed and fabricated for parametric studies (Figure 28). The rig was used to quantify injection parameters such as the starting point and duration of lubricant injection for various engine speeds, inter-ring cavity pressures, and blowby levels. The data collected and summarized in Figures 29 and 30 helped establish the injection parameters necessary to maintain the desired concentration of lubricant in the inter-ring cavity at 0.1 mole percent. Figure 29 shows the volumetric amount of lubricant which needs to be injected for a particular operating condition, as a function of the inter-ring pressure and temperature. Figure 30 shows the number of skipped cycles required to maintain the desired level for the predetermined amount of lubricant (from Figure 29) and the amount of blowby. This information on injection parameters necessary to maintain 0.1 mole percent lubricant for various engine operating conditions was programmed into the DDEC control system.

This design, with DDEC and solenoid control, allows for precision control of lubricant quantity, timing, rate and frequency of injection. The injector was installed through the engine block and cylinder liner at bottom ring reversal to minimize combustion gas backpressures on the injector. Lubricant was injected into a pocket between the top and second compression ring containing a wound wire spring insert. This spring acts to hold the lubricant, while increasing the pocket surface area, thereby promoting vaporization of the lubricant over a greater portion of the four stroke cycle. The injected volume of lubrication 


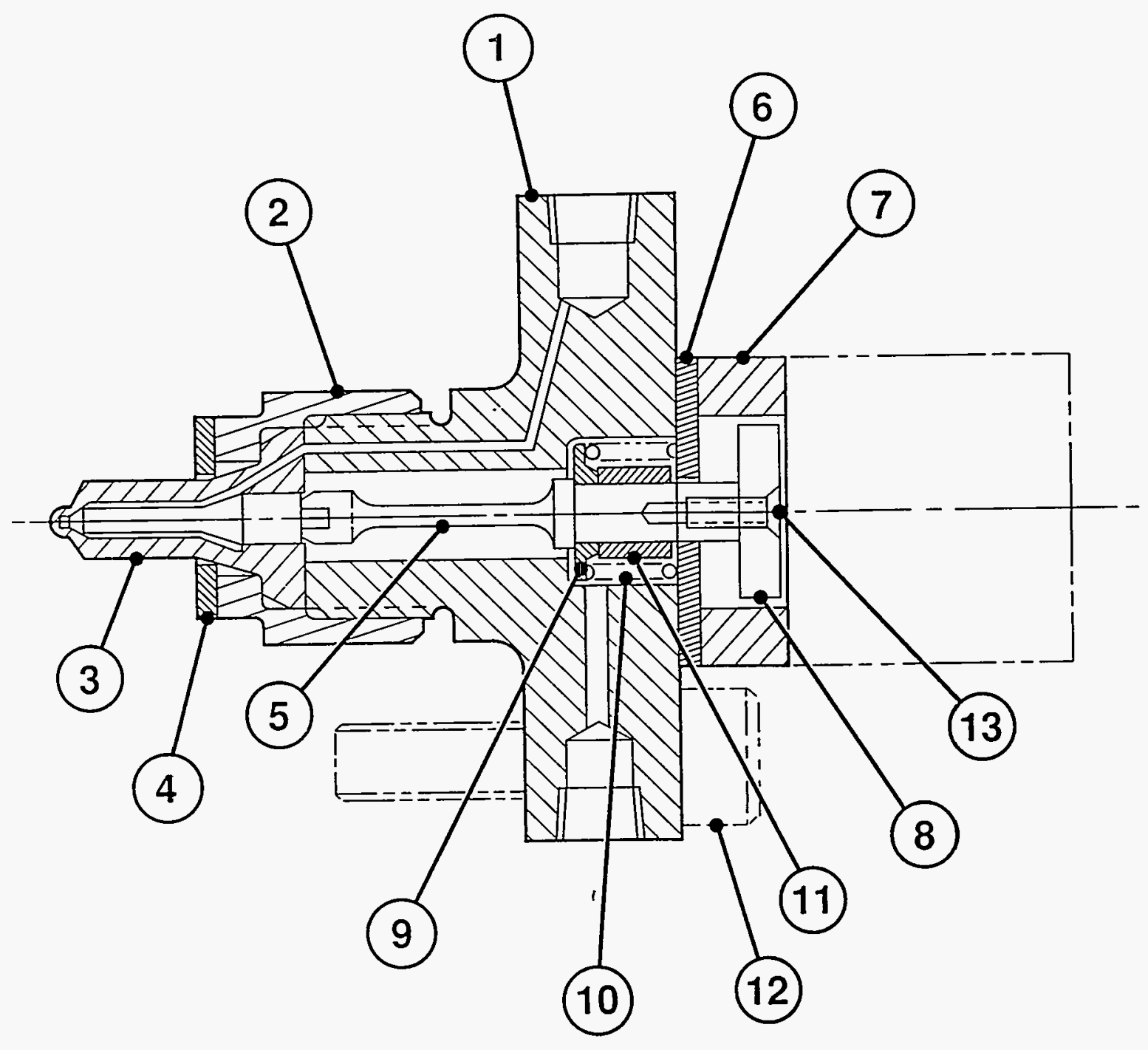

Key Description

1 Body - Injector Valve

2 Adapter-Injector

3 Tip - Injector

4 Gasket

5 Plunger - Injector

6 Plate - Spacer

7 Spacer - Solenoid

8 Armature - Solenoid

9 Seat - Spring

10 Spring

11 Stop - Plunger

12 Bolt - M8 $\times 30$ (2 Required)

13 Screw - Flat Head

Figure 26: Electronically Controlled In-cylinder Lubricant Injector 


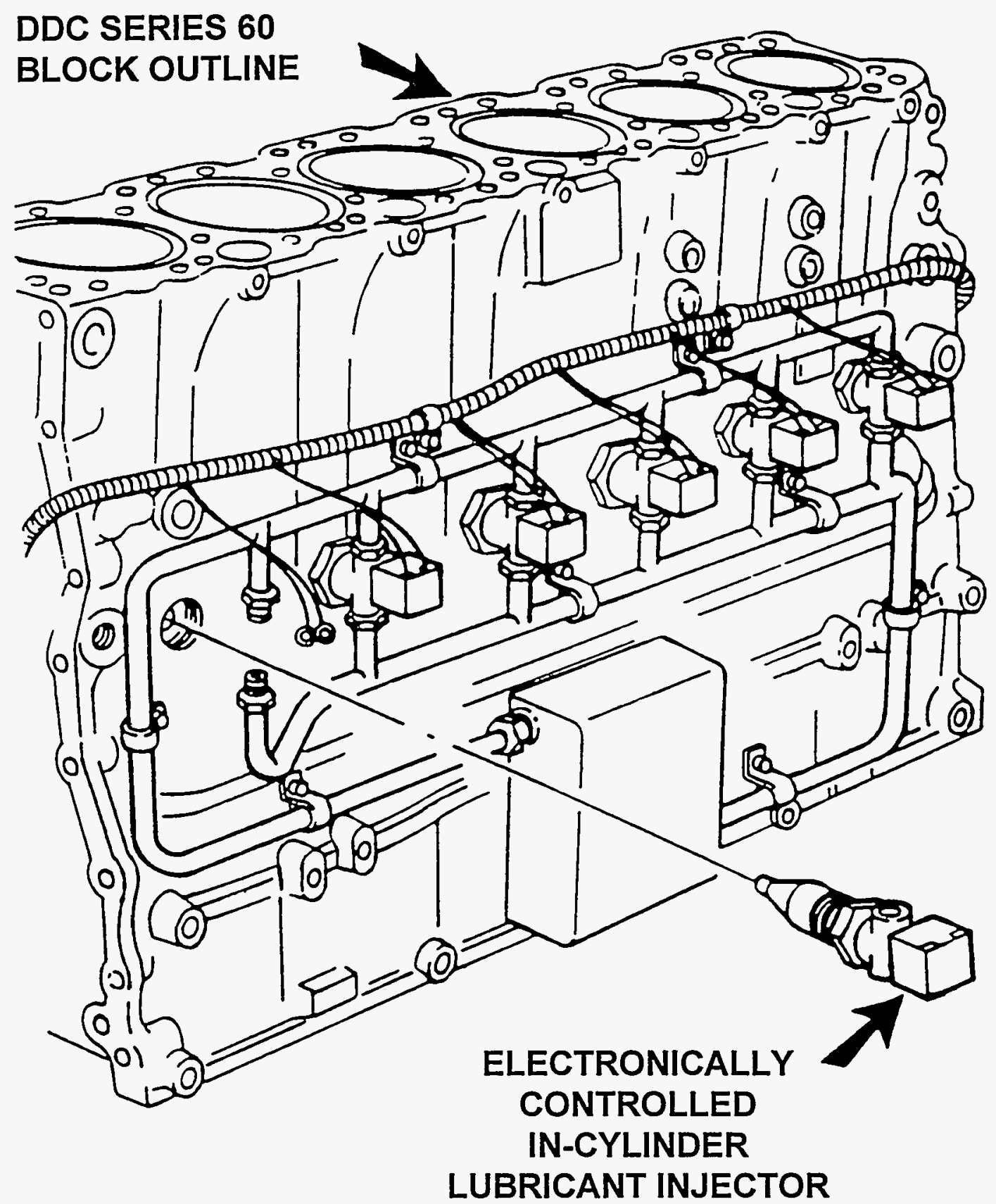

Figure 27: Conceptual Schematic: Integration of an Electronically Controlled In-cylinder Lubricant Injector into a DDC Series 60 Engine 


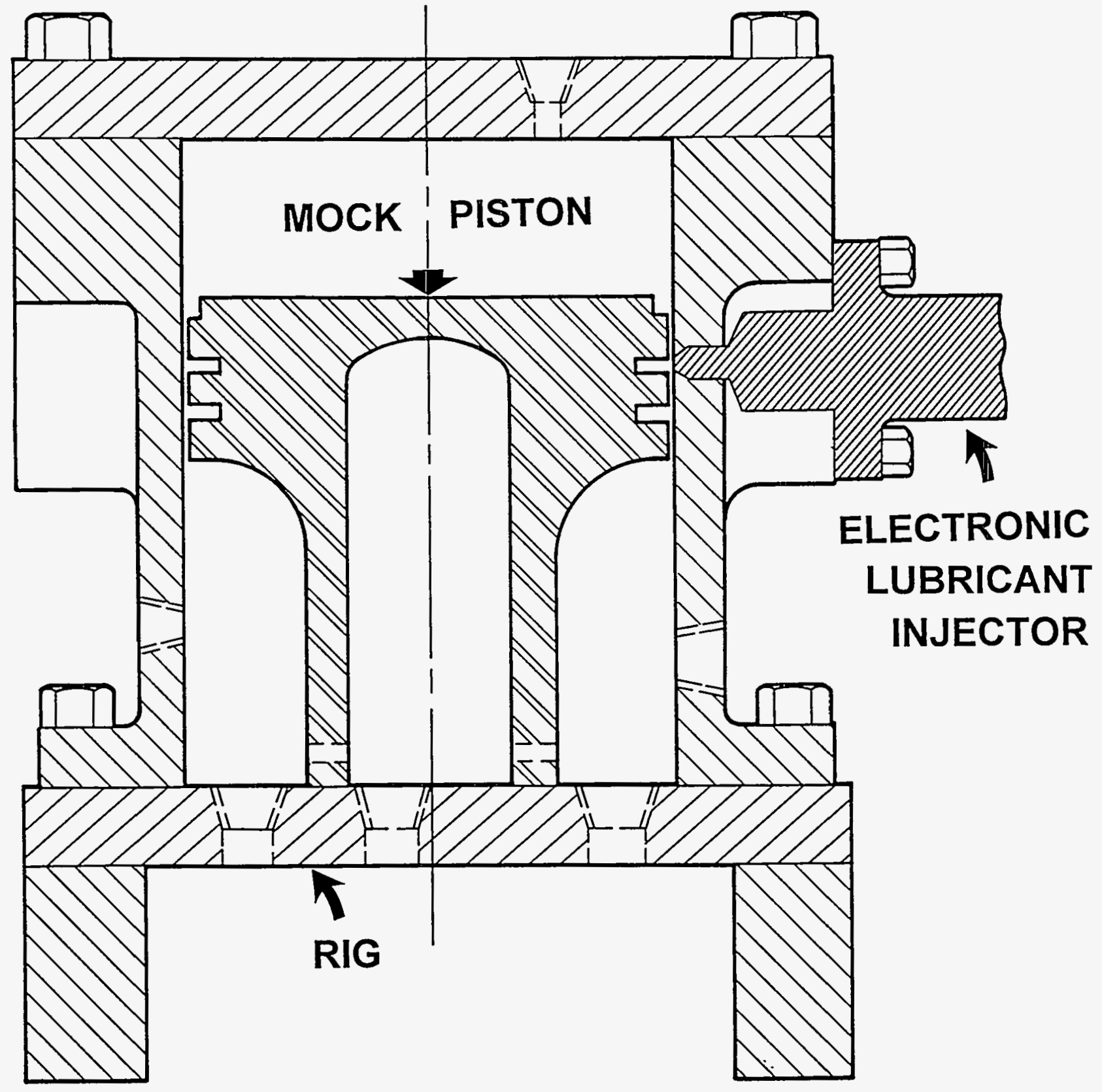

Figure 28: In-cylinder Lubricant Rig 


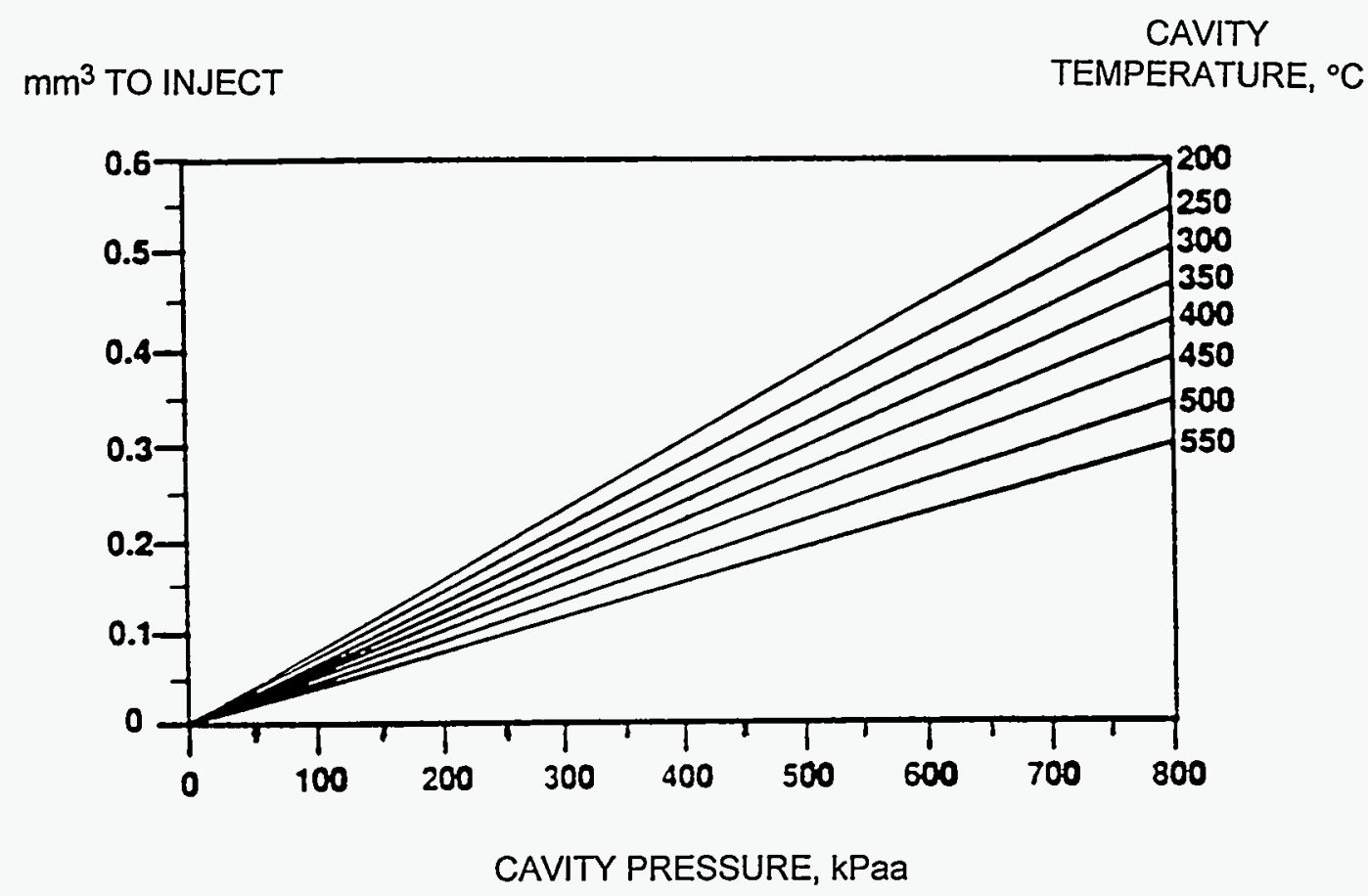

Figure 29: In-cylinder Lubricant Injector Data Injected Volume vs. Cavity Pressure 

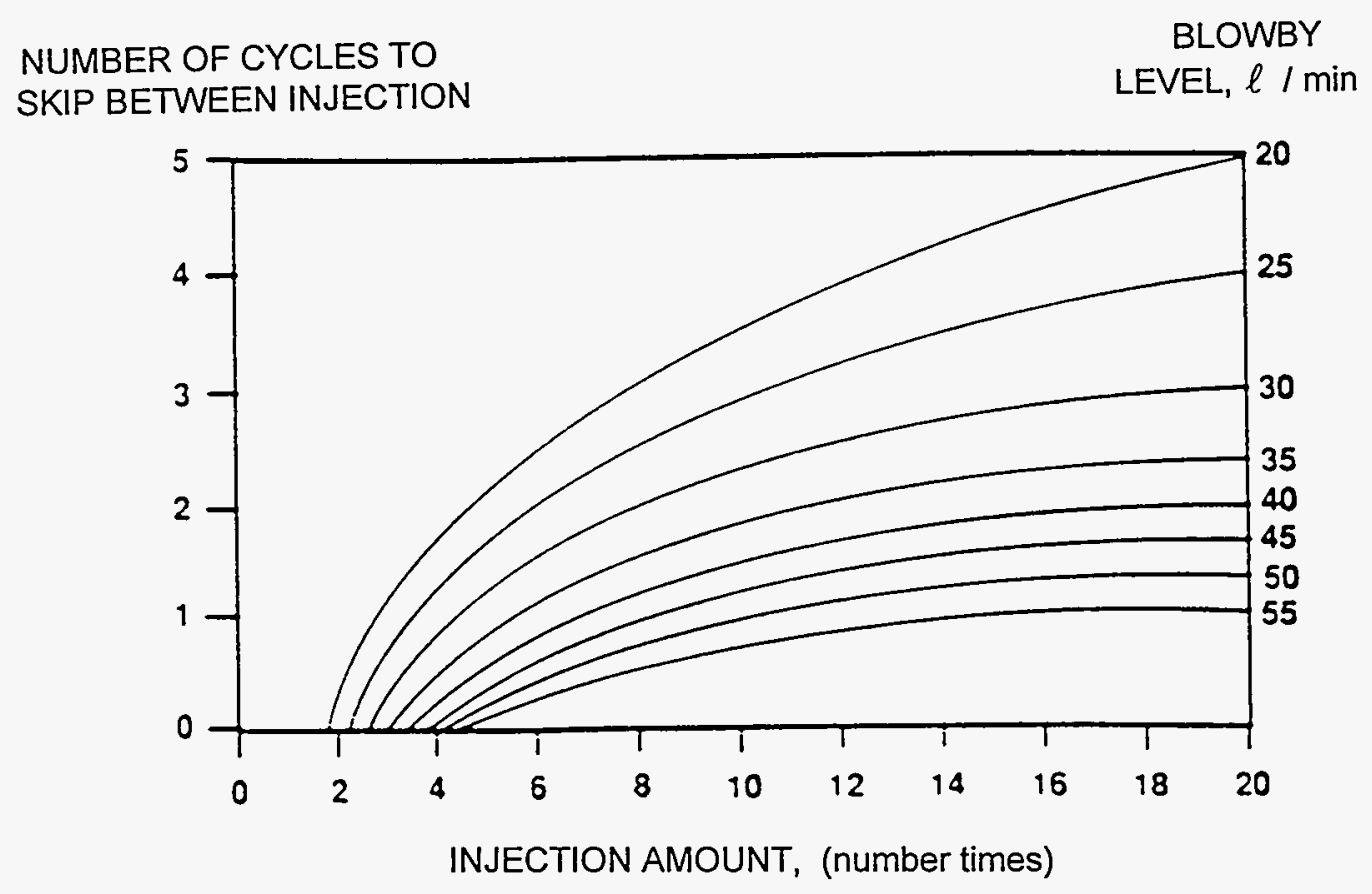

ASSUMPTION: $15 \%$ OF BLOWBY IS PURGED

Figure 30: In-Cylinder Lubricant Injector Data Number of Skipped Cycles vs Injected Volume 
was metered to insure proper concentration in the inter-ring pocket. Since the volume of the inter-ring pocket is small, only minute quantities of lubricant are necessary to provide the necessary lubricant concentration.

On the SCTB, the injector was located on the intake side at bottom ring reversal and injected at the beginning of the compression stroke. Lubricant was supplied at variable pressures to the injector by an external pressure source. Locating the injector at bottom ring reversal reduces the amount of heat flux into the injector, thus reducing the potential for tip plugging and the need for additional cooling of the injector. Injection of the lubricant just before the compression stroke and at bottom ring reversal permits lower injection pressures via reduced back pressures and provides a fresh charge of lubricant during the high cylinder pressure compression and expansion portion of the four-stroke cycle. Locating the injector on the intake side insures that the lubricant is delivered on the cooler side of the cylinder, allowing lubricant to vaporize over a greater portion of the cycle.

\subsection{PERFORMANCE COMPARISON OF LUBRICATION SYSTEMS}

A back-to-back comparison test of the lubricant injector and baseline carrier gas lubrication systems was conducted (Build \# 12 and 13). The SCTB was run first using the baseline carrier gas method and most of the lubricant injector system engine hardware: a block and liner with the lubricant injector port, the three groove piston, with the center groove containing the inter-ring pocket insert and the two ring cylinder kit consisting of a modified L-section top ring and angled step gap second ring (Section 2.7). This configuration allowed for a direct comparison of engine emissions and lubrication performance of the two lubrication systems. It also permitted the determination of inter-ring pocket pressures and temperatures, necessary for the specification of the lubricant injector electronic control parameters. Both tests were conducted with a lubricant consisting of a $6 \%$ TCP solution in white mineral oil.

Testing of the lubrication systems was conducted primarily at a $25 \%$ power level to minimize blowby purging of lubricant from the inter-ring pocket. The baseline carrier gas engine test was conducted in three phases, for a total of six hours of engine testing. During the first phase, the engine was operated at a $50 \%$ power level in an unsuccessful attempt to achieve reasonable blowby levels. Section 7.13 presents typical blowby and top ring reversal liner and head temperatures at $25 \%$ power. The separation of the exhaust and intake top ring reversal liner temperatures at points where blowby fluctuates indicated that this engine was susceptible to ring pack frictional heat deformation related to marginal lubrication causing the effectiveness of the ring seal to vary. Engine performance during the first and second phases was consistent with previous test runs[2,3], with comparable indicated power, pumping losses, and frictional power losses. In the third phase of testing, blowby was $50 \%$ higher than the previous two phases, and engine performance had degraded. After a total of six hours of engine operation, the engine was torn down to reveal a major piston failure (see Section 7.13). 
The ceramic piston dome was found to be fractured in the top outer rim for about 270 degrees of its circumference, extending into the ring grooves in some areas. Scuff marks on the piston rings and liner indicate that the most likely cause of this failure was due to scuffing of the ring, causing momentary seizure, resulting in an excessive load to ring lands. This was a result of high ring wear permitting metal to metal contact between the ring substrate material and the cylinder liner. Seizure is further supported by the top compression ring deformation in the area where the ceramic fractured. There was no evidence on the ring gap indicating ring butting. As a result of this failure, ceramic debris was introduced between the rings and liner, confounding wear measurements for the baseline carrier gas run.

The engine was rebuilt with a new head, piston, liner, ring pack and the lubricant injector for the lubricant injector test run. Section 7.14 presents typical blowby, and top ring reversal liner temperatures and head temperatures. See Figures 57 (page 97) and 58 (page 99). Note the difference in temperature separation of the exhaust and intake sides from the baseline run. This greater separation is most likely due to better lubrication on the lubricant injector side (intake) of the cylinder, permitting the piston rings to seal better. This resulted in better contact of the piston ring to the liner, thus permitting more heat flux into the intake side of the cylinder. The blowby was significantly lower than the baseline, carrier gas test run. The fueling rate, however, was slightly higher than the baseline.

During the tear down inspection of this test run, it was again found that the ceramic piston dome had fractured, although not to the extent of the baseline carrier gas run. The ceramic wear debris was contained and did not appear to affect the ring wear. The tear down inspection also revealed lubricant coating the combustion chamber surfaces, with significant amounts of carbon residue on the fire deck, sides of the piston, and in the oil ring groove, causing the oil rings to stick. The condition of both ring faces was similar to the baseline carrier gas test run, with scuffing occurring 360 degrees around the outside diameter.

Engine performance and emissions data for the two test runs are presented in Table 4. The increase of motoring torque, indicated power, and fueling rate exhibited for the lubricant injector test run indicate an increase in friction. The ISFC is about the same, indicating the combustion process has not changed. Valve event performance was also noted not to have changed, indicating that pumping losses were also most likely the same. Increases in Bosch Smoke, NOx and the carbon balance error indicate that some of the injected lubricant was consumed in combustion. Note also that the average blowby decreased despite the increase in ring gap from the carrier gas to the lubricant injector run. Overall, with the lubricant injector, engine performance is mixed in comparison to the carrier gas VPL baseline run.

To compare ring wear between use of the carrier gas and lubrication injector, wear data from the ring pack design test run, noted above, was used. This run, other than a shorter test time, was functionally not different than the baseline carrier gas run, and will be considered here as the baseline run for purposes of wear analysis because of the ceramic piston failure. During all test runs, ring wear was extremely high. Radial wear measurements of the top and second rings indicate that wear was greater than the print specified face coating 
thickness of $0.15 \mathrm{~mm}$ for the carrier gas run, and approximately the same as the thickness for the lubricant injector run. Since the wear was high for both test runs, it is not felt that the silver friction reduction coating on the lubricant injector run rings was a significant factor in the wear analysis comparison of the lubrication methods.

TABLE 4

LUBRICATION SYSTEM ENGINE PERFORMANCE COMPARISON

$\left(1800 \mathrm{r} / \mathrm{min} 30 \mathrm{~N} \cdot \mathrm{m} \quad 110 / 140 \mathrm{kPa}^{*}\right)$

\begin{tabular}{|l|l|c|c|}
\hline \multicolumn{2}{|l|}{} & $\begin{array}{c}\text { Carrier } \\
\text { Gas VPL }\end{array}$ & $\begin{array}{c}\text { Lubricant } \\
\text { Injector }\end{array}$ \\
\hline $\begin{array}{l}\text { Motoring Torque } \\
1800 \mathrm{rpm}\end{array}$ & $\mathrm{Nm}$ & -67 & -69 \\
\hline Indicated Power & $\mathrm{kW}$ & 16.7 & 17.6 (est.) \\
\hline Pumping Loss & $\mathrm{kW}$ & -2.35 & \\
\hline Max. Cylinder Pressure & $\mathrm{MPa}$ & 10.4 & $9.0(?)$ \\
\hline ISFC & $\mathrm{g} / \mathrm{kW}-\mathrm{hr}$ & 180 & 181 \\
\hline Fuel Mass & $\mathrm{kg} / \mathrm{min}$ & .050 & .053 \\
\hline Bosch Smoke & & 0.9 & 1.2 \\
\hline NOx & $\mathrm{ppm}$ & 433 & 473 \\
\hline Carbon Balance Error & & $\sim+1 \%$ & $+8 \%$ \\
\hline Blowby & liters/min & 110 & 90 \\
\hline Ring Gap & $\mathrm{mm}$ & 1.7 & 2.0 \\
\hline
\end{tabular}

* $110 / 140 \mathrm{kPa}$ intake/exhaust restriction respectively

Figures 31 and 32 present the wear rates of the top and second rings for the two lubrication methods. The injector was better at lubricating the top ring than the carrier gas. This is a result of the high blowby and the second ring blocking the top ring from lubricant in the carrier gas run. It is likely that no significant quantity of lubricant was deposited on the top ring or liner walls near its top ring reversal, the most critical area, nor was any significant quantity of lubricant carried up the liner into top ring reversal zone. This is supported by the similar wear rate of the second ring, indicating similar levels of lubrication for both methods. The larger difference in the second ring radial thickness wear is explained by the varying level of lubrication around the cylinder in the lubricant injector run.

The lower radial wear rate for the lubricant injector run implies that better lubrication is supplied to the second ring despite any potential problems with lubricant migrating about the ring zone. This decrease in ring wear rate for the lubricant injector run also occurred despite a lower than targeted level of lubrication in the inter-ring pocket. 


\section{RING WEAR COMPARISON}

MASS CHANGE

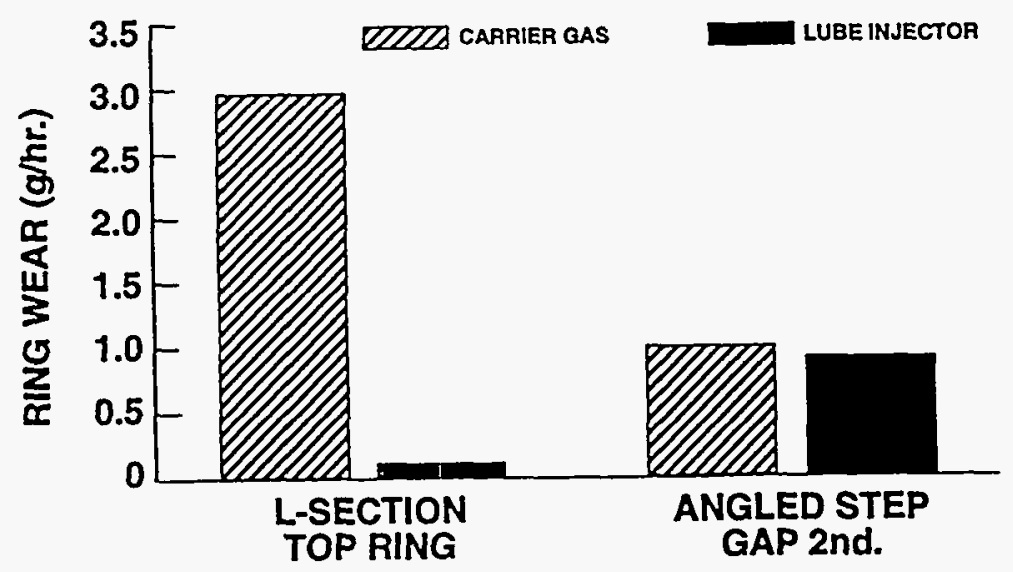

Figure 31: Ring Wear Comparison, Ring Mass Change

\section{RING WEAR COMPARISON}

RADIAL WIDTH CHANGE

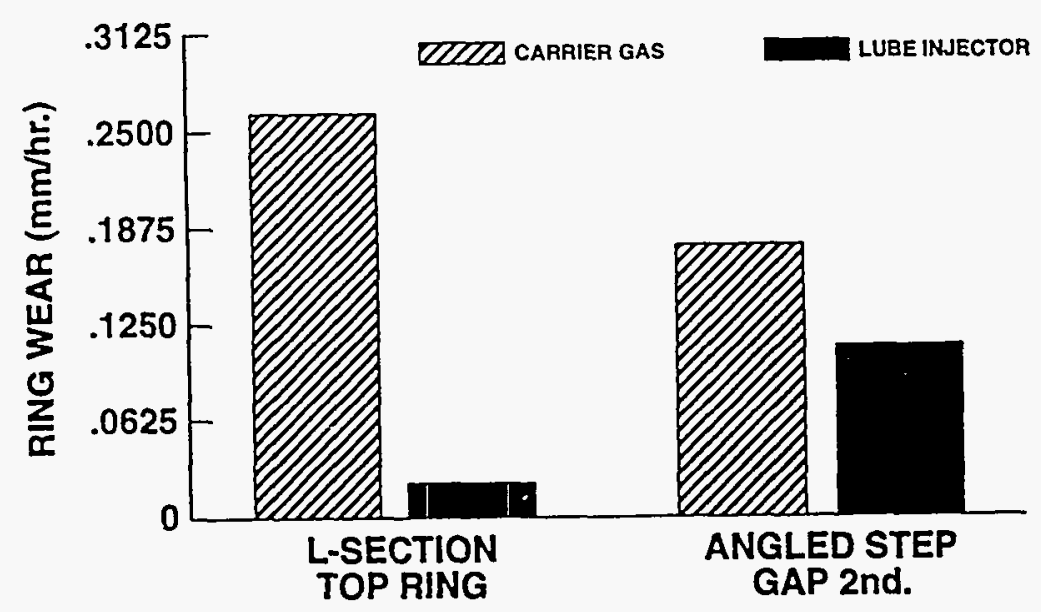

Figure 32: Ring Wear Comparison, Radial Thickness Change 
The low lubricant concentration gives some insight into the higher friction phenomenon observed in the lubricant injector run. Levels of lubricant concentration on the order of 0.01 to $0.03 \mathrm{~mol} \%$ have been seen to cause increased wear in CKTTF testing. Figures 33 and 34 presents ring and liner wear data from the CKTTF testing for several levels of vapor phase lubrication concentrations. Note the higher rate of wear for lubricant concentrations at 0.01 to $0.05 \mathrm{~mol} \%$, even higher than no intentional lubrication. It has been theorized that very low levels of VPL lubrication do not act effectively as lubricant shear layers. Rather wear debris is trapped, promoting increased wear and friction.

The lower blowby and ring wear rates of the lubricant injector run indicate that the optimal concentrations of lubrication may be lower than that for the carrier gas method. An examination of liner wear confirms that the quality of lubrication varied around the cylinder for both the lubricant injector and carrier gas test runs, as indicated by the second ring-top ring reversal liner wear step (Figure 35). Liner wear is lowest on the intake side of the cylinder where the lubricant injector was mounted. Two factors account for the difference in liner wear around the cylinder. First, the single injection port and the purge effect of the blowby do not permit the lubricant to effectively migrate around the cylinder. Second, the exhaust side of the liner is hotter, promoting wear and, as a result of the thermal distortion of the ring, a greater level of purging blowby. The higher liner wear for the lubricant injector test run is probably due to the lubricant concentration starvation conditions noted above. The top ring reversal wear step, Figure 36, indicates that both the carrier gas and lubricant injector runs had lubricant starvation conditions, as seen by the equivalent liner wear. The higher ring wear at the lubricant injector (intake side) is most likely the result of a low lubricant concentration, a condition worse than no intentional lubrication.

\section{System Comparison Conclusions}

Overall, the SCTB tests show that the lubricant injector is promising. Both lubrication methods encountered very high ring and liner wear, as compared to previous SCTB testing and conventional ring wear experience. However, this is due, in part, to the new ring pack design that was installed prior to this testing. This high tension ring pack, designed for blowby control, was not optimized for minimal ring wear in a low heat rejection engine. Nor did this ring pack entirely achieve the intended blowby control target. Second, the lubricant injector inter-ring lubricant concentration is very sensitive to blowby purge. While lubrication and blowby are interlinked -- better lubrication results in lower blowby -- it is important that blowby be controlled to ensure that good lubrication is achieved. Therefore, in order to implement the lubricant injector concept, it is absolutely necessary to control blowby.

These tests provide evidence that perhaps two lubricant injectors or injector ports are necessary for each cylinder. Data from the two test configurations indicate the inter-ring lubricant injector run produced lower blowby and lower ring wear. The injector run also produced higher liner wear and friction. It should be kept in mind that if the lubricant 


\section{EFFECT OF LUBRICATION CONCENTRATION ON WEAR (CKTTF)}

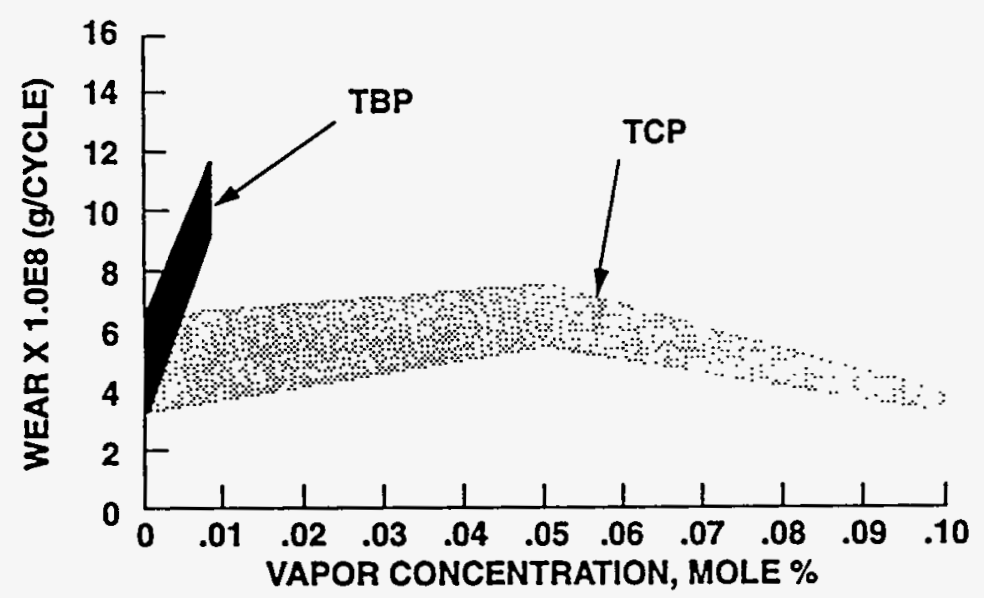

Figure 33: VPL Lubrication Concentration \& Wear
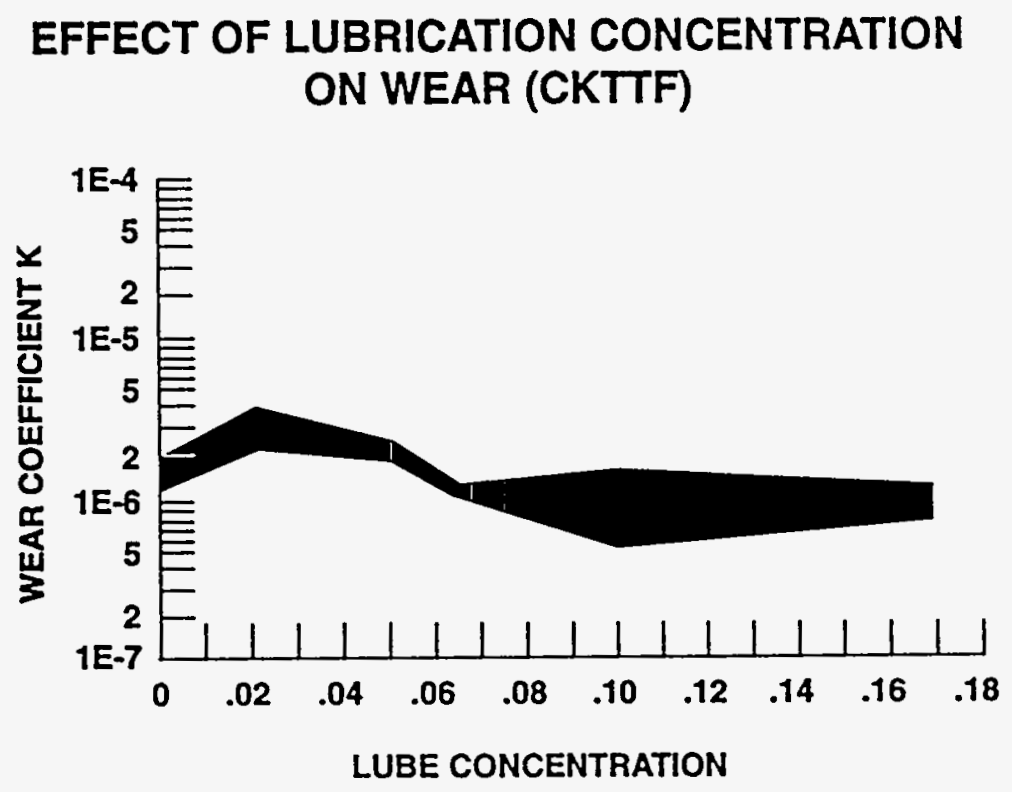

Figure 34: VPL Lubrication Concentration \& Wear 


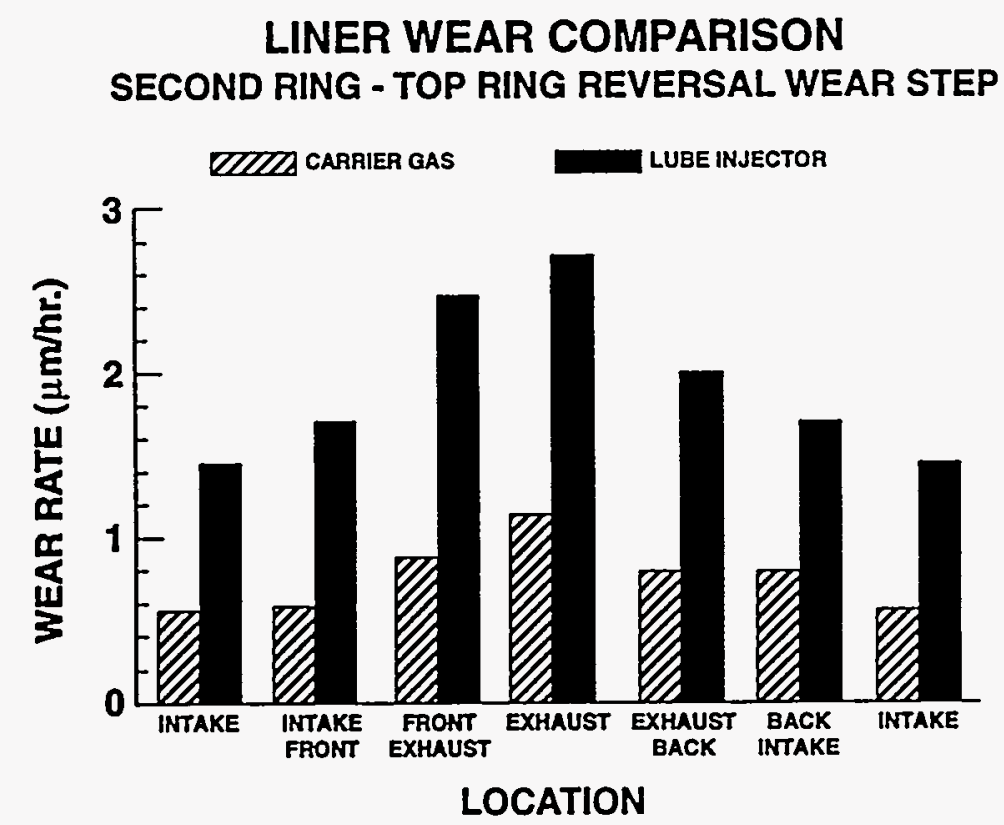

Figure 35: Liner Wear Comparison, Second Ring - Top Ring Reversal Wear Step
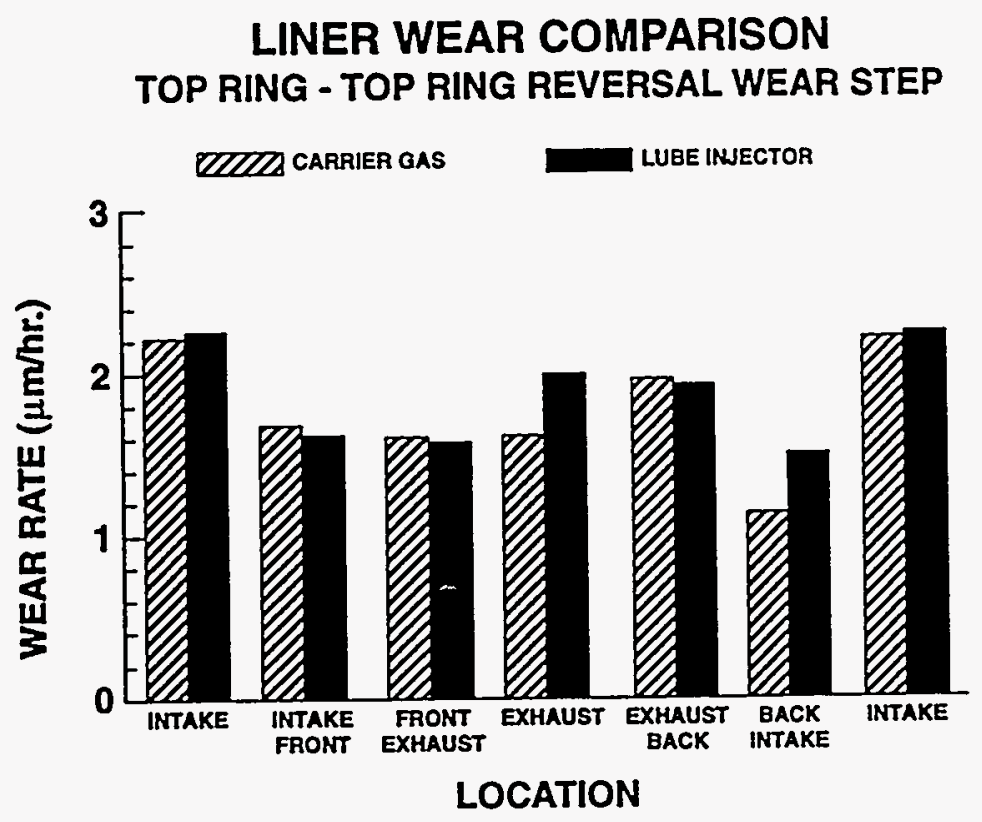

Figure 36: Liner Wear Comparison, Top Ring - Top Ring Reversal Wear Step 
concentration in the inter-ring pocket had been at the intended level, the same as the carrier gas test, these observations may have been different. Finally, some of the injected lubricant may be burned in-cylinder, as exhibited by the higher smoke, and carbon balance error. If this is the case, one of the intended strengths of this system, lower emissions through lower lubrication consumption, is lost. However, further testing of the lubricant injector on a more stable test platform is warranted before the emissions issue can be fully understood.

\section{CONCLUSIONS}

Within the context of the limited data generated in the comparison testing of the baseline carrier gas versus the lubricant injector delivery system, the following conclusions are made:

1. The lubricant injector shows potential as a practical vapor phase lubrication delivery system for low heat rejection engines, yielding lower blowby and ring wear in comparison to the carrier gas VP lubrication method.

2. Both the lubricant injector and carrier gas lubrication methods exhibited very high ring and liner wear compared to previous SCTB testing and with conventional engine test experience. However, the new ring pack implemented for blowby control during this testing is believed to be a significant factor in this higher wear.

3. The lubricant injector inter-ring lubricant concentration is very sensitive to blowby purge, resulting in lower than desired lubricant concentrations. In SCTB testing, uneven circumferential liner wear was demonstrated. Testing of the lubricant injector was conducted under non-ideal, high blowby conditions. It is unclear if reasonable blowby levels would have permitted adequate lubricant migration or whether additional injector locations are needed.

4. The lubricant injector delivery system produced higher liner wear and friction compared to the baseline carrier gas lubrication system. This observation is confounded by the poor lubricant concentration in the inter-ring pocket.

5. Some of the injected lubricant may be burned in-cylinder, resulting in higher emissions and carbon balance error over the carrier gas delivery system test.

\section{REFERENCES}

1. Klaus, E., Duda, J. and Naidu, S., "Formation of Lubricating Films at Elevated Temperatures from the Gas Phase," Report, ONRL Subcontract 19X-89616C (1986).

2. Gunsel, S., Klaus, E. and Bruce, R.W., "Friction Characteristics of Vapor Deposited Lubricant Films," SAE Paper 890148 (1989).

3. Klaus, E., Duda, J., Jeng, G., Hakim, N., Balnaves, M. and Groeneweg, M., "Vapor Phase Tribology for Advanced Diesel Engines," SAE Paper 88017 (1988). 


\section{SECTION $V$}

\section{ADVANCED ENGINE VALVE ACTUATION SYSTEM}

Phase I of the ADECD program[1] concluded that electro-hydraulic valve actuators would be developed for the single cylinder engine in Phase II/III.

\subsection{VARIABLE VALVE ACTUATION}

Variable valve actuation was undertaken for two basic reasons:

1. Elimination of conventional overhead and lube system because of high cylinder head temperatures. This approach also eliminates valve side loads for the valve stems.

2. Demonstration of advanced engine concepts for performance and operational improvements:

a. Improved fuel economy throughout the speed-load range and idle by valve overlap control and disabling valves for cylinder cutout

b. Improved startability by increased compression ratio \& expansion ratio, cylinder heating by high residuals, and cylinder cutout for higher cranking speed

c. Cold smoke control by the same items listed for startability plus reduced fuel input

d. Engine compression braking (Jacob's Brake) with higher capacity by use of two cycle valve scheduling

e. Transient engine response and smoke control improvement by early exhaust valve opening to minimize turbo lag.

DDC designed a workable version of an electro-hydraulic valve actuation system by application of electronic fuel injection technology. The design goal was approximation of DDC Series 60 engine valve lift profiles throughout the engine's speed range and retention of acceptable valve seating velocity. Analytical studies ${ }^{[2]}$ had indicated that these schedules were almost the optimum for the ADECD SCTB. However, the study indicated that more rapid valve opening and closing along with appropriate timings would provide some increase in volumetric efficiency. Therefore, more rapid valve motion and totally flexible timing are the design goals of the mature system. 


\subsection{METHOD OF OPERATION}

The electro-hydraulic valve actuator system is made up of three components, the actuator, pump and controls.

The actuator (see Figure 37) uses a solenoid-controlled spool valve to supply high pressure fuel to a piston which actuates the engine valves. One actuator for the two exhaust valves and one for the two intake valves are mounted on the engine head. Each drives a valve pair by a valve bridge. The valves use DDC S60 valve springs for closure because the actuators were single acting.

The pump used was a S60 electronic unit injector (EUI) modified with a check valve. It operated as a variable displacement pump to minimize power requirements. Each pump supplied its actuator with high pressure fuel $(35 \mathrm{MPa})$ through separate tubing and an accumulator. The pumps were mounted off the engine in a cam box which was synchronous belt driven ( $2: 1$ reduction) by the engine.

Finally, the electronics that control the actuator and pump were two modified Detroit Diesel Electronic Control (DDEC) Electronic Control Modules (ECM) - one to run the actuators and one to run the pumps. These ECMs control when valve lift or pumping occurs by creating properly timed solenoid drive currents. The events are from look-up tables for beginning of event $(\mathrm{BOE})$ and pulse width $(\mathrm{PW})$ as functions of engine speed and throttle position. Also, the ECM uses feedback to sense solenoid valve end of stroke and modifies the start of current for proper BOE of subsequent cycles.

The actuator itself is comprised of four sections - solenoid, solenoid valve assembly, check valve assembly, and piston assembly that work as follows:

Lift

At BOE, the solenoid is turned on by the ECM which supplies a high pull-in current to move the solenoid valve. At the end of the spool valve stroke, the current is reduced by pulse width modulation (PWM) to hold the solenoid valve up until the end of the event.

When the solenoid valve is lifted by the solenoid, the vent cavity is closed off and the high pressure cavity is opened to allow fuel flow through the check valve assembly. The left check valve opens for fuel passage to the piston assembly; the right check valve closes. The piston is pressurized through its $\mathrm{T}$-passage and moves in the desired direction.

\section{Max. Lift Dwell}

When the piston reaches maximum lift, it closes off the left lower fill port. This and the closed right check valve prevents further pressurization of the piston. This gives a positive limit on valve extension which is $12.3 \mathrm{~mm}$ (full closure of fill port to full closure of spill port). This prevents excess lift, which would cause longer duration of closure and possible piston contact. 


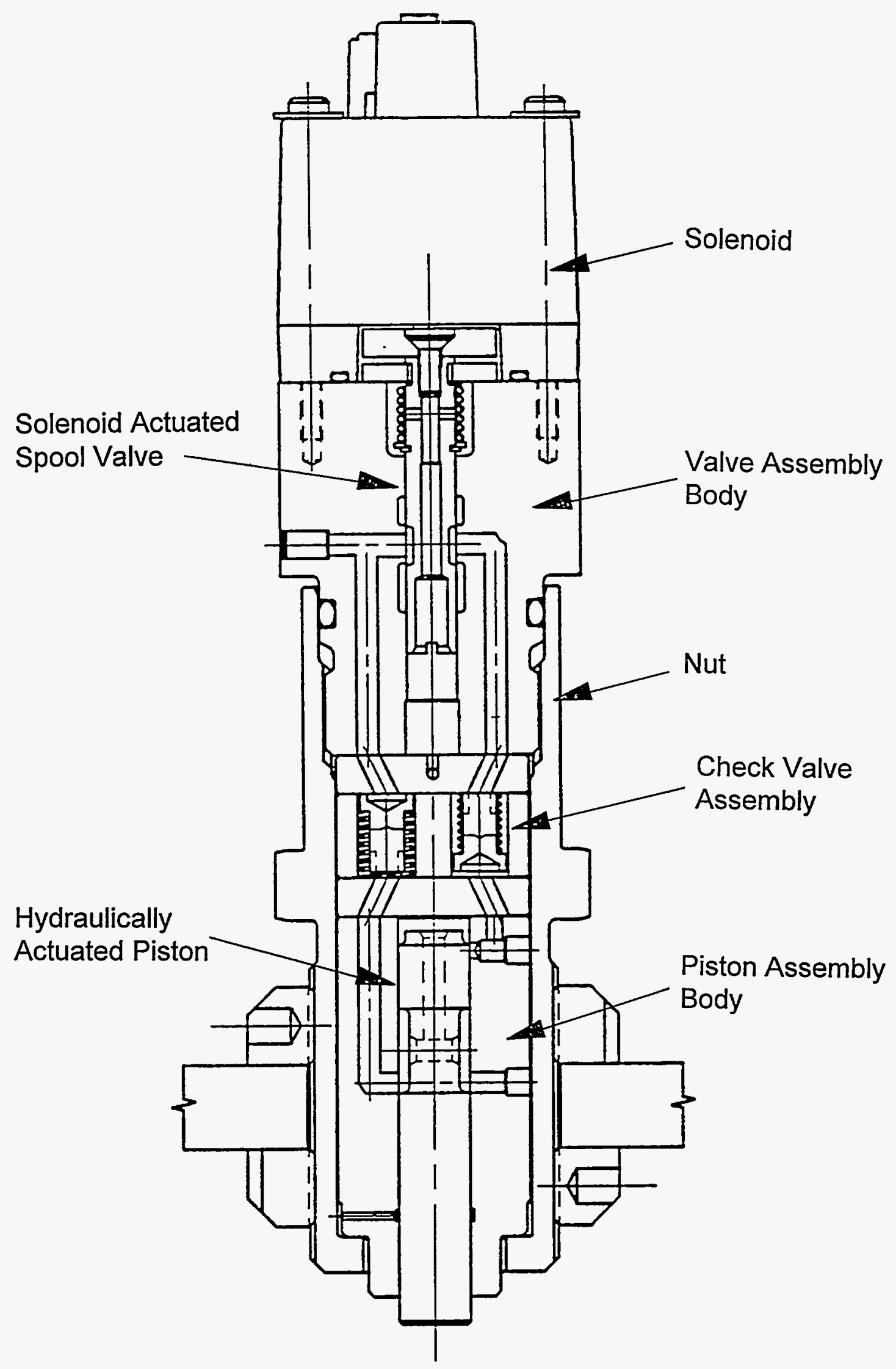

Figure 37: Valve Actuator 


\section{End of Lift}

At end of PW, the solenoid current is shut off and the solenoid valve spring pushes the spool valve down. This closes the high pressure source and opens the vent. The engine valve springs force the piston to push the fuel through the upper right spill port. The right check valve opens and the left one closes.

Unlike the fill port, the spill port is small and has a rectangular shape. As the piston approaches the end of its stroke, this port is closed by the top of the piston to provide a variable area restriction which damps valve seating velocity. The amount of damping is controlled by the position of the actuator relative to the valve stem which changes port area at end of lift. Thus the ports and check valves provide for fast fill during lift and seating velocity control at the end of lift.

\subsection{FIXTURE DEVELOPMENT}

All development of the actuator was done on the Valve Actuator, Injector Fixture (VAIF) which is shown in Figure 38. The setup of the actuator system was similar to that on the engine. This fixture uses an electric motor to drive the pump. The adjustable pressure regulator is not used for normal operation of the system, only as an over-pressure safety.

Unless otherwise specified, all fixture data presented in this report simulates SCTB valve system inertia and spring loads. Aluminum valves were used to duplicate the ceramic valve mass. Actuator piston protrusion is $4.6 \mathrm{~mm}$ for a valve seating velocity of $.5 \mathrm{~m} / \mathrm{s}$. Gas loads for the exhaust schedules are not simulated on the VAIF, but it was recognized that these could significantly retard exhaust beginning of lift.

Measurements of valve motion were made with an Optron electro-optical tracking system which was attached to a Norland 3001 programmable oscilloscope for data acquisition. The oscilloscope also monitored solenoid drive voltages and supply pressures. The computer was hooked to the two ECM's for monitoring and table editing using standard DDEC PC software.

The only fixture development problem was high pressure line cracking due to vibration. These lines are a special pump and nozzle type (140 MPa capacity) which use a variety of commercial high pressure fittings for interconnection. Few leakage problems occurred with the fittings themselves. Proper support of the line and a special vibration-proof line collar eliminated the line failure problem. 


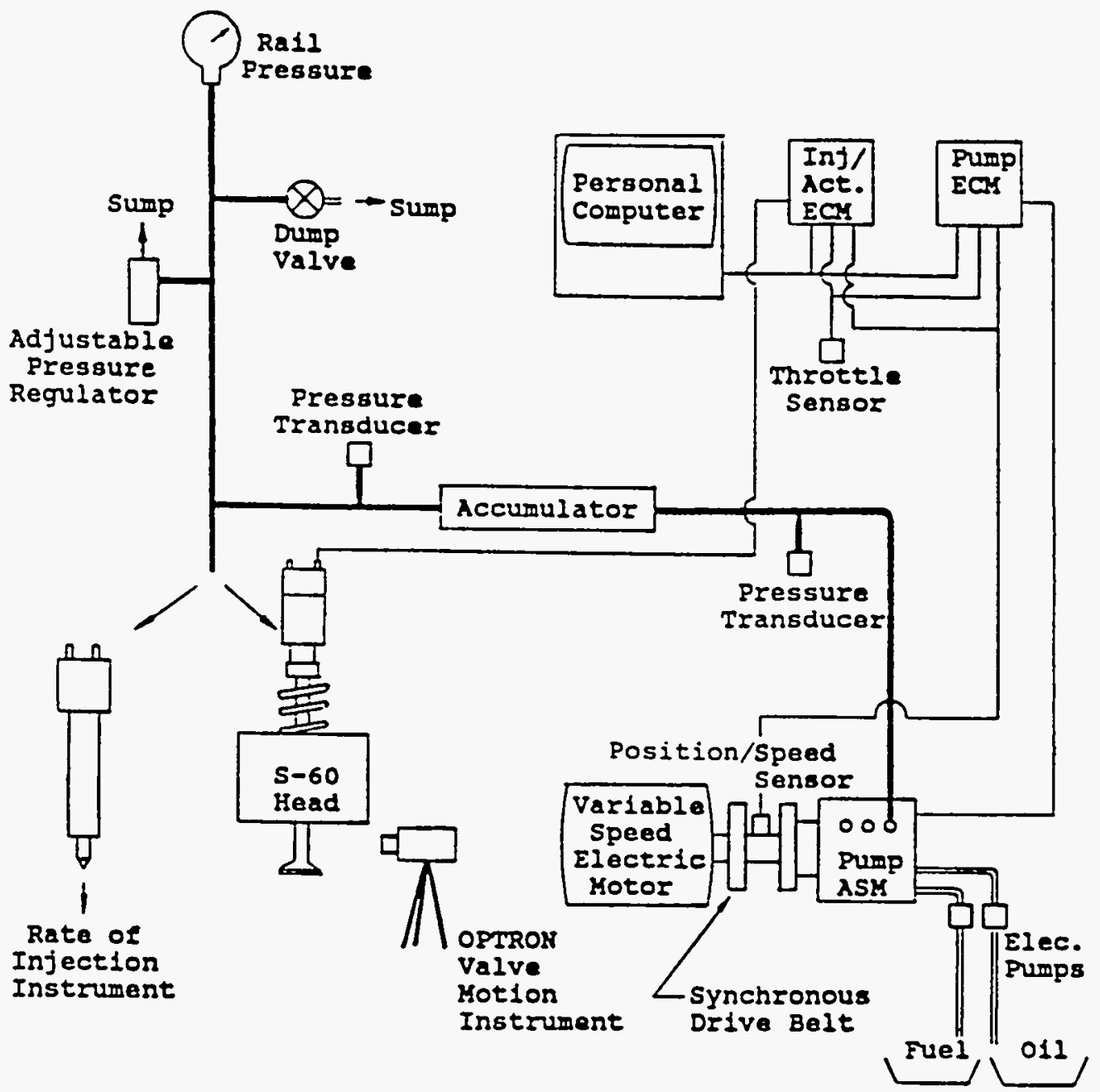

Figure 38: Common Rail Injector and Valve Actuator, Injector Fixture 
VAIF plots from the Norland oscilloscope showed the pump drive voltage, the actuator supply pressure (approximately $.3 \mathrm{~m}$ away), the actuator drive voltage and the resulting lift of one of the valves versus engine crank angle. The pump drive voltage trace indicates when the pumping took place. The BOE and PW for the pump's solenoid valve and the actuator solenoid valve were tracked.

\section{Valve Actuator Development and Operation}

As can be seen from Figure 39, close agreement was achieved between the lift on the fixture and on the SCTB. The S60 lift profile goal can also be seen. The particular lift schedule shown here was not intended to approximate the $\mathrm{S} 60$ lift profile goal. A "Safe- $\mathrm{X}$ " schedule was used to keep the valves 30 degrees crank angle away from piston top for initial engine development tests.

Some of the differences between the SCTB and fixture lift were attributed to the measurement method used on the engine, where a proximity probe sensed a ramp machined in the side of the valve bridge. This method is somewhat inaccurate, since valve side-to-side motion, which changes proximity probe gap, affects lift measurement.

The exhaust and intake valves operated throughout the engine speed range from $1900 \mathrm{r} / \mathrm{min}$ down to $500 \mathrm{r} / \mathrm{min}$. The maximum lift at high speed is reduced when there is inadequate supply pressure or excessive fill passage restriction. This results in insufficient time for the valve to achieve full lift before end of event (EOE). At mid-speeds, there is adequate pressure for maximum lift to be limited by fill port closure. For this data, the maximum possible lift was $11.4 \mathrm{~mm}$ (not $12.3 \mathrm{~mm}$ ) due to adjustment for seating velocity control. At low speeds, actuator leakage became significant and reduced supply pressure. Since maximum lift is determined by force equilibrium with the valve springs, fill port closure may not be achieved with reduced supply pressure.

For mid-speeds, the theoretical pressure necessary for $11.4 \mathrm{~mm}$ of lift was $30.4 \mathrm{MPa}$ based on measured spring rate, preload, and piston diameter. This pressure occurs just as the pressure port is closed and max. lift dwell occurs. The associated piston displaced flow for this lift is $900 \mathrm{~mm}^{3}$. Measured total flow is about $1225 \mathrm{~mm}^{3}$ with a leakage flow through the actuator of $325 \mathrm{~mm}^{3}$.

For low speed, the max. lift of $10 \mathrm{~mm}$ occurred at a pressure of about $27 \mathrm{MPa}$ with total flow of $1280 \mathrm{~mm}^{3} / \mathrm{cycle}$. The theoretical pressure is $27.9 \mathrm{MPa}$ and piston displaced flow is $780 \mathrm{~mm}^{3} /$ cycle. Leakage flow is $500 \mathrm{~mm}^{3}$, which caused the lower supply pressure. 


\section{ADECD Valve Actuators on SCTB}

1800 r/min, Exh Act \#1, Int. Act \# 4

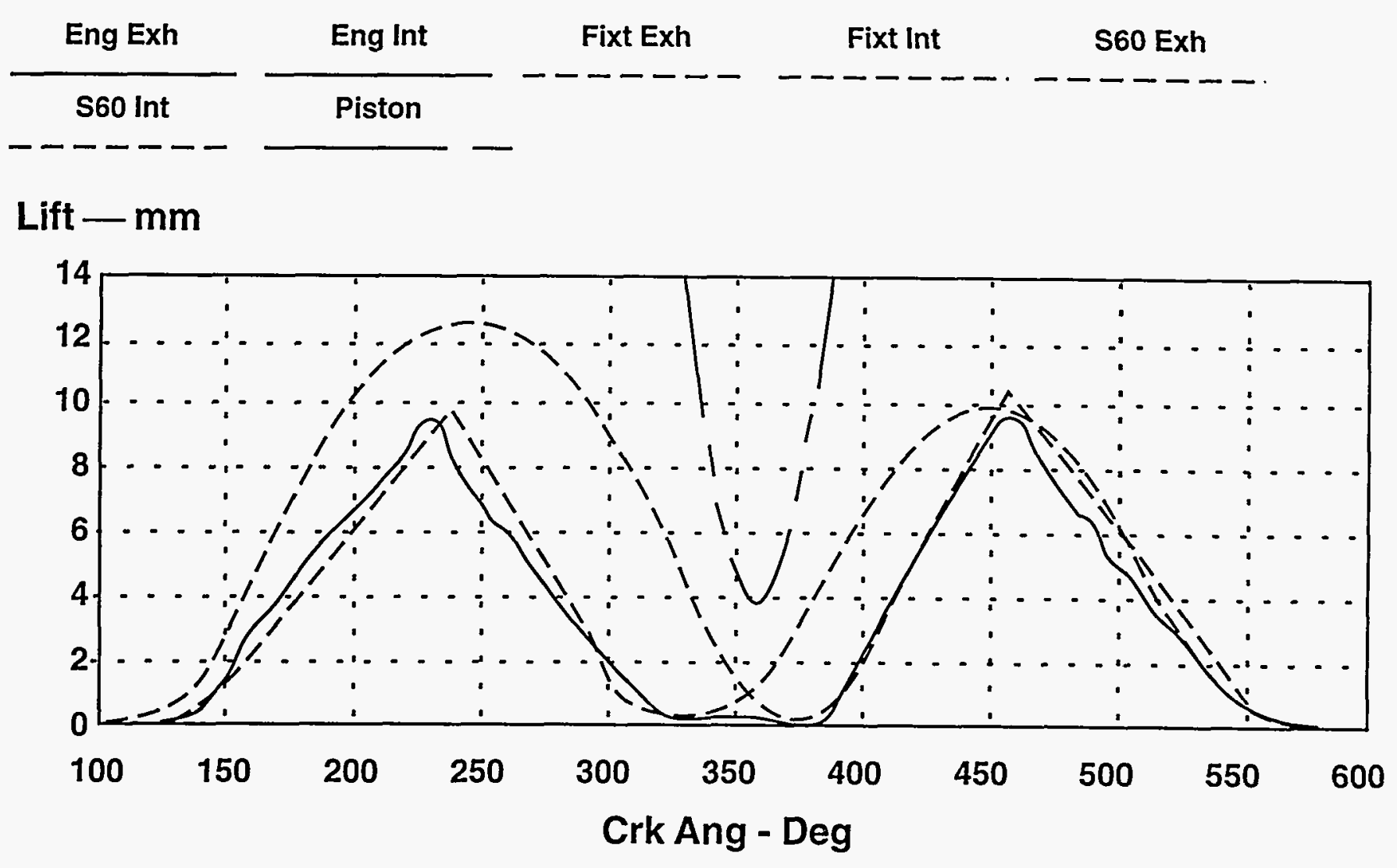

Figure 39: Valve Actuator Operation on SCTB 
Generally, the intake actuator operated at higher pressure than the exhaust. This was due to the timing of the lift event relative to the pumping event and not actuator variation. The "Safe-Y" schedule resulted in the pumping event leading the intake actuator event by 42 degrees crank angle and the exhaust event by 26 degrees crank angle.

For this design, fill restriction is determined by the solenoid valve curtain area of $5.5 \mathrm{~mm}^{2}$; all other passages have a minimum area of $7 \mathrm{~mm}^{2}$. The spill port through which all spill must flow has an area of only $0.9 \mathrm{~mm}^{2}$. The spill port was perfectly matched for low speed, but was too restrictive for high speed.

Initially, it was thought $[3]$ the monolithic ceramic valves would be stress limited to a seating velocity of $0.05 \mathrm{~m} / \mathrm{s}$. However, tests on these valves showed that they were equivalent to metallic valves and a maximum velocity of $0.5 \mathrm{~m} / \mathrm{s}$ was demonstrated (Section 3.1) on the ceramic valves. This was the goal for actuator adjustment. Valve seating velocity control was also optimized for a maximum ceramic valve thermal growth of $0.28 \mathrm{~mm}$. However, unlike a standard cam drive setup, the ECM's valve schedules can be used to compensate for this effect.

Possible failure modes associated with this design were considered. If the spill check valve leaks, duration is increased, and possible piston contact occurs. Excessive lift due to this leakage was not seen while running the actuator during static tests for maximum lift, since force balance with the valve springs served to limit the travel, not fill port closure. Further, if the fill check valve was to fail, valve seating velocity could be exceeded. Possible loss of lift control and valve seating velocity variation associated with thermal growth led to the recommended design improvement presented later in this report.

\section{Hardware Development}

Areas of development for the actuator were early distress of the check valve end plates, solenoid valve retainer and valve to housing matching.

After initial running of the actuator, check valve end plate wear was observed due to check valve impact. This led to a T-passage design which gave more load bearing area for the impact loads that occur during valve opening. No further deterioration of check valve seal surfaces was seen.

Comparisons of actuator valve measurements with and without the solenoid applying force to lift the valve showed the solenoid valve retainer plate was deflecting excessively. Soon thereafter, a plate failure occurred. The plate thickness was increased from 1 to $2.5 \mathrm{~mm}$ and no subsequent problems were noted with this improved design.

Initial tests indicated that the actuator would rapidly open the valves but had slow valve closure. Inspection of the actuator showed cavitation erosion of the valve and bore. An airflow apparatus was built to statically measure solenoid valve flow vs. position. The problem was that the valve housings were not to print. The vent cavities were too low by 
$.25-.55 \mathrm{~mm}$. To correct this, each valve was matched to each housing to lower the vent edge. This did not affect other parameters such as seal lengths, stroke, etc. and gave a quick rework of the existing hardware.

Steady- state measurement summary for actuators \#2 \& \#3 covered in this report is shown in Table 5 .

TABLE 5 VALVE ACTUATOR RESPONSE DATA

\begin{tabular}{|c|c|c|c|c|c|c|c|}
\cline { 3 - 7 } \multicolumn{2}{c|}{} & \multicolumn{2}{c|}{$\begin{array}{c}\text { Act Sol Vlv Loc } \\
\text { Per Airflow Fixture }\end{array}$} & $\begin{array}{c}\text { Act } \\
\text { Leakage at } \\
\mathbf{3 5 ~ M P a}\end{array}$ & $\begin{array}{c}\text { Pump } \\
\text { Leakdown } \\
\mathbf{3 5 - 3 0 ~ M P a}\end{array}$ \\
\hline & $\begin{array}{c}\text { Gap } \\
\mathbf{m m}\end{array}$ & $\begin{array}{c}\text { Stroke } \\
\mathbf{m m}\end{array}$ & $\begin{array}{c}\text { Vent off } \\
\mathbf{m m}\end{array}$ & $\begin{array}{c}\text { Press on } \\
\mathbf{m m}\end{array}$ & $\begin{array}{c}\text { Vent on } \\
\mathbf{m m} \text { /cyc }\end{array}$ & $\begin{array}{c}\text { Press on } \\
\mathbf{1 8 0 0} \\
\mathbf{r} / \mathbf{m i n}\end{array}$ & $\mathbf{s e c}$ \\
\hline$\# 2$ & .63 & .48 & .18 & .24 & 140 & 150 & 7 \\
\hline$\# 3$ & .58 & .50 & .21 & .24 & 350 & 130 & 6 \\
\hline
\end{tabular}

\section{Pump Characteristics}

At high speed, maximum pump output required shorter PW than at low speed. The transition appeared around $1500 \mathrm{r} / \mathrm{min}$. The rail pressure increases $5 \mathrm{MPa}$ by increasing pump BOE \& PW 28 degrees CA so that the entire cam lift was utilized.

A pump working into fixed back pressure of $35 \mathrm{MPa}$ was developed. This pressure was maintained by the pressure regulator without an actuator. The start of significant output reduction was due to pump PW reduction or BOE retard. The start of pressure rise occurs at the same location on all the plots even though the pump valve events are changing. The pressure damping effect of the accumulator and low pressure drop between the pump and actuator at maximum flow was established.

\section{Electrical System Development}

The DDEC ECM created precisely timed pulses to drive the solenoids based on crank position and speed derived from a magnetic Timing Reference Sensor (TRS) on the crankshaft. The timing pickup is mechanically adjusted to lead the Top Center/Bottom Center event by a known crank angle. This reference was set to allow enough time for the ECM to determine the electrical pulse and clock down to the most advanced beginning of event at the highest speeds. 
The system used two ECM's; one for the engine and one for the pumps which share the TRS and throttle inputs. Channels 1,2 and 3 are the injector, exhaust and intake, respectively for each box with two TRS signals per engine revolution driving them. The software was modified for each channel to have its own look-up table. These tables were rescaled to handle much larger values for the valve events. Further, the TRS reference was increased to $155^{\circ} \mathrm{CA} \mathrm{BTC}$ to allow for the exhaust valve's advanced $\mathrm{BOE}$.

Two of the channels in the engine ECM were modified to supply higher than normal pull-in current $(17 \mathrm{~A} / 12 \mathrm{~V})$ to move the solenoid valve through its long stroke $(.5 \mathrm{~mm})$.

\section{Transient Characteristics}

With the engine running at a steady speed, all events are accurately controlled. However, during a change of engine speed, timing and duration errors surfaced at low speed. Assuming a fixed acceleration power stroke during the first engine cycle, BOE lagged by as much as 10 degree CA (Int) and the EOE by 20 degree CA (Exh). Although this could be compensated for by the software, use of a multi-tooth wheel and counting teeth to initiate events instead of a timer is recommended.

\section{$\underline{\text { New Design }}$}

A proposed new design eliminates the check valve assembly and alignment pin problems. This design incorporates a fill/spill (FS) port (left) and a ramp (R) port (right). The FS port handles the fill and the majority of the spill event. There is a flow transition from the FS port to the $\mathrm{R}$ port near the beginning/end of motion, i.e., the FS port opens/closes as the $\mathrm{R}$ closes/opens. The $\mathrm{R}$ port's size and location are chosen so that a smooth transition occurs in the flow area.

At BOL, this design uses the $\mathrm{R}$ port for initial fill until the FS port starts opening since the previous design showed that the spill port didn't have to be completely closed to achieve adequate damping. The valve opening rate is initially slower, providing more overlap near piston TC. During valve closure, the greater spill area overcomes the slow closure noted earlier. At the $\mathrm{R}$ port, an adjustable restriction is provided to eliminate damping variation due to valve thermal growth.

\subsection{ELECTRO-HYDRAULIC VALVE ACTUATION}

The ceramic valves were actuated by an electro-hydraulic actuator. Each actuator operates a pair of valves through a floating bridge. Two actuator assemblies were used on a test rig to evaluate flexibility and demonstrate preliminary proof of concept operation, prior to installation into the engine. The valve actuation system successfully demonstrated flexibility on both a bench rig and on the SCTB for speeds between 500 and $1800 \mathrm{r} / \mathrm{min}$. A typical valve event produced with the electro-hydraulic valve actuator system is shown in Figure 40. 


\section{SAFE Valve Event $(1800 \mathrm{r} / \mathrm{min})$}

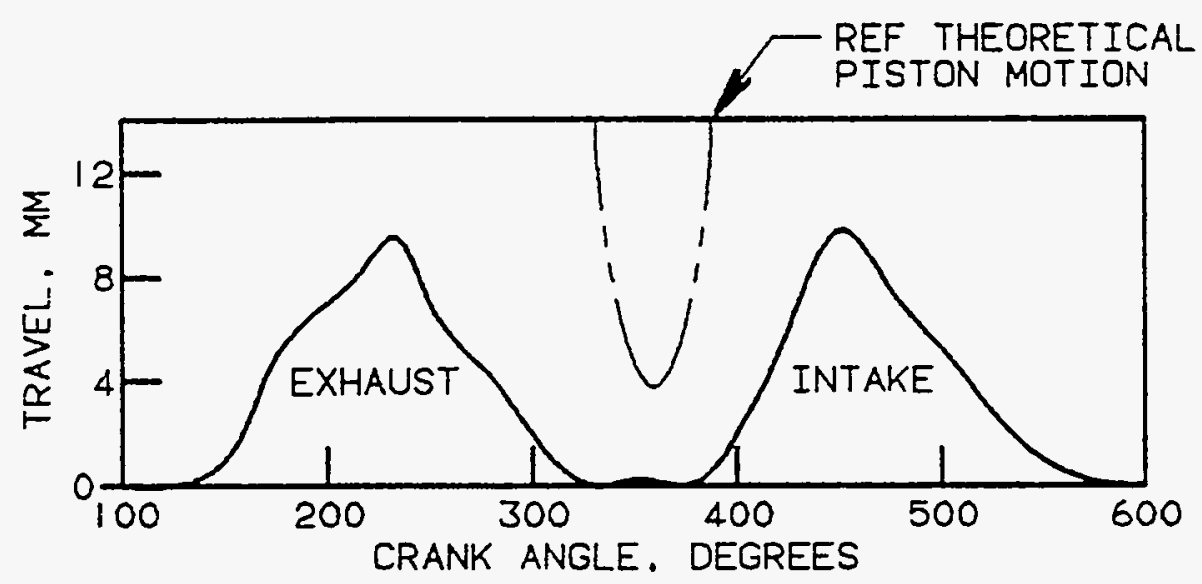

Figure 40: A Typical Valve Event Produced by the Electro-hydraulic Valve Actuator 
The beginning and end of event and event duration were directly controlled by a modified version of Detroit Diesel's Electronic Control [DDEC-II] Software. Valve seating was dampened by an internal square orifice to avoid exceeding the $0.5 \mathrm{~m} / \mathrm{s}$ design limit selected for the ceramic valve. This system demonstrated the ability to change the beginning of event, dwell, end of event, and maximum valve lift during engine operation.

During initial engine testing, inadvertent contact between the valves and the piston was avoided by using a SAFE valve schedule (Figure 40). Later, to increase the performance and power level of the engine, the valve schedules were altered to more nearly represent cam driven valve profiles. During this phase, logic errors in the modified DDEC-II software apparently occurred, negating a system pressure relief valve setting and allowing contact between valves and piston.

A detailed analysis of transient timing and investigative tests using the engine and the test fixture established the following:

- Cycle skipping was caused by a software problem. Specifically, multiples of a very narrow range of actuator pulse widths with a fixed response time, $32.5 \mathrm{~ms}+/-32 \mu \mathrm{s}$, would start the actuation sequence properly, but would halt it prematurely.

- Each skipped cycle raised the rail pressure approximately $3 \mathrm{MPa}$ over the $20 \mathrm{MPa}$ nominal value. With the existing exhaust actuator hardware, approximately six cycles would have to be missed at $20 \mathrm{MPa}$ before the SCTB's relief valve, set at $40 \mathrm{MPa}$, would limit the pressure from increasing even further. Within the pressure range, 20 to $40 \mathrm{MPa}$, the valve lift would increase from 7.3 to $11.8 \mathrm{~mm}$. Also, opening and closing rates would be effected. For the exhaust position: the opening would be earlier and the closing would be later.

- It was found that a malfunctioning electro-hydraulic valve actuator forced the two ceramic exhaust valves into the piston at approximately $820 \mathrm{r} / \mathrm{min}$, causing the failure.

- The software was modified to eliminate the malfunction. The engine's actuator system relief valve setting was reduced from 40 to $25 \mathrm{MPa}$, whereby adding a fail safe to the actuation system.

\section{CONCLUSIONS}

1. The EHVA system can actuate $S 60$ type ceramic and metal valves from $500 \mathrm{r} / \mathrm{min}$ to $1900 \mathrm{r} / \mathrm{min}$ with very little cycle-to-cycle variability of the valve lift profile. Minor timing flexibility was demonstrated.

2. Lift profiles did not duplicate production engine valve events. The test hardware was limited to $10 \mathrm{~mm}$ lift ( $80 \%$ of $\mathrm{S} 60$ exhaust lift goal) and an $1800 \mathrm{r} / \mathrm{min}$ opening duration of 80 degree $\mathrm{CA}$; closing, 95 degree $\mathrm{CA}$. The test actuator pump had to be run at its 
maximum capacity to achieve this. Excessive vent restriction prevented faster valve closure at high speed using production $\mathrm{S} 60$ valve springs.

3. Leakage of the pump check valve and actuator solenoid valve and fill passage restriction need to be minimized to reduce pump requirements.

4. Acceptable valve seating velocities were achieved. The seating velocity is adjustable, but is restricted by the maximum lift capability of the actuator. Further, valve thermal growth affects end of lift timing and seating velocity in the existing test configuration.

5. Design changes were necessary to adapt the check valves and solenoid valve retainer of the original actuator design. All other hardware worked without problems.

6. Significant valve event retard occurred during accelerations at low speeds using existing DDEC algorithms.

7. Design changes for a simpler, smaller actuator that reduces engine valve opening and closing duration with minimized valve thermal growth are required.

\section{REFERENCES}

1. Hakim, N.: "Adiabatic Diesel Engine Component Development Program - Phase 1 Interim Report, Reference Engine for On-Highway Applications", DOE/NASA/0329-1 Contract

2. Morel, $\mathrm{T}$. et al: "Adiabatic Diesel Engine Component Development - Design and Performance Analysis Support, Phase 1 Summary Report", DDA Subcontract DE078386 to Integral Technologies Incorporated

3. Weber, K.: "ADECD - Poppet Valve Paper Study for the ADRE (Phase 1)", DDC Engineering Report V1VG-076-13800-00A 


\section{SECTION VI}

\section{ADVANCED ENGINE INJECTION SYSTEM}

An advanced fuel injection system was developed for the camless single cylinder test engine. This common rail fuel injection system generated high injection pressures for reduced particulate emissions.

\subsection{COMMON RAIL INJECTION SYSTEM BENEFITS}

Mechanically actuated unit injection fuel systems, widely used in heavy-duty diesel engines, require stiff and heavy drive trains to carry the high loads produced by the injection pressure acting on the plunger, and do not provide control of the injection pressure. A common rail fuel system was selected for the ADECD program for the following three reasons: (1) it allows control of injection pressure, (2) it allows the pumping element to operate without external lubrication, and (3) it has a higher overall efficiency.

\section{Injection Pressure Control}

The fuel injection pressure in a unit injector is controlled by the area of the nozzle and the plunger pumping rate, which is a function of engine speed. Once these parameters are selected, the injection pressure is a fixed function of engine speed and fueling. In practice, this means the injection system is sized to give a tolerable peak pressure at rated power conditions, and at lower speeds and loads the pressure may be less than optimum for particulate and smoke control.

\section{Lubrication System}

The SCTB was designed to operate with a vapor phase lubrication system and an electrohydraulic valve actuator; thus the engine did not have a conventional lubrication system to lubricate the cam roller and camshaft required for a unit injection system. Therefore the high pressure fuel injection pump had to be a self-contained unit.

\section{Injection System Efficiency}

A third reason to select the common rail system was its higher overall efficiency. Although there was some high pressure fuel loss due to leakage and the control system, less fuel was compressed and spilled than in a unit injector. Thus common rail systems offer reduced power consumption.

Although the common rail fuel system has important advantages, there are concerns with its operation. Some of these are: 
1. Fuel output variability. It can be challenging to obtain good injector-to-injector control during the manufacturing process, especially over a long period of time.

2. The turndown ratio (maximum output / minimum output) can be poor, especially at high speeds. This is because it is difficult to open and close the needle fast enough to inject small quantities of fuel.

3. A simple common rail system has a nearly square rate of injection because of the constant fuel injection pressure.

4. The substantial volume of high pressure fuel creates a safety hazard if a fuel line or nozzle fails.

\subsection{COMMON RAIL INJECTION SYSTEM RESULTS}

Fuel injection via a high pressure common rail system was chosen. Three injector assemblies were procured from Diesel Technology Corporation. Proof of concept testing on a bench rig resulted in delivering between 20 and $335 \mathrm{~mm}^{3}$ of fuel/cycle independent of engine speed and achieved $125 \mathrm{MPa}$ peak injection pressure. The design goals with respect to full fuel rate, beginning of injection and duration targets were met (see Table 6).

The rate of injection when delivering $167 \mathrm{~mm}^{3}$ of fuel at $1800 \mathrm{r} / \mathrm{min}$ is shown in Figure 41 . The system is capable of providing the same amount of fuel in shorter durations by raising the rail pressure. Besides, this injection system can maintain near uniform injection pressure at the desired pressure level under all load and speed conditions.

TABLE 6

COMPARISON OF ACTUAL COMMON RAIL INJECTION PARAMETERS VS. TARGET VALUES

\begin{tabular}{|c|c|c|}
\hline & TARGET & ACTUAL \\
\hline Speed & $1200 \mathrm{r} / \mathrm{min}$ & $1200 \mathrm{r} / \mathrm{min}$ \\
Fuel/cycle & $207.4 \mathrm{~mm}$ & $208.3 \mathrm{~mm}$ \\
Beginning of Injection & $-14.0 \mathrm{deg}$. & $-14.1 \mathrm{deg}$. \\
Duration of Injection & $25.0 \mathrm{deg}$. & $23.9 \mathrm{deg}$. \\
\hline Speed & $1500 \mathrm{r} / \mathrm{min}$ & $1500 \mathrm{r} / \mathrm{min}$ \\
Fuel/cycle & $191.7 \mathrm{~mm}$ & $190.5 \mathrm{~mm}$ \\
Beginning of Injection & $-16.0 \mathrm{deg}$. & $-16.0 \mathrm{deg}$. \\
Duration of Injection & $28.0 \mathrm{deg}$. & $27.7 \mathrm{deg}$. \\
\hline Speed & $1800 \mathrm{r} / \mathrm{min}$ & $1800 \mathrm{r} / \mathrm{min}$ \\
Fuel/cycle & $167.0 \mathrm{~mm}$ & $166.7 \mathrm{~mm}$ \\
Beginning of Injection & $-17.9 \mathrm{deg}$. & $-16.8 \mathrm{deg}$. \\
Duration of Injection & $29.0 \mathrm{deg}$. & $31.8 \mathrm{deg}$. \\
\hline
\end{tabular}




\section{Rate of Fuel Injection}

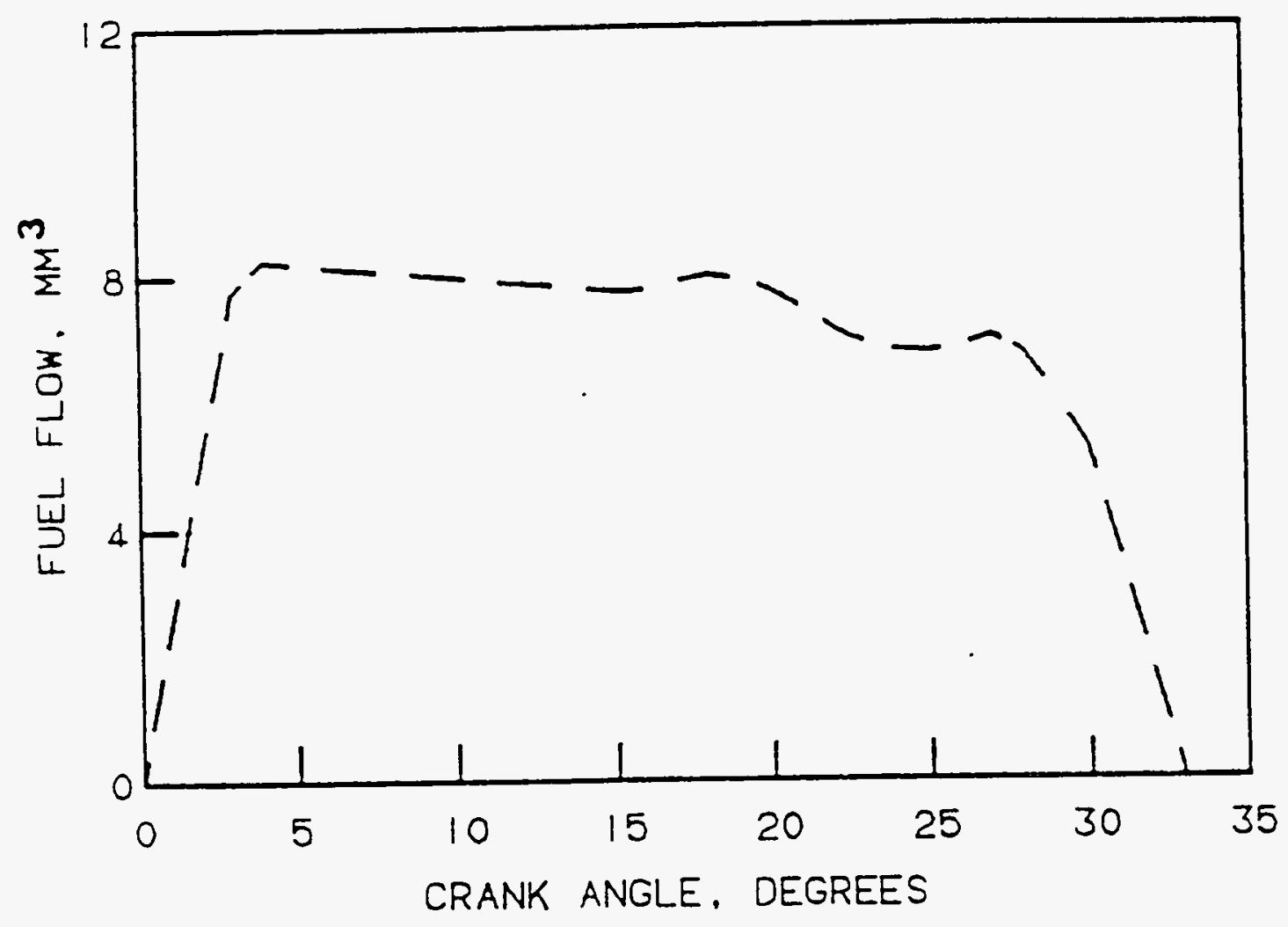

Figure 41: Rate of Injection Characteristic for the High Pressure Common Rail System (delivering $167 \mathrm{~mm}$ at $1800 \mathrm{r} / \mathrm{min}$ ) 
This system was integrated into the SCTB during Build \# 4 and 5 (Section 7) and demonstrated the ability to vary the fueling rate and pressure during engine operation. End of event response time with this system was significantly reduced by optimizing the air gap and solenoid travel.

The rail pressure of the injection system was increased from $41.4 \mathrm{MPa}$ to $68.9 \mathrm{MPa}$ (Section 7.6) and engine testing continued without any other hardware changes. The $68.9 \mathrm{MPa}$ rail pressure of the injection system greatly reduced the smoke level. During operation at 1800 $\mathrm{r} / \mathrm{min}$ and $20 \mathrm{~N}-\mathrm{m}$ brake torque, a Bosch smoke number of 0.7 was measured. This is an $84 \%$ improvement over the 4.4 level (Build \#4) with a $41.4 \mathrm{MPa}$ rail pressure.

The cylinder liner temperatures were reduced, as well, with the higher injection rail pressure (Section 7.6). The maximum liner temperature on the exhaust side at top ring reversal decreased from $470^{\circ} \mathrm{C}$ to $355^{\circ} \mathrm{C}$ and the circumferential temperature gradient from the exhaust to intake side was reduced by approximately $50 \%$ with the higher rail pressure. These improvements are attributed to better combustion.

The reduced circumferential temperature variation on the cylinder liner for the higher rail pressure case (Build \#5) resulted in improved piston ring to liner sealing and less blowby as shown in Figure 42. For comparison, the lower rail pressure data is also shown. The reduced blowby is most likely due to less thermal distortion of the liner. Specifically, the higher rail pressure condition resulted in a relatively constant level of blowby, $40 \mathrm{I} / \mathrm{min}$, compared to the lower rail pressure case, where the blowby rapidly increased to over $85 \mathrm{l} / \mathrm{min}$ (limit) after 20 minutes of operation.

In an effort to boost engine power to $50 \%$ (Section 7.11 , Build \#10), the high pressure fuel for the common rail injection system was increased by about 20 percent over previous levels. The Build \#10 injection event, as developed on the VAIF, is shown in Figure 43. For comparison, the previous injection event is also shown in Figure 45. As with previous valve and injection event changes, the Build $\# 10$ valve and injection events were verified on the VAIF, prior to installation into the SCTB.

The testing effort concentrated on establishing a reliable operating condition for the vapor phase lubrication study. A maximum power level of $14.8 \mathrm{BkW}, 80 \mathrm{~N}-\mathrm{m}$ brake torque at $1800 \mathrm{r} / \mathrm{min}$, was generated during this effort. In total, over 200 hours were accumulated on the common rail injector.

\section{CONCLUSIONS}

1. The common rail fuel injection system hardware was fabricated and successfully demonstrated on the SCTB. Design goals with respect to fuel rates and events were met.

2. Benefits of reduced particulate emissions with increasing injection pressure and control of injection pressures independent of engine speed and load were successfully demonstrated. 
Blowby vs. Time

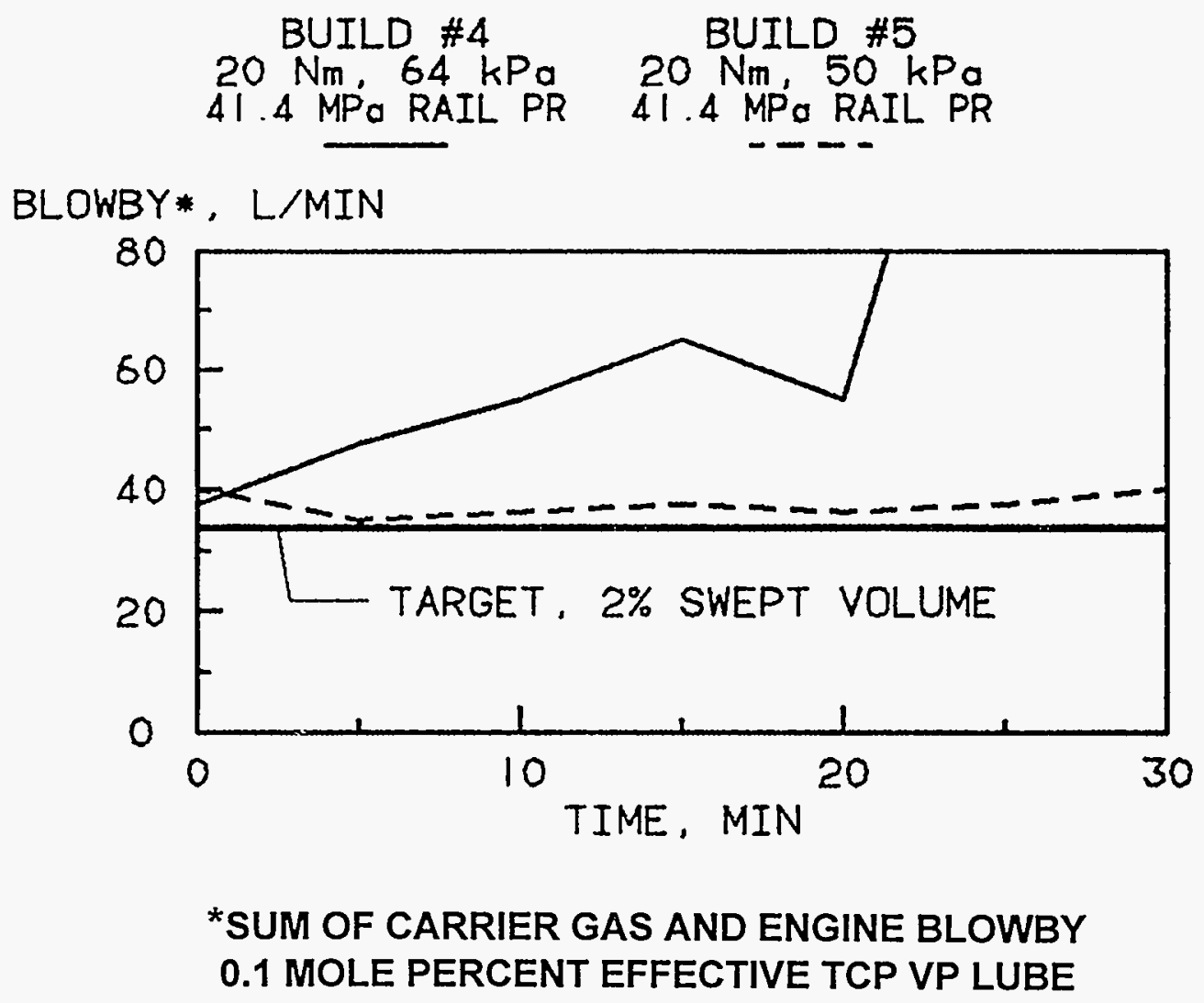

Figure 42: Blowby Comparison, Build \#5 vs. Build \#4 


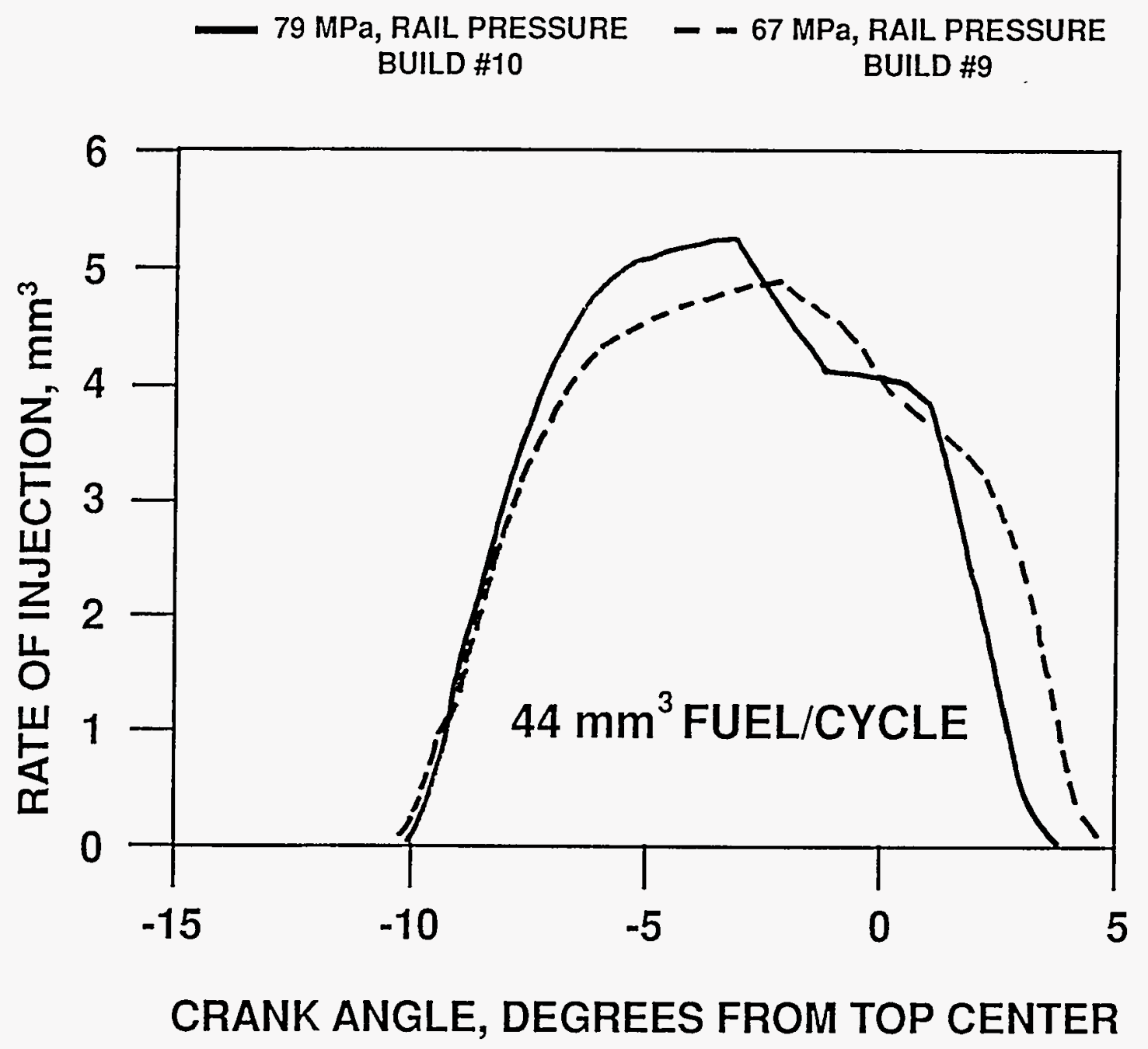

Figure 43: Build \#10 Injection Event 


\section{SECTION VII}

\section{SINGLE CYLINDER TEST BED}

\subsection{SINGLE CYLINDER ENGINE \& TESTING}

During Phase II/III of the program, each of the advanced concepts successfully passed preliminary proof of concept testing as described in Sections II through VI. This was followed by the integration of concepts into the single cylinder test bed [SCTB] fabricated during 1987. This test bed is a vital laboratory tool in studying the many advanced technologies of the ADECD Program, as well as other advanced LHR technologies necessary to meet the overall Heavy Duty Transport Technology (HDTT) Program Goals. The SCTB simulates the reciprocator for a system having no cooling system, turbo compounding, Rankine bottoming cycle, variable area turbocharger, common rail injection, and variable valve actuation to achieve fuel consumption of $160 \mathrm{~g} / \mathrm{kW}-\mathrm{hr}(.26 \mathrm{lb} / \mathrm{hp}-\mathrm{hr})$.

The integration of all advanced concepts (Sections II-VI) was done in a step-wise manner. These efforts are summarized in Table 7.

TABLE 7

INTEGRATION OF CONCEPTS INTO SCTB

\begin{tabular}{|l|l|}
\hline Concept & Integration \\
\hline Separated Ring Belt (SRB) Piston & Feb., 1988 \\
\hline Gasketless Seal (Firedeck/Liner) & Mar., 1988 \\
\hline Cast-in-Place Ceramic Ports & Mar., 1988 \\
\hline Electro-hyd. Valve Actuation & Apr., 1988 \\
\hline Common Rail Injection & Apr., 1988 \\
\hline Ceramic Piston Ring & May, 1988 \\
\hline Vapor Phase Lubrication & June, 1988 \\
\hline Ceramic Valves & June, 1988 \\
\hline
\end{tabular}

In total, 13 SCTB builds were made. This section will describe each of the builds. A summary of this effort is shown in Table 8.

\subsection{BUILD \#1}

The SCTB was used to evaluate the effect of inertia loads on one SRB piston assembly via motoring operation. Verification of the piston assembly integrity (ceramic piston cap to piston dome joint and the carrier wrist pin connection) under inertial loading was conducted. 
TABLE 8

ADECD SCTB ACTIVITY

\begin{tabular}{|c|c|c|c|}
\hline $\begin{array}{c}\text { BUILD } \\
\text { NUMBER }\end{array}$ & OBJECTIVE & OPERATION & $\begin{array}{l}\text { HOURS } \\
\text { ACCUM. }\end{array}$ \\
\hline 1 & $\begin{array}{l}\text { SRB Proof of Concept } \\
\text { (POC) Feasibility }\end{array}$ & $600-2000 \mathrm{r} / \mathrm{min}$, no load & 13.0 \\
\hline 2 & $\begin{array}{l}\text { EHVA \& Common Rail } \\
\text { Injection POC }\end{array}$ & $500-1800 \mathrm{r} / \mathrm{min}, 7.5 \mathrm{~kW}$ & 11.5 \\
\hline 3 & $\begin{array}{l}\text { Vapor Phase Lubrication } \\
\text { POC }\end{array}$ & $500-1800 \mathrm{r} / \mathrm{min}, 0 \mathrm{~kW}$ & 7.3 \\
\hline 4 & $\begin{array}{l}\text { Fully Configured } \\
\text { Operation, } 8 \% \text { of Rated } \\
\text { Power }\end{array}$ & $500-1820 \mathrm{r} / \mathrm{min}, 5.7 \mathrm{~kW}$ & $* 5.7$ \\
\hline 5 & $16 \%$ of Rated Power & $500-1800 \mathrm{r} / \mathrm{min}, 14.8 \mathrm{~kW}$ & 17.1 \\
\hline 6 & $\begin{array}{l}\text { Baseline ring wear rate } \\
\text { with } 0.1 \text { mole } \% \text { TCP }\end{array}$ & $500-1800 \mathrm{r} / \mathrm{min}, 7.5 \mathrm{~kW}$ & 12.2 \\
\hline 7 & $\begin{array}{l}\text { Evaluate Reduced Ring } \\
\text { Gap }\end{array}$ & $500-1800 \mathrm{r} / \mathrm{min}, 0 \mathrm{~kW}$ & 2.8 \\
\hline$\overline{8}$ & $50 \%$ of Rated Power & & $* 0.1$ \\
\hline 9 & $\begin{array}{l}\text { Same as 6, except no } \\
\text { intentional lubrication }\end{array}$ & $500-1800 \mathrm{r} / \mathrm{min}, 7.5 \mathrm{~kW}$ & 20.0 \\
\hline 10 & $50 \%$ of Rated Power & $1800 \mathrm{r} / \mathrm{min}, 23.8 \mathrm{~kW}$ & 63.8 \\
\hline 11 & $75 \%$ of Rated Power & $1800 \mathrm{r} / \mathrm{min}$ & 4.8 \\
\hline 12 & $\begin{array}{l}\text { Piston ring redesign, } \\
\text { baseline carrier gas }\end{array}$ & $500-1800 \mathrm{r} / \mathrm{min}$ & 45.7 \\
\hline 13 & Lubricant injector test & $500-1800 \mathrm{r} / \mathrm{min}$ & 11.3 \\
\hline
\end{tabular}


To avoid unnecessary risk to the cylinder head, a $25.0 \mathrm{~mm}$ thick steel plate with a $75.0 \mathrm{~mm}$ hole to relieve cylinder compression was used. Tests were run at engine speeds up to 2000 $\mathrm{r} / \mathrm{min}$, approximately $10 \%$ over speed. During the motoring tests, torque, oil control between the lower cylinder liner and oil control ring and piston motion near TDC were determined. The dynamic piston to cylinder head clearance at TDC was measured with a proximity sensor.

The initial static piston to cylinder head clearance of $0.6 \mathrm{~mm}$ decreased to $0.47 \mathrm{~mm}$ at $600 \mathrm{r} / \mathrm{min}$ and $0.18 \mathrm{~mm}$ at $2000 \mathrm{r} / \mathrm{min}$. The change in dynamic piston to head clearance was due to a combination of bearing clearances, distortions, and stretch of the cylinder kit components.

A total of 676,000 cycles ( 8.75 hours) were accumulated on the SRB piston without incident, including sixty-five minutes at $600,800,1000,1200,1400,1600,1800$, and 2000 $\mathrm{r} / \mathrm{min}$. This test indicates slightly more than $10 \%$ margin is available, as compared to the $1800 \mathrm{r} / \mathrm{min}$ engine operational speed goal. The modified hardware significantly improved the oil control between the ring to lower liner interface. The motoring friction was considered normal.

\subsection{BUILD \#2}

The electro-hydraulic valve actuators and common rail injection systems were integrated into the SCTB. A valve actuation schedule associated with $183 \mathrm{~mm} 3 /$ stroke fueling was run with the head removed using a production $\mathbf{S 6 0}$ piston. The friction measured is shown in Figure 44. A second run was made with valves and injector inoperative. The power measured is also shown. The difference between these two power curves shows that the power to operate the valve and injection systems when delivering $183 \mathrm{~mm}^{3} /$ stroke fuel was determined to be $2.8 \mathrm{~kW}$ at $1800 \mathrm{r} / \mathrm{min}$.

Intake and exhaust valve travel were also measured. Excellent agreement between the engine and fixture valve motion was seen throughout the speed range. Motoring P-t data was also taken with the valve actuators and injector inoperative. Peak cylinder pressure decreased as speed increased, producing a minimum peak cylinder pressure of $4352 \mathrm{kPa}$ at $1800 \mathrm{r} / \mathrm{min}$ and a maximum peak cylinder pressure of $4835 \mathrm{kPa}$ at $1200 \mathrm{r} / \mathrm{min}$. It should be noted that for a compression ratio of $18: 1$ and a specific heat ratio of 1.33 , the theoretical polytropic pressure is $4675 \mathrm{kPa}$. Pressure gages used to monitor valve leakage confirmed absence of any leakage, further validating the good agreement seen between the measured cylinder pressures and the theoretical polytropic compression.

Visual post-test inspection of the cylinder kit, cylinder head assembly, ceramic firedeck, metallic valves, ceramic guides, electro-hydraulic valve actuators and the injector showed no distress. In total, 11.5 hours were accumulated achieving a maximum operational speed of $1800 \mathrm{r} / \mathrm{min}$ without component distress. During this operation, a maximum brake torque of $75 \mathrm{~N}-\mathrm{m}$ and a maximum brake power of $7.5 \mathrm{~kW}$ at $900 \mathrm{r} / \mathrm{min}$ was generated. 


\section{Motoring Power vs. Speed}

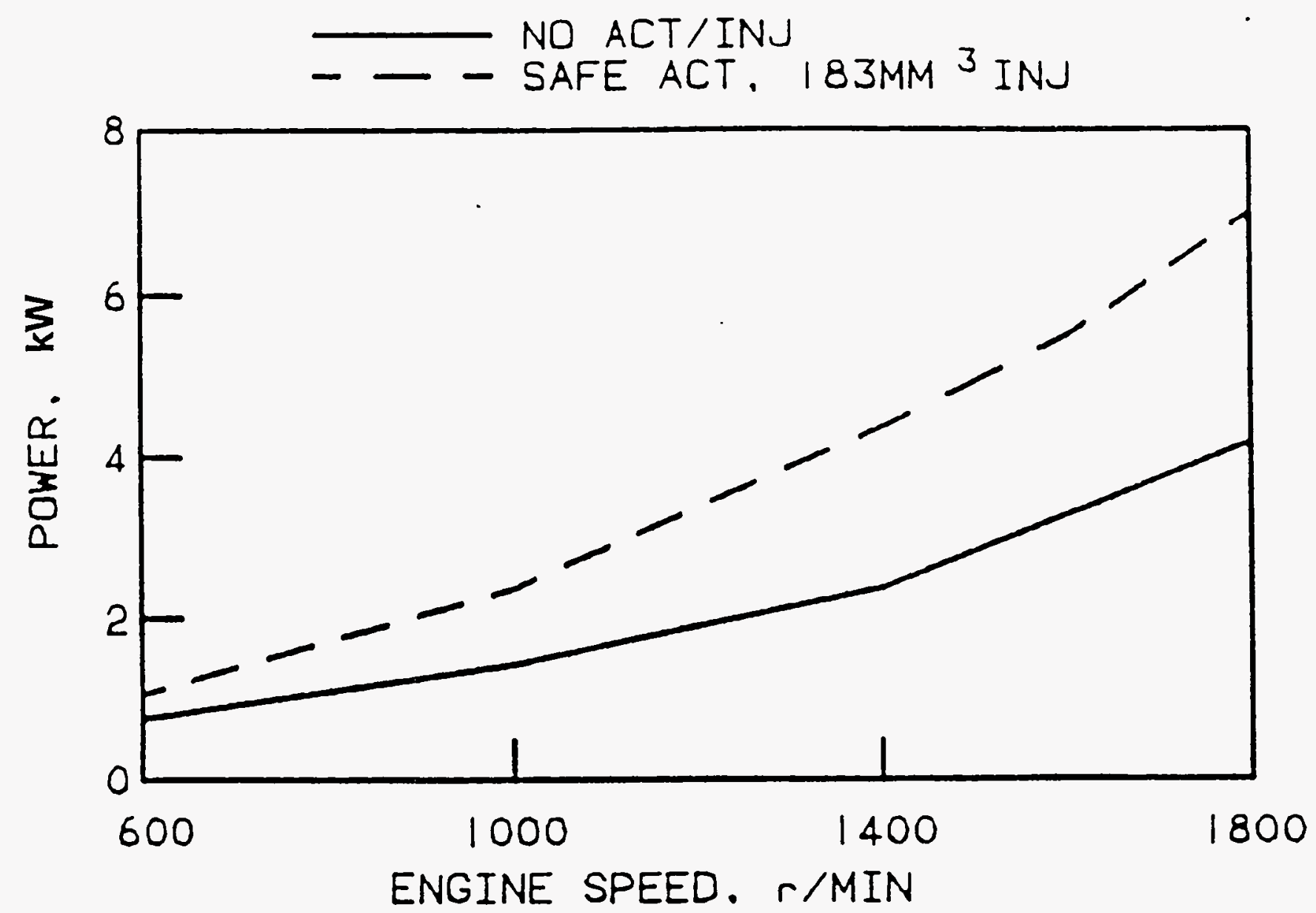

Figure 44: Motoring Friction Power vs. Speed (183 $\mathrm{mm}^{3}$ fuel, SAFE valve event) 


\subsection{BUILD \#3}

During this build, the advanced VP lubrication system and ceramic valves were added to the SCTB. It was at this point that all advanced concepts were integrated as shown in Section 1. In total, 7.3 hours were accumulated during this build under low load operation. Specific efforts included i) refinement of the vapor delivery system and ii) development of a procedure to adjust the delivery of lubricant based on blowby dilution and carrier gas rate to maintain an effective 0.1 mole percent concentration of TCP in the cavity behind the cermet compression ring.

Axial cylinder liner temperature profiles were measured $2.0 \mathrm{~mm}$ below the surface at both intake and exhaust sides. The intake and exhaust temperature profiles obtained during $1500 \mathrm{r} / \mathrm{min}$ operation are shown in Figure 45 . The P-t data and valve events for this condition are shown in Figure 46.

The temperature exceeded $400^{\circ} \mathrm{C}$ near $\mathrm{TRR}$ and there was a $50^{\circ} \mathrm{C}$ circumferential temperature gradient between the exhaust and intake sides (near TRR). It was at this condition, after operating 17 minutes with very high Bosch smoke numbers, 6.4, that the blowby began to rise rapidly and the engine was shut down for inspection.

Teardown and post-test inspection revealed no structural failures. Measurements indicated that the liner was still within original print limits. While the ring was experiencing significant wear (0.0336 gram weight loss), no scuffing or destruction of the running surface was observed. Samples of carbon deposits were forwarded to Penn State University for chemical analysis. The analysis showed that the TCP was reaching the upper liner running surface and that the deposit formation was similar to the deposits seen during laboratory and Tribotester evaluation.

A major accomplishment for Build \#3 was the successful integration of all advanced concepts, followed by the accumulation of 7.3 hours of low load operation, including surviving $400^{\circ} \mathrm{C} \mathrm{TRR} \mathrm{temperatures} \mathrm{with} \mathrm{VP} \mathrm{lubrication.}$

\section{$\underline{7.5}$ BUILD \#4}

An irradiated cermet ring was placed into the SCTB for quantification of in-situ ring wear during ongoing VP lubrication development. Higher power levels and better combustion were attempted. The changes made to increase the power levels included changing the valve event schedule from SAFE to SAFEX (see Figure 47) and increasing the injection rail pressure. The SAFEX schedule moved the exhaust event 20 crank degrees closer to the piston, keeping the same beginning of event and adding 20 crank degrees of dwell. Similarly, the intake event was moved 10 crank degrees closer to the piston TDC, by starting the beginning of event 10 crank degrees sooner and adding 10 crank degrees to the duration. 


\section{Liner Temperature vs. Location}

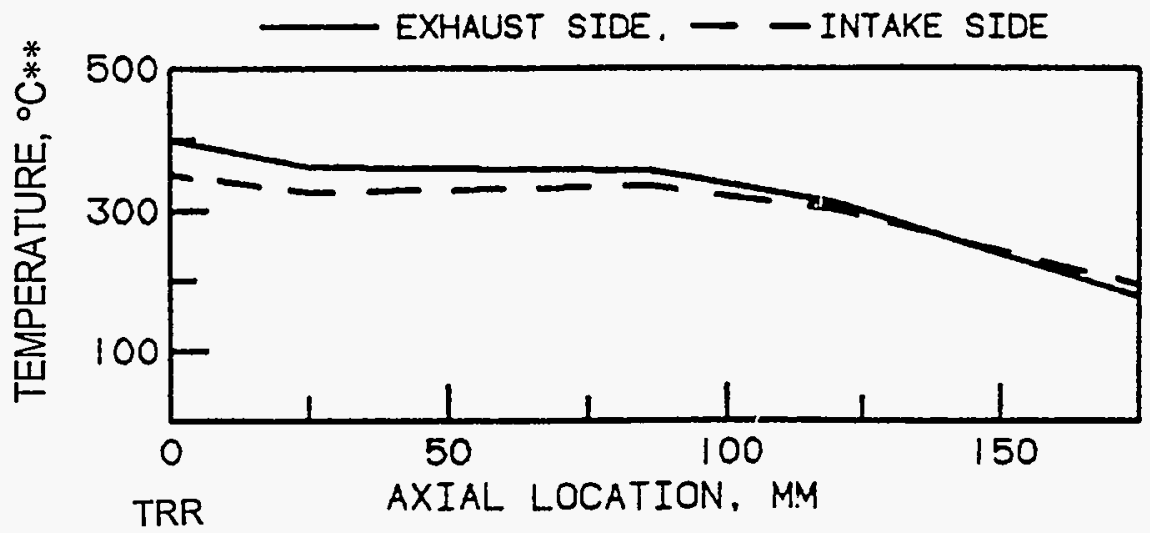

**MEASURED 2MM BELOW SURFACE

Figure 45 - Liner Temperature Profiles at 1500 r/min, No Load, Fully Configured SCTB 


\section{Cylinder Pressure and Valve Travel \\ vs. Crank Angle}

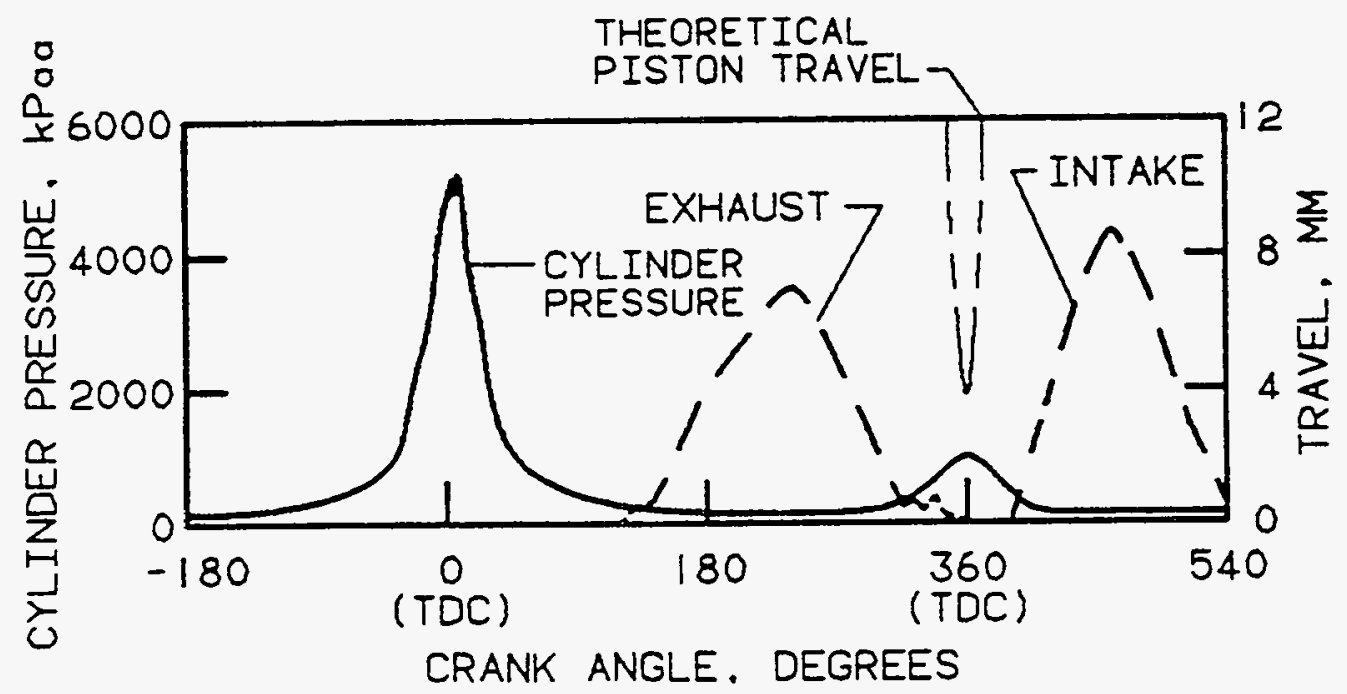

Figure 46: P-t and Valve Event Data $1500 \mathrm{r} / \mathrm{min}$, No Load, Fully Configured SCTB

Valve Travel vs. Crank Angle

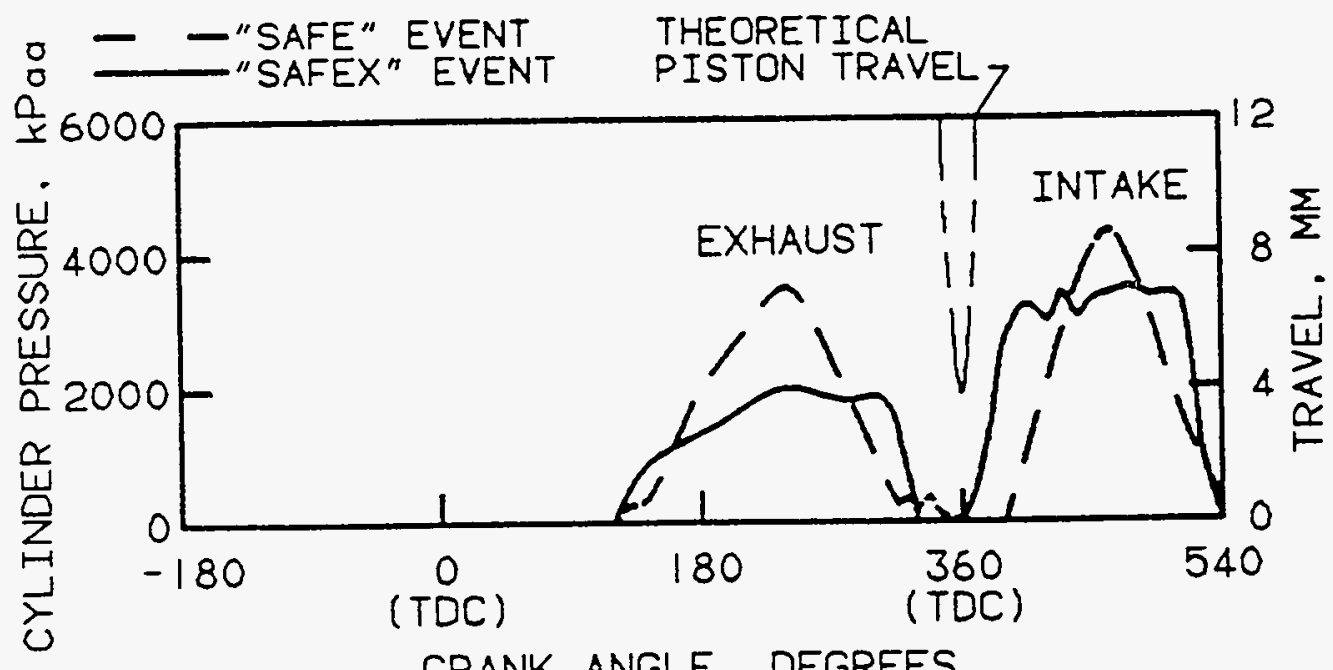

Figure 47: SAFEX vs. SAFE Valve Events 
The engine was operated at various conditions, including $1820 \mathrm{r} / \mathrm{min}, 64 \mathrm{kPa}$ boost, and 53 $\mathrm{mm}^{3} /$ cycle of fuel, $33 \%$ of full fuel rating. As a result, $20 \mathrm{Nm}$ brake torque, and a brake power of $3.73 \mathrm{BkW}$, was generated. High cylinder temperatures and a Bosch smoke number of 4.4 continued to indicate poor combustion. Blowby levels for various conditions are shown in Figure 48. The cylinder liner temperatures for $1820 \mathrm{r} / \mathrm{min}, 64 \mathrm{kPa}$ boost, and 53 $\mathrm{mm}^{3} /$ cycle fuel are shown in Figure 49 and the cylinder head temperatures at various locations are shown in Figure 50. The temperatures of the back surface of the firedeck and the temperatures of the iron behind the firedeck, across the air gap, were also measured.

Another significant event was in-situ ring wear measurement via SLA. A total of ten measurements were made on the piston ring. These measurements were made slightly below top dead center [TDC] and slightly above bottom dead center [BDC] on both the intake and exhaust strokes. Table 9 shows the calculated wear of the ring based on these measurements.

TABLE 9

IN SITU RING WEAR MEASUREMENTS, BUILD \#4

Ring Wear, microns

\begin{tabular}{|l|c|c|c|c|}
\cline { 2 - 5 } \multicolumn{1}{c|}{} & \multicolumn{2}{c|}{ Exhaust Side } & \multicolumn{2}{c|}{ Intake Side } \\
\cline { 2 - 5 } \multicolumn{1}{c|}{} & TDC & BDC & TDC & BDC \\
\hline Meas. 1 & 12.8 & 4.9 & 11.2 & -7.3 \\
Meas. 2 & 11.6 & 0.0 & 9.3 & -13.5 \\
Meas. 3 & 8.9 & - & 8.6 & - \\
& & & & \\
Mean & 11.1 & 2.4 & 9.7 & -10.4 \\
Std. Dev. & 1.3 & 3.5 & 2.0 & 4.4 \\
\hline
\end{tabular}

The mean of all TDC measurements was 10.4 microns with a standard deviation of 1.7 microns. The mean of all BDC measurements is -4.0 microns with a standard deviation of 8.1 microns. Based on these results, it is believed that activated ring wear debris was collecting at the bottom of the cylinder with the intake side collecting most of the debris. The blowby gases, the scraping action of the ring, or a combination of the two could be the reason why the debris collected at the bottom of the cylinder. Furthermore, it is speculated that the vent for the vapor lube system promotes the concentration of the wear debris on the intake side of the engine.

The TRR measurements provided very repeatable measurements with a standard deviation of 1.7 microns and a wear rate of approximately 2.1 microns per hour. Unfortunately, the 


\section{Blowby vs. Time}

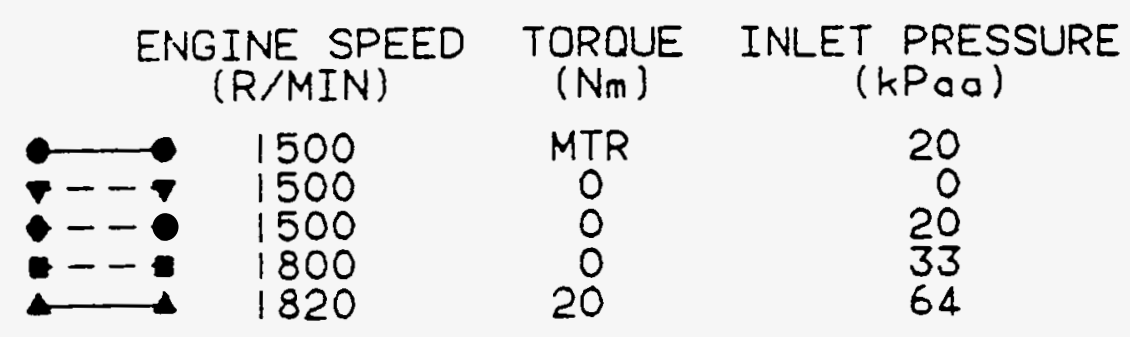

BLOWBY*, L/MIN

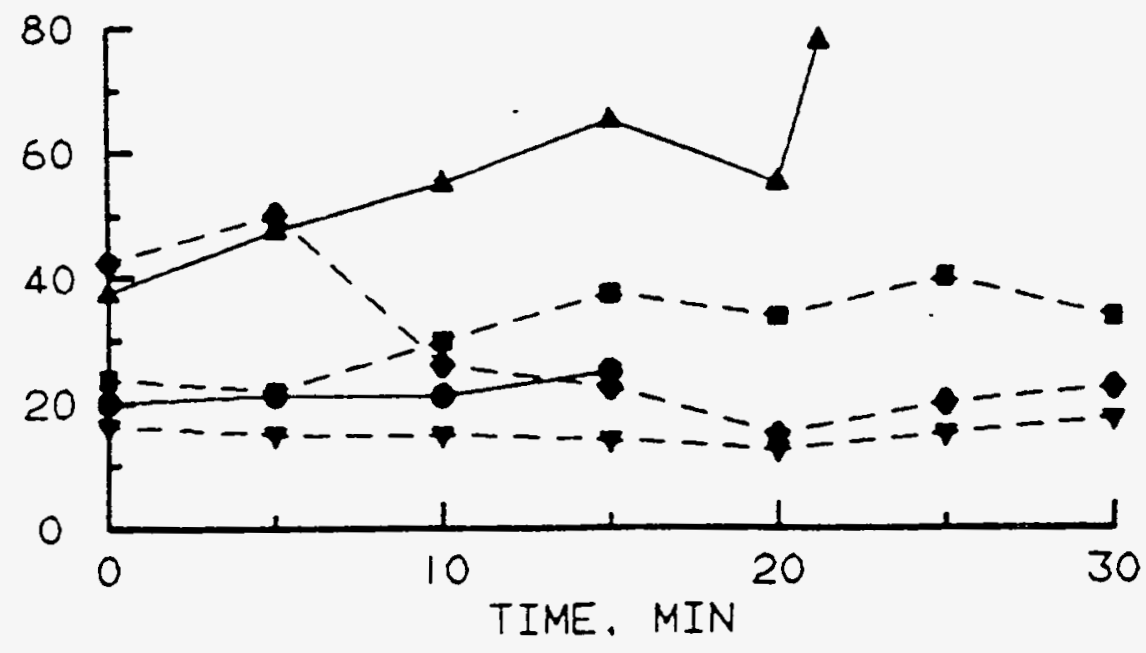

* Sum of carrier gas and engine blowby, 0.1 MOLE PERCENT EFFECTIVE TCP VP LUBE

Figure 48: Build \#4 Blowby Levels 


\section{Liner Temperature vs. Location}

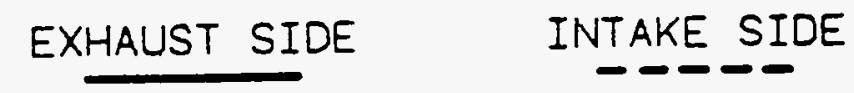

TEMPERATURE , $C * *$

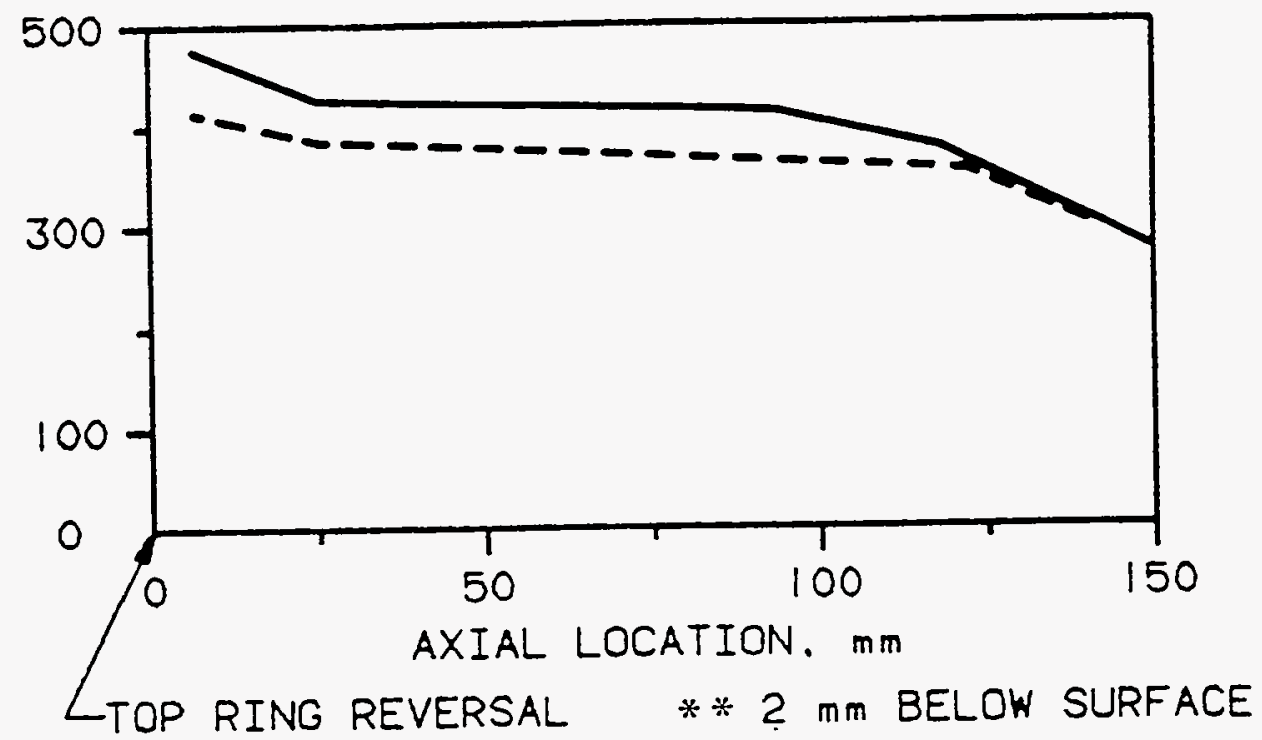

Figure 49: Build \#4 Liner Temperatures 
Cylinder Head Temperature vs. Location

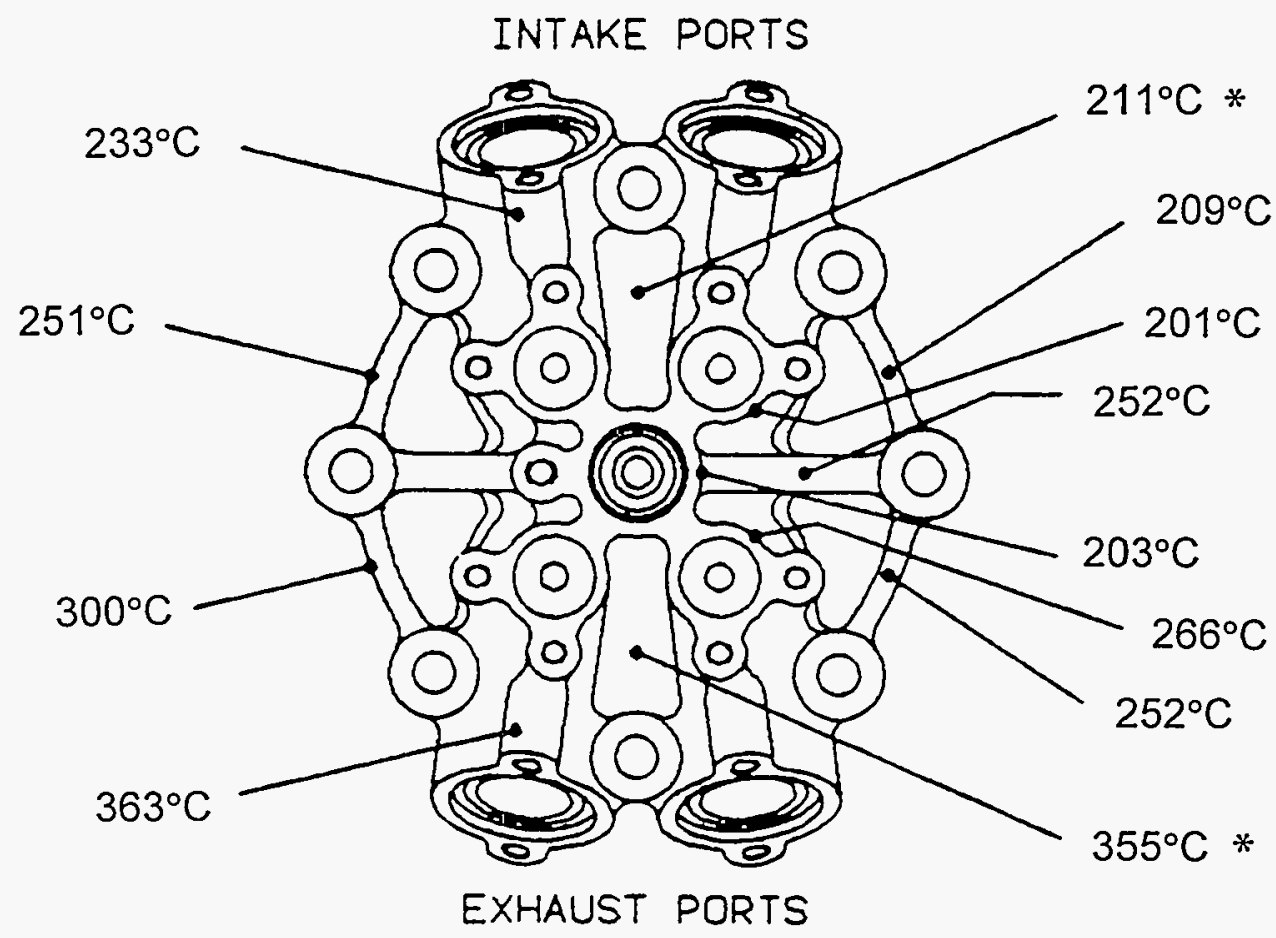

* internal iron temperature

BETWEEN PORTS. 2 LOCATIONS

Figure 50: Build \#4 Cylinder Head Temperatures 
engine suffered a failure prior to a second set of measurements. No post-test measurements were made since it was not possible to recover all the pieces of the broken ring. The lack of a second set of data prevented determination of wear or deposit trends. Due to the severity of damage, all hardware was replaced (see Build \#5). Approximately 5.7 additional hours were accumulated during this engine build on the advanced concepts prior to encountering the catastrophic failure.

\subsection{BUILD \#5}

This build had four objectives: (1) determine and resolve the cause of the Build \#4 failure, (2) increase the power output, (3) improve the combustion process, and (4) establish power point operation for subsequent VP lubrication development.

In total, 7.9 hours were accumulated at various operating conditions in an attempt to identify the cause of the Build \#4 failure. It was determined that skipped actuation cycles due to incorrect software logic increased the valve actuator rail pressure. As the rail pressure increased, the valve lift increased, resulting in the actuator forcing the exhaust valves into the piston. Hence a protection against misactuation was put into effect. The protection was a pressure relief valve that did not allow the pressure to build up beyond $25 \mathrm{MPa}$.

The rail pressure of the injection system was increased from $41.4 \mathrm{MPa}$ to $68.9 \mathrm{MPa}$ and engine testing continued without any other changes. The testing effort concentrated on establishing a reliable operating condition for the development of VP lubrication. A maximum power level of $14.8 \mathrm{~kW}, 80 \mathrm{~N}$-m brake torque at $1800 \mathrm{r} / \mathrm{min}$ was generated. In total, 9.2 additional hours were accumulated on the Build \#5 hardware. Based on this effort, the $1800 \mathrm{r} / \mathrm{min}, 20 \mathrm{~N}$-m brake torque operating condition was selected for VP developmental testing. Data taken at this operating condition was summarized and is shown in Table 10.

The 68.9 $\mathrm{MPa}$ rail pressure greatly reduced the smoke level over previous levels. During operation at $1800 \mathrm{r} / \mathrm{min}$ and $20 \mathrm{~N}$-m brake torque, a Bosch smoke number of 0.7 was measured. This is an $84 \%$ improvement over the 4.4 level (Build \#4) with a $41.4 \mathrm{MPa}$ rail pressure.

The higher injection rail pressures also reduced the cylinder liner temperatures. The liner temperatures for the two rail pressures are plotted in Figure 51. Specifically, the maximum liner temperature (exhaust side at TRR) decreased $115^{\circ} \mathrm{C}$ from $470^{\circ} \mathrm{C}$ to $355^{\circ} \mathrm{C}$, and the circumferential temperature gradient from the exhaust to intake side was reduced by approximately $50 \%$ with the higher rail pressure. These improvements are attributed to better combustion. 


\section{Liner Temperature vs. Location}

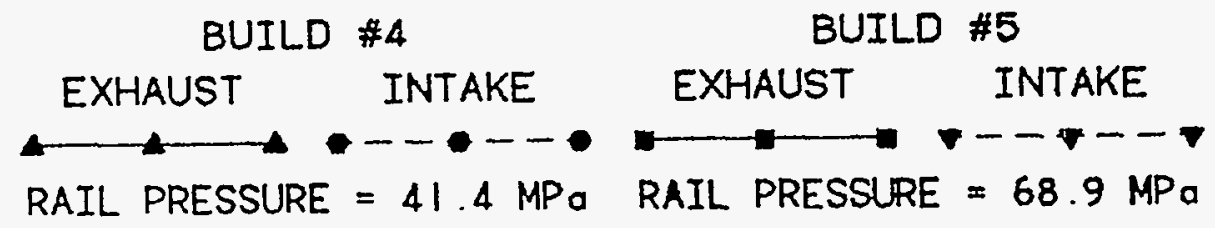

TEMPERATURE , $\mathrm{C} *$

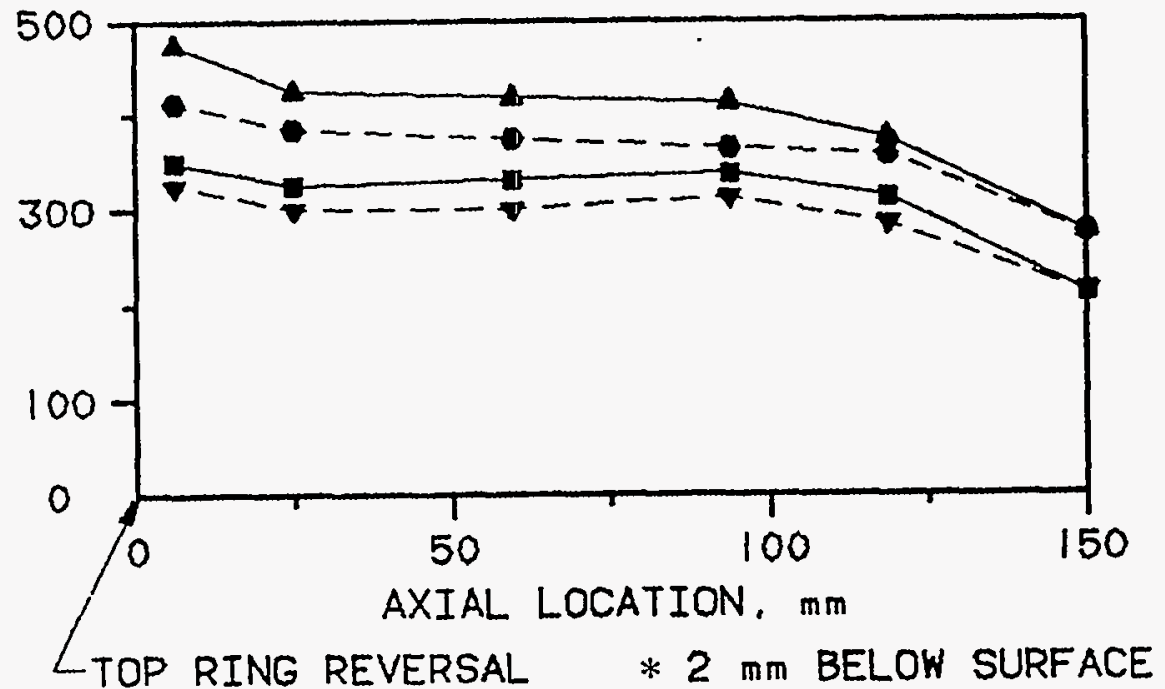

Figure 51 - Cylinder Liner Temperatures 
TABLE 10

ADECD SCTB BUILD \#5 RESULTS

(Indicated Basis)

\begin{tabular}{|l|l|}
\hline SPEED & $1800 \mathrm{r} / \mathrm{min}$ \\
\hline TORQUE & $59 \mathrm{~N}-\mathrm{m}$ \\
\hline POWER & $11.2 \mathrm{~kW}$ \\
\hline & \\
\hline $\begin{array}{l}\text { PEAK CYL. } \\
\text { PRESSURE }\end{array}$ & $9393 \mathrm{kPaa}$ \\
\hline IMEP & $404 \mathrm{kPa}$ \\
\hline ISFC & $174 \mathrm{~g} / \mathrm{kW}-\mathrm{hr}$ \\
\hline & $\begin{array}{l}910 \quad \mathrm{PPM} \text { or } \\
16.2 \mathrm{~g} / \mathrm{kW}-\mathrm{hr}\end{array}$ \\
\hline NO & $\begin{array}{l}69 \quad \mathrm{PPM} \text { or } \\
0.6 \mathrm{~g} / \mathrm{kW}-\mathrm{hr}\end{array}$ \\
\hline CO & $\begin{array}{l}102 \quad \mathrm{PPM} \text { or } \\
0.5 \mathrm{~g} / \mathrm{kW}-\mathrm{hr}\end{array}$ \\
\hline HC &
\end{tabular}

The reduced circumferential temperature variation on the cylinder liner for the higher rail pressure case resulted in improved piston ring to liner sealing and lower blowby. The blowby comparisons are shown in Figure 42 (Section 6, page 70). The reduced blowby was most likely due to less thermal distortion of the liner. Specifically, the higher rail pressure condition resulted in a relatively constant level of blowby, $40 \mathrm{l} / \mathrm{min}$, compared to the lower rail pressure case, where the blowby rapidly increased to over $85 \mathrm{l} / \mathrm{min}$ after 20 minutes of operation.

A post-test inspection of the Build \#5 hardware was conducted. Visual inspection of the piston ring and liner surface revealed no scuffing or scoring. The piston ring and groove area was free of deposits. Wear debris samples were collected from five locations and sent to the Pennsylvania State University for evaluation. Results are discussed in Section 2.4. This evaluation confirmed the presence of TCP and its reaction products in the upper section of the cylinder liner. In summary, a maximum power level of $14.8 \mathrm{BkW}, 80 \mathrm{~N}-\mathrm{m}$ brake torque at $1800 \mathrm{r} / \mathrm{min}$ was generated during this build through improvement of the combustion process. In total, 17.1 hours were accumulated. Based on this effort, the 1800 $\mathrm{r} / \mathrm{min}, 20 \mathrm{~N}-\mathrm{m}$ brake torque operating condition was selected for vapor phase lubrication development. The cause of Build \#4 failure was corrected. 


\subsection{BUILD \#6}

The objective of this build was to quantify the piston ring wear rate under low load operating conditions. Based on CKTTF results, 0.1 mole percent of vaporized TCP lubricant was selected for the cermet piston ring/nitralloy liner evaluation. In total, 12.2 hours were successfully accumulated during this test without scuffing or seizure. And, 10.7 hours were accumulated at $1600 \mathrm{r} / \mathrm{min}$ and $30 \mathrm{~N}-\mathrm{m}$ brake torque and the remainder was accumulated at $1800 \mathrm{r} / \mathrm{min}$ and $30 \mathrm{~N}-\mathrm{m}$ brake torque $(7.5 \mathrm{BkW})$.

The cermet piston ring weight, gap, thickness and profile were measured before installation into the SCTB. During the testing, the radioactivity level of the ring was monitored and recorded using SLA technique. This effort included the transformation of in situ activity readings into equivalent ring wear depths. Approximately 2 minutes of this operation were without delivery of lubricant, due to high blowby levels stalling the pump.

The firedeck, cylinder head, and liner temperature distributions were monitored throughout this test work. These temperature distributions for the $1600 \mathrm{r} / \mathrm{min}$ and $30 \mathrm{~N}-\mathrm{m}$ brake torque point are discussed in Section 2.2. Steady-state TRR temperatures measured $2.0 \mathrm{~mm}$ below the liner surface varied between 340 and $440^{\circ} \mathrm{C}$, depending on the load point.

Since steady-state TRR temperatures of 340 to $440^{\circ} \mathrm{C}$ were tolerated without scuffing or seizure, it was demonstrated that the vapor phase lubrication technology could be a feasible lubrication solution to extreme LHR operating conditions.

\subsection{BUILD \#7}

The objective of this build was to evaluate the effect of a reduced ring end gap on blowby level. Specifically, this test was to compare the blowby level of a silicon nitride ring with a $0.3 \mathrm{~mm}$ end gap to the blowby level of a cermet ring with a $1.1 \mathrm{~mm}$ ring gap. No other parameters were changed.

Since no difference in blowby level could be detected, the test was suspended after 12.2 hours of operation at $1600 \mathrm{r} / \mathrm{min}$ and $0 \mathrm{~N}-\mathrm{m}$ brake torque. It should be noted that 0.1 mole percent vaporized TCP lubricant was delivered to the ring/liner interface, as it was in previous engine builds. Upon disassembly, no ring or upper liner scoring or scuffing was found. However, the lower liner, which is lubricated with SDL1 was scored.

\subsection{BUILD \#8}

The objective of this build was to quantify the performance and emission levels at $50 \%$ power. During start-up, prior to achieving the $50 \%$ power level, a failure was encountered. From inspection of the hardware and electronic controls, it was determined that the failure occurred because the intake valves were opened $50^{\circ}$ before intended, resulting in valve/piston contact. Substantial secondary damage also occurred. The objective of this 
build could not be met because replacement hardware was not available. Upon disassembly of the SCTB, the cermet piston ring was found to be failed. The failure occurred approximately $145^{\circ}$ from the gap. As a result of this effort, the start-up procedure was modified to include a check of valve events.

\subsection{BUILD \#9}

The objective of this test was to quantify the ring wear rate with no intentional delivery of lubricant and to compare these results with those obtained during Build \#6 that had 0.1 mole percent of vaporized TCP lubricant delivered.

In total, 20.0 hours were accumulated during the Build \#9 test sequence. The test sequence consisted of two parts and is shown in Table 11.

\section{TABLE 11}

\section{BUILD \#9 TEST SEQUENCE}

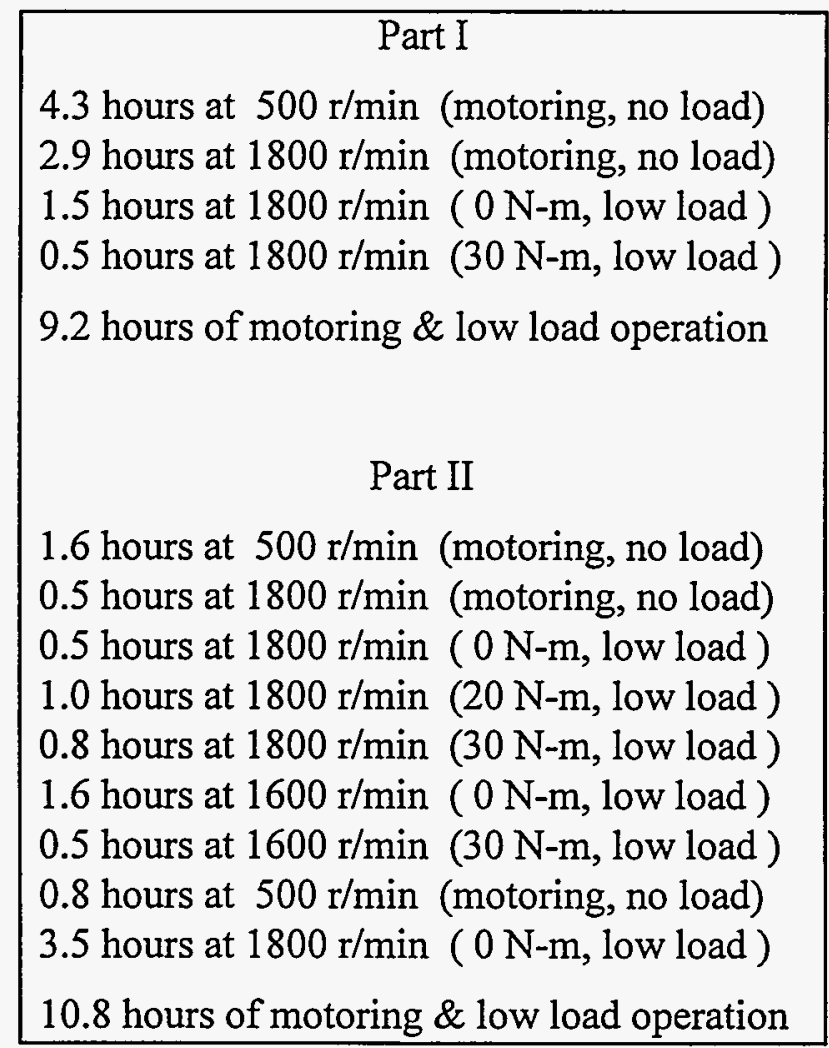

Upon completion of Part I, the cylinder head was removed from the SCTB and the in-cylinder components were inspected. The components appeared to be in good condition. The cylinder liner, however, had shallow vertical scuff marks all around the circumference. 
Upon reassembly, Part II of the test sequence was run. The cylinder liner temperatures and blowby levels from this effort were monitored. The cylinder liner temperature distributions from $1600 \mathrm{r} / \mathrm{min}, 30 \mathrm{~N}-\mathrm{m}$ and $1800 \mathrm{r} / \mathrm{min}, 30 \mathrm{~N}-\mathrm{m}$ and are shown in Figures 52 and 53, respectively. The blowby levels from $1600 \mathrm{r} / \mathrm{min}, 30 \mathrm{~N}-\mathrm{m}$ and $1800 \mathrm{r} / \mathrm{min}, 30 \mathrm{~N}-\mathrm{m}$ are shown in Figure 54.

The performance and emissions data taken during this effort have been reduced. The cylinder pressure vs. time for the five $1800 \mathrm{r} / \mathrm{min}$ load cases were monitored. First case was the motoring case $(-43$ brake $N-m)$ and this was followed by $0,23,31$, and 32 brake N-m load cases. The maximum cylinder pressure recorded for each of these cases were 5852, $8145,7896,8396$, and $7780 \mathrm{kPaa}$, respectively.

The compression coefficients were calculated for the five Build \#9 cases by performing best fit analyses between initial valve closing and BOI. The compression coefficients were: $1.33,1.29,1.30,1.32$, and 1.31. Similarly, the expansion coefficients for the five cases were calculated. For these calculations, best fit analyses were performed between the end of combustion [EOC] and exhaust valve open [EVO]. The resulting expansion coefficients were: $1.33,1.28,1.26,1.24$, and 1.25 .

A difference between the actual and 'best fit' cylinder pressure exists. It is hypothesized that leakage past the piston ring was responsible. If this is true, on a mass basis the leakage could be as high as $9 \%$, if all the pressure loss were due to leakage. If the theoretical polytropic coefficient, 1.32 , was used in place of the best fit values, the actual data would begin to diverge from the theoretical cylinder pressure line sooner, at approximately 35 degrees before top center.

The specific indicated and brake fuel economy levels and performance data at three $1800 \mathrm{r} / \mathrm{min}$ load cases were calculated $(0,23$, and 31 brake $\mathrm{N}$-m loads). The fuel economy levels were excellent and highlight the merit and promise of the EHVA and common rail injection systems.

The indicated and brake emissions data for the 0,23 , and 31 brake $\mathrm{N}$-m load cases were also calculated. The NOx emission was high, the $\mathrm{HC}$ emission is within the standard limit, and the $\mathrm{CO}$ is much lower than the standard limit (typical of diesel engines). Tables 12 and 13 give representative performance and emissions.

Upon completion of Part II of the Build \#9 test sequence, the SCTB was disassembled for an in-cylinder component inspection. During this inspection, the cermet piston ring was found to be fractured and excessively worn. See Section 2.5. The ring and liner wear rates from Build \#9 were measured, converted to wear coefficients, and compared to Build \#6 results. These results are discussed in Section 2.5. 


\section{Liner Temperature vs. Location}

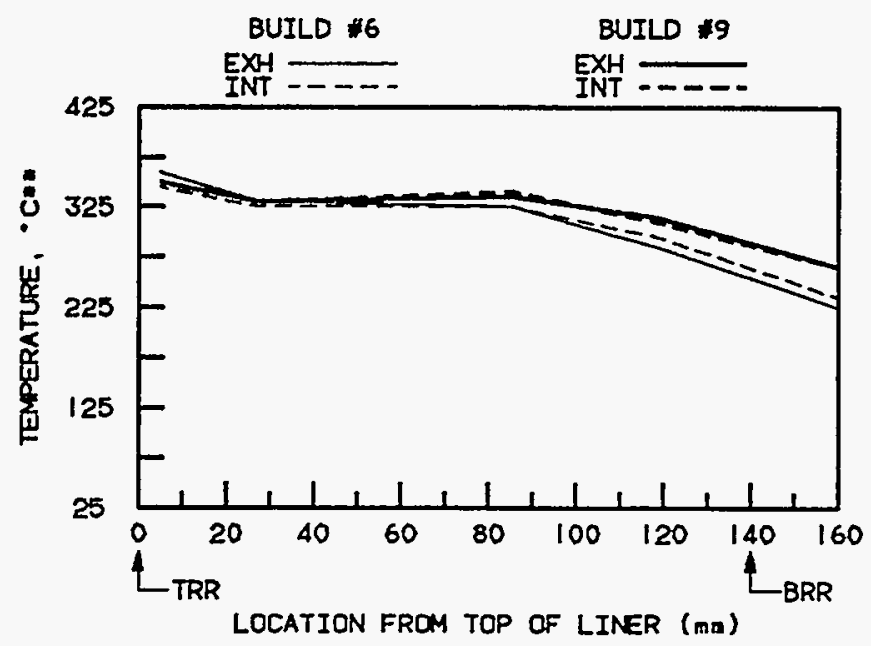

* MEASUREo $2 \mathrm{~mm}$ Below surface

Figure 52 - Build \#9 vs. \#6 Liner Temperatures, $1600 \mathrm{r} / \mathrm{min}$ and $30 \mathrm{~N}-\mathrm{m}$

\section{Liner Temperature vs. Location}

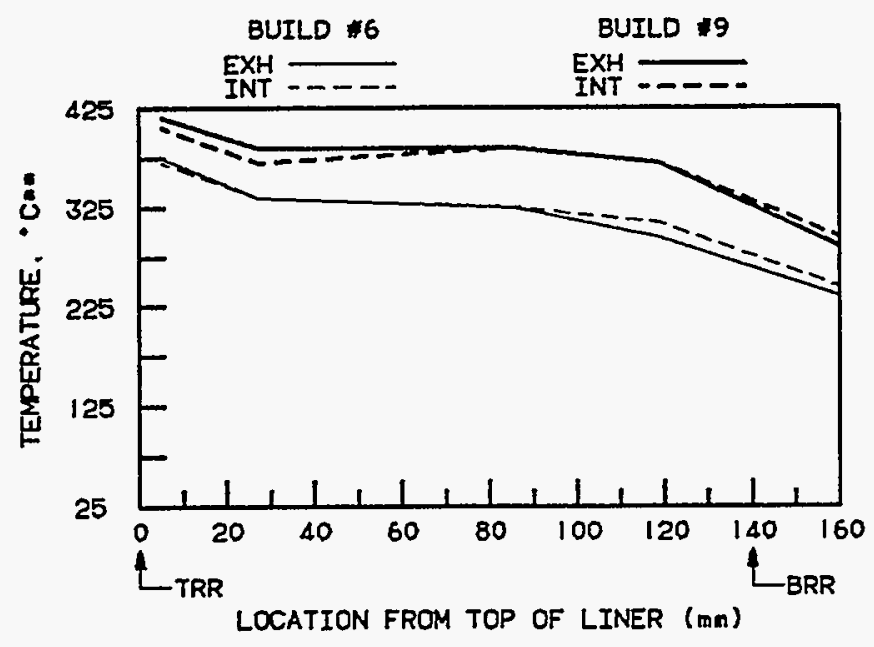

* MeAsUred $2 \mathrm{~mm}$ BELOW sURface

Figure 53 - Build \#9 vs. \#6 Liner Temperatures, $1800 \mathrm{r} / \mathrm{min}$ and $30 \mathrm{~N}-\mathrm{m}$ 
Blowby vs. Time

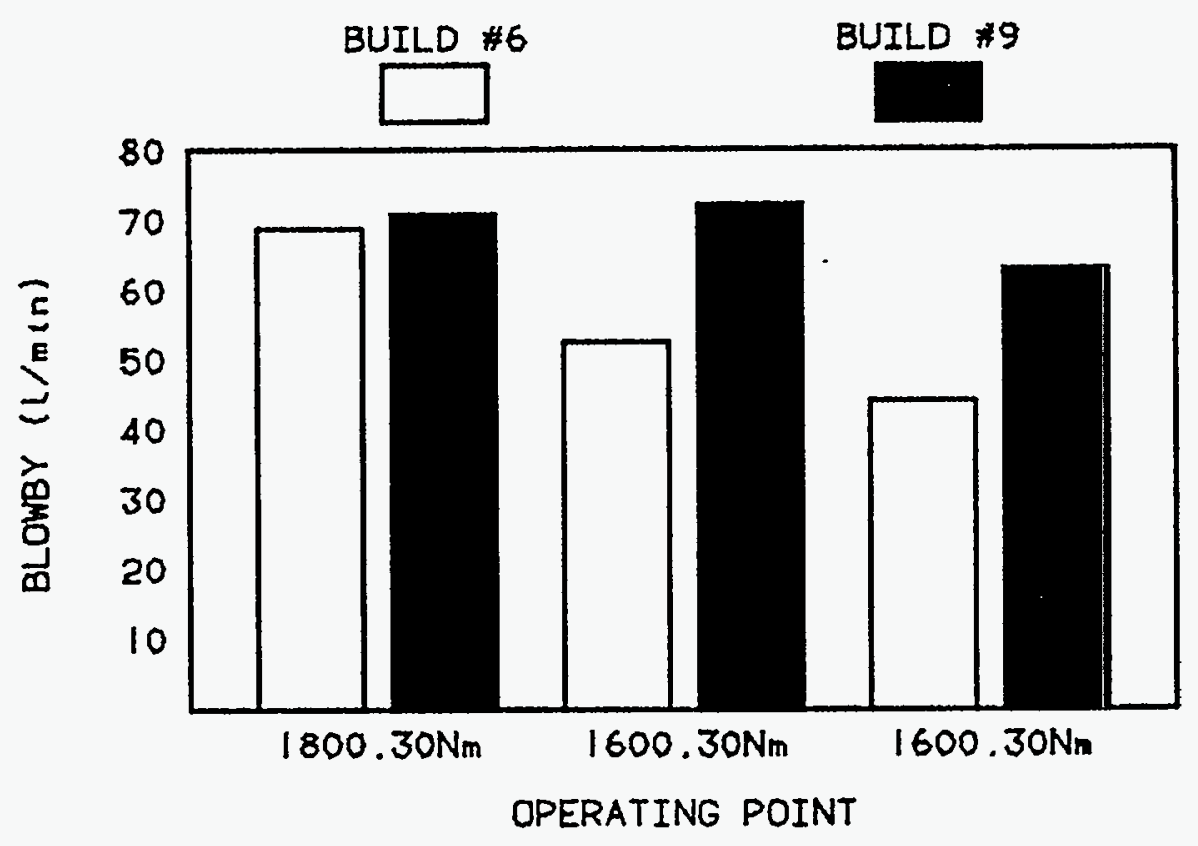

Figure 54 - Build \#9 Blowby Levels 
TABLE 12

SCTB BUILD \#9 PERFORMANCE DATA 1800 R/MIN, 23 BRAKE N-M, -15 DEGREE BOI

\begin{tabular}{|c|c|c|}
\hline & $\begin{array}{r}\text { Speec } \\
\text { Peak Cylinder Pressure } \\
\end{array}$ & $\begin{array}{l}1800 \mathrm{r} / \mathrm{min} \\
7896 \mathrm{kPa}\end{array}$ \\
\hline & Brake Basis & Indicated Basis \\
\hline TORQUE & $23 \mathrm{~N}-\mathrm{m}$ & $66 \mathrm{~N}-\mathrm{m}$ \\
\hline POWER & $4.3 \mathrm{~kW}$ & $11.5 \mathrm{~kW}$ \\
\hline MEP & $157 \mathrm{kPa}$ & $416 \mathrm{kPa}$ \\
\hline SFC & $440 \mathrm{~g} / \mathrm{kW}-\mathrm{hr}$ & $166 \mathrm{~g} / \mathrm{kW}-\mathrm{hr}$ \\
\hline
\end{tabular}

TABLE 13

SCTB BUILD \#9 EMISSIONS DATA 1800 R/MIN, 23 BRAKE N-M, -15 DEGREE BOI

\begin{tabular}{|c|c|c|}
\hline Emission & Indicated Basis & Brake Basis \\
\hline NOx & $15.0 \mathrm{~g} / \mathrm{kW}-\mathrm{hr}$ & $40.1 \mathrm{~g} / \mathrm{kW}-\mathrm{hr}$ \\
\hline $\mathrm{CO}$ & $1.1 \mathrm{~g} / \mathrm{kW}-\mathrm{hr}$ & $2.9 \mathrm{~g} / \mathrm{kW}-\mathrm{hr}$ \\
\hline $\mathrm{HC}$ & $0.9 \mathrm{~g} / \mathrm{kW}-\mathrm{hr}$ & $2.4 \mathrm{~g} / \mathrm{kW}-\mathrm{hr}$ \\
\hline
\end{tabular}

Failure analysis of the Build \#9 piston ring revealed a fatigue failure initiating at the top chamfered corner. Since the fractured surface was determined to be free of defects, it was concluded that the failure was simply due to exceeding the strength of the base material while running in the unlubricated mode. Based on these results, it was concluded that vapor phase lubrication is superior to no intentionally delivered lubricant and that no intentionally delivered lubricant is unacceptable. 


\subsection{BUILD \#10}

The objective of this test was to operate at a $50 \%$ power level and to quantify the piston ring wear rate and the performance and emissions levels. In order to operate at a $50 \%$ power level, the following two items were identified as needing to be accomplished:

- modify the valve event

- increase the injection rail pressure

As stated earlier, previous valve events were purposely kept away from the piston in order to avoid a catastrophic situation. However, with several reliable demonstrations of the EHVA system and the need to operate at $50 \%$ power, it was decided that the valve events had to occur closer to top center. Specifically, the exhaust and intake valve events would be placed within 10 degrees of the piston motion, similar to mechanically driven valve events utilized in today's diesel engines.

As shown in Figure 55, the valve event for Build \#10 was moved to within 10 degrees of the piston motion, as desired. For comparison, the previous intake and exhaust valve events are also shown. In a similar effort, the high pressure fuel for the common rail injection system was increased by about 20 percent over previous levels. The Build \#10 injection event, as developed on the VAIF, is discussed in Section 6.

In total 63.8 hours were accumulated using the Build \#10 valve and injection events. Most of this time was used to identify and stop the lower cylinder liner's liquid lubrication from leaking into the hotter upper cylinder area. As a result of this effort, a second compression ring was added to the piston configuration. Upon resolution of the lower cylinder liner's oil leakage problem, $50 \%$ power operation was achieved.

The cylinder pressure vs. time data taken at this moderate power level is shown in Figure 56. As shown in Figure 56, the peak cylinder pressure reached 12.2 MPa. The performance and emissions data taken at this moderate power level is shown in Table 14.

The excessively high amount of blowby, 233 liters per minute, prohibited stable SCTB operation at this power point. Consequently, ring wear rate data were not obtained. At this point, the SCTB was disassembled so each component could be inspected. Upon disassembly, the top (cermet) piston ring was found to be fractured, about $175^{\circ}$ from the gap, as discussed in Section 2.4. Further disassembly revealed localized fractures in the ceramic piston cap on its thrust and anti-thrust surfaces, see Section 2.4. The ceramic coating on the second compression ring was severely chipped. No cracks were detected after dye penetrant checking of the ceramic valves, firedeck, and ports. 


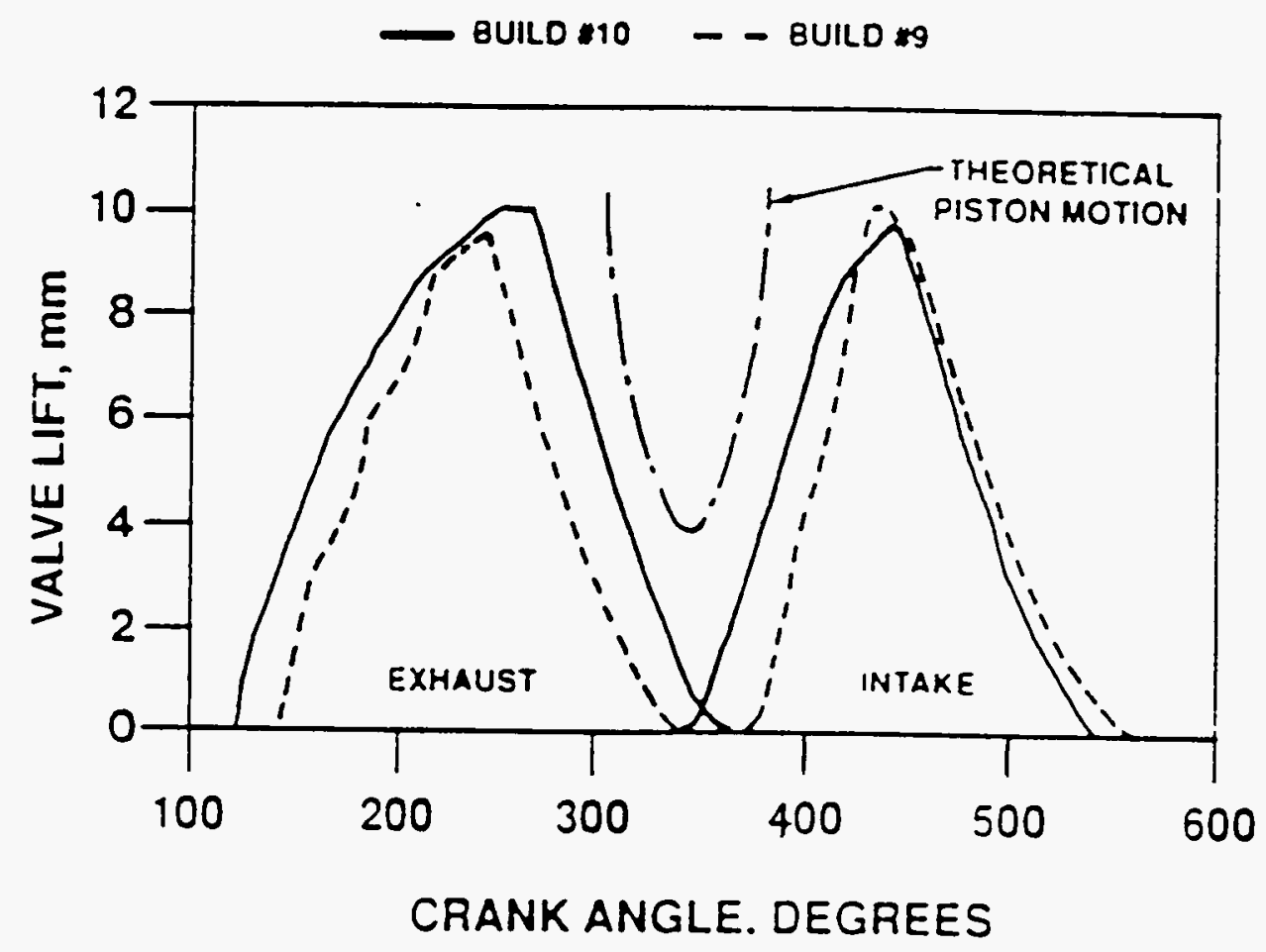

Figure 55 - Build \#10 Valve Event 

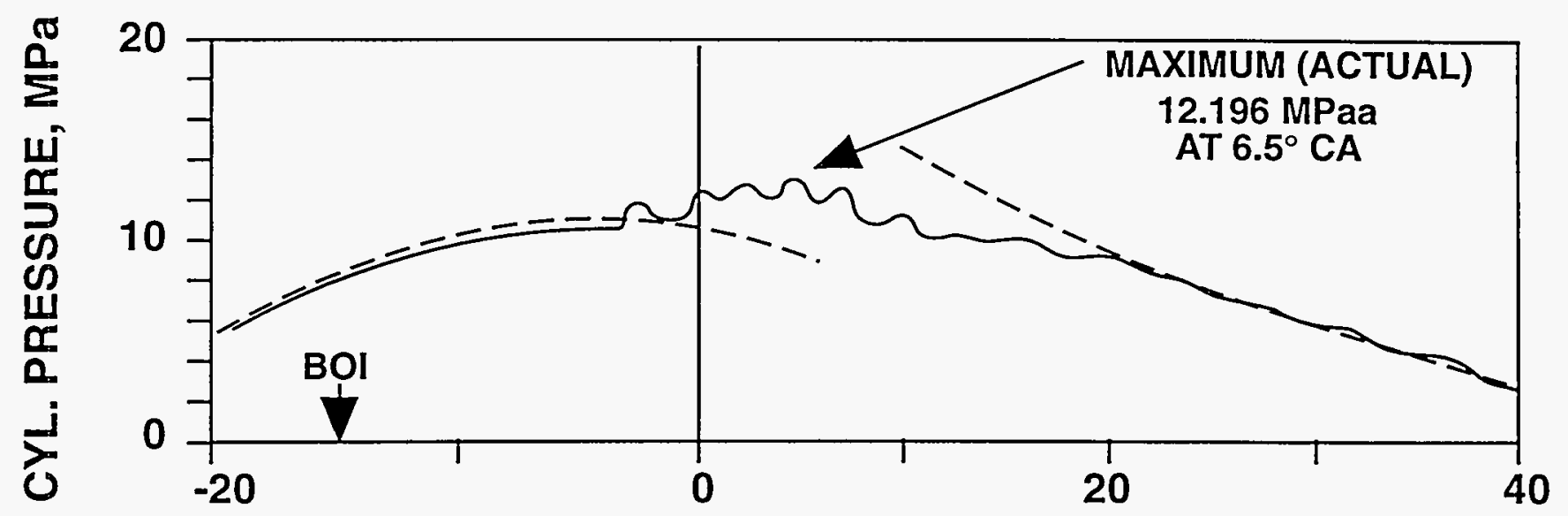

\section{CRANK ANGLE DEGREES}
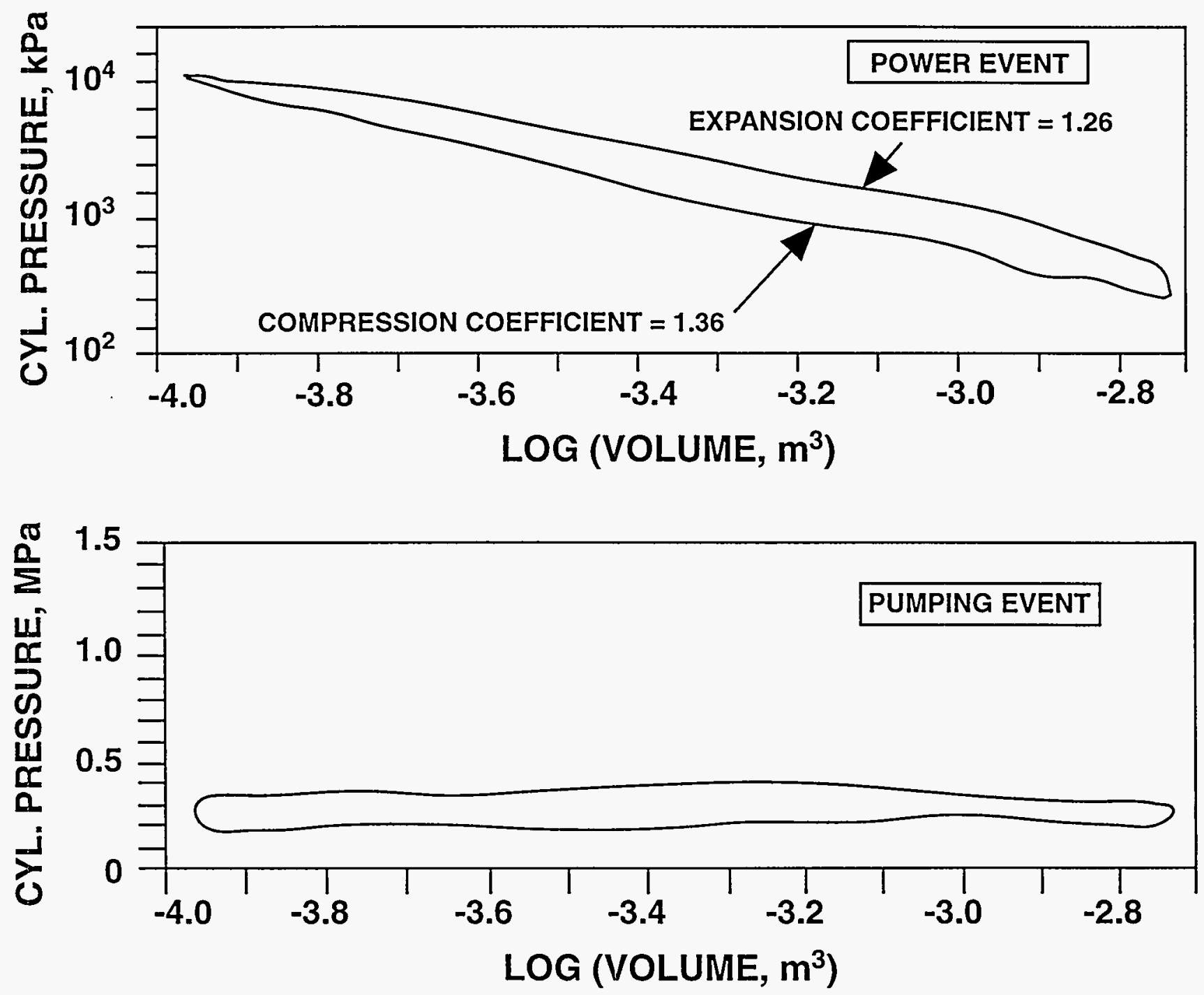

Figure 56 - Build \#10 Pressure vs. Time, at $110 \mathrm{kPa}$ Inlet/140 kPa Exhaust 
TABLE 14

SCTB- BUILD \#10, PERFORMANCE AND

EMISSIONS DATA AT 50\% POWER POINT

\begin{tabular}{|l|r|}
\hline \multicolumn{1}{|c|}{ Valve Event } & SAFE-Y \\
\hline Injector Tip, holes & 9 \\
Injection Pressure, MPa & 77 \\
Speed, r/min & 1800 \\
Power, kW & 22.5 \\
& \\
Peak Firing Press., MPa & 12.2 \\
Mean Eff. Press., $\mathrm{kPa}$ & 813 \\
Top Ring Reversal, ${ }^{\circ} \mathrm{C}$ & 320 \\
Blowby, 1/min & 233 \\
& \\
Specific Fuel Consumption & 197 \\
g/kW-hr . & \\
& \\
NOx, g/kW-hr & 9.3 \\
CO, g/kW-hr & 2.3 \\
HC, g/kW-hr & 1.2 \\
\hline
\end{tabular}

Based on an extensive failure analysis, it was determined that the primary cause of failure was due to butting the second compression ring, which resulted when the ring's thermal expansion exceeded the gap allowance. This produced a bending stress at the root of the piston cap groove, which exceeded the cap's strength level and locally fractured the cap. All other damage, including the extensive chipping of the second compression ring's ceramic coating, was determined to be secondary.

\subsection{BUILD \#11}

The SCTB was configured with the same components as Build \#10 with the exception of a ceramic-faced stainless steel top ring replacing the prime path monolithic cermet version. It was reasoned that the stainless steel ring, with a stiffness 50 percent lower than the cermet ring, would improve the ring-to-liner conformability and reduce the blowby.

Equipped with the stainless steel ring, Build \#11 initially achieved a stable blowby at 1800 $\mathrm{rev} / \mathrm{min}$ under motoring and low power levels. However, at higher power levels, blowby increased radically after the operating point was held for a period of time. The blowby 
stability of the stainless steel ring was improved over cermet ring, giving a longer time of blowby stability at any given load point. A maximum of $28 \mathrm{~N}-\mathrm{m}$ torque at $1800 \mathrm{rev} / \mathrm{min}$ and a peak firing pressure of $11.1 \mathrm{MPa}$ was achieved, but a radical increase in blowby resulted in the test run being terminated after 4.8 hours were accumulated on the SCTB, only 0.7 of which were firing. The 75 percent power point was not achieved.

Section 2.4 discusses some temperature and blowby results of this test run. There was a sudden, large increase in the blowby, and it appeared to be related to the in-cylinder temperatures. This is supported by the observation that the blowby returned to its initial level as the engine cooled down.

Due to the time/temperature nature of this radical increase in blowby, it was surmised that either thermally or mechanically induced ring or bore distortion was involved. The next objective for the SCTB work was to increase understanding of the excessive blowby through computer modeling, thus enabling modifications of the SCTB configuration to reduce the blowby to an acceptable level so that additional component and higher power level testing could continue.

\subsection{BUILD \#12}

The SCTB was rebuilt with a redesigned L-section top ring and an angled step-gap second ring. See Sections 2.5 and 2.6 for modeling and design details. The SCTB was run using the baseline carrier gas method and most of the lubricant injector system engine hardware. Closed cylinder motoring and test firing of the SCTB was done for a total of 33.1 hours to verify injector and valve operation at the $25 \%$ power point. The tests were conducted with a lubricant consisting of a $6 \% \mathrm{TCP}$ solution in white mineral oil. In the baseline carrier gas test, the lubricant concentration was $0.1 \mathrm{~mol} \%$, adjusted for blowby.

Testing of the lubrication systems was conducted primarily at a $25 \%$ power level to minimize blowby purging of lubricant from the inter-ring pocket. The baseline carrier gas engine test was conducted over a period of three days. During the first day, time was spent running the engine at a $50 \%$ power level in an unsuccessful attempt to achieve reasonable blowby levels. Figure 57 presents typical blowby and top ring reversal liner and head temperatures at $25 \%$ power. Note the separation of the exhaust and intake top ring reversal liner temperatures at points where blowby fluctuates. Since the ring pack redesign effort (Sections 2.5 and 2.6) indicated that this engine was susceptible to ring pack frictional heat deformation, this temperature separation may be related to marginal lubrication causing the effectiveness of the ring seal to vary. Engine performance during the first and second days was consistent with previous test runs with comparable indicated power, pumping losses, and frictional power losses. On the third day of testing, blowby was $50 \%$ higher than the

previous two days, and engine performance had degraded. After a total of 12.6 hours of engine operation, the engine was torn down to reveal a major piston failure. 


\section{IN-CYLINDER TEMPERATURES AND BLOWBY CARRIER GAS RUN}

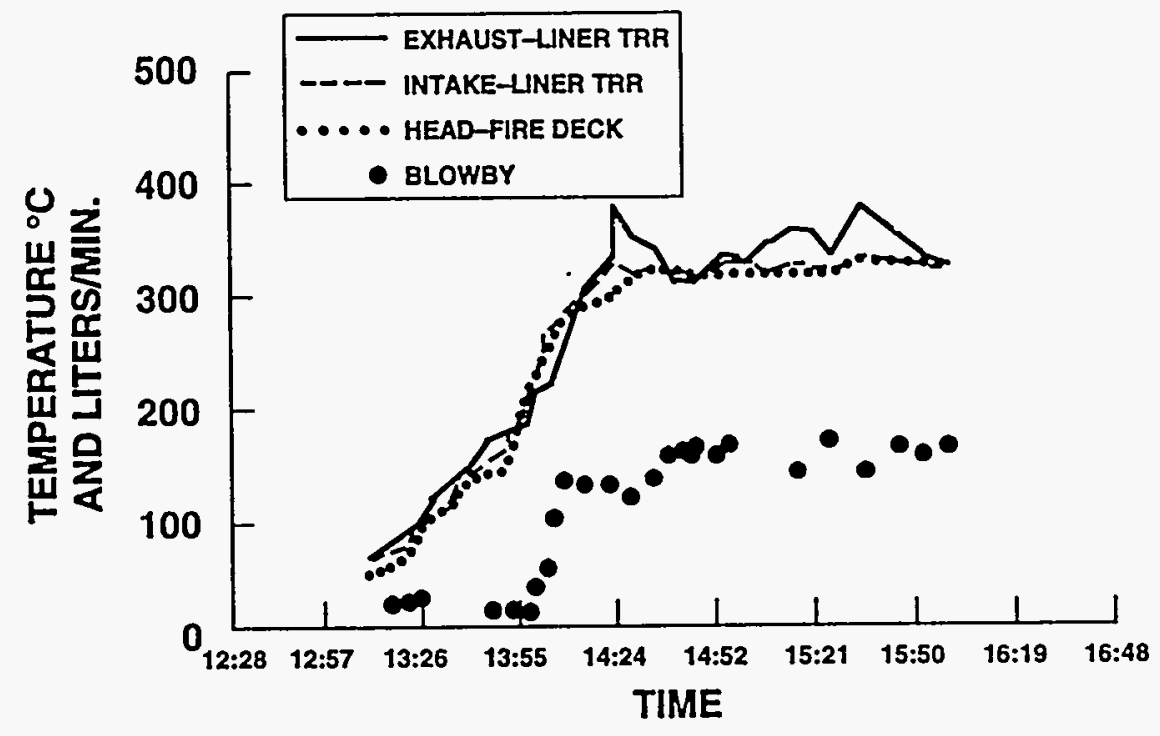

Figure 57: In-Cylinder Temperatures \& Blowby Baseline Carrier Gas Run 
The ceramic piston dome was found to be fractured in the top outer rim for about 270 degrees of its circumference, extending into the ring grooves in some areas. Scuff marks on the piston rings and liner indicate that the likely cause of this failure was due to scuffing of the ring, causing momentary seizure, resulting in an excessive load to ring lands. This was a result of high ring wear permitting metal to metal contact between the ring substrate material and the cylinder liner. Seizure is further supported by the top compression ring being bent into the area where the ceramic fractured. There was no evidence on the ring gap indicating that ring butting occurred. As a result of this failure, ceramic debris was introduced between the rings and liner, confounding wear measurements for the baseline carrier gas run.

\subsection{BUILD \#13}

The engine was rebuilt with a new head, piston, liner, ring pack, and the lubricant injector for the lubricant injector test run. Ring pack components differed from the baseline test run in that they were coated with an anti-friction silver coating, intended to reduce the blowby via reduced thermal ring distortions. Testing of the lubricant injector was conducted over two days for a total of eight hours of engine run. Figure 58 presents typical blowby and top ring reversal liner temperatures and head temperatures. Note the difference in temperature separation of the exhaust and intake sides from the baseline run. This greater separation is most likely due to better lubrication on the lubricant injector side (intake) of the cylinder, permitting the piston rings to seal better. This resulted in better contact of the piston ring to the liner, thus permitting more heat flux into the intake side of the cylinder. The blowby was significantly lower than the baseline, carrier gas test run. The fueling rate, however, was slightly higher than the baseline.

During the teardown inspection of this test run, it was again found that the ceramic piston dome had fractured, although not to the extent of the baseline carrier gas run. This failure occurred in the piston ring lands and inter-ring lubricant pocket on the lubricant injector side, and 180 degrees to the lubricant injector. The piston damage, on the lubricant injector side, appears to be from thermal shock of the ceramic from the relatively cool injected liquid lubricant, and opposite to the lubricant injector, from lubrication starvation. The ceramic wear debris was contained and did not appear to affect the ring wear. The teardown inspection also revealed lubricant coating the combustion chamber surfaces, with significant amounts of carbon residue on the fire deck, sides of the piston, and in the oil ring groove, causing the oil rings to stick. The high blowby, as expected, caused the lubricant to purge from the inter-ring pocket. The condition of both ring faces was similar to the baseline carrier gas test run, with scuffing occurring 360 degrees around the outside diameter.

\section{CONCLUSIONS}

1. The design of major ceramic components (piston cap, firedeck, ports, valves and valve guides) was successfully validated in the SCTB under varying engine speeds and loads.

2. Revolutionary engine systems such as common rail injection, electro-hydraulic valve actuation and vapor phase lubrication were successfully integrated into the SCTB to demonstrate potential for improved fuel economy and reduced emissions. 


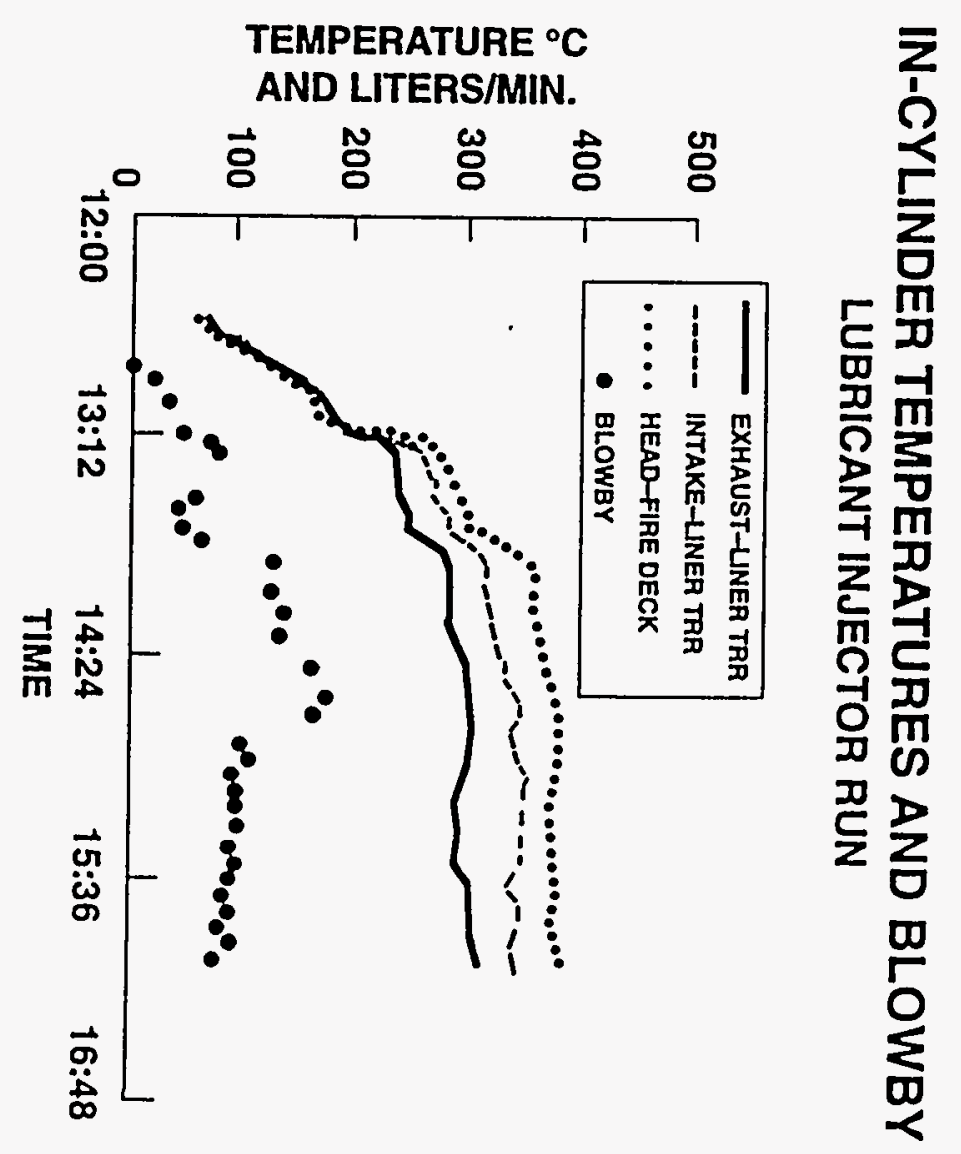




\section{SECTION VIII}

\section{ADVANCED EMISSIONS PARAMETRIC STUDIES}

The primary concern of current production heavy-duty diesel engines is to meet the regulated levels of nitrogen oxides (NOx) and particulate emissions. Unfortunately engine design changes which reduce NOx emissions frequently increase particulates or visa versa. In developing near term emissions reduction technology, it is therefore necessary to characterize engine component contributions and trade-offs to the emission equation.

Through extensive analytical and laboratory experience in reducing emissions in production engines, it was determined that the most promising engine components for emissions characterization were injector cam lobe profiles, injectors and injector tips, and piston ring packs. Analysis of these components suggested four areas warranted specific investigation; 1) camshaft generation of very high injection pressures, 2) Injector component parameters, 3) Ring pack design for oil control, and 4) injector and camshaft related injection rate shaping. Components were designed, fabricated, and then tested on a DDC Series 60 engine under transient and steady-state operating conditions.

\subsection{VERY HIGH INJECTION PRESSURES}

Experience has provided ample evidence that smoke and particulates are generally reduced by increasing injection pressures. However, the magnitude of the reduction and/or the NOx trade-off had not been fully characterized in a low-emission engine. Of the available design strategies to increase injection pressures, the approach with the most flexibility and least impact on the injection drive train was to increase the lift velocity of the injection camshaft. By increasing cam lift-velocity, greater pressure is applied to the fuel in the injector, thereby resulting in higher injection pressures.

Two camshaft lobe profiles with higher values of constant lift-velocities were analyzed and designed to produce higher levels of injection pressure relative to a production baseline lift-velocity. Table 15 summarizes the cam lift-velocities and their corresponding higher injection pressures. Figure 59 plots the Brake Specific NOx (BSNOx) versus the Brake Specific Particulates (BSP) produced during the EPA transient emission test cycle for the three cam designs. In order to make an objective comparison of the particulate/NOx trade-off for different camshaft velocities, it was necessary to adjust the injection timing to give a similar NOx level. Note that the NOx level selected corresponds to the requirement necessary to meet 1994 regulated levels. As can be seen, both experimental cams confirmed that higher cam lift-velocities produce a significant emissions improvement relative to the baseline. 
TABLE 15

CAM LIFT-VELOCITY AND INJECTION PRESSURE

\begin{tabular}{|ccc|}
\hline $\begin{array}{c}\text { Cam Lift - Velocity } \\
(\mathrm{mm} / \text { degree })\end{array}$ & $\begin{array}{c}\text { Injection Pressure } \\
\text { (MPa) }\end{array}$ \\
0.30 & 151 & (Baseline) \\
0.34 & 170 & \\
0.38 & 194 & \\
\hline
\end{tabular}

To improve understanding of the transient test results, steady-state emissions measurements were also made at low and high power operation. Figure 60 shows the BSNOx versus BSP trade-off for the three camshaft velocities at low power as fuel injection timing is retarded to reduce the NOx. As cam lift-velocity is increased, particulate emissions decrease. However, as Figure 61 indicates, at high power steady-state conditions, as cam lift-velocity is increased, particulate emissions increase when injection timing is retarded to reduce NOx levels. This is significant finding in view of the fact that higher power operation is the major contributor to emissions in the EPA transient emissions test cycle. It also tends to explain why the $0.34 \mathrm{~mm} /$ degree camshaft performs slightly better than the $0.38 \mathrm{~mm} /$ degree camshaft in transient operation (Figure 59).

In summary, with NOx emissions equalized through injection timing, transient particulates were reduced approximately $20 \%$ with the higher velocity camshaft relative to the baseline production camshaft. Finally, as cam lift-velocity (injection pressure) is increased under steady-state engine operation at higher power levels, particulates increase at low NOx levels. At lower power levels, particulates decrease as cam lift-velocity is increased.

\subsection{INJECTOR COMPONENT PARAMETERS}

Four injector design parameters were selected for study as likely candidates to reduce particulate emissions. They were: 1. Injector Valve Opening Pressure, 2. Tip Spray Hole Location, 3. Low Sac versus Valve Covered Orifice Spray Tip Style, and 4. Spray Tip Hole Length. Selection of injector component parameters was based on injector supplier input and previous emissions test experience. The Valve Covered Orifice (VCO) production spray tip style was used as the baseline. 


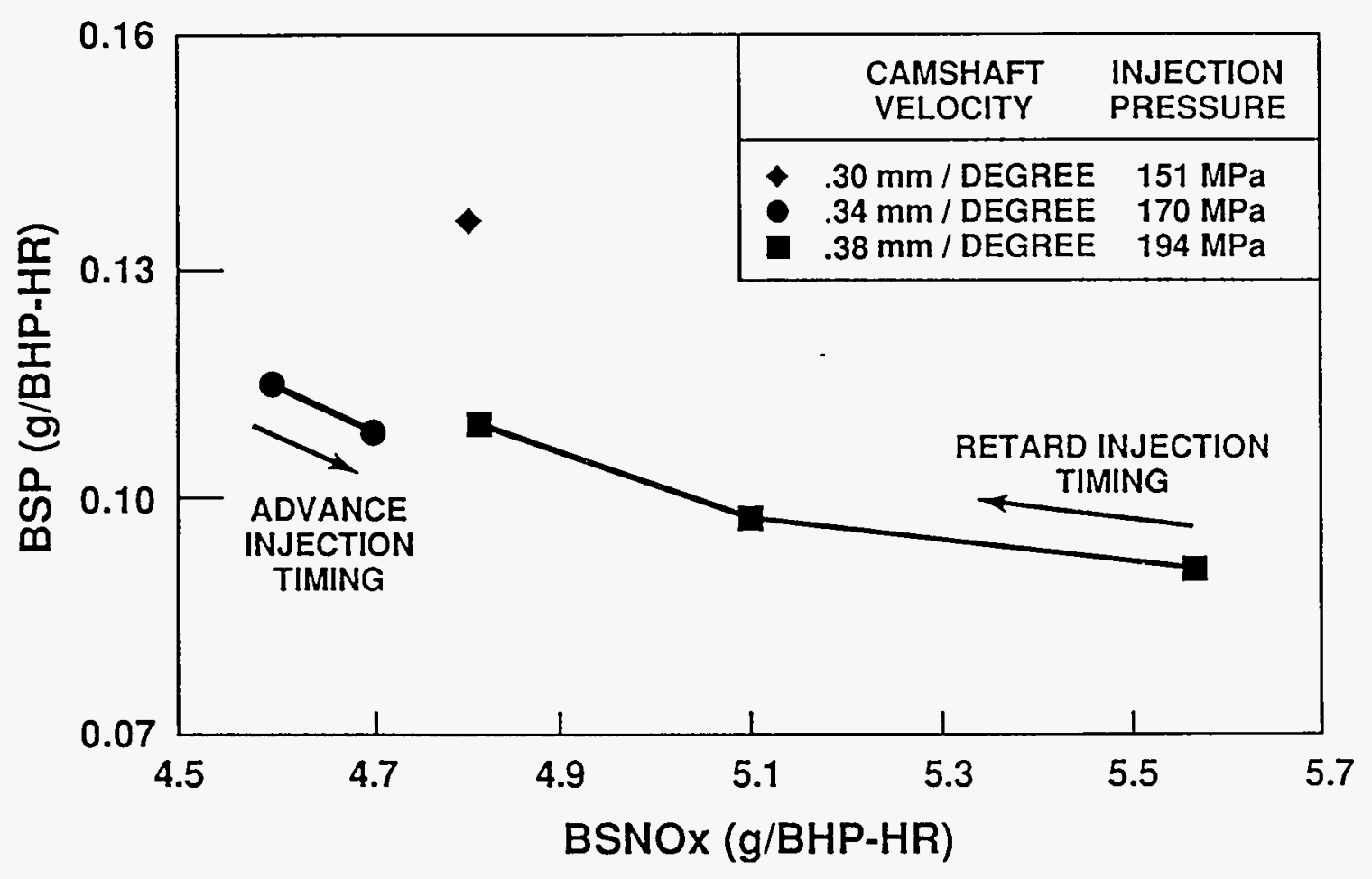

Figure 59: Very High Injection Pressures - Transient Emissions 


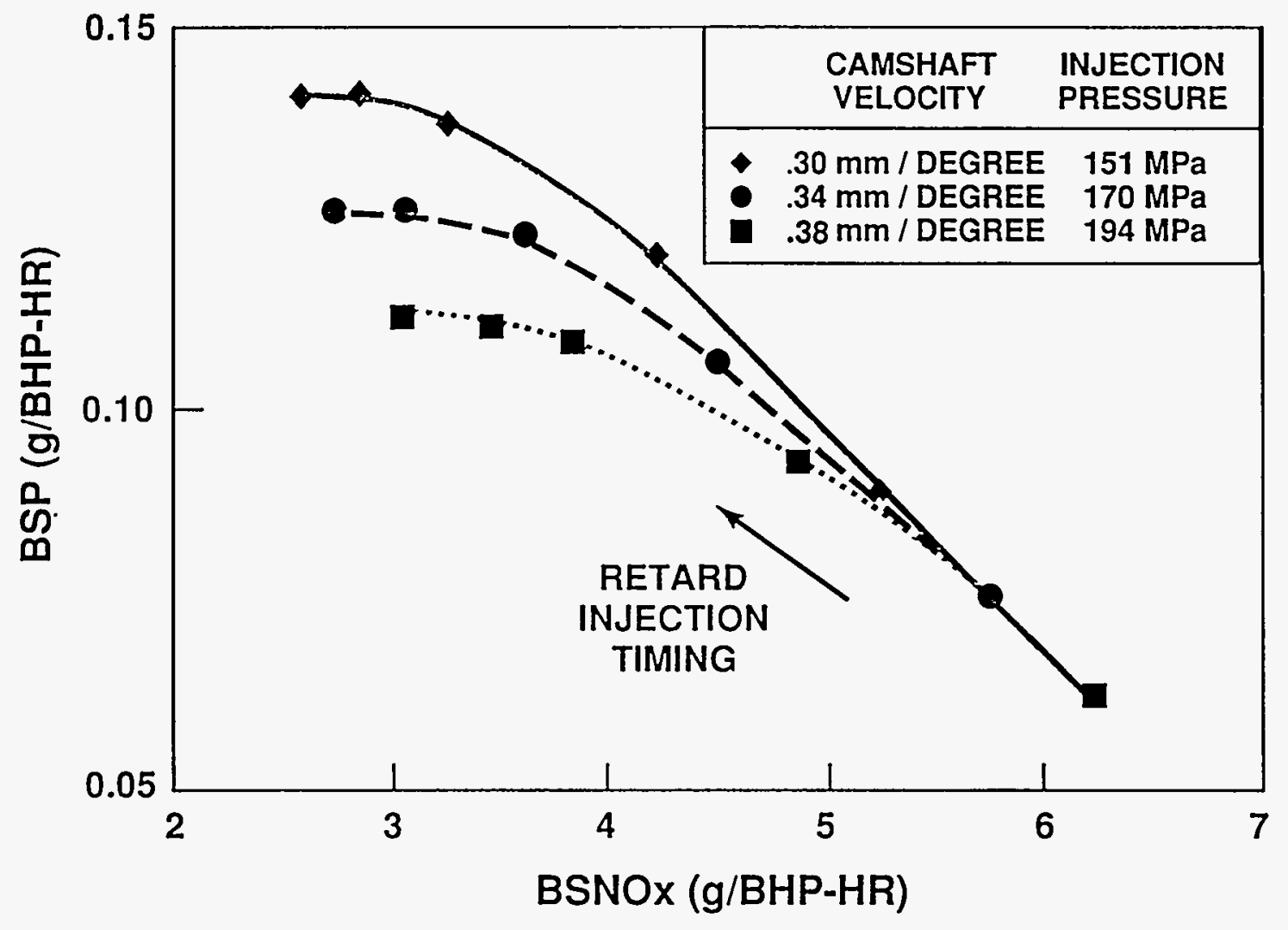

Figure 60: Very High Injection Pressures - Steady-State Low Power 


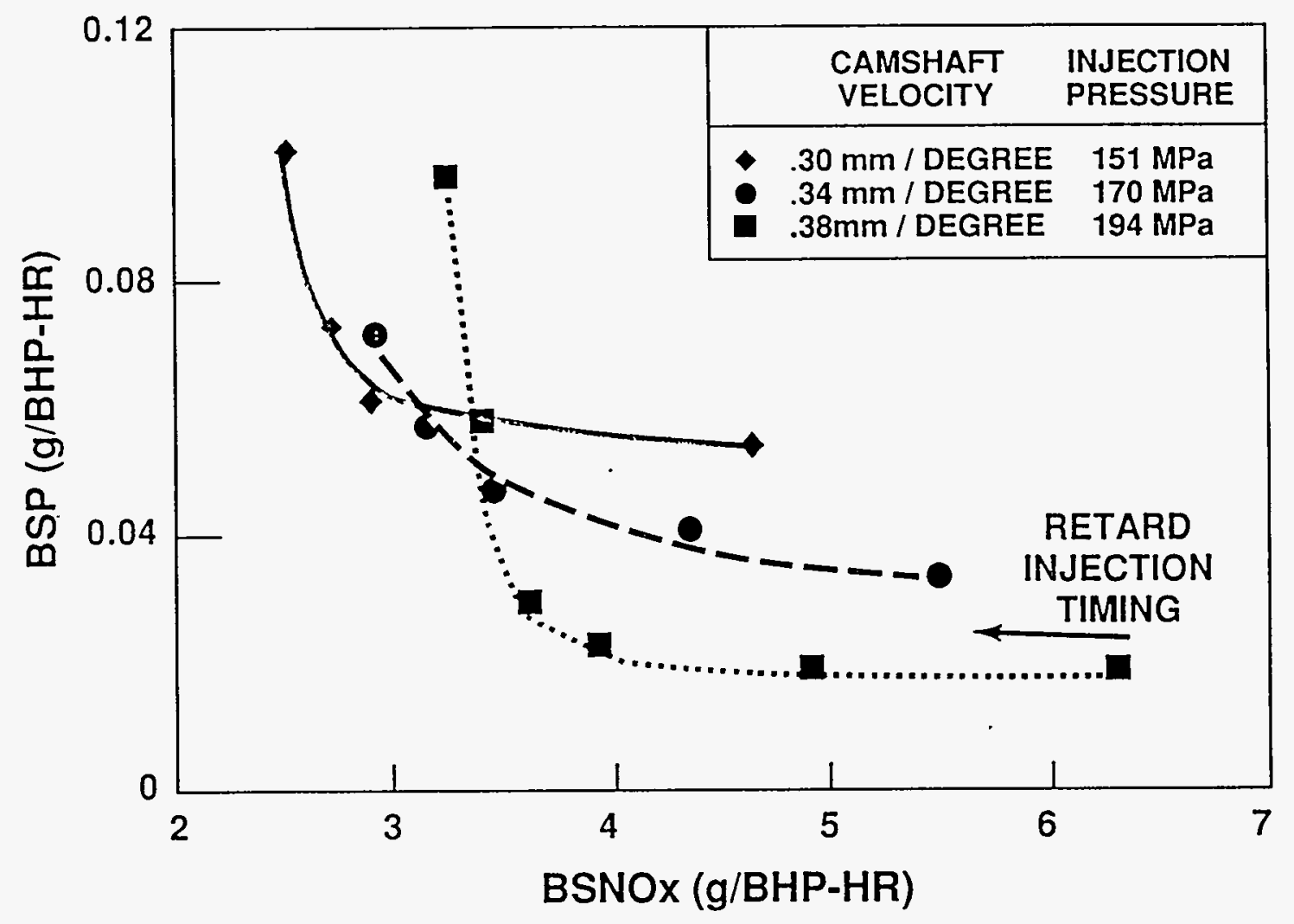

Figure 61: Very High Injection Pressures - Steady-State High Power 
Table 16 presents the BSNOx, BSP, and brake specific fuel consumption (BSFC) resulting from this injector parameter study. The measurements are generated by operating an engine on the EPA Transient Emissions Cycle with the injection timing adjusted as necessary to produce an approximately equivalent BSNOx that is below the 1994 regulated level. This normalized BSNOx permits an objective comparison of the injector parameter's influence on particulate emissions. Each different parameter set was tested at different times, and in some cases, on different engines. As such, the results should be considered developmental and conclusions should be based on relative emission levels.

TABLE 16

INJECTION COMPONENT PARAMETERS - TRANSIENT EMISSIONS

\begin{tabular}{|lccccc|}
\hline \multicolumn{2}{c}{$\begin{array}{c}\text { Injector } \\
\text { Component Parameter }\end{array}$} & $\begin{array}{c}\text { BSNOx } \\
\text { g/bhp-hr }\end{array}$ & $\begin{array}{c}\text { BSP } \\
\text { g/bhp-hr }\end{array}$ & $\begin{array}{c}\text { BSFC } \\
\text { lbs/bhp-hr }\end{array}$ & $\begin{array}{c}\text { BSP } \\
\text { Change }\end{array}$ \\
Valve Opening & $32.4 \mathrm{MPa}$ & 4.89 & 0.149 & 0.370 & $-3 \%$ \\
Pressure & $41.1 \mathrm{MPa}$ & 4.87 & 0.142 & 0.365 & \\
& & & & & \\
VCO (Baseline) & 4.56 & 0.170 & 0.365 & $-12 \%$ \\
Low Sac (Retarded) & 4.57 & 0.131 & 0.372 & \\
& & & & \\
VCO (Baseline) & 4.16 & 0.197 & 0.383 & $-25 \%$ \\
Lowered Holes & 4.26 & 0.173 & 0.377 & \\
& & & & \\
Baseline Hole Length & 4.83 & 0.169 & 0.388 & $+17 \%$ \\
Shortened Holes & 4.66 & 0.198 & 0.389 & \\
\hline
\end{tabular}

\section{Injector Valve Opening Pressure}

When diesel particulate emission regulations were first instituted, it was found that a reliable method of reducing particulates was to increase the injector valve opening pressure (VOP). This strategy was not used in the development of the low-emission Series 60 , thus making it a viable candidate for study. Testing found that an increase of $9 \mathrm{MPa}$ in VOP did not produce any meaningful difference in emissions.

\section{Low Sac versus Valve Covered Orifice Spray Tip Style}

There are two general classes of spray tip designs as illustrated in Figure 62. The VCO spray tip style has a needle valve which seats such that it covers the spray holes. The low sac spray tip style has spray holes which enter into a small cavity (the sac) below the needle 
valve. The VCO design minimizes the sac volume, and may directly impact the spray plume shape during opening and closing of the valve. Naturally, both the sac volume and the spray plume shape can influence the NOx and particulate emissions.

When the VCO tip and the low sac tip emissions are compared, a 23\% decrease in the BSP is found after the injection timing was retarded to reduce the BSNOx to a comparable level. The BSP was insensitive to this injection timing adjustment to reduce NOx. However, the BSFC increased by a significant amount of $1.9 \%$.

\section{Tip Spray Hole Location}

The VCO style spray tip was the subject of the spray hole location parameter test. The spray hole location was varied by moving the hole lower on the valve sealing surface than the baseline production spray hole location. This modification produced a $12 \%$ decrease in BSP with a $1.5 \%$ decrease in BSFC. The BSNOx also increased by a nominal $2 \%$ which is consistent with the fuel consumption improvement.

\section{Spray Tip Hole Length}

The spray tip hole length was varied by changing the thickness of the spray tip wall. The spray hole length was shorted by $0.18 \mathrm{~mm}$ changing the length to diameter ratio (L/D) from 7.9 to 6.9. This modification produced a $17 \%$ increase in BSP with no significant change in fuel consumption. Since this produced an increase in the particulates, no attempt was made to retard the injection timing to normalize BSNOx, as this would also increase the particulates.

In summary, lowered valve covered orifice spray tip holes and low sac style spray tips can improve particulate emissions. However, a fuel consumption penalty occurred with the low sac style spray tips.

\subsection{RING PACK DESIGN}

Since fuel and oil volatiles can contribute a significant proportion of the total particulate filter weight from a transient emissions test, effective means of oil control in the ring pack area are an important strategy towards meeting regulated particulate emission levels. As oil control and cylinder kit tribology continue to evolve, hardware testing remains the critical step in the evaluation process. For this program, ring pack suppliers were asked to take a clean sheet approach towards the design of a ring pack for the Series 60 with the objective of reducing the lubricant oil contribution to particulate emissions. 


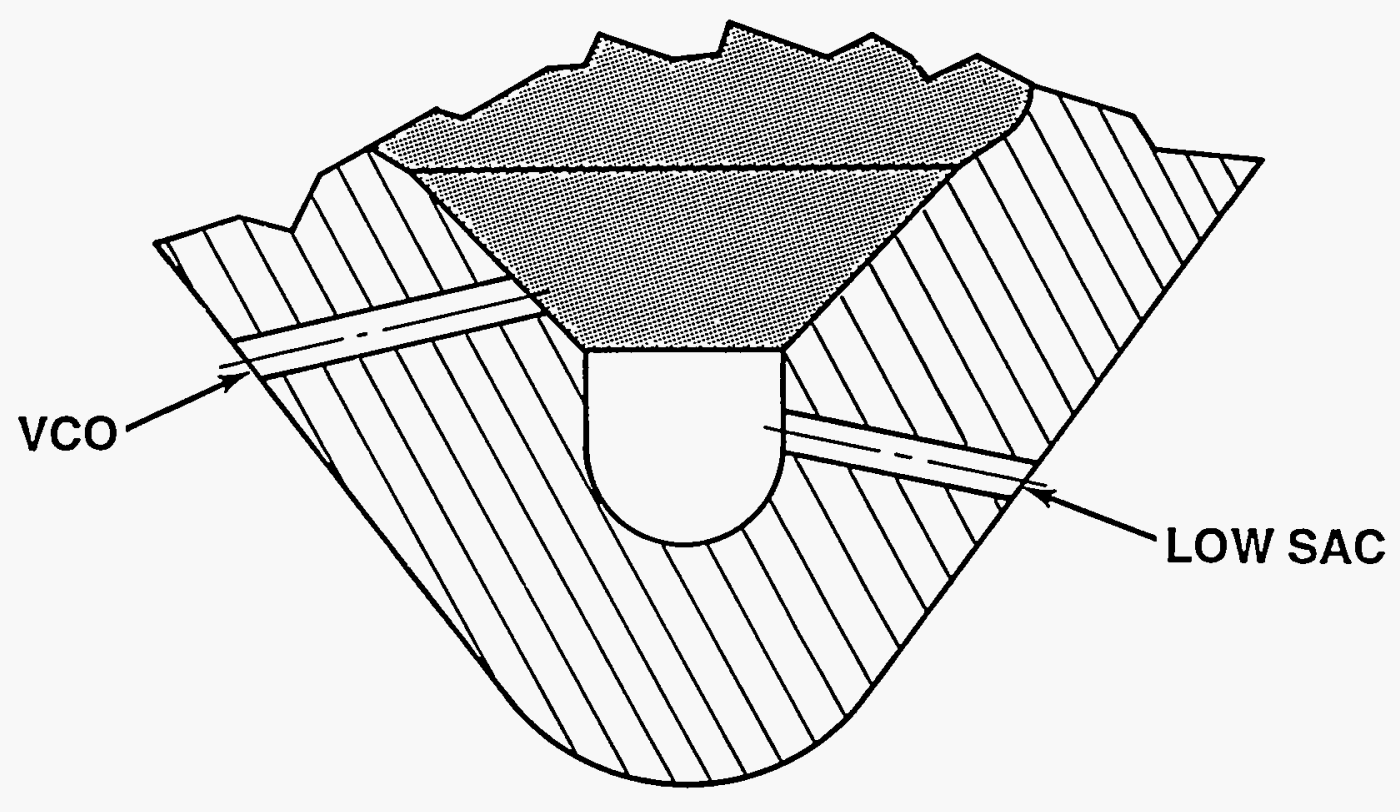

Figure 62: Injector Spray Tip Style Comparison 
Two clean sheet designs were produced and tested:

Design 1

- Plasma coated top ring with front contact and without twist

- Unplated second ring

- Higher tension oil ring

Design 2

- Plasma coated top ring with rear contact and positive twist

- Unplated second ring

- More conformable oil ring design

Table 17 presents the BSNOx and BSP results of the EPA Transient Emissions Test Cycle, including the baseline production ring pack. As expected, there is no significant difference in the BSNOx measurements for the three ring packs. However, significant increases in particulate emissions were observed with the clean sheet designs. The constant level of volatile contribution to particulates for all three ring packs suggests that some of the oil is being converted into soot. A post-test analysis of the wear patterns on one of the ring packs indicated a great sensitivity of the ring groove to ring geometry, which may have been influential in the oil consumption.

TABLE 17

RING PACK DESIGN FOR OIL CONTROL - TRANSIENT EMISSIONS

\begin{tabular}{|lcccc|}
\hline \multicolumn{1}{|c}{ Ring Pack } & $\begin{array}{c}\text { BSNO } \\
\text { g/bhp-hr }\end{array}$ & $\begin{array}{c}\text { BSP } \\
\text { g/bhp-hr }\end{array}$ & $\begin{array}{c}\text { \% } \\
\text { Volatiles }\end{array}$ & $\begin{array}{c}\text { BSP } \\
\text { Change }\end{array}$ \\
Baseline (Production) & 4.87 & 0.103 & $20 \%$ &.-- \\
Design 1 & 4.81 & 0.123 & $22 \%$ & $+19 \%$ \\
Design 2 & 4.74 & 0.155 & $19 \%$ & $+51 \%$ \\
\hline
\end{tabular}

In summary, no improvement was demonstrated with the clean sheet ring pack designs. However, more investigation of these designs may yield significantly better understanding of the oil control mechanics in the DDC Series 60. 


\subsection{INJECTION RATE SHAPING}

Control of fuel delivery rate into the cylinder, or injection rate shaping, can greatly influence emissions generation. Injection parameters such as spray plume shape and injection pressure are directly impacted. Through supplier input and DDC emission test experience, three injection rate shaping methods were determined to be feasible: 1) a Dual Velocity Camshaft, 2) a Pressure Limiting Injector, and 3) a Dual Spring Needle Valve Injector.

Table 18 presents BSNOx, BSP, and BSFC measured for the injection rate shaping methods studied. The emission measurements were made from an engine operating on the EPA Transient Emissions Test Cycle. Because particulate emissions are sensitive to injector hardware details, in each case, only the pressure-limiting and dual-spring sub-components of the injector were removed and replaced with production hardware when producing the baseline emission measurements.

TABLE 18

INJECTION RATE SHAPING - TRANSIENT EMISSIONS

\begin{tabular}{|lcccc|}
\hline \multicolumn{1}{|c}{ Rate Shaping Method } & $\begin{array}{c}\text { BSNOx } \\
\text { g/bhp-hr }\end{array}$ & $\begin{array}{c}\text { BSP } \\
\text { g/bhp-hr }\end{array}$ & $\begin{array}{c}\text { BSFC } \\
\text { lbs/bhp-hr }\end{array}$ & $\begin{array}{c}\text { \% BSP } \\
\text { Change }\end{array}$ \\
Production Cam (Baseline) & 4.84 & 0.109 & 0.354 & $-12 \%$ \\
Dual Lift-Velocity Cam & 4.84 & 0.096 & 0.355 & \\
& & & & \\
Baseline & 4.77 & 0.130 & 0.371 & $+25 \%$ \\
Pressure Relief Injectors & 4.69 & 0.163 & 0.380 & \\
& & & & \\
Baseline & 4.77 & 0.160 & 0.369 & $+22 \%$ \\
Dual-spring Injectors & 4.65 & 0.195 & 0.384 & \\
\hline
\end{tabular}

\section{Dual Lift-Velocity Camshaft}

As the very high injection pressure emission test results revealed earlier, there are advantages in having different cam lift-velocities at different engine loads. From those encouraging results, it was determined that a dual lift-velocity cam should be tested. Figure 63 presents a comparison of the $0.34 \mathrm{~mm} /$ cam degree constant lift-velocity cam and a $0.30 \mathrm{~mm} / \mathrm{cam}$ degree increasing to $0.38 \mathrm{~mm} / \mathrm{cam}$ degree dual lift-velocity cam. Figure 64 plots the BSP versus BSNOx generated at different injection timings for the dual lift-velocity camshaft and a production camshaft. As can be seen, there is a significant emissions improvement with the dual velocity camshaft relative to the production camshaft. 


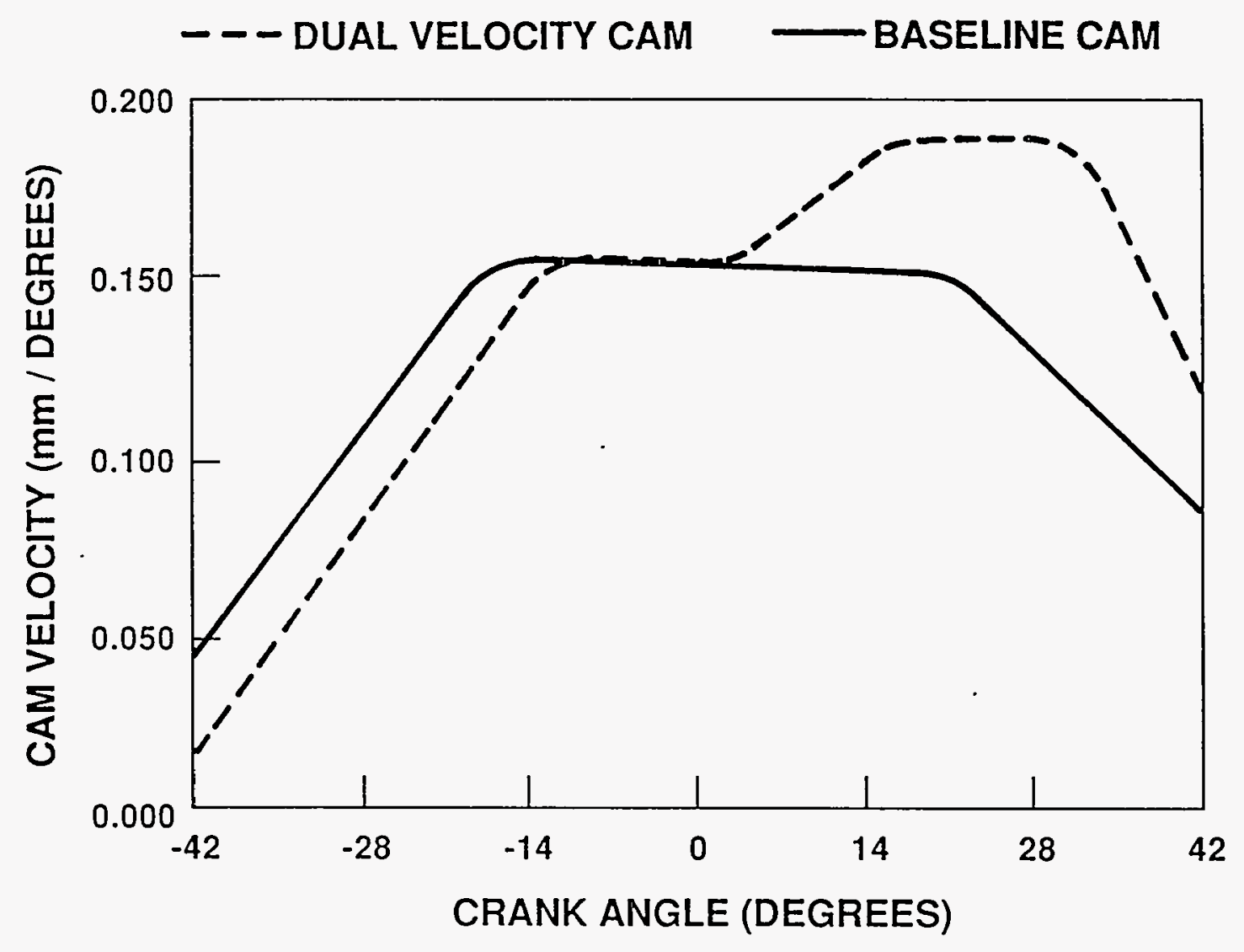

Figure 63: Lift-Velocity Comparison - Constant and Dual Velocity Cam 
उ. Meets EPA's 1994 Emission Standard

- Beginning of Injection occurs at $0^{\circ}$ before Top Center

- Beginning of Injection occurs at $2^{\circ}$ before Top Center

- Beginning of Injection occurs at $4^{\circ}$ before Top Center

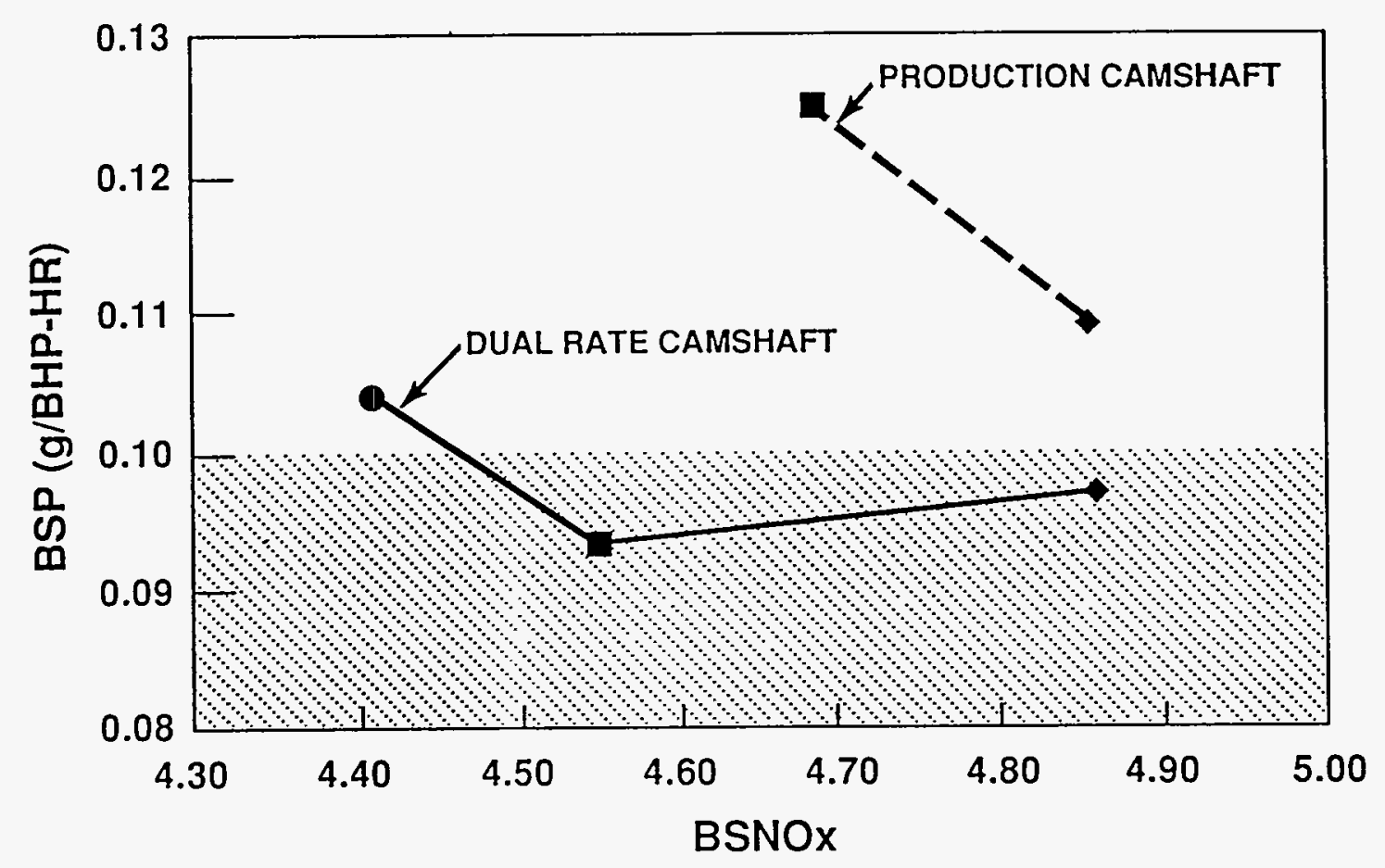

Figure 64: Dual Velocity Cam - Transient Emissions Test Results 
The 1994 regulated emissions levels were also achieved in this test, although not with sufficient margin to meet production variability requirements.

\section{Pressure Limiting Injector}

The pressure limiting injector is designed to increase the average injection pressure while limiting the peak injection pressure. A smaller spray tip is matched with the pressure relief valve to reduce the amount of fuel injected early in the injection event. As the results show, the particulate increased by $25 \%$, while BSNOx declined a nominal $2 \%$, and BSFC increased $2 \%$. Assuming there were no mechanical problems with the injectors, such as leaking relief valves reducing the average injection pressure, these results support the earlier very high injection pressure conclusions. It appears that by limiting the peak injection pressure, very high injection pressures are not reached at the higher engine speeds and loads, and thus reduced particulate emissions are not observed.

\section{Dual Spring Needle Valve Injector}

The dual spring needle valve injector is designed to reduce the initial injection rate and provide an increased needle closure rate. As shown in Table 18, particulates increased by $22 \%$, while NOx declined by a nominal $3 \%$, and BSFC increased by $4 \%$. With dual spring injectors, needle valve lift is limited during the initial part of the injection, due to a preload on the second spring. This limited lift may result in excessive fuel throttling at low speeds and light loads, thereby reducing injection pressures and increasing particulates. Furthermore, the greater mass of the additional components may have induced delays in needle closure near the end of the injection.

\section{CONCLUSIONS}

1 Injection rate shaping through cam profile modifications provides a significant improvement in particulate emissions.

2 The stringent 1994 particulate emission levels were demonstrated with production feasible hardware in the laboratory.

3 Rate shaping of injectors and novel piston ring designs were evaluated but did not provide the desired emission improvements in limited testing. 


\section{SECTION IX}

\section{RECOMMENDATIONS FOR FUTURE WORK}

The ADECD program developed a variety of advanced technologies and demonstrated their viability on a single cylinder engine that served as the test bed. Further refinements to these technologies are needed in order to demonstrate their commercial viability. Such an effort would require demonstration of these technologies on multi-cylinder engines, as well as a critical examination of the scale-up and manufacturing issues. In addition, custcmer benefits in the areas of fuel economy, durability and emissions reduction need to be determined. The following are some suggestions for future work in the areas of emissions reduction, advanced materials and advanced engine systems.

\subsection{EMISSION REDUCTION}

1. Further work on diesel injection and combustion systems is needed to meet the more stringent $\mathrm{NOx}$ and particulate standards anticipated in the future. This could include injection system details and variability, combustion chamber shape, in-cylinder mixture motion, and control of lubricating oil. Analytical and experimental investigations should be coordinated to maximize the cost effectiveness of this effort.

2. There are increasing regulatory requirements towards lower emissions of NOx. Diesel engines have limited capability to reduce this emission without seriously increasing fuel consumption. In addition, reduced heat rejection and increased engine efficiency results in higher NOx as observed in this program. Consequently, NOx aftertreatment has become more attractive. Concepts that have the potential to significantly reduce NOx (e.g. lean-NOx catalysts, exhaust gas recirculation, etc.) with reasonable cost and fuel consumption penalties need to be explored.

\subsection{ADVANCED MATERIALS}

1. The top compression ring wear is a serious concern on engines with low heat rejection, high output, and high cylinder pressure. Concepts and designs that have promise need to be studied in order to permit production of advanced engine designs.

2. The silicon nitride valves operated successfully on the single-cylinder test bed. The issue now is to find the best application for ceramic valves and develop a design that would be cost effective for production. A likely platform for introduction of ceramic valves is high output two-stroke engines, since expensive metallic valves would be replaced. 
3. Insulated ceramic exhaust and intake port liners were demonstrated on the singlecylinder test bed. Their design needs modification to be cost effective for production engines. Two-stroke and high output marine engines appear to be attractive applications for this technology.

\subsection{ADVANCED ENGINE SYSTEMS}

1. The high pressure injection system on the single-cylinder test bed demonstrated the feasibility of the common rail injection concept. However, design modifications and considerable optimization will be necessary to make this concept practical for production engines.

2. The vapor phase lubricant injection concept was able to deliver lubricant to the piston rings. Further work on a more mature engine platform with exceptionally good oil control is needed to evaluate the ability of the lubricant injector to reduce ring wear. Injection rates of several lubricants should be correlated with the wear at various engine operating conditions. As part of the lubricant injector control system, real time measurement of injected lubricant should be conducted to insure that the inter-ring pocket lubrication concentration is achieved. The injector may need redesign to resist injector tip plugging and to prevent engine failure due to insufficient lubrication.

3. The electro-hydraulic valve actuation system was successfully demonstrated on the single-cylinder test bed. Additional development is needed to improve the efficiency of the system and to demonstrate its applicability to engine compression braking, where the exhaust valves are opened near the end of the compression stroke. 


\section{APPENDIX A}

\section{ADECD GASKETLESS COMBUSTION SEAL STUDY}

\section{Analysis}

At the outset of the program, the cylinder head configuration had yet to be determined. Therefore, a finite element model of the cylinder head was generated that would allow some flexibility in modifying the basic structure. To do this, a three-dimensional model of the cylinder head was generated that was basically a "cube" which could be modified by removing elements. Additionally, since the sealing capability portion of the design study did not include thermal effects and since the design concept was for a geometrically symmetric cylinder head, a one-fourth section finite element model was generated for each component.

Figure 65 shows the three components modeled for the gasketless combustion seal study. The cylinder head represents the final configuration that was evaluated. Table 19 indicates the material properties used for each component in the finite element analysis.

After modeling was completed, cylinder head bolt loads were applied to the components at positions that simulated either a four bolt or eight bolt cylinder head configuration. Also, the magnitudes of the bolt loads were varied to study the effects of higher grade or larger diameter cylinder head bolts.

The eight cylinder head bolt per cylinder bore (six effective bolts per bore) was determined to be the best configuration to develop for the ADECD Advanced Engine. Figures 66 and 67 show the large variation in sealing pressure obtained with the four bolt cylinder head configuration. In fact, when combustion pressure is applied, the inside diameter of the sealing surface is no longer in contact (i.e., sigma $z=0$ ), allowing combustion gas leakage.

As Figures 68 and 69 indicate, with the eight bolt cylinder head configuration, the joint sealing stresses are somewhat less cyclic due to the better distribution of cylinder head bolt load. When combustion pressure is applied for the eight bolt configuration the liner-to-deck surfaces remain in contact with a minimum sealing pressure of $67 \mathrm{MPa}$.

The cylinder head bolt was sized based on the desire for a compact engine and to ensure adequate sealing pressure and fatigue resistance. The $14 \mathrm{~mm}$ cylinder head bolts provide a clamping force per cylinder bore exceeding the combustion force by 3.7 times. Standard industry practice is to provide a joint clamping force exceeding the separation force by at least three (3) times. To ensure adequate fatigue resistance, an estimate of the safety factor of the cylinder head bolt was made based on bolt fatigue test data available in the literature. Critical to the fatigue safety factor calculation is an estimate of the joint. For this estimate, a typical "hard" joint was analyzed and it was determined that the bolt carried $11.3 \%$ of the cyclic load. This estimate of the cyclic (separation) force carried by the bolt was used in the calculation of the ADECD cylinder head bolt fatigue safety factor. 

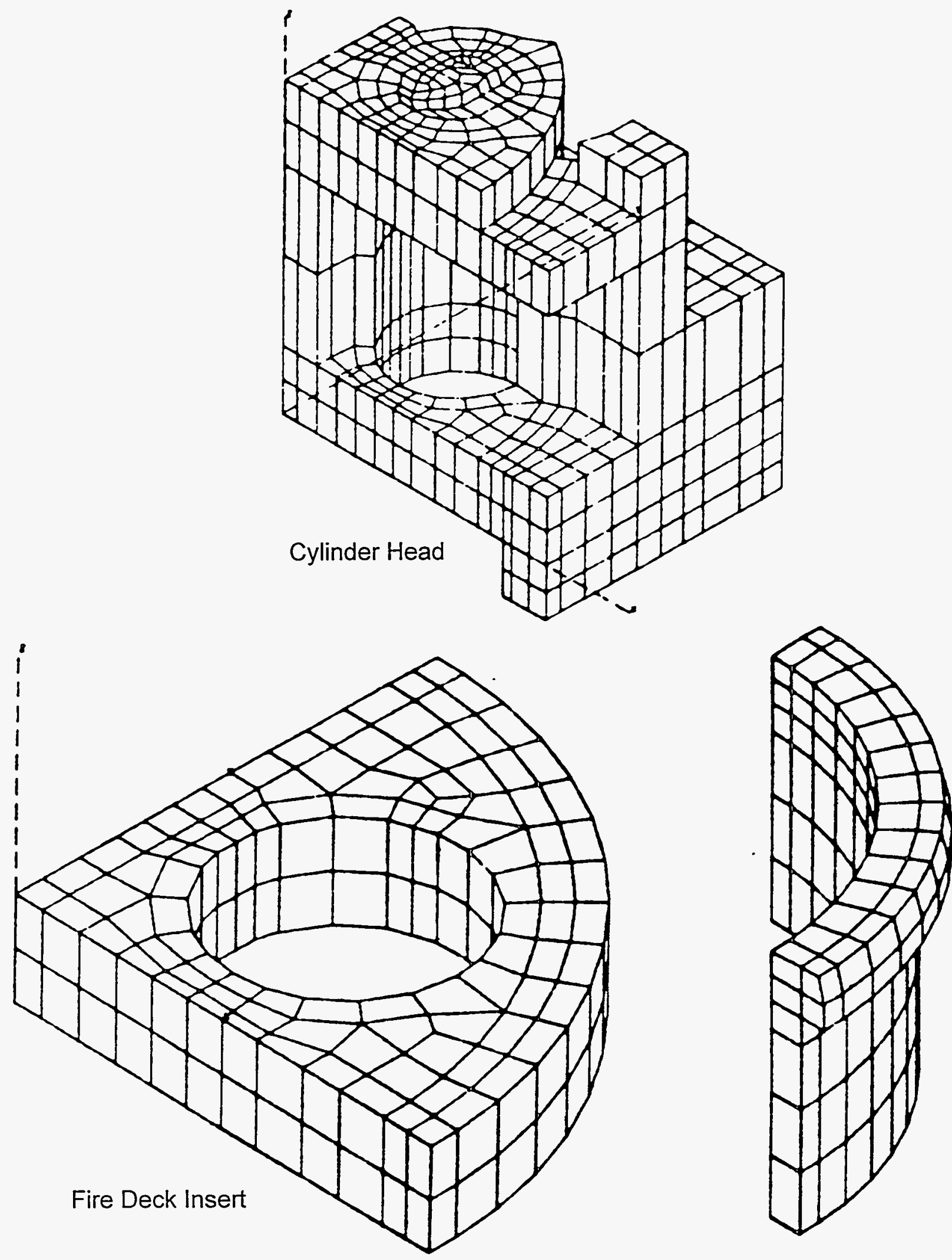

Cylinder Liner

Figure 65: ADECD Gasketless Combustion Seal Study Finite Element Model Geometries 
TABLE 19

ADECD GASKETLESS COMBUSTION SEAL STUDY FINITE ELEMENT MODEL COMPONENT PROPERTIES

\section{Cylinder Head and Liner}

Material:

Gray Cast Iron

Modulus of Elasticity:

$1.034 \mathrm{E}+05 \mathrm{MPa}$

Poissons Ratio:

0.26

Density:

$7.20 \mathrm{E}-09 \mathrm{Mg} / \mathrm{mm}^{3}$

Firedeck Insert

Material:

Silicon Nitride

Modulus of Elasticity:

$3.00 \mathrm{E}+05 \mathrm{MPa}$

Poissons Ratio:

0.279

Density:

$3.20 \mathrm{E}-09 \mathrm{Mg} / \mathrm{mm}^{3}$ 


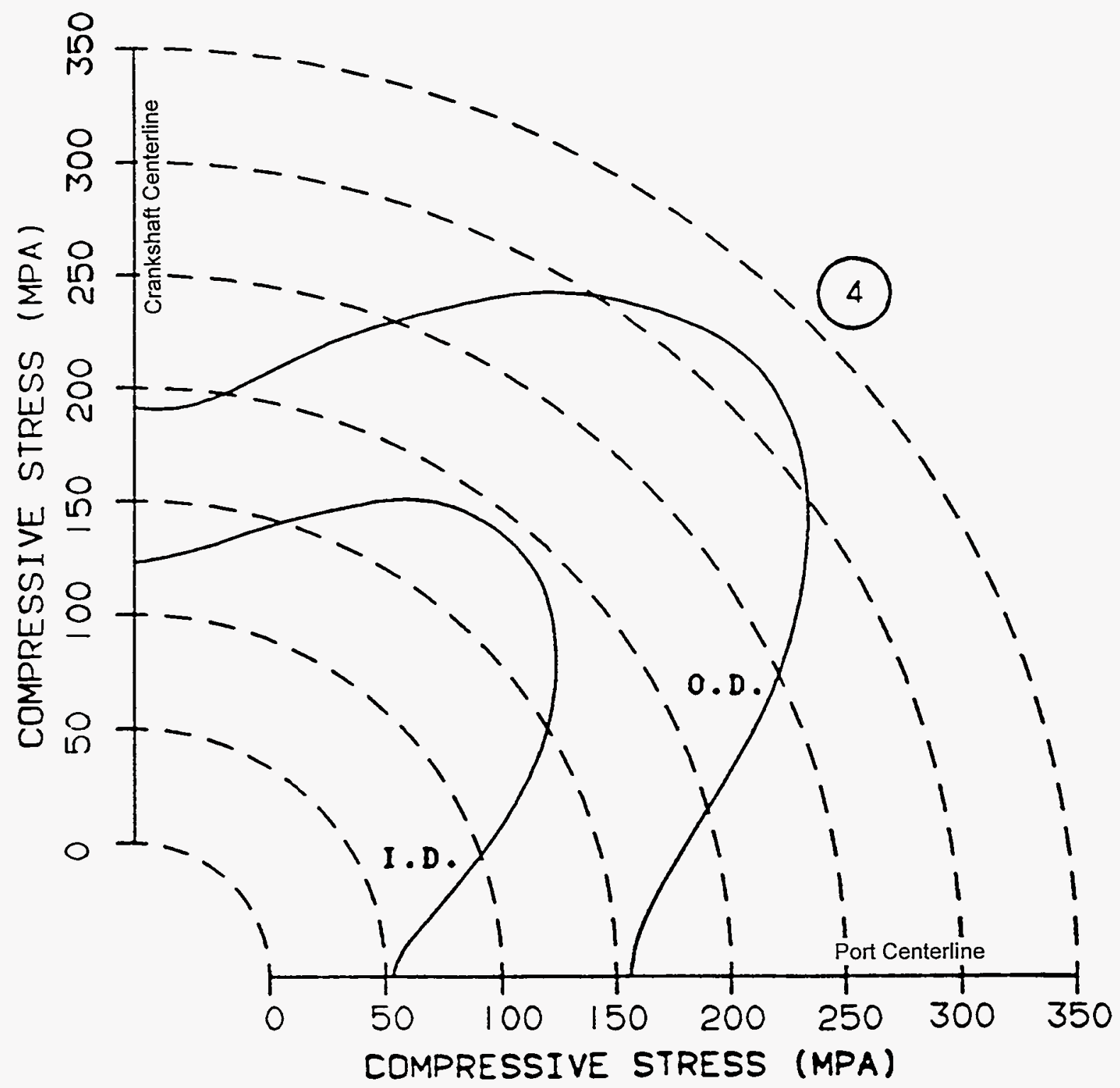

Figure 66: Liner/Insert Joint Sealing Stress 4 Bolt Cylinder Head Configuration $14 \mathrm{~mm}$ Grade 10.9 Cylinder Head Bolts Bolt Up Only 


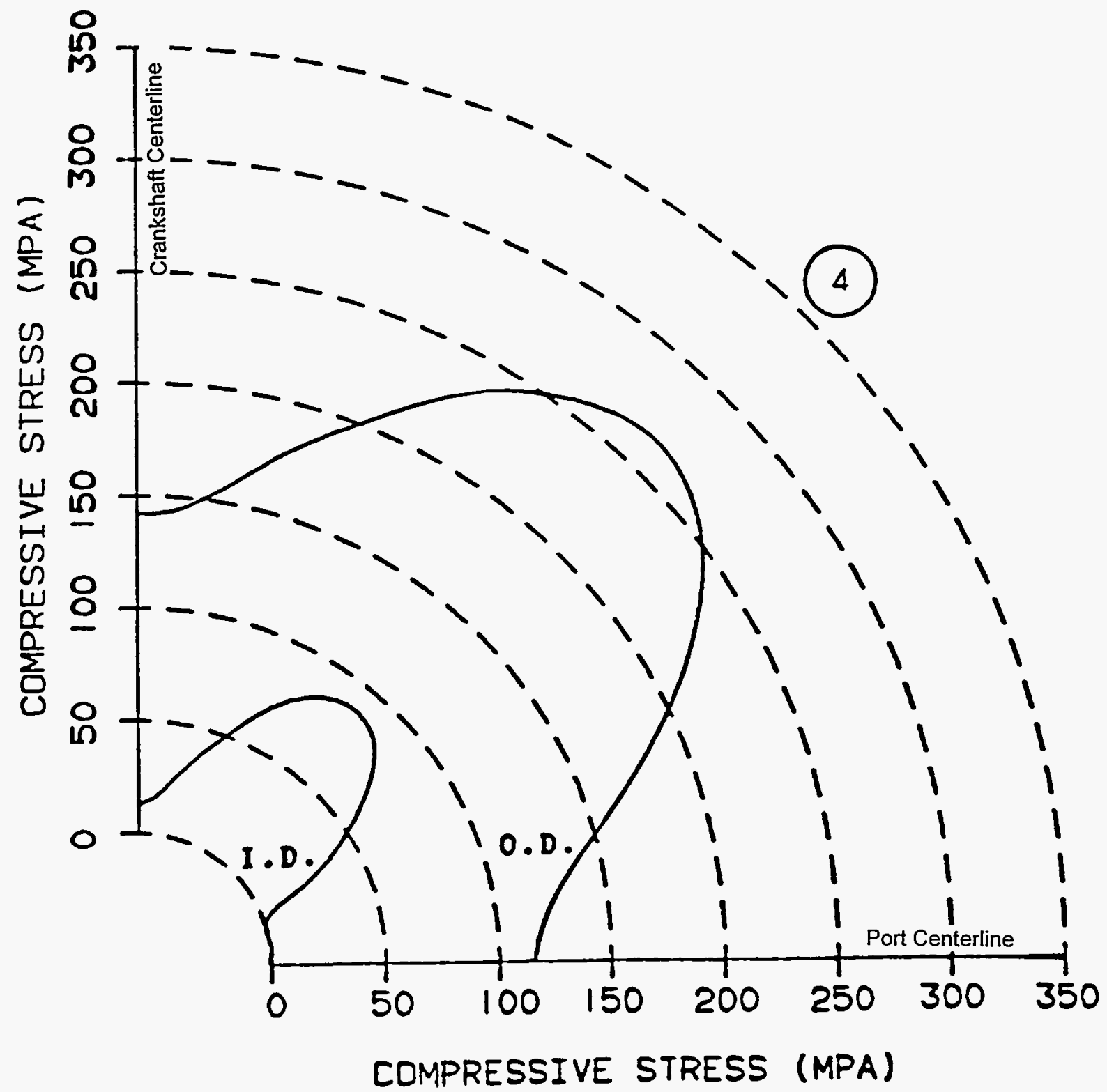

Figure 67: Liner/Insert Joint Sealing Stress 4 Bolt Cylinder Head Configuration $14 \mathrm{~mm}$ Grade 10.9 Cylinder Head Bolts Bolt Up + 16.2 MPa Comb. Pressure 


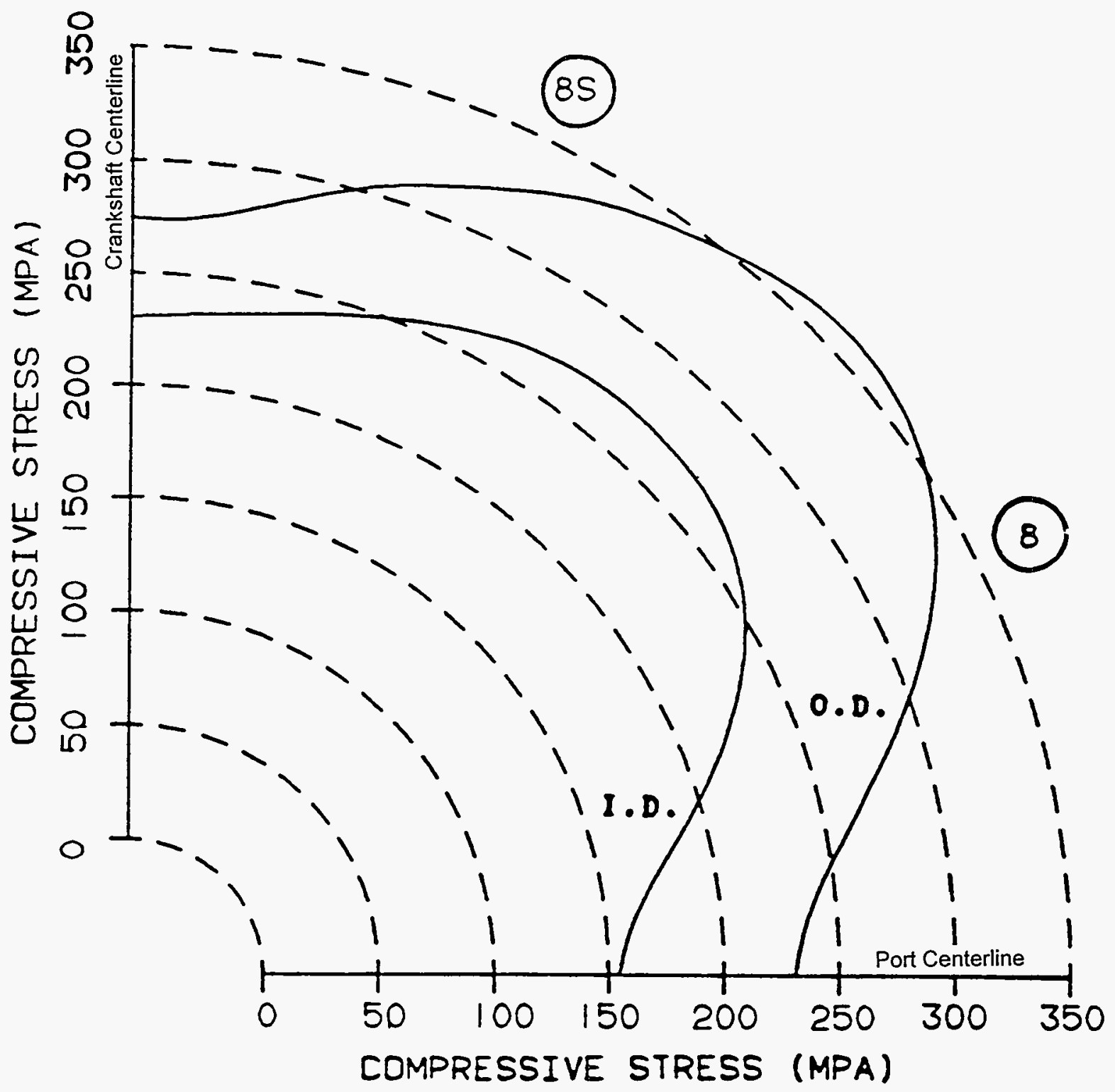

Figure 68: Liner/Insert Joint Sealing Stress 8 Bolt Cylinder Head Configuration $14 \mathrm{~mm}$ Grade 10.9 Cylinder Head Bolts, Bolt Up Only 


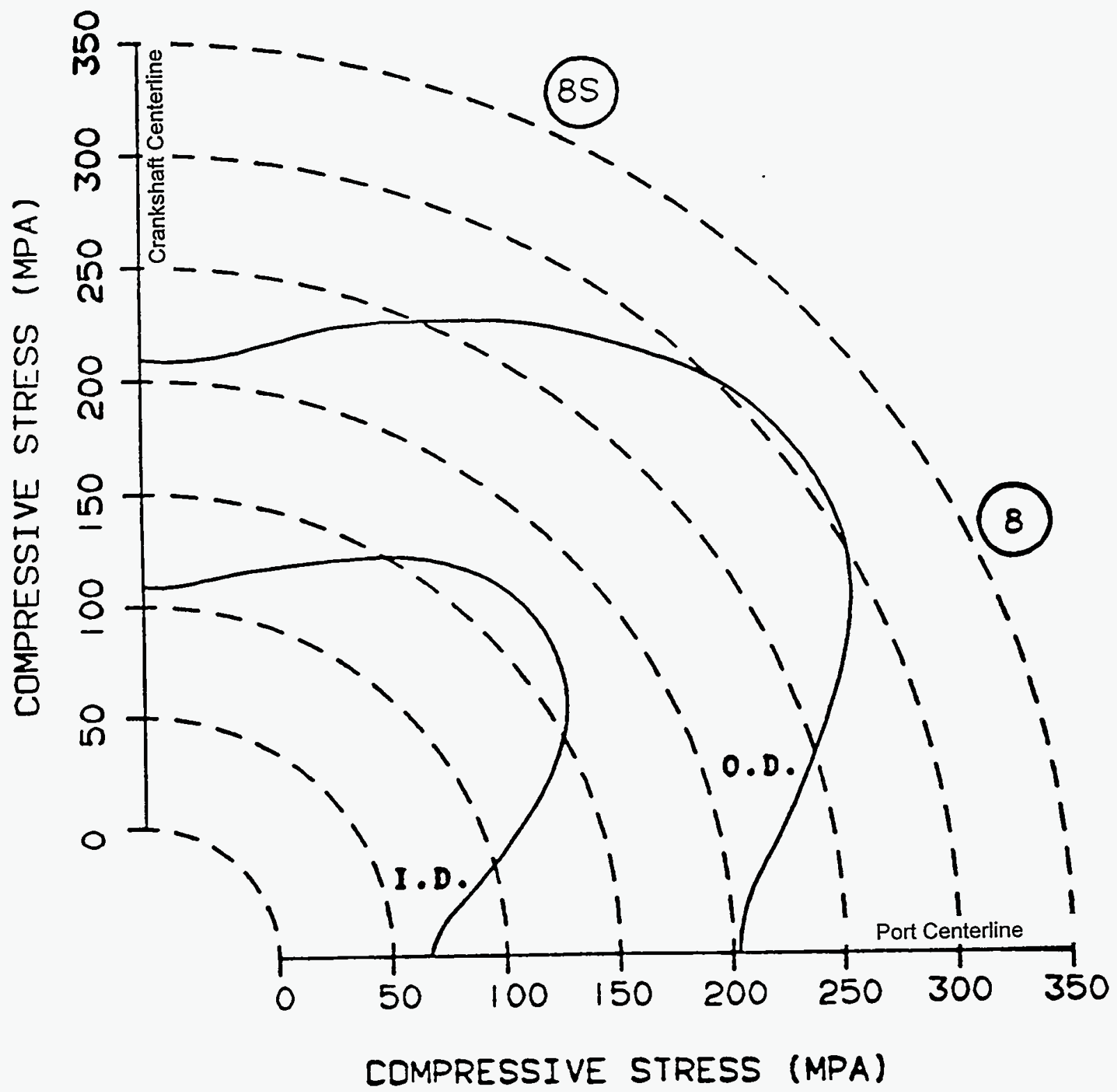

Figure 69: Liner/Insert Joint Sealing Stress 8 Bolt Cylinder Head Configuration 14mm Grade 10.9 Cylinder Head Bolts, Bolt Up + 16.2 MPa Comb. Pressure 
The cylinder head bolts should be $14 \mathrm{~mm}$ diameter Grade 10.9 bolts which will have a fatigue safety factor of 4.6 for the worst cyclic load condition. The compressive sealing stress (joint pressure) for the 8 bolt per bore configuration varies from a maximum of 306 $\mathrm{MPa}$ to a minimum of $67 \mathrm{MPa}$ at a design combustion pressure of $16.2 \mathrm{MPa}\left(2350 \mathrm{lb} / \mathrm{in}^{2}\right)$.

Figures 70 and 71 show the effects of increasing the bolt loads at the shared bolt positions. While the head bolt clamp loads were increased significantly by upgrading bolt material or bolt size, the sealing pressure was increased slightly. This indicates that the limiting factor to increased joint sealing pressure is the bending stiffness of the cylinder head. Table 20 is a summary of the cylinder head to fire deck insert joint sealing stress information presented in Figures 66 through 71 .

\section{Experimental Investigation of Cylinder Head}

The purpose of this test was to experimentally evaluate three aspects of the ADECD cylinder head. These are: (1) Sealing of the gasketless cylinder head to liner joint. (2) Measurement of strains in critical locations of the cylinder head under clamp and statically simulated combustion pressure loads. (3) Proof load test of the monolithic ceramic firedecks.

The cylinder head for the single cylinder ADECD engine incorporates many unique features. Four identical ceramic ports shields are cast directly into the cast iron head structure. The port shields are made of sintered silicon nitride and are wrapped externally with a compliant material

TABLE 20

ADECD LINER/HEAD JOINT SEALING STRESS SUMMARY

\begin{tabular}{|c|c|c|}
\hline & \multicolumn{2}{|c|}{ Cealing Stress (MPa) } \\
\cline { 2 - 3 } & Maximum & Minimum \\
\hline $\begin{array}{c}\text { 4 Bolt Cyl Head, 14mm (GR 10.9) Bolts } \\
\text { Bolt Up Only }\end{array}$ & 320 & 53 \\
\hline $\begin{array}{c}\text { 4 Bolt Cyl Head, 14mm (GR 10.9) Bolts } \\
\text { Bolt Up and 16.2 MPa Comb Pressure }\end{array}$ & 266 & 0 \\
\hline $\begin{array}{c}\text { 8 Bolt Cyl Head, 14mm (GR 10.9) Bolts } \\
\text { Bolt Up Only }\end{array}$ & 358 & 155 \\
\hline $\begin{array}{c}\text { 8 Bolt Cyl Head, 14mm (GR 10.9) Bolts } \\
\text { Bolt Up and 16.2 MPa Comb Pressure }\end{array}$ & 306 & 67 \\
\hline $\begin{array}{c}\text { 8 Bolt Cyl Head, 14mm (GR 12.9) Shared Bolts } \\
\text { Bolt Up and 16.2 MPa Comb Pressure }\end{array}$ & 319 & 69 \\
\hline $\begin{array}{c}\text { 8 Bolt Cyl Head, 16mm (GR 10.9) Shared Bolts } \\
\text { Bolt Up and 16.2 MPa Comb Pressure }\end{array}$ & 335 & 72 \\
\hline
\end{tabular}




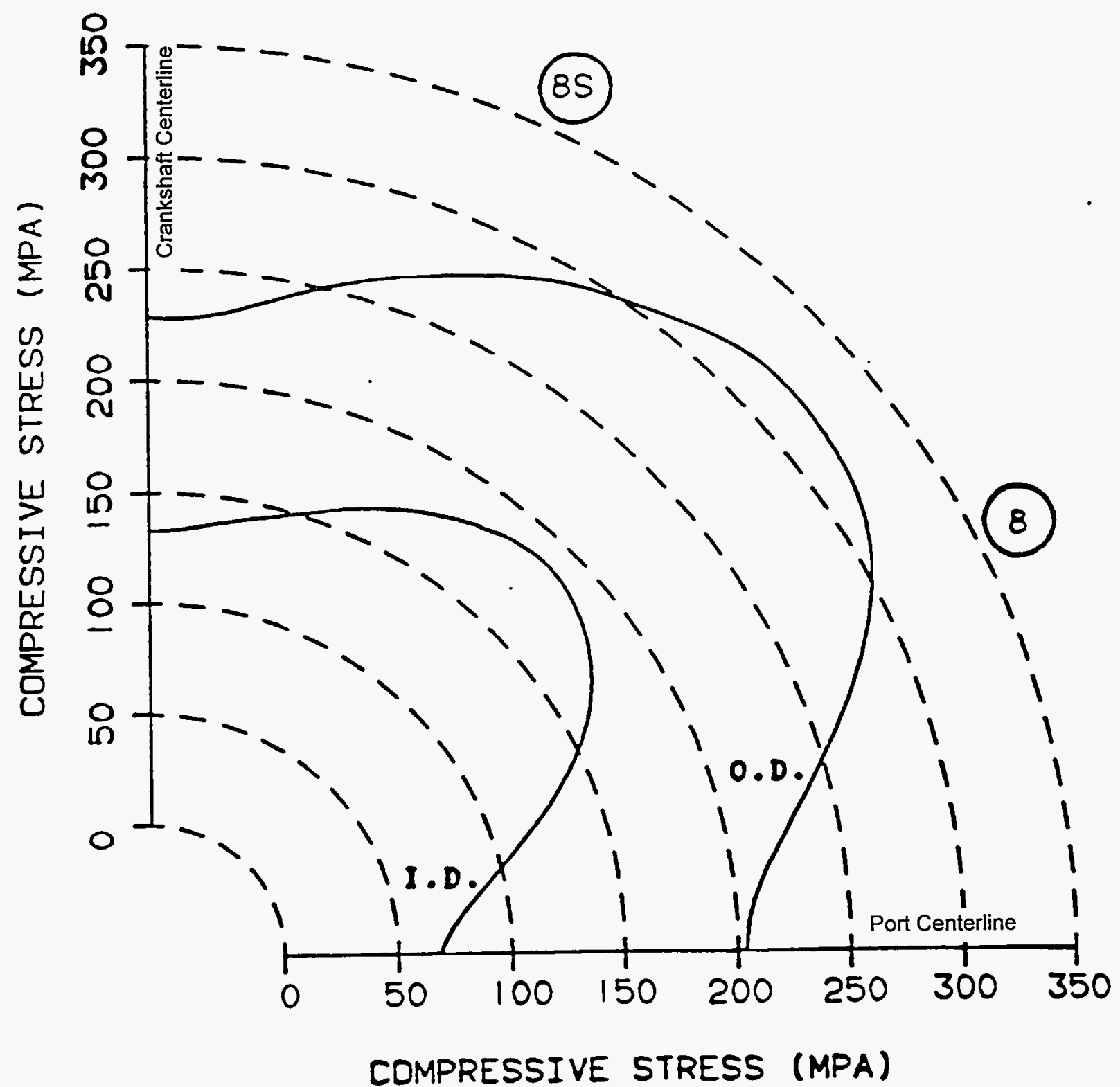

Figure 70: Liner/Insert Joint Sealing Stress

8 Bolt Cylinder Head Configuration

$14 \mathrm{~mm}$ Grade 10.9 Cylinder Head Bolts

$14 \mathrm{~mm}$ Grade 12.9 "Shared" Cylinder Head Bolts

Bolt Up +16.2 Comb. Pressure 


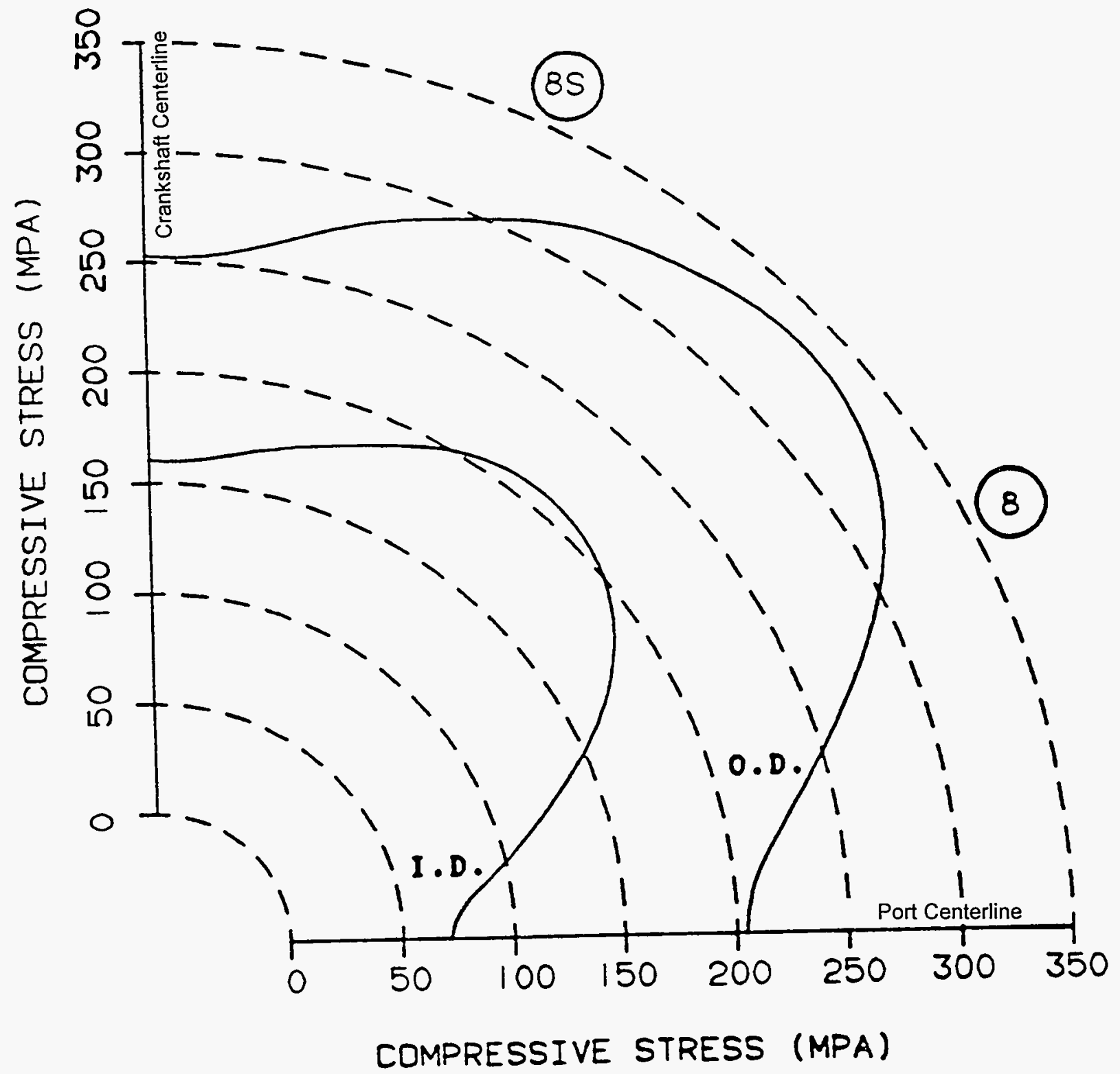

Figure 71: Liner/Insert Joint Sealing Stress 8 Bolt Cylinder Head Configuration $14 \mathrm{~mm}$ Grade 10.9 Cylinder Head Bolts $16 \mathrm{~mm}$ Grade 10.9 "Shared" Cylinder Head Bolts Bolt Up + 16.2 MPa Comb. Pressure 
to mechanically and thermally isolate them from the iron during the casting process. A monolithic silicon nitride firedeck and valve guides are retained in the finished cylinder head by interference fits. Eight equally spaced studs clamp the cylinder head onto the top of the liner flange with no intervening head gasket. Effective sealing of the combustion gas pressure was achieved through control of the geometry, clamp load and material properties of the cylinder liner and ceramic firedeck. A top view and partial section of the head are shown in Figures 72 and 73 respectively.

One major purpose of this test program was to experimentally evaluate the ability of the gasketless head to liner joint to seal combustion gas pressures. This was done in a fixture test by mapping the boundary between leaking and sealing at various levels of cylinder head clamp load and simulated combustion gas pressures. One firedeck design and three liner flange designs were evaluated as part of the sealing test. The other major purpose of this test was to take strain gage measurements in selected locations on the head so that stresses due to stud clamp load and combustion pressures could be calculated. The strain gage data was recorded during the sealing test. The data from the two tests were used to recommend minimum and maximum stud clamp loads based on sealing capability and stress levels in the head. Further, the static proof test of the ceramic firedecks with head bolt and simulated gas pressure loading was accomplished.

The test fixture is shown in Figure 74 and consists of the upper portion of a cylinder liner sandwiched between a cylinder head assembly and a metal plate. The fixture is fastened together with studs. The head assembly includes a partially machined ADECD cylinder head which was cast without port shields, a ceramic firedeck, four ceramic valve guides and four reworked metallic Series 60 exhaust valves. A bolt and a copper washer were used to plug the injector hole in the firedeck. A hydraulic pressure source was connected to the inside of the cylinder liner to statically simulate combustion gas pressure loading on the cylinder head and firedeck.

Sealing of the statically simulated combustion pressures occurred as long as the clamping force due to the cylinder head studs exceeded the pressure force applied to the firedeck. Fine features on the cylinder liner flange (circular grooves) and variations in liner hardness (hard vs. soft) did not have any effect on sealing. The 17.2 MPa peak cylinder pressure planned for the ADECD engine was duplicated without leakage at about $35.6 \mathrm{kN}$ per stud clamp load.

Strains were measured on two stiffening ribs on the upper surface of the head and on two head bolt (stud) bosses, at various levels of clamp load and statically simulated combustion gas pressure. The strains were found to be predominantly due to static stud clamp loads. At the most severe test condition; $75.6 \mathrm{kN}$ per stud clamp load and 20.7 MPa cylinder pressure, a maximum principle stress of $87.0 \mathrm{MPa}$ (tensile) occurred on the upper surface of one of the stiffening ribs which connect the stud bosses. The corresponding minimum principle stress of -190.6 MPa (compressive) occurred on the boss undercut by the two intake/exhaust ports. 


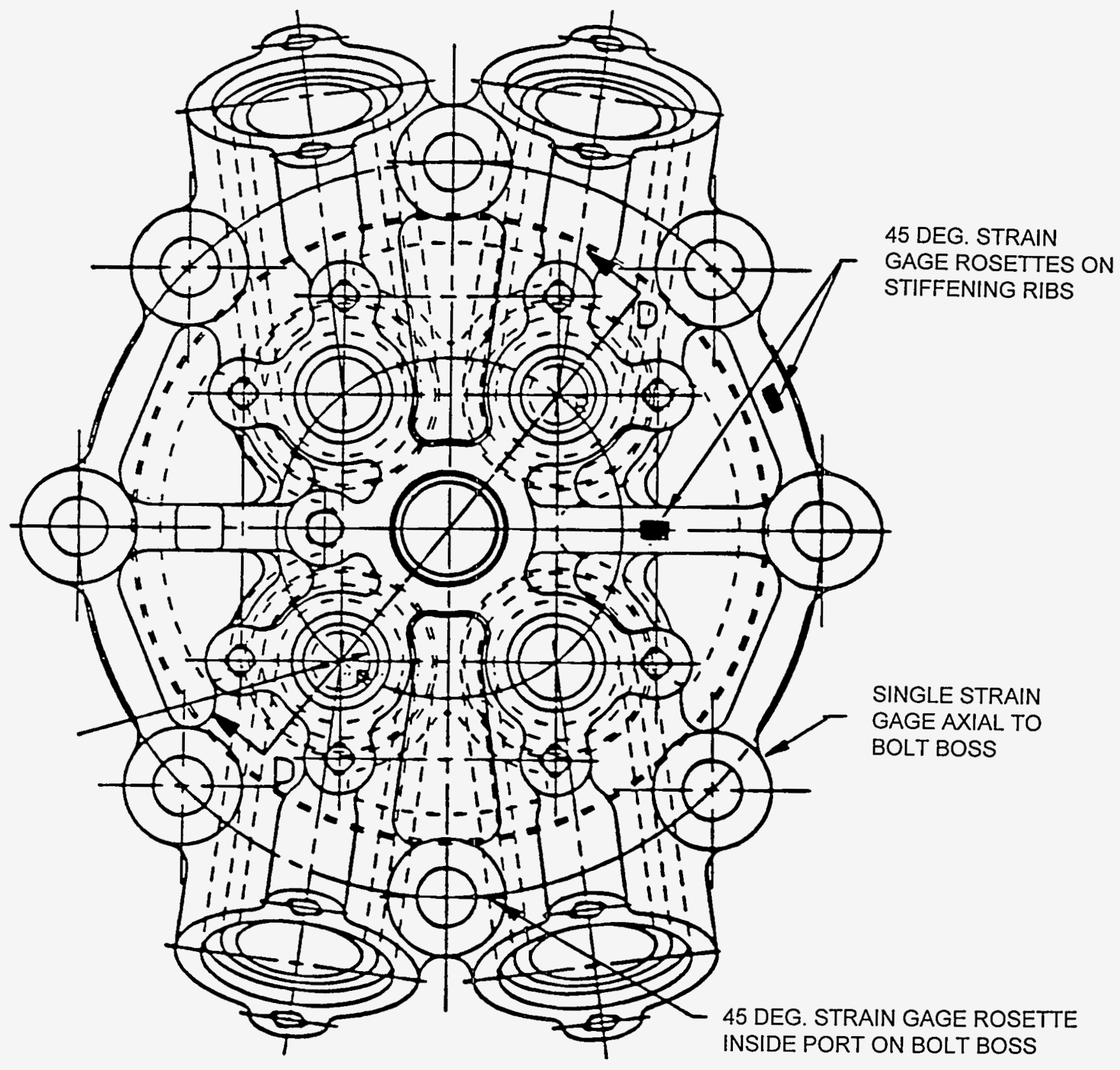

Figure 72: Cylinder Head - Top View, Strain Gage Locations Also Shown 


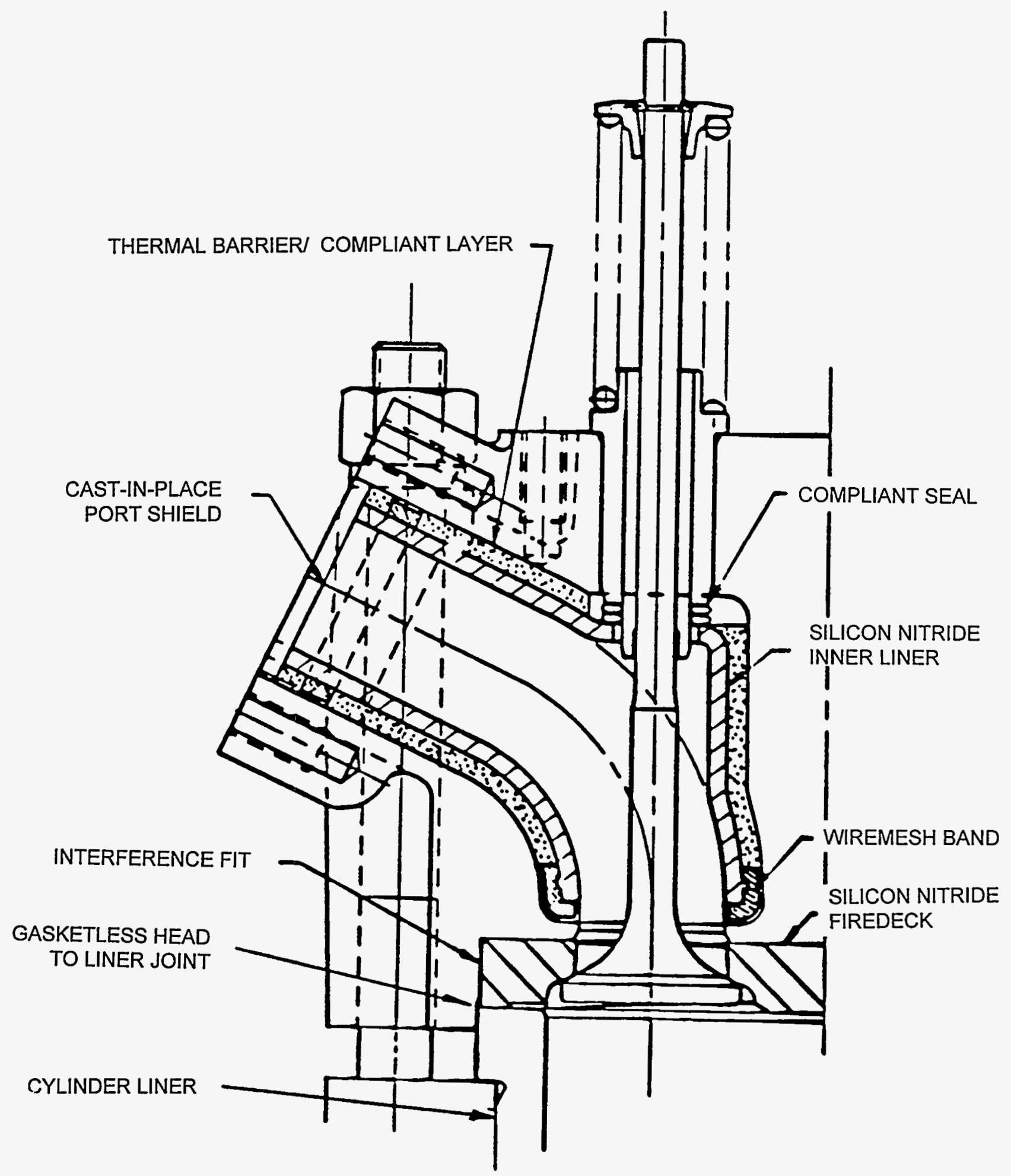

Figure 73: Cylinder Head - Section Thru Port 


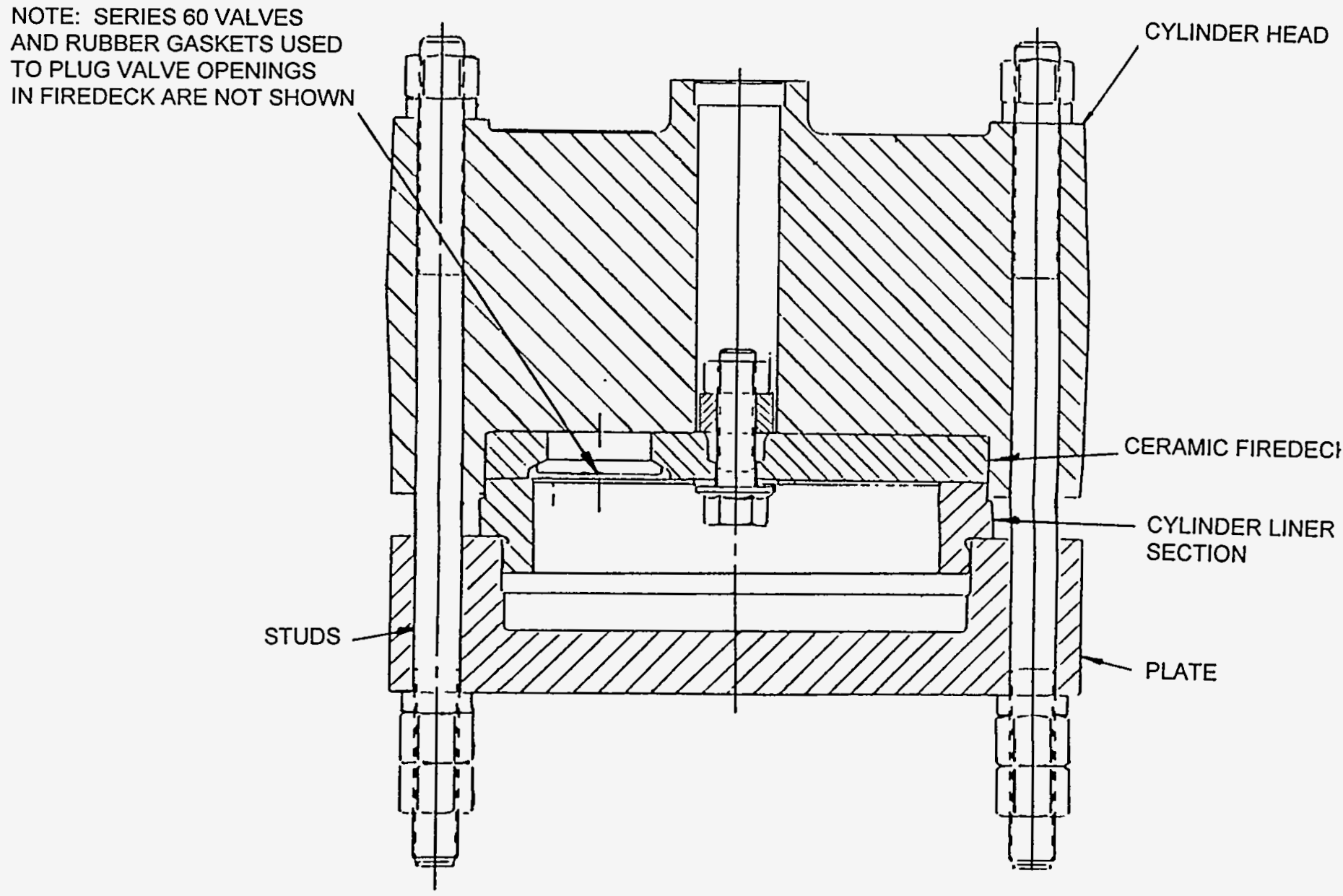

Figure 74: Fixture Assembly 
The purpose of the leakage test was to investigate the sealing capability of the gasketless cylinder head to liner joint planned for the ADECD single cylinder test bed. Test variables included cylinder pressure, stud clamp load and several liner flange variations.

The fixture studs were designed so that yield would occur in the studs prior to failure of the cylinder head as predicted by FEA. Force versus elongation calibration data for these studs was generated so an ultrasonic extensometer could be used to precisely control the clamping force to the desired levels. The fixture was initially assembled with clamp load set at $25 \%$ of the studs' yield strength. Hydraulic pressure was applied and incrementally increased until some indication of leakage became apparent. The pressure was then reset to zero, clamp load increased by $15 \%$, and hydraulic pressure again applied incrementally until leakage occurred. This procedure was repeated, as shown in Figure 75, to check joint seal integrity up to $85 \%$ of the yield point of the studs. Upon completion of the test, the fixture was disassembled and the ceramic firedeck checked for cracks.

After the completion of the prescribed test cycle for a specific build configuration, the fixture was reassembled with a different cylinder liner flange and the test repeated. Three liner flange variations were evaluated: (1) A hard liner with a smooth sealing face. Simulating the hardened Nitralloy upper liner procured for the single cylinder engine, (2) A soft liner with a smooth sealing face to promote sealing by locally conforming and distributing the load more evenly, (3) A soft liner with a circumferentially grooved sealing face, expected to conform better than the plain soft liner because of a higher unit load at the sealing/contact area. The grooves were expected to function similar to a labyrinth seal (see Table 21).

Four locations identified as areas of interest during the modeling of the cylinder head were instrumented with strain gages as shown in Figure 72. Two locations on stiffening ribs on the top of the head were instrumented with 45 degree rosettes. The stresses on these ribs were predicted to be due to the stud clamp load trying to "pull down" the unsupported perimeter of the cylinder head and "arch" it over the top of the cylinder liner. The other two strain gage locations were intended to document compressive stresses on head bolt (stud) bosses. Of concern were the two bosses between the intake/exhaust port pairs which are undercut by the ports and weakened. One boss of this type was strain gauged with a 45 degree rosette at the minimum cross section location from the inside of the port. Another, non-undercut boss, was instrumented with a single gage axial to the boss to provide a reference for comparison.

The strain gage data was evaluated at the highest stud clamp load, $75.6 \mathrm{kN}$, used during the second fixture test both with and without the $20.7 \mathrm{MPa}$ simulated gas pressure. After resolving the measured strains into principle stresses, safety factors were calculated for both the static and fatigue cases. For the static case, the Coulomb-Mohr criteria, which takes into account the differing tensile and compressive strengths of cast iron, was applied (Figure 76). For the fatigue case, the stress differential between the clamped and clamped plus cylinder pressure conditions was assumed to be the amplitude of the alternating stress resulting in the Goodman diagram shown in Figure 77. 


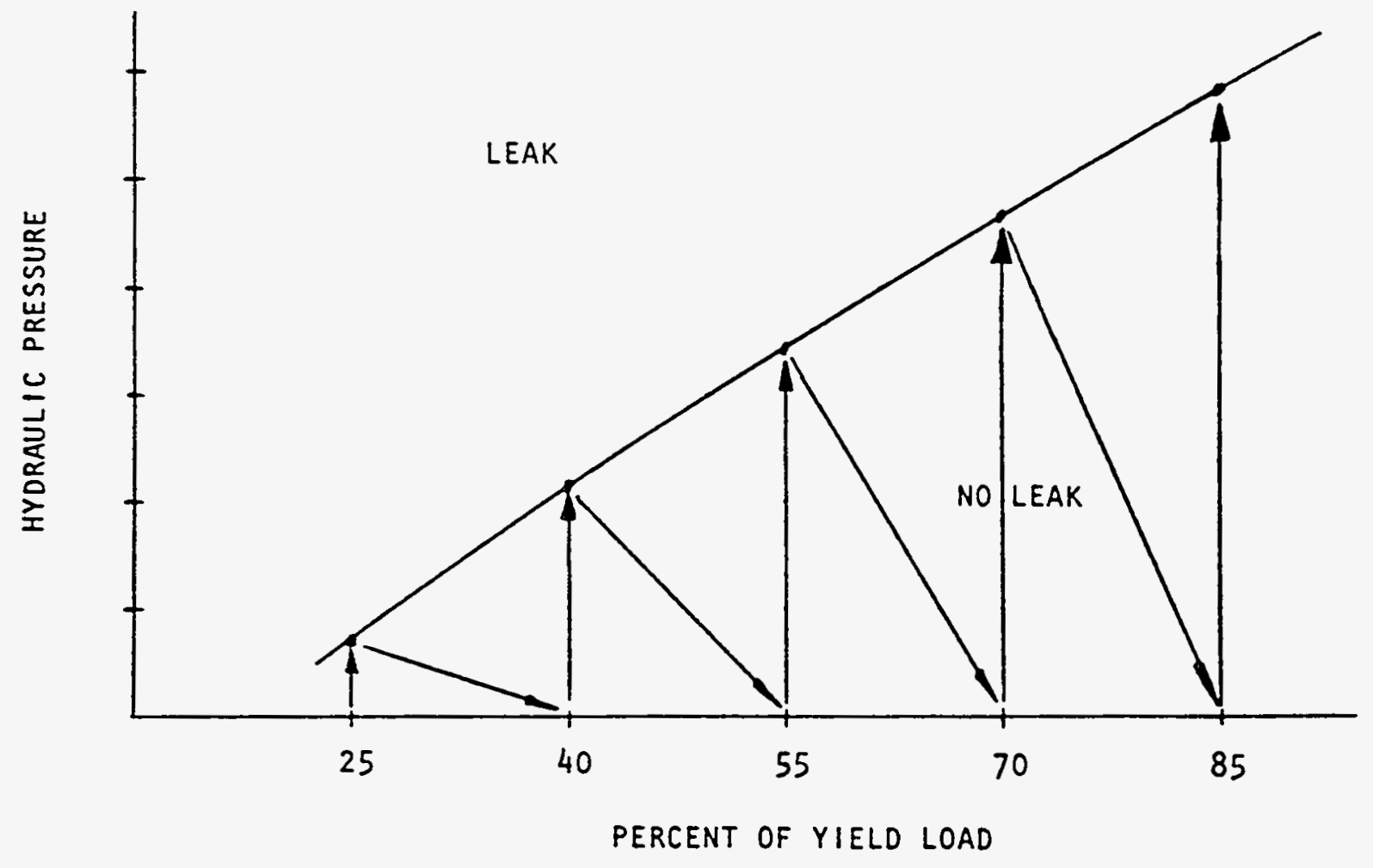

Figure 75: Fixture Test - Mapping Leakage Pressure Versus Clamp Load 
TABLE 21

CLAMP LOAD VS. LEAKAGE

\begin{tabular}{|c|c|c|}
\hline $\begin{array}{c}\text { PER STUD } \\
\text { CLAMP LOAD (kN) }\end{array}$ & PRESSURE (MPa) \\
\hline 0.0 & 0.0 & LEAK STOP \\
13.3 & 5.5 & 0.0 \\
22.2 & 10.2 & 5.2 \\
28.9 & 14.0 & 9.0 \\
35.6 & 18.0 & 13.4 \\
42.3 & 20.5 & 17.2 \\
48.9 & $*$ & 20.1 \\
62.3 & $*$ & 20.7 \\
75.6 & $*$ & 20.7 \\
\hline
\end{tabular}

* No leakage could be generated at these levels of clamp.

A summary of the stresses and safety factors calculated follows in Table 22. Selecting a minimum safety factor of 2.0 to account for the impracticality of locating the strain gage at the exact location of maximum stress, and proportioning to the calculated static stress safety factor a maximum clamp load of to $87.0 \mathrm{kN}$ per stud was found acceptable in terms of cylinder head stress levels.

The test procedure consisted of assembling a ceramic firedeck into the fixture and applying the maximum stud clamp load and simulated combustion gas pressure. Then the fixture was disassembled, the firedeck inspected for cracks using the dye check technique and the test repeated with another firedeck.

It should be noted that based on Finite Element Analysis of the cylinder head, no significant tensile stresses or failures were expected during this test. No damage of any kind was noted on any of the firedecks. 
TABLE 22

ADECD CYLINDER HEAD

CALCULATED STRESS LEVELS AND SAFETY FACTORS

UNDER CLAMP AND CLAMP PLUS PRESSURE LOAD

\begin{tabular}{|c|c|c|c|c|}
\hline \multicolumn{5}{|c|}{ STRESSES DUE TO STUD CLAMP LOAD ONLY* (MPa) } \\
\hline & $\begin{array}{c}\text { Radial } \\
\text { Rib } \\
\end{array}$ & $\begin{array}{l}\text { Circ. } \\
\text { Rib }\end{array}$ & $\begin{array}{c}\text { Port } \\
\text { Bolt Boss }\end{array}$ & Bolt Boss \\
\hline S Max & 51.5 & 84.2 & 45.7 & 0.0 \\
\hline S Min & 2.2 & -17.2 & -189.1 & -17.1 \\
\hline Tmax & 24.6 & 50.7 & 117.4 & 8.6 \\
\hline \multicolumn{5}{|c|}{ STRESSES DUE TO STUD CLAMP LOAD PLUS GAS PRESSURE** (MPa) } \\
\hline & $\begin{array}{c}\text { Radial } \\
\text { Rib }\end{array}$ & $\begin{array}{l}\text { Circ. } \\
\text { Rib }\end{array}$ & $\begin{array}{c}\text { Port } \\
\text { Bolt Boss }\end{array}$ & Bolt Boss \\
\hline S Max & 59.9 & 87.0 & 47.1 & 0.0 \\
\hline S Min & 2.1 & -15.0 & -190.6 & -9.0 \\
\hline Tmax & 28.9 & 51.0 & 118.8 & 4.5 \\
\hline \multicolumn{5}{|c|}{ MEAN +/- ALTERNATING STRESS (MPa) } \\
\hline & $\begin{array}{c}\text { Radial } \\
\text { Rib }\end{array}$ & $\begin{array}{l}\text { Circ. } \\
\text { Rib }\end{array}$ & $\begin{array}{c}\text { Port } \\
\text { Bolt Boss }\end{array}$ & Bolt Boss \\
\hline S Max & $55.7+/-4.2$ & $85.6+/-1.4$ & $46.4+/-0.7$ & 0.0 \\
\hline S Min & $2.1+/-0$ & $-16.1+/-1.1$ & $-189.8+/-0.8$ & $-13.1+/-4.1$ \\
\hline$T \max$ & $26.8+/-2.1$ & $50.8+/-0.1$ & $118.1+/-0.7$ & $6.5+1-2.0$ \\
\hline \multicolumn{5}{|c|}{ STRESS SAFETY FACTORS } \\
\hline & $\begin{array}{c}\text { Radial } \\
\mathrm{Rib} \\
\end{array}$ & $\begin{array}{l}\text { Circ. } \\
\text { Rib }\end{array}$ & $\begin{array}{c}\text { Port } \\
\text { Bolt Boss } \\
\end{array}$ & Bolt Boss \\
\hline STATIC & 3.6 & 2.3 & 2.4 & 43.0 \\
\hline FATIGUE & 2.7 & 2.4 & 4.9 & 4.6 \\
\hline
\end{tabular}

* $\quad 75.6 \mathrm{kN}$ per stud clamp

** $75.6 \mathrm{kN}$ per stud clamp, 20.7 MPa cylinder pressure 
TENSILE YIELD STRESS $\quad S_{\mathrm{yt}}=217 \mathrm{MPa}$

COMPRESS YE YIELD STRESS $S_{y c}=-896 \mathrm{MPa}$

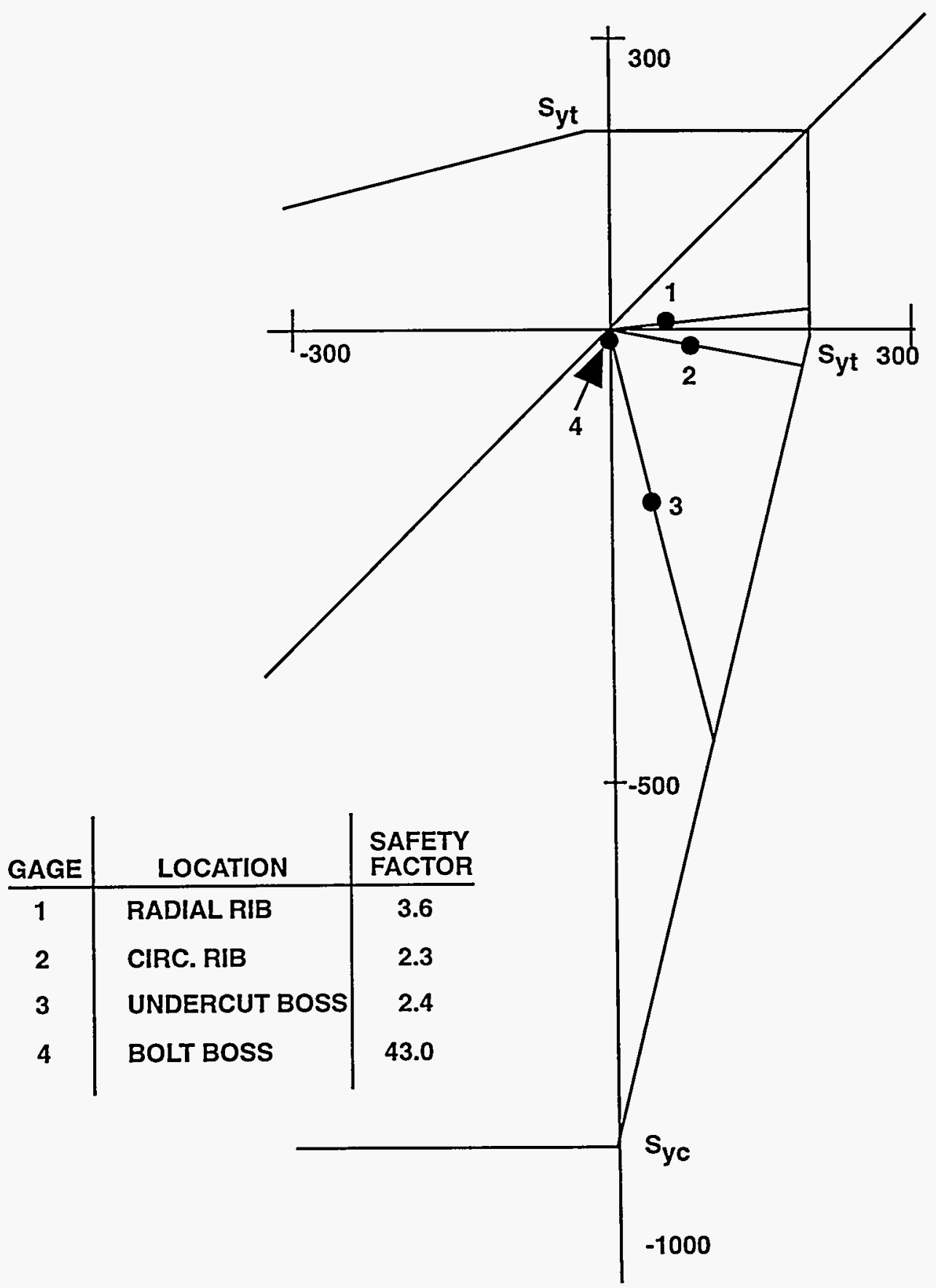

Figure 76: Coulomb-Mohr Static Failure Criteria and Resulting Safety Factors ADECD Cylinder Head 


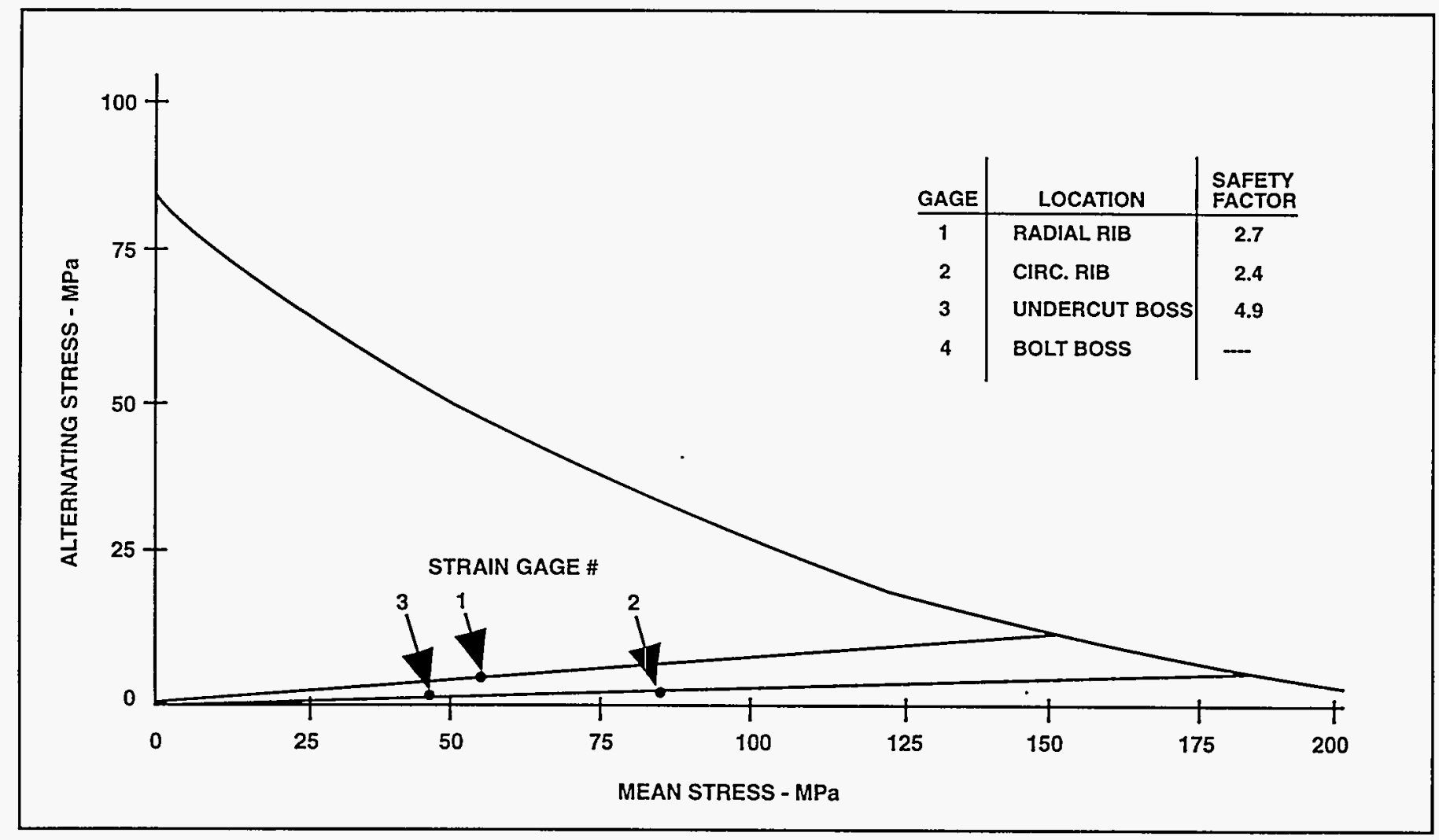

Figure 77: Mean Alternating Stress Diagram - GM-13M Cast Iron 


\section{APPENDIX B}

\section{CERAMIC VALVE DEVELOPMENT}

\section{Initial Valve Geometry}

Consideration of a single, common valve configuration suitable for the two intake and two exhaust positions, and compatibility with as many off-the-shelf, state-of-the-art, production components as possible resulted in the "starting point" design. A $39.5 \mathrm{~mm}$ valve head diameter was selected to provide the maximum amount of air flow area into and out of the cylinder without contacting the cylinder liner wall. The valve lock geometry and valve stem diameter were sized to reflect the Series 60 lock geometry. The height of the lock groove was positioned to insure adequate spring preload. The backside of the valve head was radiused for added strength requirements.

\section{Supplier Input}

Seven potential suppliers were contacted relative to obtaining input and recommendations on a ceramic valve design; their input included tolerancing, processing and material selection. Their inputs have been condensed and were as follows:

- Six of the seven suppliers were interested in supplying the monolithic ceramic valves.

- Two suppliers offered design recommendations, based on their experience with operation in small gasoline engines. Both suggestions involved the lock areas: a shallow angled locking radius with a radius bead lock and a wide grooved rectangular lock area with a clamp type lock were suggested.

- Each supplier offered their strongest ceramic material: silicon nitride or Sialon. Some suppliers recommended hot isostatic pressing for further strength. No supplier had any relative experience to support assured success with their particular material recommendation.

- All six suppliers claimed that they could make a ceramic valve and achieve any tolerance specified.

- The lead times and estimated costs varied significantly.

\section{Material Selection}

Because of the anticipated thermal and mechanical stresses, silicon nitride and Sialon were the initially considered material candidates. After reviewing the silicon nitride and Sialon material properties and assessing the preliminary feedback from the potential suppliers, the silicon nitride material properties were selected for use in the subsequent analysis efforts. 


\section{Analysis}

By combining the suppliers' inputs with DDC's valve design technology, several modifications were made to the proposed "starting point" design. An axisymmetric finite element model of the valve using eight node elements was used in an iterative process to choose a ceramic valve design capable of LHR engine operation.

Four load cases were applied to the axisymmetric valve model:

(1) Thermal loading due to the extreme thermal conditions generated in an LHR engine. A heat transfer analysis, using the thermal boundary conditions shown in Figure 78, was conducted to estimate the thermal loading of various valve head and stem locations.

(2) Mechanical loading, due to a 16.2 MPa peak cylinder firing pressure was considered.

(3) The combined in-cylinder thermal and mechanical loads of (1) and (2) were used.

(4) The dynamic loading due to the impact of seating forces associated with closing the valve were considered.

The finalized silicon nitride valve resulting from this effort is shown in Figure 79, along with the "starting point" design.

The maximum principal stress in the valve, due to the thermal loading, Case 1, was 474 $\mathrm{MPa}$, located on the fillet portion of the valve. The maximum stress in the valve, due to the thermal loading, Case 2, was $52 \mathrm{MPa}$, located on the outer surface of the valve's head diameter. The maximum stress of the in-cylinder combined loading, Case 3, was $448 \mathrm{MPa}$, located on the fillet radius of the valve's head, as shown in Figure 80. The seating load, Case 4 , was equivalent to a $1741 \mathrm{~N}$ tensile load based on the system mass and a closing velocity limitation of $0.5 \mathrm{~m} / \mathrm{s}$. This resulted in a maximum stress of $198 \mathrm{MPa}$, located at the minimum diameter of the valve's locking groove, as shown in Figure 81.

The POS of this silicon nitride valve was calculated, based on Weibull analysis. The POS for each of the load cases is as follows: Case 1 POS - .99980; Case 2 POS $=1.00000$; Case 3 POS $=.99998$; and Case 4 POS $=1.00000$.

The iterative finite element modeling led to reduction of the ceramic valve weight by $50 \%$ as compared to the conservative "starting point" design, while achieving a POS equal to .99980 . 


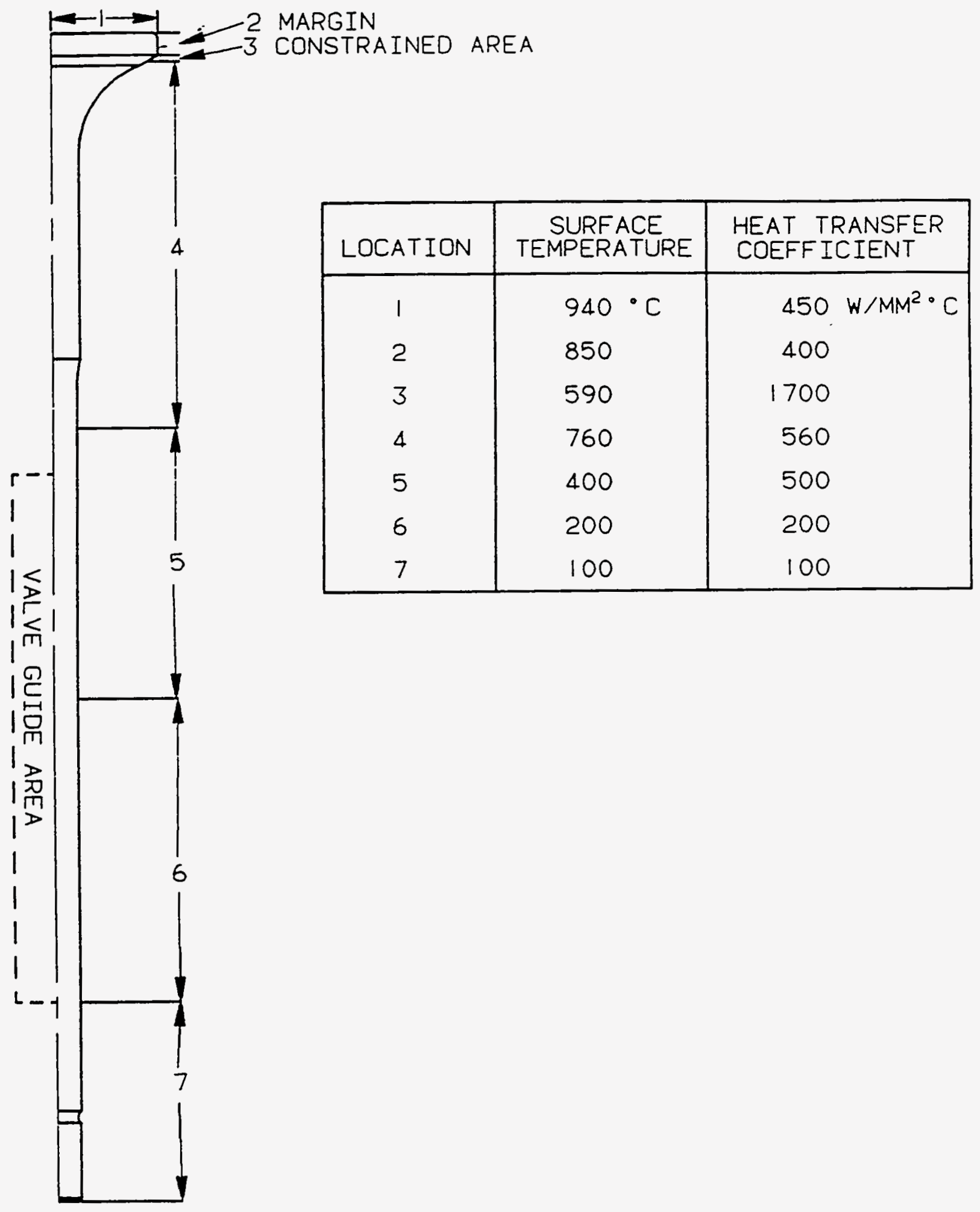

Figure 78: Thermal Boundary Conditions for ADECD Silicon Nitride Ceramic Valves' Valve Head Transfer Analysis 
8.9

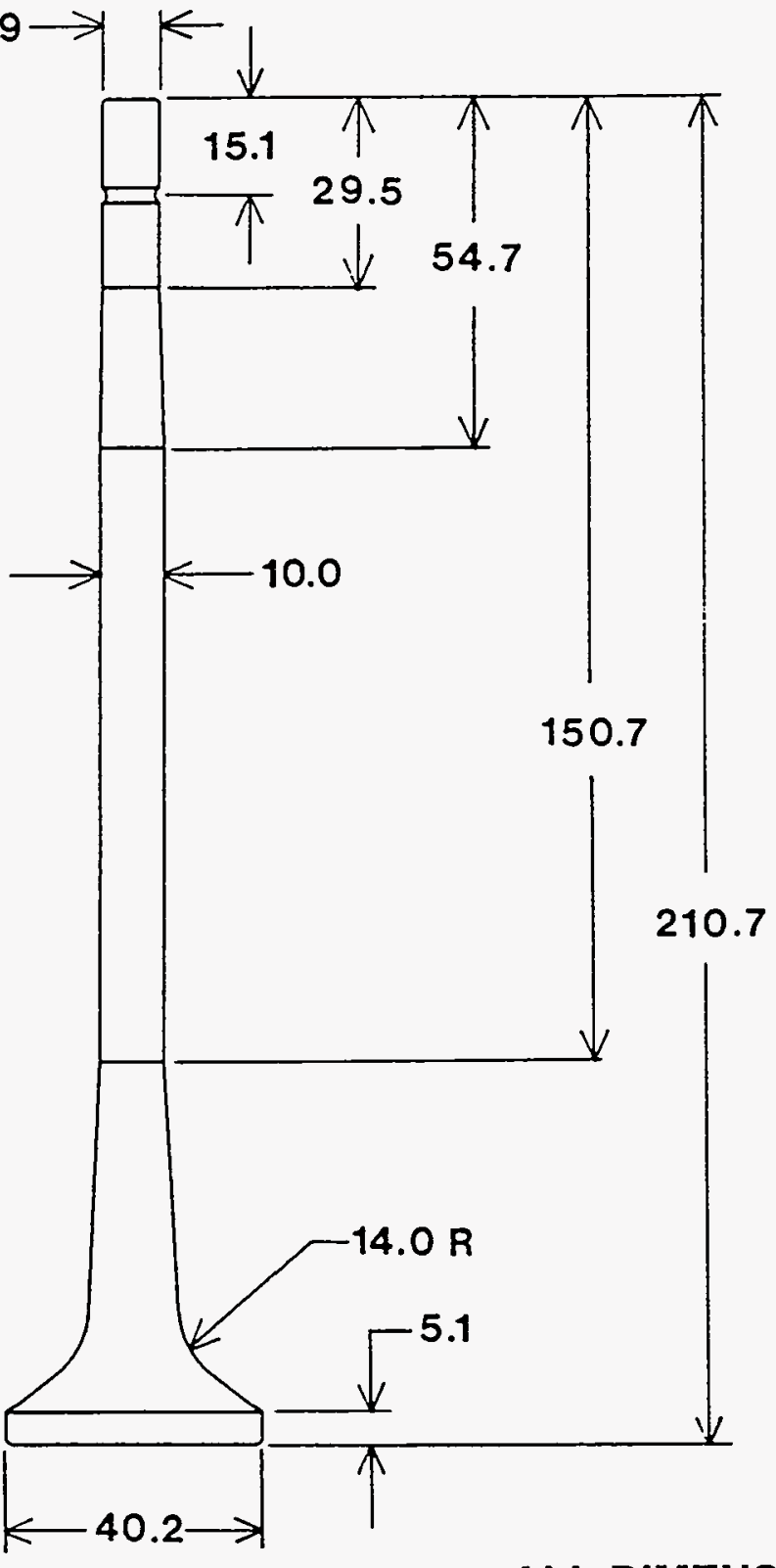

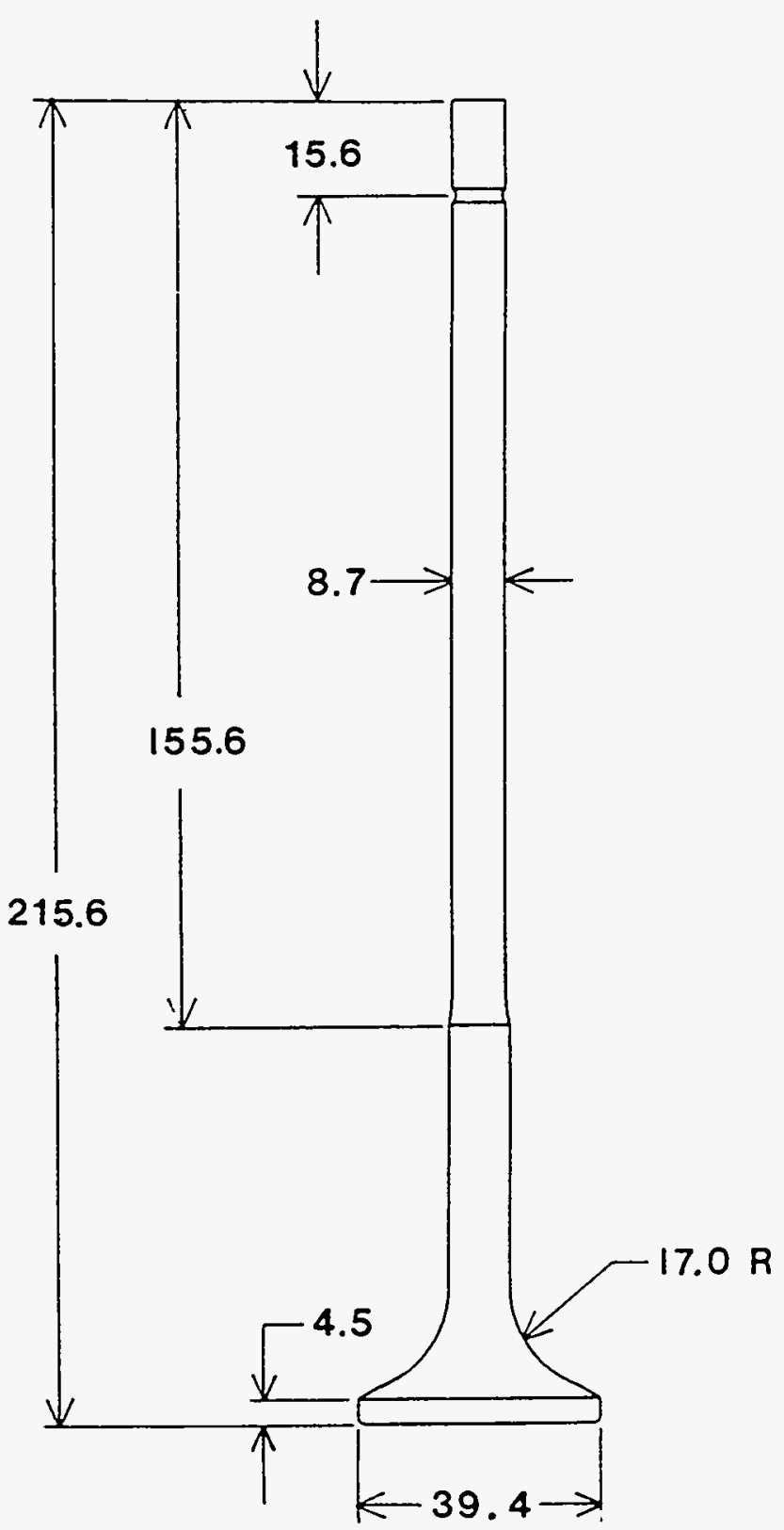

ALL DIMENSIONS ARE mm i44.0 grams

STARTING POINT
73.7 grams

FINALIZED DESIGN

Figure 79: ADECD Monolithic Silicon Nitride Valves

("Starting Point" vs Finalized Designs) 


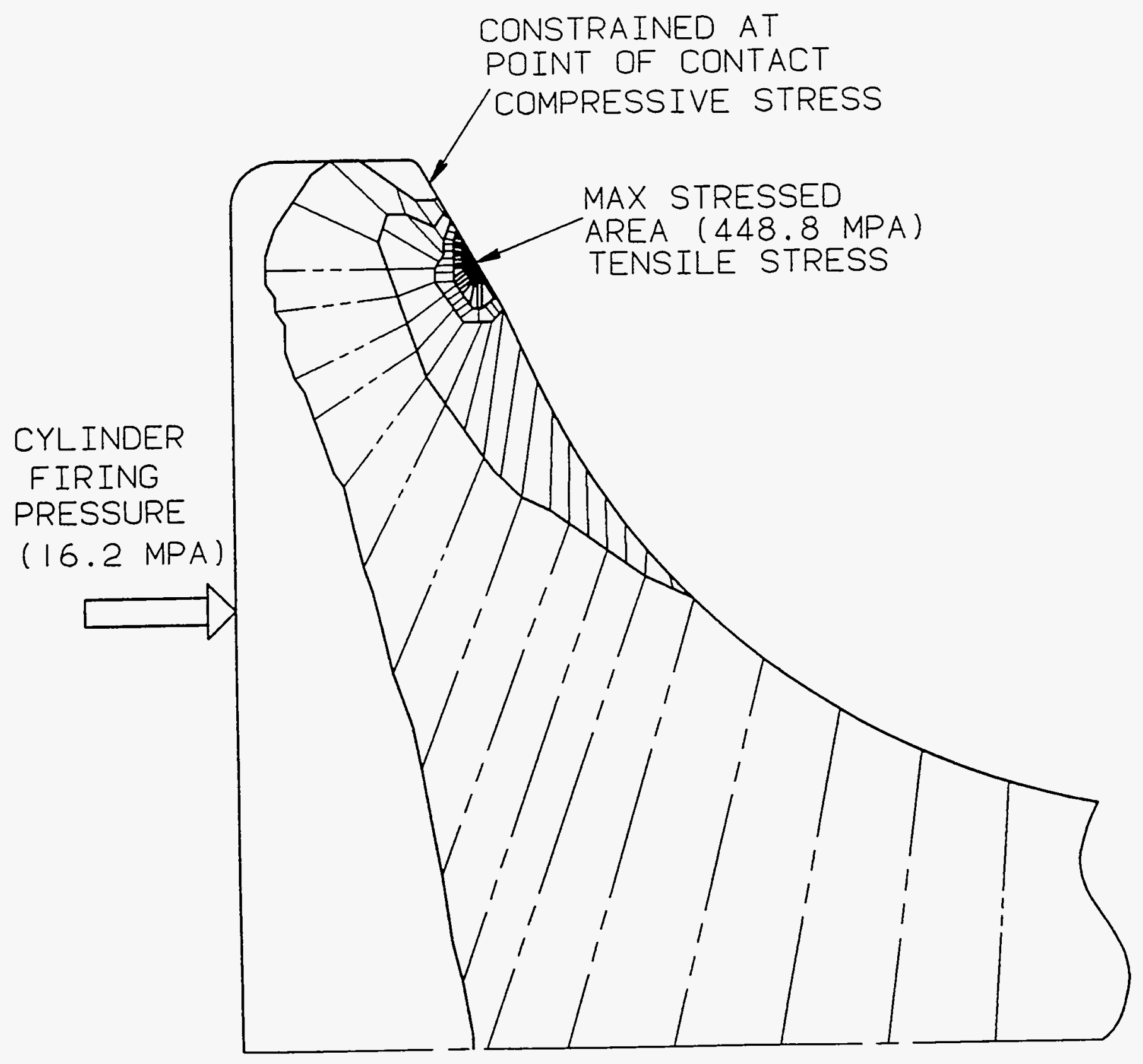

Figure 80: ADECD Monolithic Silicon Nitride Valve Stresses Due to In-cylinder Loading 


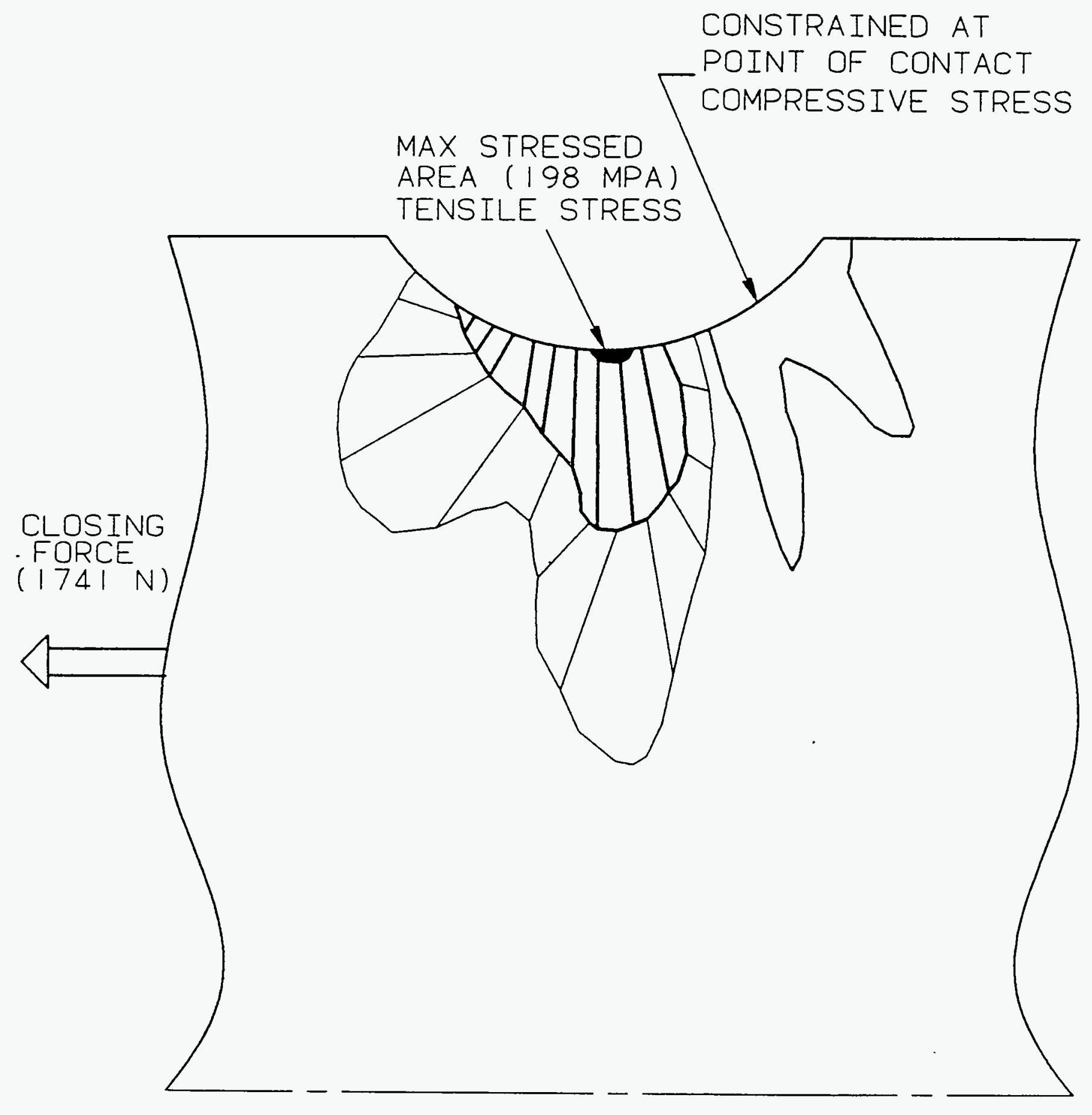

Figure 81: ADECD Monolithic Silicon Nitride Valve Stresses Due to Valve Closing 


\section{Supplier Selection and Procurement}

Based on the supplier's input, an assessment value was assigned to each supplier. The assigned values ranged from 0 to 8 , where 10 was the most favorable and highest possible. Both Kyocera and GTE Laboratories received an 8. Based on these favorable assessments, both suppliers were selected.

Eight valves each were ordered from Kyocera (SN-220M) and GTE Laboratories (HIPed AY6). The Kyocera valves were received in four months and the GTE valves in six months. All valves were dimensionally to print and either met or exceeded the suppliers' published material properties. All valves (four from each supplier) passed the preliminary proof of concept testing criteria shown in Table 23.

The mean flexural strength of the Kyocera valves at room temperature was $744.6 \mathrm{MPa}$ with a Weibull Modulus of 15.2. The mean flexural strength of the GTE valves at room temperature was $938.4 \mathrm{MPa}$ with a Weibull Modulus of 14.5 . At $800^{\circ} \mathrm{C}$, the mean flexural strength of the GTE valves was 836.1 MPa with a Weibull Modulus of 20.2. The bend bars used were made from valves selected from the purchased lots.

\section{Proof of Concept Testing}

Failure of a ceramic valve due to high seating loads would normally be expected to occur through the minimum cross section at the lock diameter. However, possibility of hidden material imperfections in this case justified the requirement of strict microfocus $\mathrm{X}$-ray inspection. A valve failure of this type could result in dropping the valve into the cylinder.

Failure of the valve due to concentrated seat loading was also a concern. In this case, the bending moment and corresponding stress level can increase to the point where a head-tostem fracture occurs. Out-of-round geometries, thermal distortion, and eccentric positioning can contribute to concentrated, nonuniform loading conditions. Established data on the effect of out-of-round and eccentric geometries on valve stresses were used to define and limit the ADECD valve, firedeck, and guide dimensions.

Failure of the valve due to high cylinder pressure would normally be catastrophic. The finite element analysis predicted a probability of survival equal to 1.000 under these conditions. Thus, a proof test for equivalent cylinder pressure loading was not necessary. Additionally, imperfections that were not detected in the microfocus X-ray evaluation could contribute to a catastrophic failure; for example, the imperfection is too small to be detected but large enough to drastically reduce the strength.

As shown in the valve screening, Table 23, and proof of concept testing matrix, Figure 82, each valve was subjected to a dynamic bench rig test up to the design load condition $(.5 \mathrm{~m} / \mathrm{s}$ seating velocity at $1800 \mathrm{r} / \mathrm{min}$ ). This was accomplished using the DDC Series 60 Valve Train Fixture, VT-1, which provided the camshaft lobe profile action representing the ADECD 


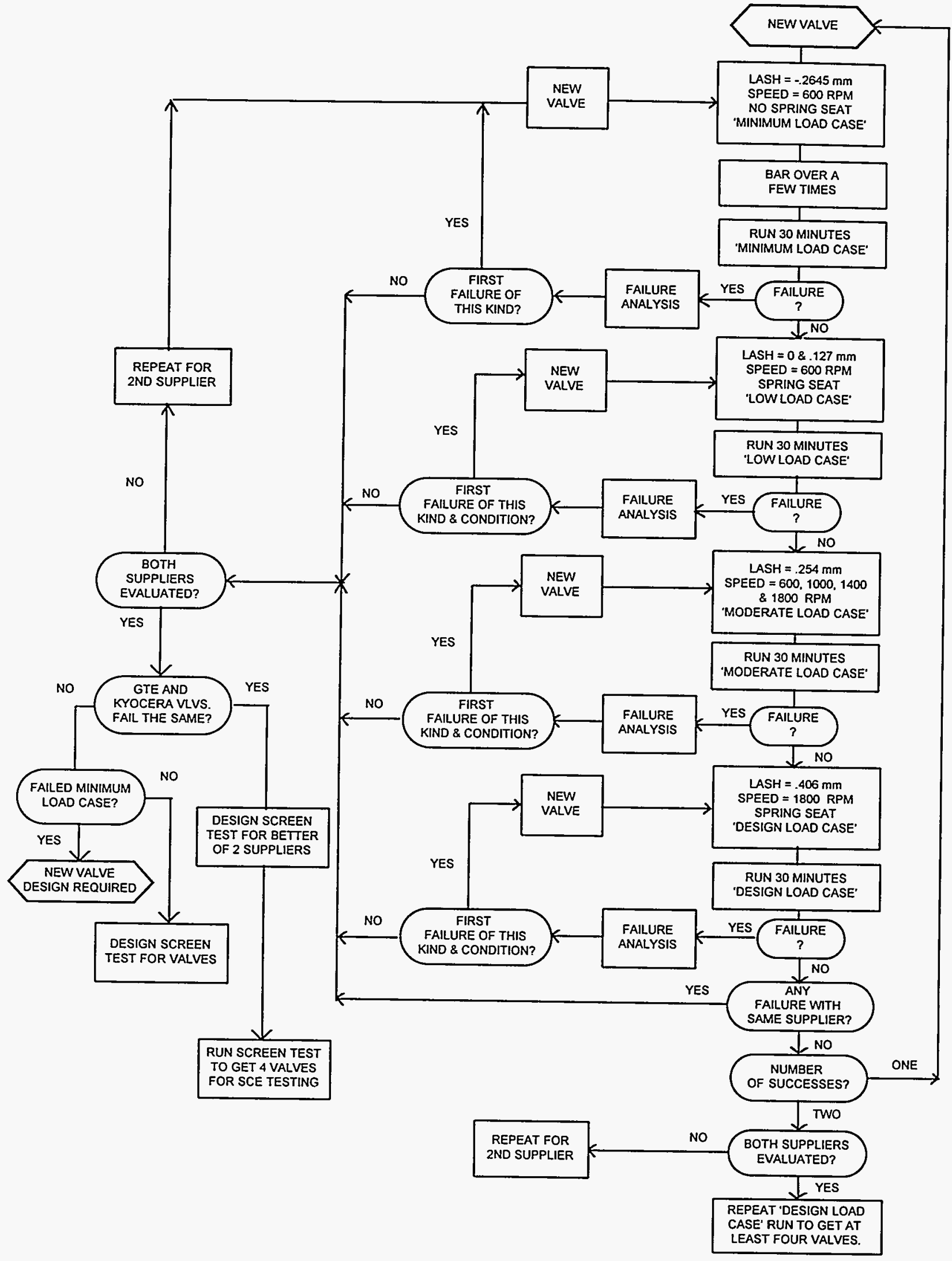

Figure 82: Proof of Concept Testing Matrix for ADECD Ceramic Valve 
TABLE 23

TEST CYCLE TO DEMONSTRATE DESIGN CRITERIA

\begin{tabular}{|l|}
\hline Ceramic Valve Testing Criteria \\
\hline 30 minutes at $600 \mathrm{r} / \mathrm{min}$ with $-0.2645 \mathrm{~mm}$ lash \\
30 minutes at $600 \mathrm{r} / \mathrm{min}$ with $0.0000 \mathrm{~mm}$ lash \\
30 minutes at $600 \mathrm{r} / \mathrm{min}$ with $0.1270 \mathrm{~mm}$ lash \\
30 minutes at $600 \mathrm{r} / \mathrm{min}$ with $0.2540 \mathrm{~mm}$ lash \\
30 minutes at $1000 \mathrm{r} / \mathrm{min}$ with $0.2540 \mathrm{~mm}$ lash \\
30 minutes at $1400 \mathrm{r} / \mathrm{min}$ with $0.2540 \mathrm{~mm}$ lash \\
30 minutes at $1800 \mathrm{r} / \mathrm{min}$ with $0.2540 \mathrm{~mm}$ lash \\
30 minutes at $1800 \mathrm{r} / \mathrm{min}$ with $0.4060 \mathrm{~mm}$ lash \\
\hline
\end{tabular}

electrohydraulic valve actuation dynamics. All eight valves, four from each supplier, passed the entire test. After successfully completing the proof of concept testing, four of the eight valves, two from each supplier, were subjected to an over speed test designed to produce failure (see Table 24). An additional million cycles of severe loading conditions were accumulated on each of the four ceramic valves during the first six steps of over speed test prior to failure. However, sometime during the final 2 hour step at $3600 \mathrm{r} / \mathrm{min}$, all four valves failed.

TABLE 24

TEST CYCLE TO ESTABLISH THE CERAMIC VALVE DURABILITY

\section{Ceramic Valve Test To Failure Sequence}

90 minutes at $1800 \mathrm{r} / \mathrm{min}$ with $0.4060 \mathrm{~mm}$ lash 180 minutes at $2100 \mathrm{r} / \mathrm{min}$ with $0.4060 \mathrm{~mm}$ lash 180 minutes at $2400 \mathrm{r} / \mathrm{min}$ with $0.4060 \mathrm{~mm}$ lash 180 minutes at $2700 \mathrm{r} / \mathrm{min}$ with $0.4060 \mathrm{~mm}$ lash 180 minutes at $3000 \mathrm{r} / \mathrm{min}$ with $0.4060 \mathrm{~mm}$ lash 180 minutes at $3300 \mathrm{r} / \mathrm{min}$ with $0.4060 \mathrm{~mm}$ lash 180 minutes at $3600 \mathrm{r} / \mathrm{min}$ with $0.4060 \mathrm{~mm}$ lash 
The point of failure on all four valves was at the exact predicted location - through the minimum diameter of the locking radius. However, the failed valves were retained by their locks, keeping them from dropping into the cylinder.

\section{Engine Testing}

As stated in the SF tribology section, the valve stems were coated with cesium trithioxymolybdate by Pennwalt for operation in an otherwise unlubricated environment. These valves were integrated into the single cylinder test bed. Initial operation showed the coating to be functional, but not optimal. No structural problems were encountered during initial engine testing.

Since the ADECD valve-to-guide interface was not to be supplied with lube oil, a solid lubricant was applied to several valves slated for engine operation. During an accumulation of 275 hours of engine operation under various speed and load conditions (Section VII), no primary valve failures occurred. 


\section{APPENDIX C}

\section{FINITE ELEMENT ANALYSIS OF PORT SHIELD}

The finite element model was used for the ceramic cast-in-place port shield analysis is shown in Figure 83. The model consisted of about 640 nodes and 470 elements. Due to symmetry, half of the port was modeled. The ceramic structure was modeled with four noded shell elements and the wire mesh bands were modeled with eight noded solids. Shells were selected due to the nature of the port structure and the ability to easily change the thickness of the shield. The wire mesh elements were jointed to the shell structure through constraint equations. This constraint method assumed no slip at the mesh-ceramic interface. Silicon nitride was selected for the ceramic material based on high temperature strength and manufacturing considerations. Material properties for a generic silicon nitride and several different wire mesh materials used in the analyses are summarized in Table 25. The analysis was conducted with DDA's STRATA finite element program using PATRAN as the pre and post processor.

TABLE 25

ADECD EXHAUST PORT SHIELD

MATERIAL PROPERTIES

\begin{tabular}{|ccc|}
\hline SILICON NITRIDE & Elastic & Thermal Expansion Coeff. \\
Temperature & $\left(1 /{ }^{\circ} \mathrm{C}\right)$ \\
$\left({ }^{\circ} \mathrm{C}\right)$ & 300000 & $3.0 \mathrm{E}-06$ \\
25 & 300000 & $4.0 \mathrm{E}-06$ \\
800 & & \\
& Podulus $(\mathrm{MPa})$ & \\
Temperature & $\left(\mathrm{W} / \mathrm{mm}^{-}{ }^{\circ} \mathrm{C}\right)$ & 0.27 \\
$\left({ }^{\circ} \mathrm{C}\right)$ & 0.03 & \\
25 & 0.026 & \\
200 & 0.021 & \\
400 & 0.018 & \\
600 & 0.017 & \\
800 & & Thermal Conductivity \\
& & $\left(\mathrm{W} / \mathrm{mm}-{ }^{\circ} \mathrm{C}\right)$ \\
MESH BANDS & Elastic & \\
Type & Modulus $(\mathrm{MPa})$ & 0.004 \\
Solid S.S. & 206850 & 19 \\
Metex Unsintered & 42 & \\
Kyocera $(5 \mathrm{~mm})$ & &
\end{tabular}





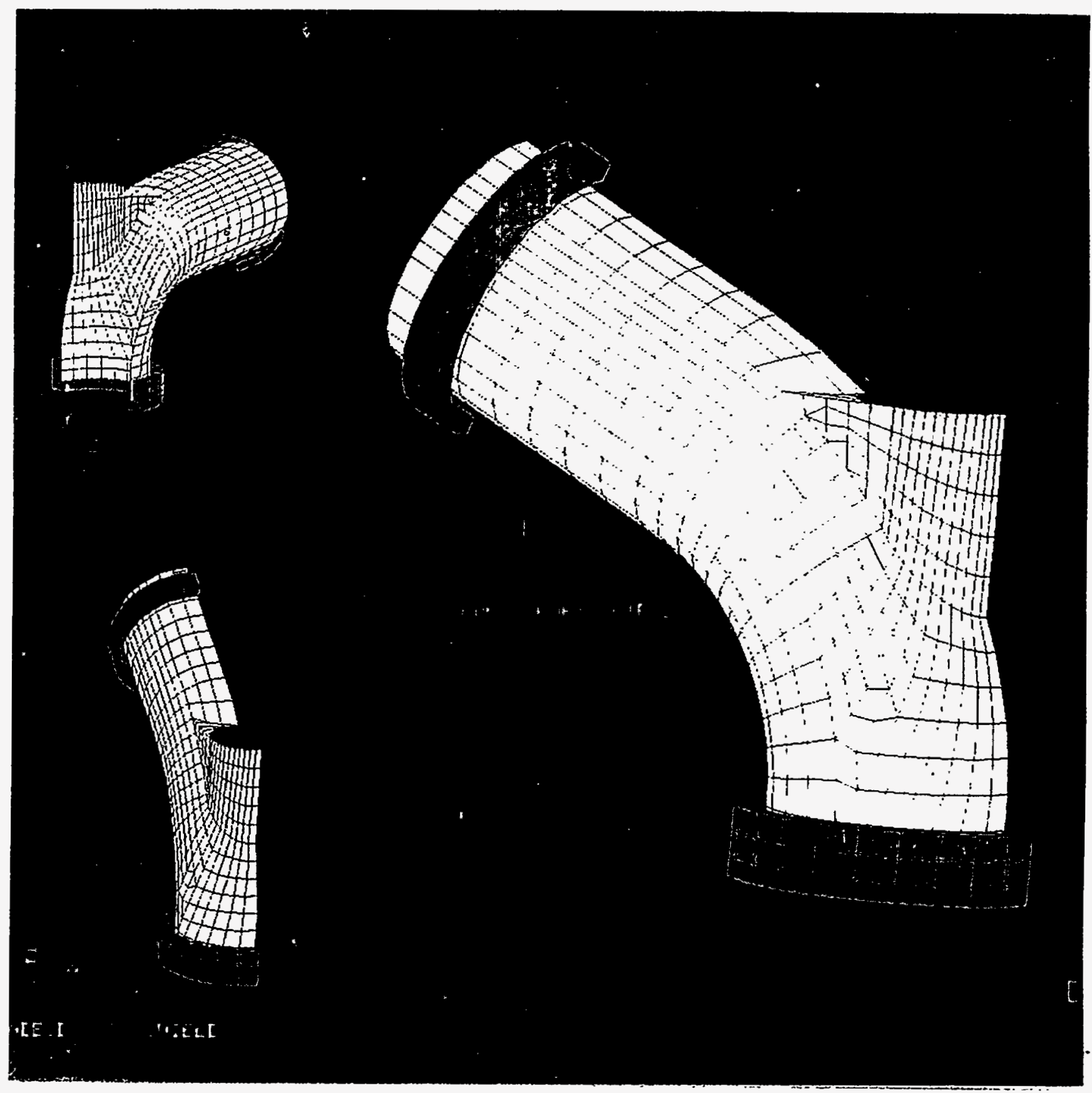

Figure 83: ADECD Port Shield Finite Element Model 

Two load conditions were considered during the analysis. The first case consisted of the casting shrink loading. The loads due to the shrinkage of the cylinder head metal were approximated by imposing a deflection at each of the nodes on the outer diameter of the wire mesh bands based on their $\mathrm{x}, \mathrm{y}$, and $\mathrm{z}$ coordinate values times an assumed shrinkage rate. A shrinkage rate of $.008 \mathrm{~mm} / \mathrm{mm}$ was used as an approximate value for cooling iron. Figure 84 further describes the mechanical boundary conditions for the casting shrink load. This method of loading the port shield assumes a uniform shrinkage of the entire head casting, but was considered the best approximation available.

The second load case was the combination of casting shrink and peak torque thermal loads for the exhaust port shield. In addition to the imposed displacements described above, the port shield was subjected to the predicted peak torque temperature field. The boundary conditions used in the thermal analysis are shown in Figure 85. The time averaged gas temperature was obtained from ITI IRIS performance simulation. The time averaged heat transfer coefficient on the interior of the port was calculated with the DDA port shield heat transfer program. For thermal modeling purposes the port was considered at four connecting channels. Temperatures on the outer diameter of the wire mesh bands were taken from heat transfer results for the full cylinder head model. Although the temperature distribution in the exhaust port is not expected to be exactly symmetric, the asymmetry was not predicted to be large enough to warrant a full port shield model.

A probability of survival (POS) calculation was performed on the ceramic for each loading condition. The NASA written SCARE program, Ref 1 , was used to predict the reliability of the port shield. Available test bar data for Kyocera SN230 silicon nitride at 25 and $800^{\circ} \mathrm{C}$ was used. The Batdorf shear sensitive model with penny shaped cracks and strain energy release rate fracture criteria was employed. This is judged to be the most conservative failure theory for POS calculations. The stress results for the shell elements, inner and outer fibers, were changed to the solid element format in order to be compatible with DDA's SCARE input routines.

An initial investigation of the sensitivity of the two-bank wire mesh cast-in-place port shield to mesh stiffness was conducted for the originally proposed $3 \mathrm{~mm}$ thick port. The results for the casting shrink loading are shown in Table 26. If solid steel is used in place of the mesh bands, the maximum principle stress, sigma 1 , far exceeds the strength of the port and the probability of surviving the casting process is 0.000 . On the other hand, if a low elastic modulus wire mesh such as the Metex or Kyocera types is employed, stress levels are very low and the POS is nearly $100 \%$. These findings illustrate the importance of using compliant mesh material to transfer the casting shrink load to the silicon nitride port shield.

Eight shields each of these two design types were made by Kyocera. The two designs are shown in Figure 91. 


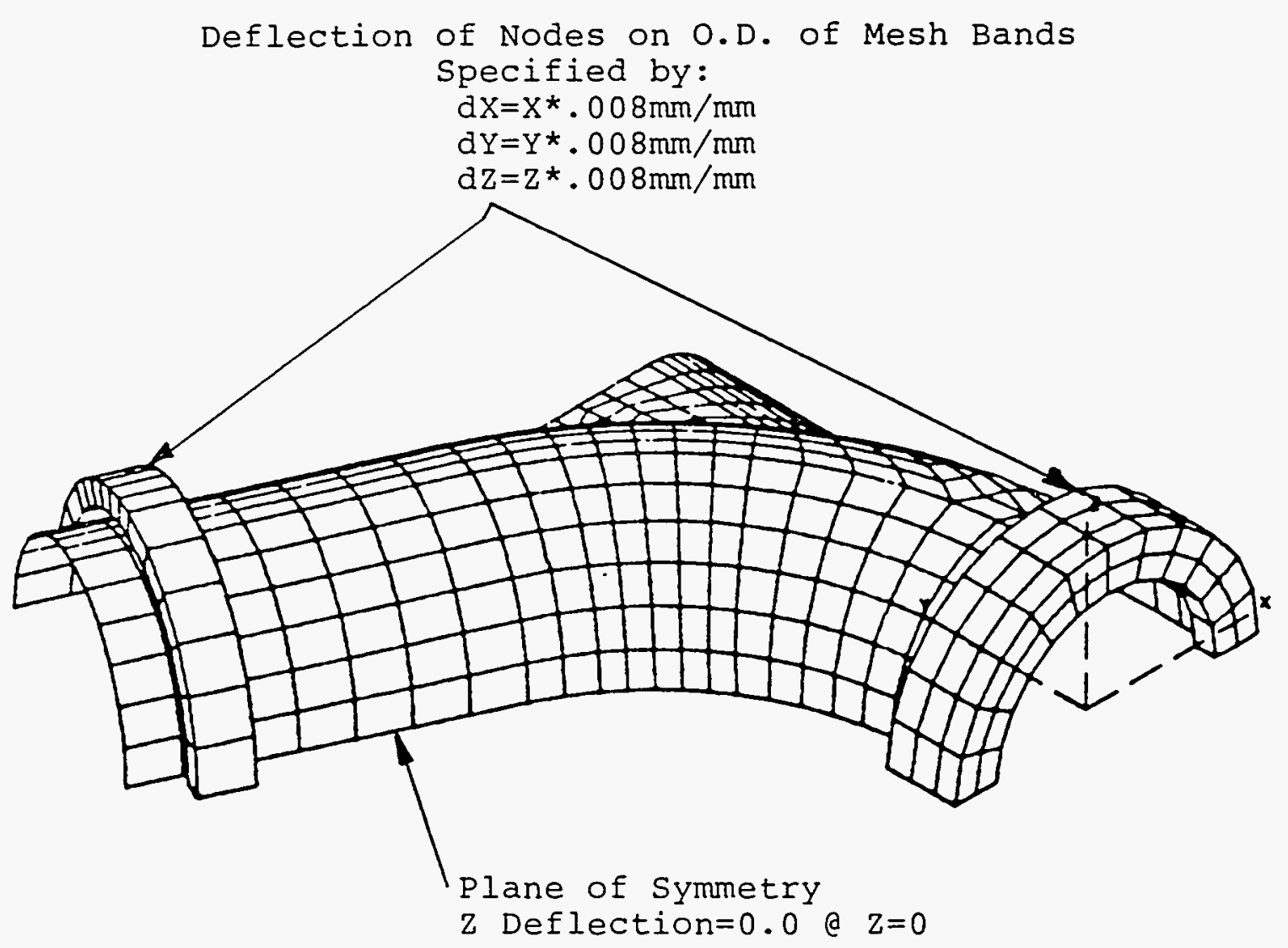

Figure 84: ADECD Port Shield Analysis - Casting Shrink Load Boundary Conditions 

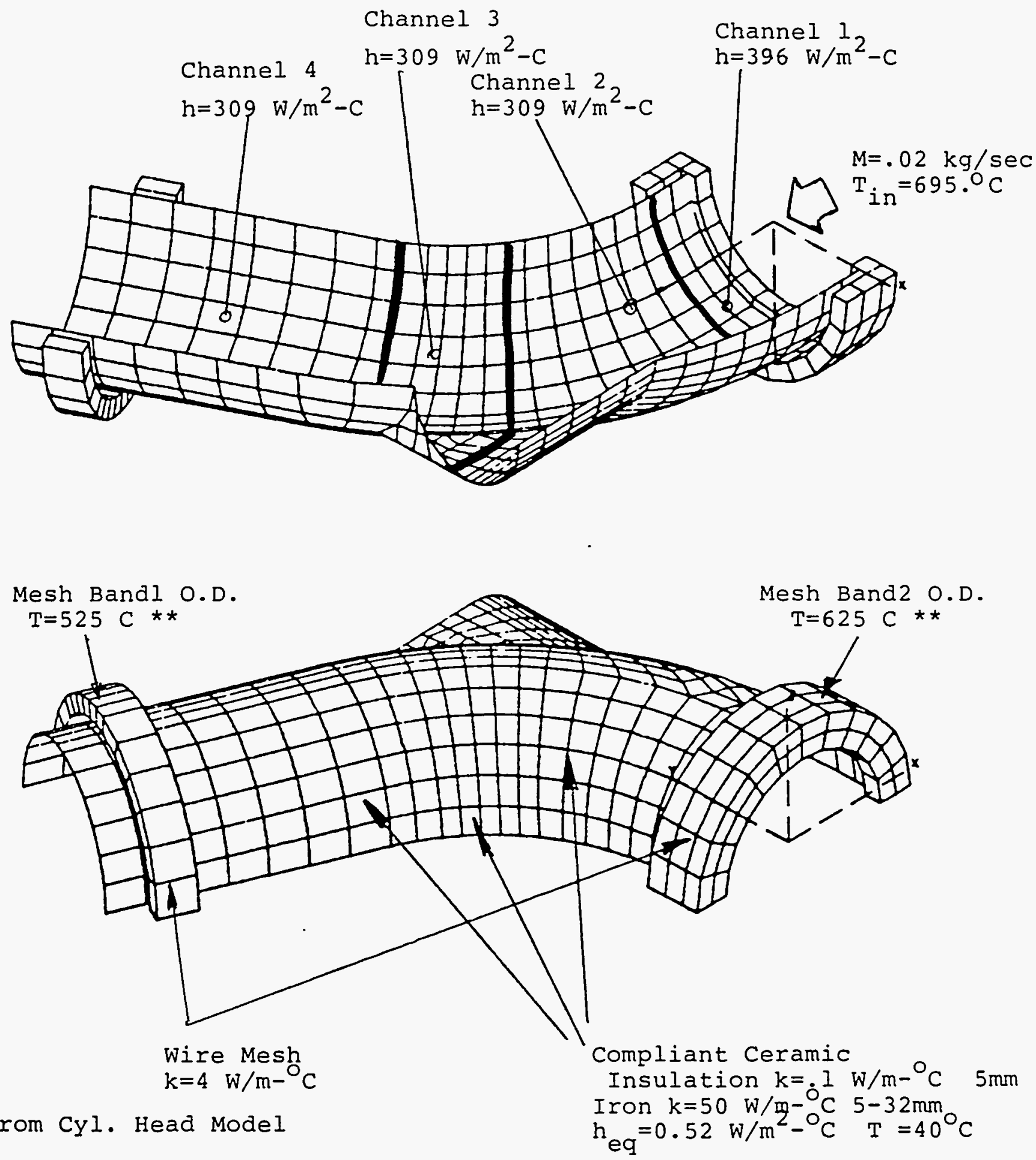

Figure 85: ADECD Port Shield Analysis - Thermal Boundary Conditions 
TABLE 26

ADECD SILICON NITRIDE PORT SHIELD ANALYSIS

EFFECT OF MESH STIFFNESS ON PORT STRESS-CASTING SHRINK LOAD

(3MM WALL)

\begin{tabular}{|c|c|c|}
\hline Mesh Configuration & $\begin{array}{c}\text { Sigma1 (max) } \\
\text { (MPA) }\end{array}$ & P.O.S. \\
\hline Solid Stainless Steel & 2232 & 0.0000 \\
Metex Unsintered & 12 & 1.0000 \\
Kyocera (41 MPa) & 28 & 1.0000 \\
\hline
\end{tabular}

The results of the casting shrink analysis for the proposed $4 \mathrm{~mm}$ wall silicon nitride port shield with two Kyocera $42 \mathrm{MPa}$ mesh bands are shown in Table 27. The stress contour results for both the outer (Fiber1) and inner (Fiber2) surfaces of the shield were determined by FEA. Table 26 indicates that the principle stresses generated by this loading are low. For example, the maximum tensile stress occurs on Fiber2 at the top of the valve guide boss with a magnitude of only $36.5 \mathrm{MPa}$. The analysis predicts a probability of survival of 1.000 under the approximated casting shrink load.

TABLE 27

ADECD SILICON NITRIDE PORT SHIELD ANALYSIS

(4MM WALL-TWO BAND DESIGN-42 MPA MESH)

\begin{tabular}{|c|c|c|c|}
\hline Load Case & $\begin{array}{c}\text { Sigma1 (max) } \\
\text { (MPa) }\end{array}$ & $\begin{array}{c}\text { Sigma3 (min) } \\
\text { (MPa) }\end{array}$ & P.O.S. \\
\hline Casting Shrink & 36.5 & -45.4 & 1.0000 \\
Casting Shrink + Thermal & 53.3 & -62.9 & 1.0000 \\
(Peak Torque) & & & \\
\hline
\end{tabular}

The results of the casting shrink plus the peak torque thermal load analysis for the $4 \mathrm{~mm}$ thick, two bank design are shown in Table 27 and Figures 86 thru 90. The calculated temperature distribution for the port shield is shown in Figure 86. The insulating effect of the ceramic blanket allows the valve boss area of the shield to reach $690^{\circ} \mathrm{C}$, while the mesh 
(כo) suo!!!puoว әnbגo $\perp$ yeəd

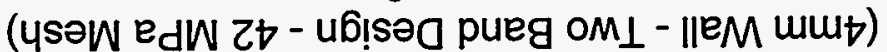

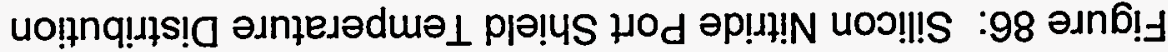

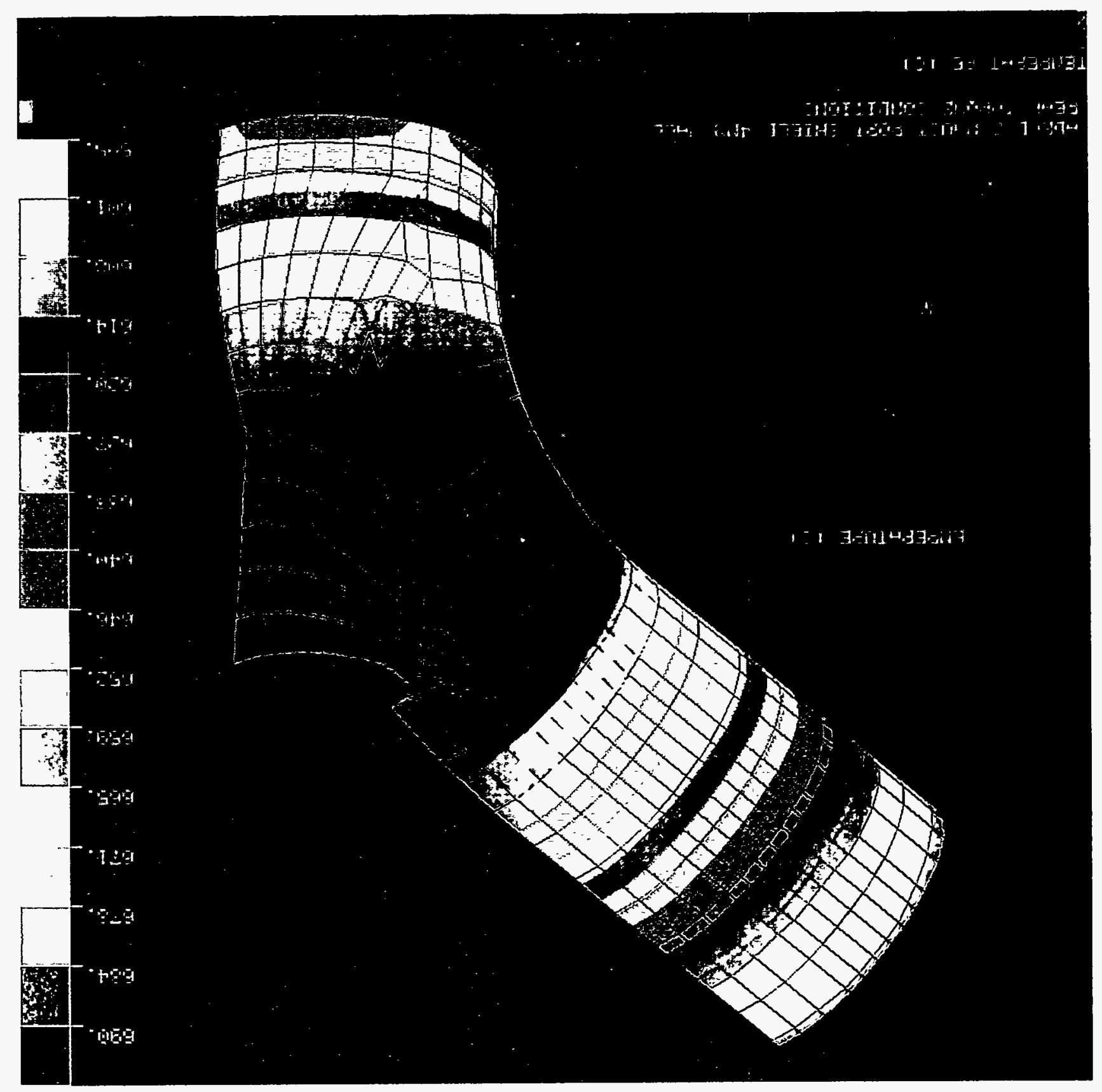





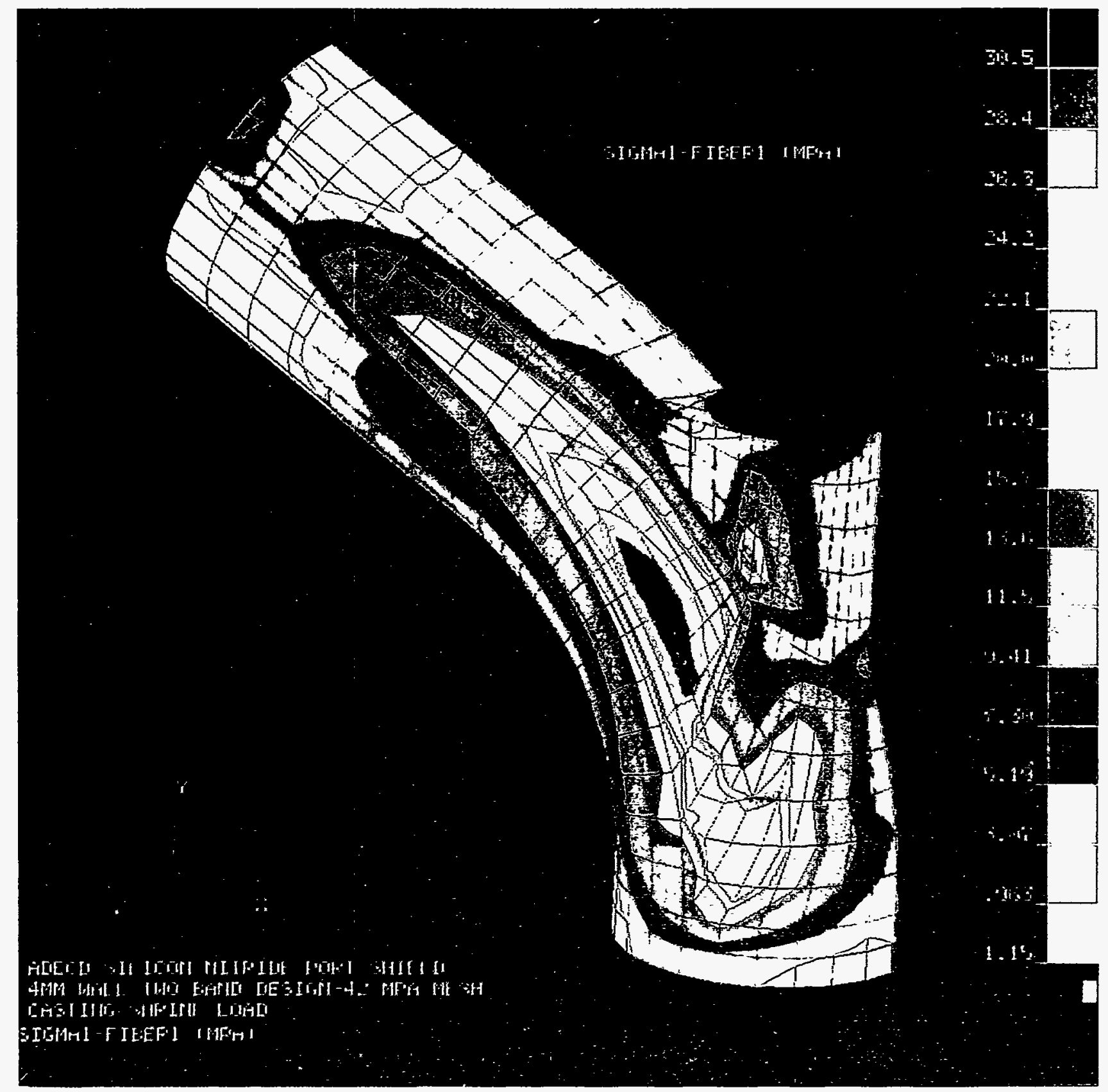

Figure 87: Silicon Nitride Port Shield Temperature Distribution (4mm Wall - Two Band Design - $42 \mathrm{MPa}$ Mesh) Casting Shrink + Thermal Load - Max Principle Stress Outer Surface 


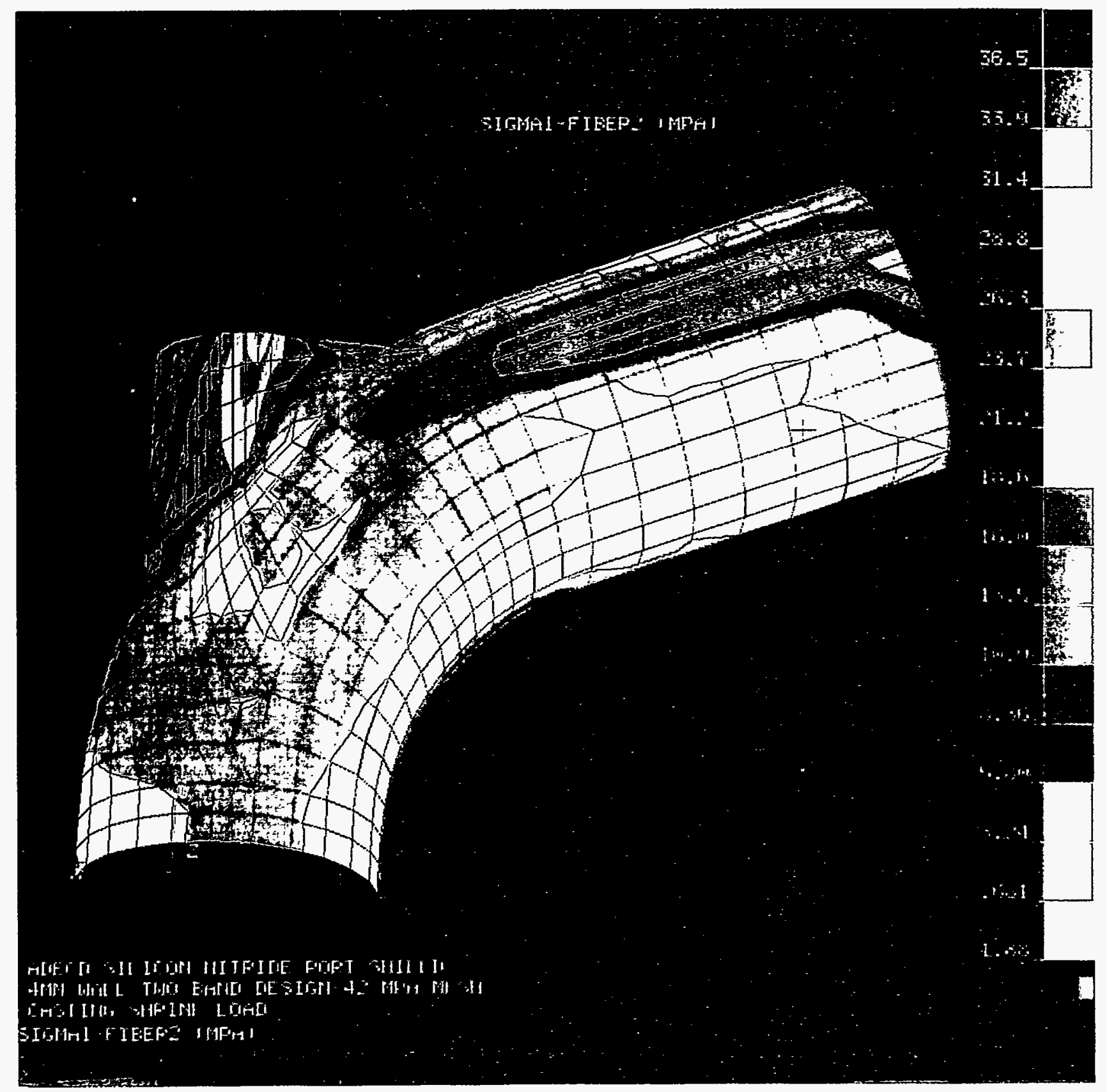

Figure 88: Silicon Nitride Port Shield Temperature Distribution (4mm Wall - Two Band Design - 42 MPa Mesh) Casting Shrink + Thermal Load - Max Principle Stress Inner Surface 



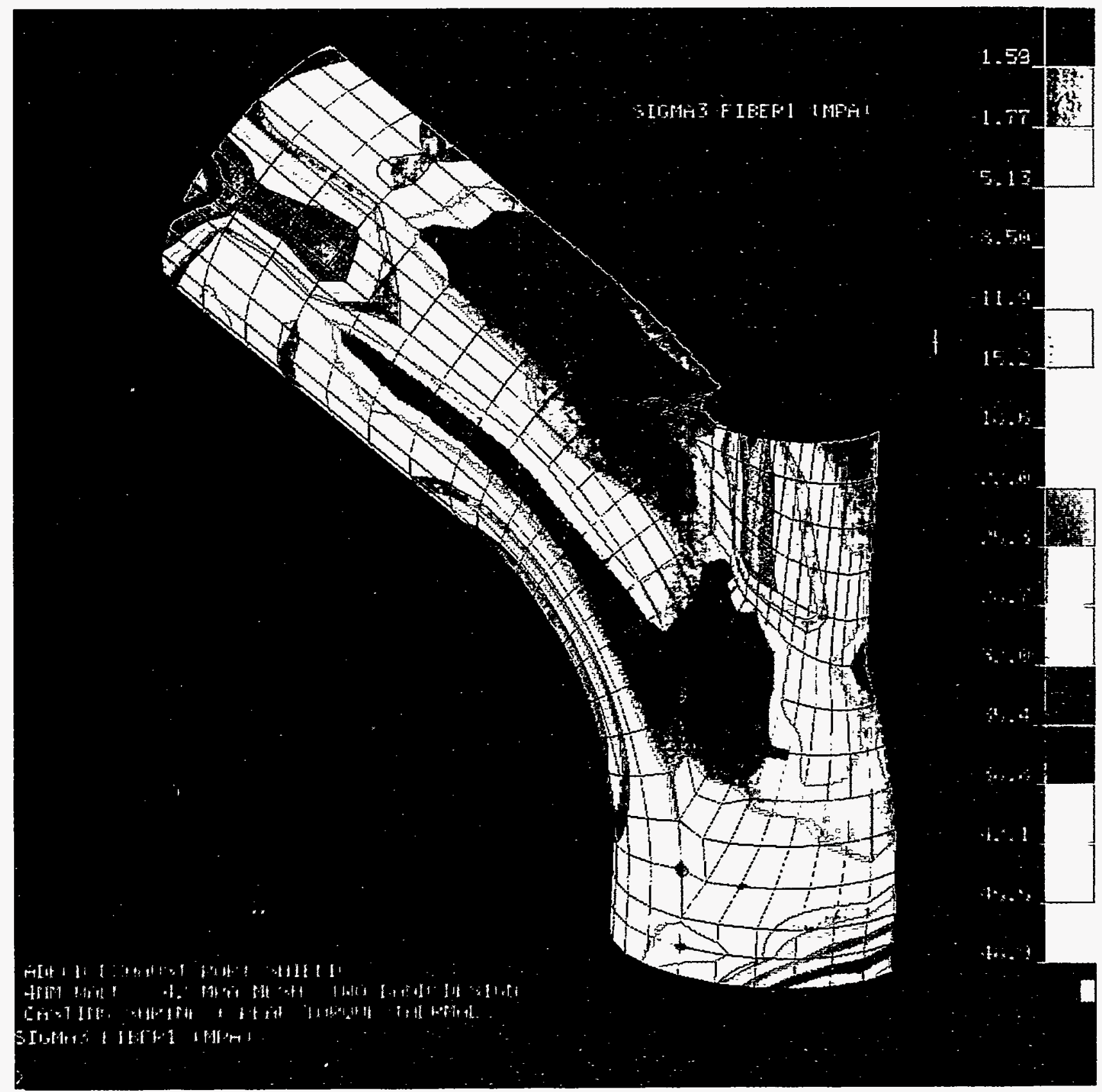

Figure 89: Silicon Nitride Port Shield Temperature Distribution (4mm Wall - Two Band Design - 42 MPa Mesh) Casting Shrink + Thermal Load - Min Principle Stress Outer Surface 



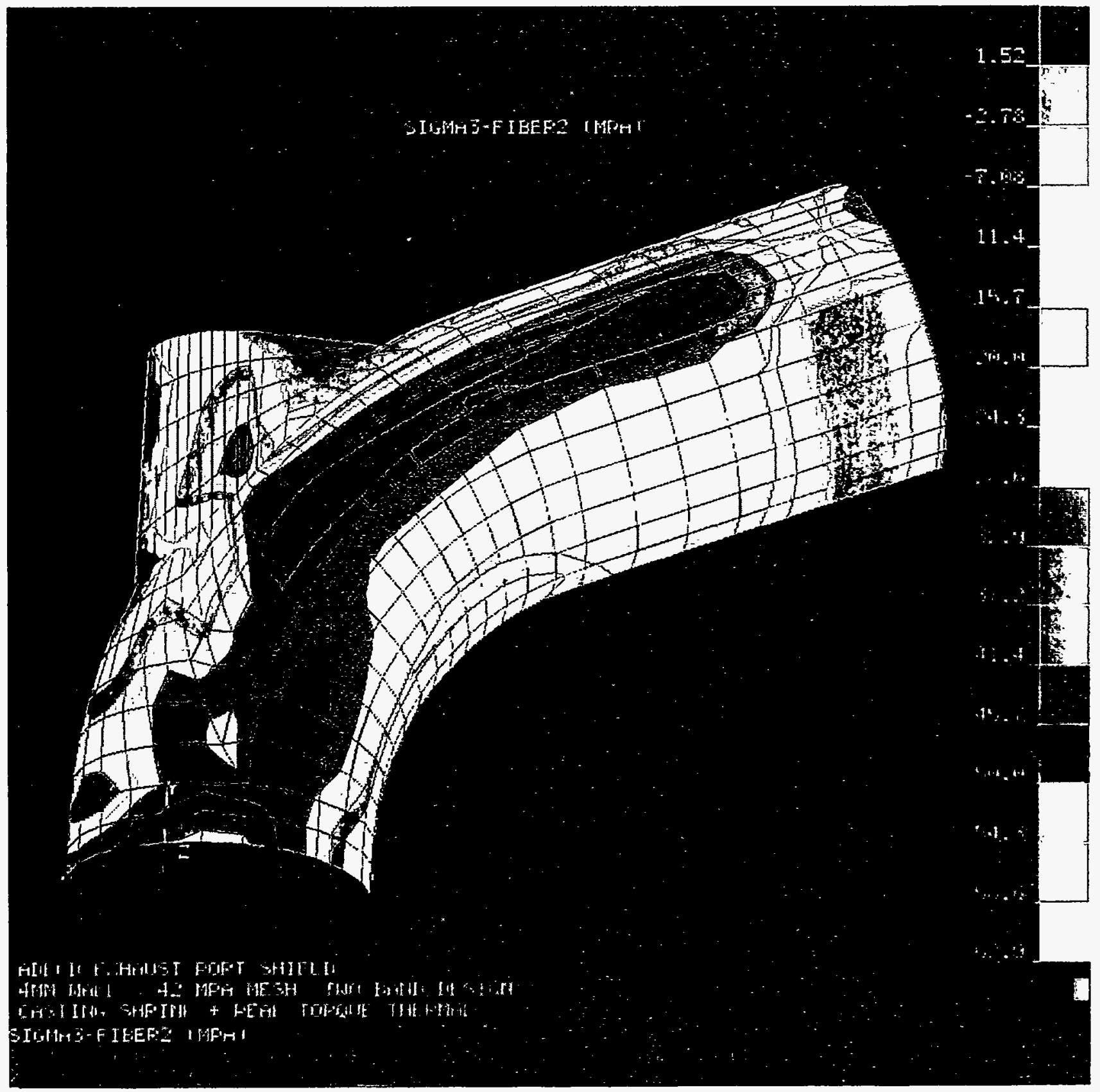

Figure 90: Silicon Nitride Port Shield Temperature Distribution (4mm Wall - Two Band Design - 42 MPa Mesh) Casting Shrink + Thermal Load - Min Principle Stress Inner Surface 

bands cool the ends of the port. The combined thermal and casting shrink stress distributions, Figures 87 thru 90 , are very similar to the shrink only case with the exception of the stress magnitudes. The addition of the thermal loading increases the maximum principal stress (sigma1) to $53.3 \mathrm{MPa}$. As shown in Figure 88, the location of the maximum tensile stress remains in the valve boss on the inside of the port. In spite of the increase due to thermal loading the POS remains very high at 1.000 .

In summary, the success of the ADECD ceramic port shield depended greatly on the use of a very compliant material for the load carrying wire mesh bands. Under simulated casting shrink and peak torque thermal loads the $4 \mathrm{~mm}$ silicon nitride shield with two $42 \mathrm{MPa}$ wire mesh bands is predicted to experience very low tensile stresses and a very high probability of survival. Although the analysis does not account for uneven shrinkage of the casting or thermal shock of the ceramic by molten metal, the proposed silicon nitride two bank port shield design appears to be viable for use in the ADECD cylinder head.

\section{Recommendations}

1. The $4 \mathrm{~mm}$ wall silicon nitride port shield with low modulus wire bands should be incorporated in the ADECD cylinder head.

2. The exhaust port shields on the ADECD demonstration engine should be instrumented in order to obtain temperature data for analysis validation. If scrap cylinder heads are available, experimental stress analysis should be performed on the port to verify casting shrink loads.
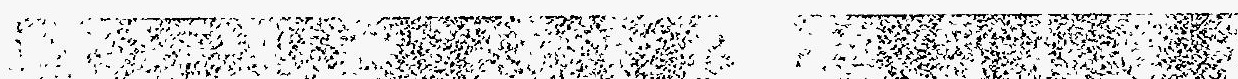


\section{Ceramic Port Design \#1}

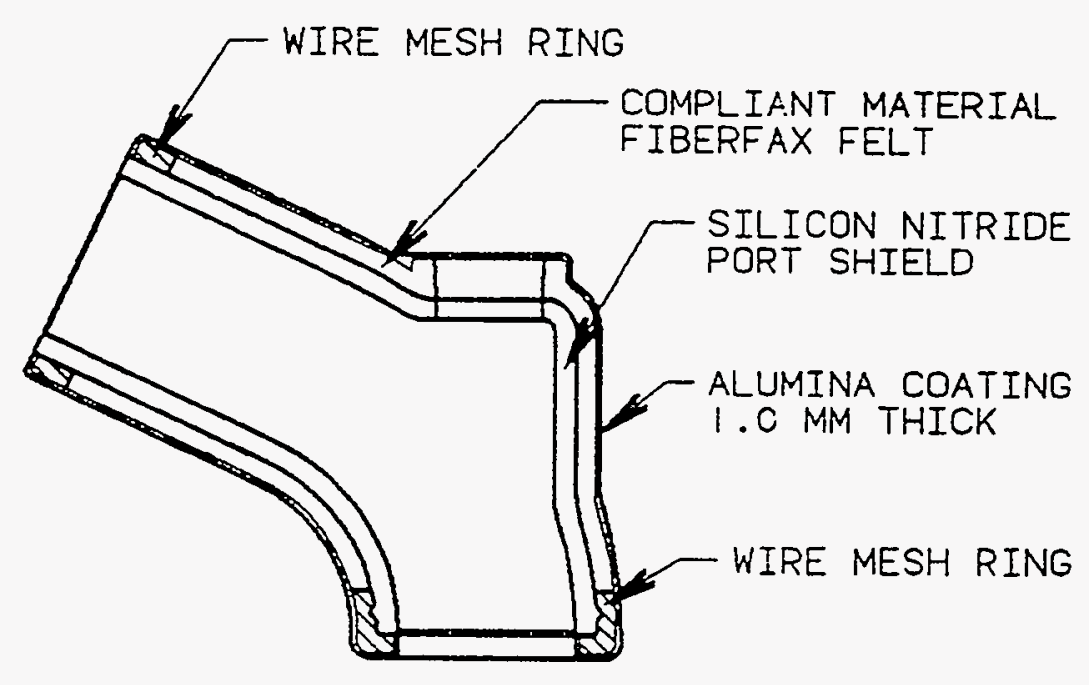

Ceramic Port Design \#2

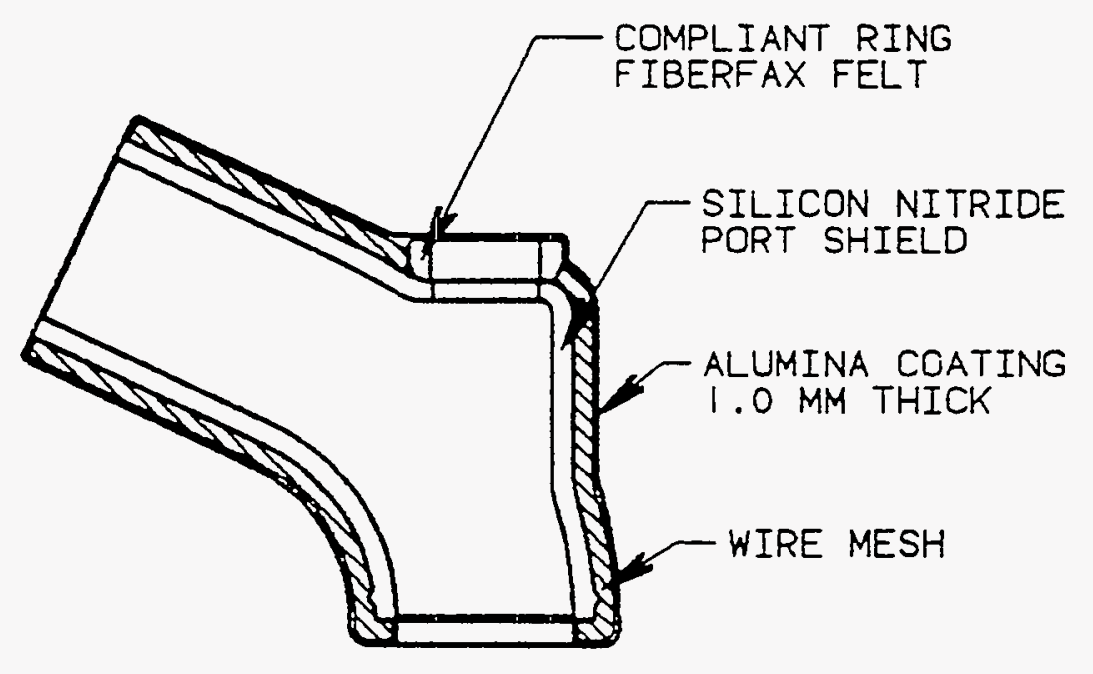

Figure 91: Ceramic Port Designs 


\section{APPENDIX D}

\section{CYLINDER KIT TRIBOLOGY TEST FIXTURE RESULTS}

Testing on the CKTTF was conducted to evaluate the potential of a ceramic piston ring and vapor phase lubrication. The design of this simulation fixture is discussed in Section 4.3.

The first set of tests, the Phase 1 investigation, utilized low ring loads and production cylinder liners. This pair was lubricated with vaporized TCP at concentrations between 0.0 and 0.11 mole percent. The second set of tests, Phase 2, incorporated elevated ring loading and finer finish ground cylinder liners. TCP and two additional phosphate ester lubricants with a mole concentration range of 0.0 to 0.17 percent were evaluated. The test conditions and test specimen descriptions are summarized in Tables 28 and 29. The average liner temperatures of approximately $350^{\circ} \mathrm{C}$ were limited by fixture shaft seal considerations. A ceramic ring coating and ferrous liner combination were selected to simulate the proposed LHR engine hardware. Ring wear was evaluated through weight loss measurements. Qualitative ring and liner performance was investigated with pre- and post-test surface topography.

\section{Test Results}

The Phase 1 piston ring wear results for the TCP lubricated tests are shown in Figure 92, expressed as a nondimensional wear coefficient, $k$, is given as:

$$
k=\frac{V H}{X L}
$$

where $V=$ worn volume, $H=$ hardness, $X=$ distance slid and $L=$ normal load. The results given in Figure 92 indicate that ring wear varies with TCP vapor concentration. When the concentration is less than approximately 0.05 mole percent lubricant deposition is apparently insufficient and wear increases. However, when the TCP concentration exceeds 0.1 mole percent, wear also begins to accelerate. This phenomenon is thought to result from excess lubricant deposition which results in the entrapment of wear debris at the rubbing surface and the generation of three body wear. The trend observed in Figure 92, wear passing through a minima with increasing vapor concentration, is similar to the results of four-ball wear tests on TCP lubricated surfaces. 
TABLE 28

TEST HARDWARE

\begin{tabular}{|l|l|l|}
\hline Ring & \multicolumn{1}{|c|}{ PHASE 1 } & \multicolumn{1}{c|}{ PHASE 2 } \\
+ Running Surface & $\begin{array}{l}\text { Plasma Sprayed } \\
\text { Alumina-Titania } \\
\text { (Lapped) }\end{array}$ & $\begin{array}{l}\text { Plasma Sprayed } \\
\text { Alumina-Titania } \\
\text { (Lapped) }\end{array}$ \\
+ Base Mat'1 & Iron & Iron \\
\hline $\begin{array}{l}\text { Liner } \\
+ \text { Mat'l } \\
+ \text { Finish }\end{array}$ & $\begin{array}{l}\text { Iron, } \mathrm{R}_{\mathrm{c}}=40 \\
\text { Production Cross } \\
\text { Hatch Hone } \\
\left(1.0 \mu \mathrm{m} \mathrm{R}_{\mathrm{a}} \mathrm{max}\right)\end{array}$ & $\begin{array}{l}\text { Iron } \mathrm{R}_{\mathrm{c}}=40 \\
\text { Ground } \\
0.15 \mu \mathrm{m} \mathrm{R}_{\mathrm{a}}\end{array}$ \\
\hline
\end{tabular}

TABLE 29

TEST CONDITIONS

\begin{tabular}{|l|c|c|}
\hline & PHASE 1 & PHASE 2 \\
\hline $\begin{array}{l}\text { Ring Load } \\
\text { (Total) }\end{array}$ & $220 \mathrm{~N}$ & $1210 \mathrm{~N}$ \\
\hline $\begin{array}{c}\text { Average Liner } \\
\text { Temperature }\end{array}$ & $334^{\circ} \mathrm{C}$ & $356^{\circ} \mathrm{C}$ \\
\hline Lubricant(s) & TCP $0.0-0.11 \%$ & $\begin{array}{c}\text { TCP } 0.0-0.17 \% \\
\text { TBP } 0.0-0.10 \% \\
\text { DDPP } 0.0-0.10 \%\end{array}$ \\
\hline Carrier Gas & $\begin{array}{c}\text { Nitrogen } \\
\text { Nitrogen }\end{array}$ \\
\hline Test Duration & $45,3 \mathrm{l} / \mathrm{min}$ & $\mathrm{l} / \mathrm{min}$ \\
\hline $\begin{array}{l}\text { Average Sliding } \\
\text { Speed }\end{array}$ & $600 \mathrm{~mm} / \mathrm{sec}$ & $600 \mathrm{~mm} / \mathrm{sec}$ \\
\hline
\end{tabular}




\section{Wear Coefficient $\mathbf{k}$}

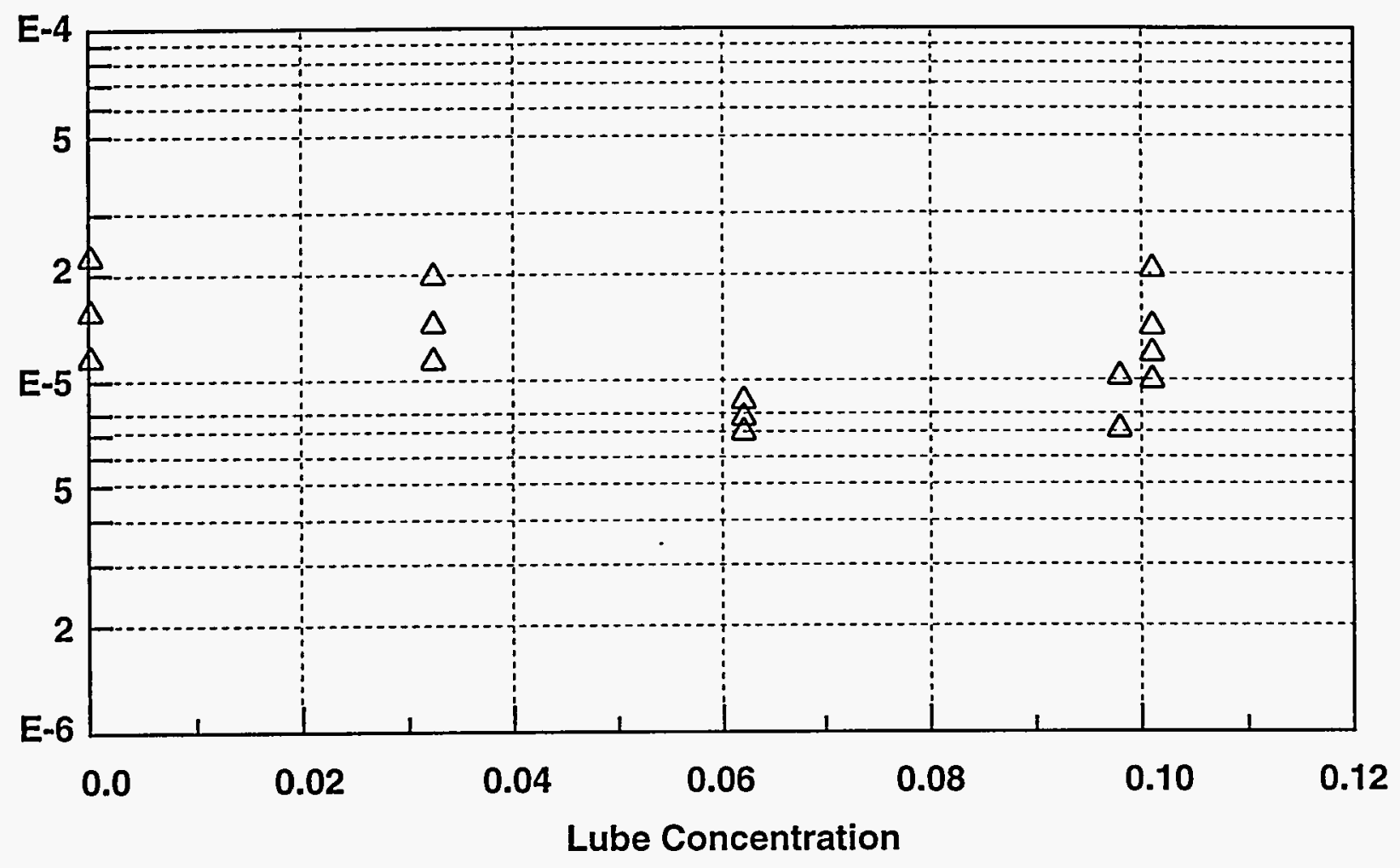

Figure 92: Vapor Phase Lubrication CKTTF Phase 1 Ring Wear Results 
The wear data shown in Figure 92 for the 0.0 percent concentration level is not as high as expected. This effect is attributed to a small amount of oil film that is smeared past the fixture shaft seals and into the hot test chamber. This oil film would itself be vaporized and contribute to ring lubrication. Therefore, the 0.0 percent conditions in the fixture tests would be considered a "no intentional lubrication" (NIL) case, and not as an unlubricated or completely dry interface. The amount of oil transported past the fixture seals is believed to be constant for all tests, thus the NIL tests serve as an effective baseline.

The Phase 1 piston ring surface topography and ring face profiles were measured for both pre-test and post-test conditions. The 0.0 percent case showed severe surface damage and scuff, while the vapor lubricated rings exhibited only a smoothing of the ring surface. The vapor lubricated ring profiles resembled typical examples of a conventionally lubricated engine piston ring. This lends qualitative support to the effectiveness of vapor lubrication at the piston ring-cylinder liner interface.

Chemical analysis of wear debris collected from the CKTTF cylinder liner was performed to investigate the lubrication chemistry of the vapor lubricated ring-liner system. A micrograph taken with a Scanning Electron Microscope (SEM) of the wear debris taken from the CKTTF was compared to a similar TCP vapor lubricated four-ball wear test. The general morphology of both sets of debris was similar, consisting of agglomerated particles less than one micron in size. EDAX analysis of the CKTTF debris showed primarily iron and phosphorous from the lubrication chemistry with traces of ceramic debris from the ring face. Further investigation with the Transmission Electron Microscope (TEM) and Selected Area Diffraction (SAD) showed the presence of crystalline iron phosphate in the CKTTF debris. These results showed that the morphology and the chemical analysis of the wear debris from the CKTTF and the four-ball wear test using steel on ceramic were essentially the same.

Based on Phase 1 of concept test results, the rig test program was extended to include vaporized tri-butyl phosphate (TBP) and diphenyl ditertibutyl phenyl phosphate (DDPP) in addition to TCP. During these tests the ring loading was increased, and the ring geometry shown in Phase 2 of Table 28 was employed. In these tests the apparent unit loading of the piston ring was maintained at a pressure of $1.48 \mathrm{MPa}$, which was close to the BMEP of a high output diesel engine. In addition, the cylinder liner surface finish was changed to a ground $(0.15 \mu \mathrm{m})$ finish on the premise that the production honed liner surface was optimized for liquid lubrication, and that a smoother surface would give better performance for the VP lubrication conditions.

Ring wear results for the elevated load ring tests using three different phosphate ester lubricants are shown in Figure 93. For these tests the TCP rings show wear coefficients below the 0.0 percent lubrication levels with little sensitivity to concentrations up to 0.17 mole percent. TBP at similar concentrations, resulted in high rates of lubricant deposition, the formation of sludge, and an average ring wear coefficient which was 10 times greater than the TCP tests at 0.1 mole percent. 


\section{Wear Coefficient $k \quad \Delta$ TCP $\bullet$ TBP $\square$ DDPP + NIL}

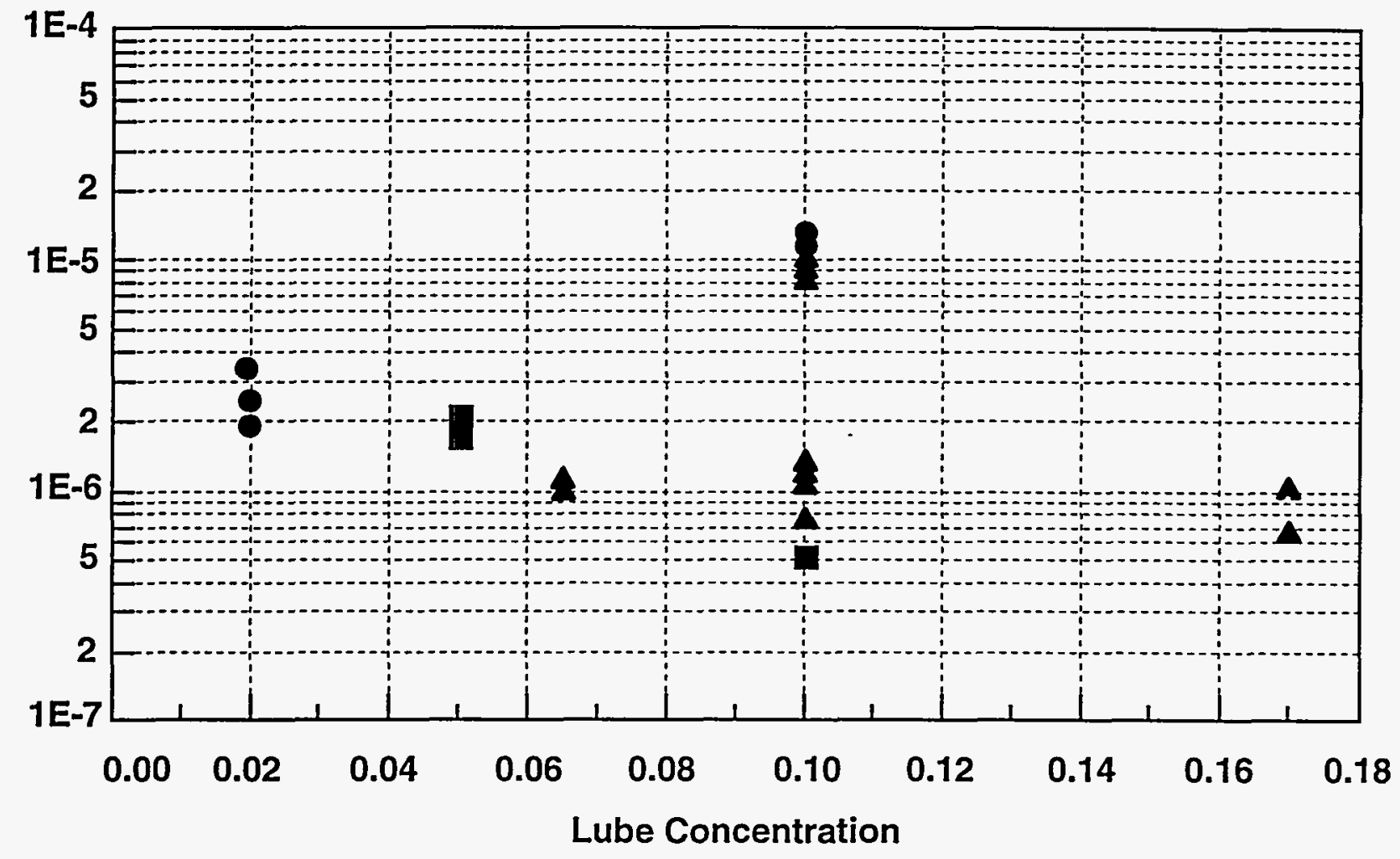

Figure 93: CKTTF Vapor Phase Lubrication Ring Wear Summary 
Laboratory observation of TBP vs. TCP vapor lubricant deposition rates (1) shows TBP deposition to be an order of magnitude greater than TCP for a ferrous substrate at $650^{\circ} \mathrm{C}$. Therefore, while the TBP performance was inferior to TCP at 0.02 and 0.1 mole percent, concentrations below 0.02 may provide rig wear levels comparable to the higher TCP concentrations while avoiding the sludge formation observed in the current tests.

The third lubricant, DDPP, produced an excellent ring wear rate at 0.1 mole percent, but showed an increase in ring wear at 0.05 mole percent compared to the 0.0 mole percent lubrication tests. This trend needs further validation before an explanation is postulated.

The Phase 2 ring results indicate that vapor lubricated ring wear rates are sensitive to hardware configuration. Although the Phase 2 test rings were subjected to bulk ring loads of an order of magnitude higher than the proof of concept rings, the average TCP wear coefficients near $.065-.10$ mole percent were actually seven to eight times lower. Therefore, the net result of an increase in ring loads, a design (component geometry) change, and the application of vaporized TCP lubricant shows lubrication of the high temperature surfaces was maintained and, in fact, actually improved as reflected in the wear coefficients. Separate quantification of the contribution of each factor to ring wear is required for optimum application of vapor lubrication to an actual engine.

With the exception of the .10 mole percent TBP data, liner wear was found to be undetectable with the available conventional measurement techniques during the VP rig tests. Representative axial profile traces of the vapor lubricated liner surface which ran from the untouched surface through the visible wear band were obtained. In the case of the TBP 0.10 mole percent test where deposits were excessive, severe liner surface damage is observed within an obvious wear band. However, the remaining tests showed almost no difference between the worn and unworn surface.

The ring wear rates of this investigation are summarized in Figure 94.

\section{Conclusions}

Several conclusions can be drawn from the rig test data. First, although the number of tests run limits the statistical confidence, vapor lubrication was found to reduce the wear of actual diesel engine components at elevated temperatures compared to no intentional lubrication conditions. Additionally, the ring surface topography of the vapor lubricated piston rings resembles the topography of conventional well lubricated engine rings. Different lubricants exhibit different optimal vapor concentrations. Therefore, the vapor concentration used in the VP lubrication of an actual engine must be controlled to obtain the optimum ring wear rate. The lubrication chemistry found in the VP lubricated ring tests appears to be the same as laboratory four-ball wear tests. Thus, the same lubricating mechanisms and relative performance can be expected for a VP lubricated engine cylinder kit as those observed in basic laboratory wear tests. 
Ring Wear Rate vs. Lubricant
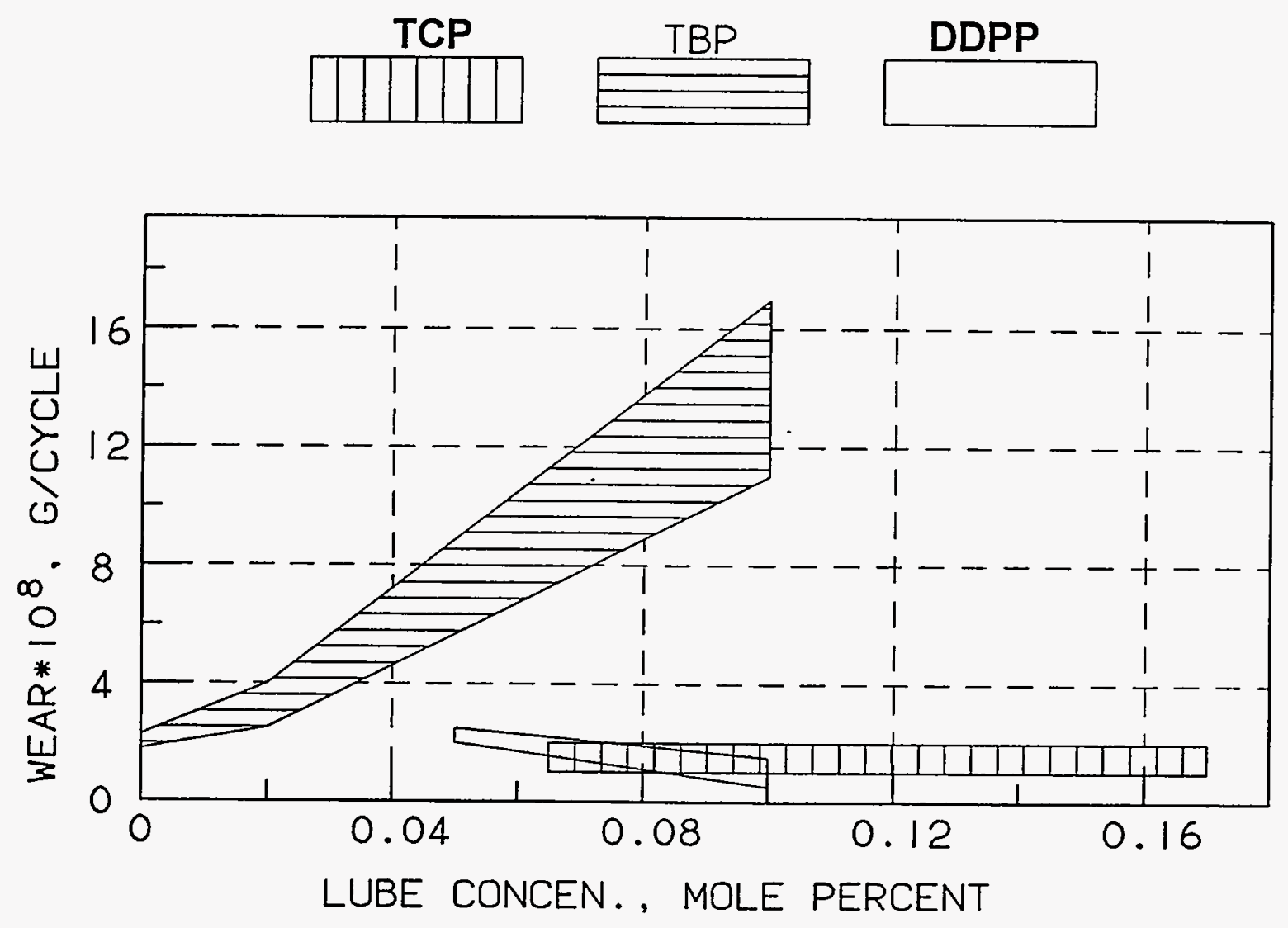

Figure 94: VP Lubrication Evaluation Results 


\section{DISTRIBUTION}

Navistar International 10400 W. North Avenue Melrose Park, IL 60160

Attn: William Lenzi

GM Research Lab

Engine Research Department

Warren, MI 48090-9055

Attn: Library

Caterpillar, Inc.

Technical Center

Bldg. L

P.O. Box 1875

Peoria, IL 61656-1875

Attn: G. L. Waltz

Caterpillar, Inc.

Technical Center

Bldg. E

P.O. Box 1875

Peoria, IL 61656-1875

Attn: D. Biehler

Eaton Corporation

Engine and Research Center

26201 Northwestern Highway

P.O. Box 766

Southfield, MI 48037

Attn: Library

Detroit Diesel Corporation

Speed Code A-7

13400 W. Outer Drive

Detroit, MI 48239-4001

Attn: Manager, Technical Data

Detroit Diesel Corporation

Speed Code A-7

13400 W. Outer Drive

Detroit, MI 48239-4001

Attn: C. Savonen
Energetics

7146 Gateway Drive

Columbia, MD 21046

Attn: S. R. Ventateswaran

Staff Research Engineer

General Motors Research Labs

Warren, MI 48090-9055

Attn: Alex C. Alkidas

Caterpillar, Inc.

Technical Center

Bldg. A

P.O. Box 1875

Peoria, IL 61656-1875

Attn: M. L. Greenhalgh

Caterpillar, Inc.

Engine Division

MOS 15

P.O. Box 1875

Peoria, IL 61656-1875

Attn: J. Sibley

Detroit Diesel Corporation

Speed Code B-16

13400 W. Outer Drive

Detroit, MI 48239-4001

Attn: R. Allran

Detroit Diesel Corporation

Speed Code B-10

13400 W. Outer Drive

Detroit, MI 48239-4001

Attn: D. Merrion

Detroit Diesel Corporation Speed Code A-7

13400 W. Outer Drive

Detroit, MI 48239-4001

Attn: Richard Winsor 
Detroit Diesel Corporation

Speed Code A-7

13400 W. Outer Drive

Detroit, MI 48239-4001

Attn: Nabil Hakim

Detroit Diesel Corporation

Speed Code K-15

13400 W. Outer Drive

Detroit, MI 48239-4001

Attn: Tony Kaushal

The Pentagon

Attn: Dr. Charles Church

Asst. Director of Army Research \& Tech.

Washington, DC 20310

Oak Ridge National Laboratory

Ceramic Tech. for Advanced Heat Engines

Bldg. 4515, M.S. 6066

Oak Ridge, TN 37831-6066

Attn: Dr. Ray Johnson

Oak Ridge National Laboratory

P.O. Box 2009, M.S. 8087

Oak Ridge, TN 37831

Attn: Ronald Graves

Allison Engine Company

P.O. Box 420

Indianapolis, IN 46206-0420

Attn: D. L. Clingman-W5

Deere and Company

Technical Center

3300 River Drive

Moline, IL 61265

Attn: Library

Carborundum Company

1625 Buffalo Avenue

Niagara Falls, NY 14302

Attn: R. Storm
Detroit Diesel Corporation

Speed Code A-7

13400 W. Outer Drive

Detroit, MI 48239-4001

Attn: James C. Hoelzer

Torrington Company

Corporate Research

59 Field Street

Torrington, CT 06790

Attn: Mr. William J. Chmura

Oak Ridge National Laboratory

P.O. Box 2008

Oak Ridge, TN 37831-6069

Attn: E. R. Long, Jr., Bldg. 4515

Oak Ridge National Laboratory

P.O. Box X

Oak Ridge, TN 37831

Attn: R. A. Bradley

Concept Analysis Corporation

Dupont Automotive Development BIdg.

950 Stephenson Highway

Troy, MI 48007-7013

Attn: P. C. Glance

Mueller Associates

1401 South Edgewood Street

Baltimore, MD 21227

Attn: T. Timbario

John Deere and Company

Product Engineering Center

P.O. Box 8000

Waterloo, IA 50704

Attn: Robert Parker, Manager Engine Tech.

Coors Porcelain Company

Director, Technical Operations

Golden, CO 80401

Attn: D. G. Wirth 
PACCAR Inc.

Business Center Building

P.O. Box 1518

Bellevue, WA 98009

Attn: J. M. Dunn, Vice President

Mack Trucks, Inc.

1999 Pennsylvania Avenue

Hagertown, MD 21740

Attn: Chuck Salter

Southwest Research Institute

Engines \& Vehicle Research Div.

Post Office Drawer 28510

6220 Culebra Drive

San Antonio, TX 78284

Attn: Shahed

American Trucking Associations, Inc. 2200 Mill Road

Alexandria, VA 22314

Attn: V. Suski

Adiabatics, Inc.

630 S. Mapleton

Columbus, IN 47201

Attn: R. Kamo, President

U.S. Army Tank Automotive Command and Development Center

Warren, MI 48397-5000

Attn: W. Bryzik (AMSTA-RGR)

U.S. Department of Energy

MS 5G-322/FORS

Office of Transportation Technologies

1000 Independence Avenue., S.W.

Washington, DC 20585

Attn: J. Fairbanks (20 copies)

NAVSEA

1000 Jefferson Davis Highway

Washington, DC 20007

Attn: D. Grohgan
Freightliner Corporation

Research \& Development

4747 N. Channel Avenue

P.O. Box 4849

Portland, OR 97208

Attn: R. Murphy, Director

Southwest Research Institute

Department of Material Sciences

Post Office Drawer 28510

6220 Culebra Drive

San Antonio, TX 78284

Attn: James Lankford

Southwest Research Institute

Engines, Fuel \& Vehicle Research Division

Post Office Drawer 28510

6220 Culebra Drive

San Antonio, TX 78284

Attn: Ed C. Owens

Ricardo North American, Inc.

7850 Grant Street

Burr Ridge, IL 60521-5822

Massachusetts Institute of Technology

Dept. of Mechanical Engineering.

Sloan Laboratory

Cambridge, MA 02139

Attn: Dr. V. Wong, Bldg. 31

NASA Headquarters

Washington, DC 20546

Attn: RP/Neal Nijhawan

(5 copies)

Advanced Product Engineering

GM Technical Center

AES Engineering Bldg.

Warren, MI 48090

Attn: Stanley L. Genslak

NAVSEA

1000 Jefferson Davis Highway

Washington, DC 20007

Attn: Sam Shepard 
David Mann

ARO

P.O. Box 12211

Research Triangle Park, NC 27709

U.S. Maritime Administration

Room 7330, Code MAR-760

4007 th. Street, SW

Washington, DC 20590

Attn: Mr. Frank Crotelli

Morgantown Energy Technology Center

P.O. Box 880

Morgantown, WV 26505

Attn: Mr. Larry K. Carpenter

Chrysler Corporation

P.O. Box 1118

Detroit, MI 48288

Attn: Library

Waukesha Engine Division

Dresser Industries

P.O. Box 379

Waukesha, WI 53167

Attn: Dr. Warren E. Snyder

Massachusetts Institute of Technology

Department of Mechanical Engineering

Cambridge, MA 02139

Attn: Prof. J. B. Heywood, Rm. 3-339

Department of Mechanical Engineering

Carnegie-Mellon University

Pittsburgh, PA 15213-3890

Attn: Professor J. I. Ramos

Argonne National Laboratory

9700 South Cass Avenue

Lemont, IL 60439-4801

Attn: Robert Holtz/CT0331
Combustion Applications Division

Sandia National Laboratories

Livermore, CA 94550

Attn: Dr. Michael Dyer

Schwitzer

6040 West 62 nd Street

P.O. Box 80-B

Indianapolis, IN 46206

Attn: Steve Laymon

University of Illinois

Dept. of Mech. \& Industrial Engineering

144 Mechanical Engineering Bldg.

1206 West Green Street

Urbana, IL 61801

Attn: Prof. Robert Lucht

Electromotive Division

General Motors Corporation

LaGrange, IL 60525

Attn: Library

TRW, Inc.

1455 East 185 Street

Cleveland, $\mathrm{OH} \quad 44110$

Attn: Dr. Roger R. Wills

Association of American Railroads Energy and Special Studies Div.

50 F. Street, N.W.

Washington, DC 20001

Attn: Richard Cataldi

Argonne National Laboratory

9700 South Cass Avenue

Building 362-2B

Lemont, IL 60439-4801

Attn: Robert P. Larsen

E. W. Gregory II

9404 Park Hunt Court

Springfield, VA 22153 
General Electric Company

2901 East Lake Road

Erie, PA 16531

Attn: Dr. Paul L. Flynn

Engineered Coatings, Inc.

65 Inwood Road

Rocky Hill, CT 06067

Attn: R. C. Novak

Teledyne Continental

76 Getty Street

Muskegon, MI 49442

Attn: Library

Norton Company

1 Bond Street

Worcester, MA 01606

Attn: Dr. James G. Hannoosh

Michigan Technological University Mechanical Engineering Dept.

Houghton, MI 49931

Attn: Prof. Oner Arici

Cummins Engine Company

Mail Code 50183

P.O. Box 3005

Columbus, IN 47002-3005

Attn: Jim Patten, 50183

Cummins Engine Company

Mail Code 50193

P.O. Box 3005

Columbus, IN 47202-3005

Attn: Dean H. Reichenbach

Cummins Engine Company

Mail Code 50160

P.O. Box 3005

Columbus, IN 47202-3005

Attn: John Wall
The University of Wisconsin-Madison

Engineering Research Bldg.

1500 Johnson Drive

Madison, WI 53706

Attn: Prof. Rolf Reitz

U.S. Department of Commerce

National Institute of Standards and Technology

RM. A-263/Bldg. 223

Gaithersburg, MD 20899

Attn: Stephen M. Hsu

Chief, Ceramics Division

Norton Company

Goddard Road

Northboro, MA 01532-1545

Attn: Joseph N. Panzarino, PhD

Michigan State University

Mechanical Engineering Dept.

2857 Jolly Road

Okemos, MI 48864

Attn: Dr. Harold J. Schock

Cummins Engine Company

Mail Code 50183

P.O. Box 3005

Columbus, IN 47202-3005

Attn: Tom Yonushonis

Cummins Engine Company

Mail Code 50180

P.O. Box 3005

Columbus, IN 47202-3005

Attn: Roy J. Primus

Cummins Engine Company

Mail Code 50181

P.O. Box 3005

Columbus, IN 47202-3005

Attn: Pat Flynn

Electromotive Division

General Motors Corporation

LaGrange, IL 60525

Attn: Mr. D. Scott 
Electromotive Division

General Motors Corporation

LaGrange, IL 60525

Attn: Mr. T. Uzkan

Garrett Automotive Group

3201 West Lomita Blvd., MS VIZ

Torrance, CA 90505-5064

Attn: Keith Rochford

Mr. Alex Lawson

Ortech International

2395 Speakman Drive

Mississauga, Ontario

CANADA L5K $1 \mathrm{~B} 3$

University of Michigan

College of Engineering

Dept. of Mechanical Eng.

325 W. E. Lay Automotive Laboratory

Ann Arbor, MI 48109-2121

Attn: Prof. Dennis N. Assanis
Electromotive Division

General Motors Corporation

LaGrange, IL 60525

Attn: D. E. Brann

Brunswick Technetics

2000 Brunswick Lane

Deland, FL 32724-9990

Attn: David M. Day

R. A. Harmon

25 Schalren Drive

Latham, NY 12110

NASA Lewis Research Center

21000 Brookpark Road

Cleveland, $\mathrm{OH} 44135$

Attn: Coordination Office, MS 60-1 (9 copies)

J. Wood, MS 86-6 (15 copies)

C. Delacorte, MS 23-2

R. Miller, MS 24-1

W. Brindley, MS 24-1

M. Valco, MS 86-6

C. Ball, MS 3-8

R. Bill, MS 77-12

G. Bobula, MS 77-12

F. Berkopec, MS 86-6

Chief, Propulsion Systems, Division, MS 86-1

CASI

800 Elkridge Landing Road

Lithicum Heights, MD 21090-2934

( 25 copies)

Lemont, IL 60439-4801

Attn: F. A. Nichols

U.S. DOE - TIC

P.O. Box 62

Oak Ridge, TN 37830

(Note: Send 2 copies with Form RA-426) 
Public reporting burden for this collection of information is estimated to average 1 hour per response, including the time for reviewing instructions, searching existing data sources, gathering and maIntalning the data needed, and completing and reviewing the collection of information. Send comments regarding this burden estimate or any other aspect of this collection of Information, including suggestions tor reducing this burden, to Washington Headquarters Services, Directorate for information Operations and Reports, 1215 Jefferson Davis Highway, Suite 1204, Arlington, VA 22202-4302, and to the Office of Management and Budget, Paperwork Reduction Project (0704-0188), Washington, DC 20503.
1. AGENCY USE ONLY (Leave blank)
2. REPORT DATE
3. REPORT TYPE AND DATES COVERED
Final Contractor Report

4. TITLE AND SUBTITLE

5. FUNDING NUMBERS

Advanced Diesel Engine Component Development Program Final ReportTasks 4-14

6. AUTHOR(S)

WU-778-34-2A

DEN3-329

Tony S. Kaushal and Karen E. Weber

Detroit Diesel Corporation

13400 Outer Drive West

Detroit, Michigan 48237-4001

8. PERFORMING ORGANIZATION

REPORT NUMBER

E-8198

9. SPONSORING/MONITORING AGENCY NAME(S) AND ADDRESS(ES)

10. SPONSORING/MONITORING AGENCY REPORT NUMBER

National Aeronautics and Space Administration

Lewis Research Center

Cleveland, Ohio 44135-3191

NASA CR-191203

11. SUPPLEMENTARY NOTES

Project Manager, James C. Wood, Advanced Propulsion Applications Office, NASA Lewis Research Center, organization code $2710,(216)$ 433-3419.

12a. DISTRIBUTIONAVAILABILTYY STATEMENT

12b. DISTRIBUTION CODE

Unclassified - Unlimited

DOE Category UC-96

13. ABSTRACT (Maximum 200 words)

This report summarizes the Advanced Diesel Engine Component Development (ADECD) Program to develop and demonstrate critical technology needed to advance the heavy-duty low heat rejection engine concept. Major development activities reported are the design, analysis and fabrication of monolithic ceramic components, vapor phase and solid film lubrication, electrohydraulic valve actuation and high pressure common rail injection. An advanced single cylinder test bed was fabricated as a laboratory tool in studying these advanced technologies. This test bed simulates the reciprocator for a system having no cooling system, turbo compounding, Rankine bottoming cycle, common rail injection, and variable valve actuation to achieve fuel consumption of $160 \mathrm{~g} / \mathrm{kW}-\mathrm{hr}(.26 \mathrm{lb} / \mathrm{hp}-\mathrm{hr})$. The advanced concepts were successfully integrated into the test engine. All ceramic components met their functional and reliability requirements. The firedeck, cast-in-place ports, valves, valve guides, piston cap, and piston ring were made from silicon nitride. Breakthroughs required to implement a "ceramic" engine included the fabrication of air-gap cylinder heads, elimination of compression gaskets, machining of ceramic valve seats within the ceramic firedeck, fabrication of cast-in-place ceramic port liners, implementation of vapor phase lubrication, and elimination of the engine coolant system. Silicon nitride valves were successfully developed to meet several production abuse test requirements and incorporated into the test bed with a ceramic valve guide and solid film lubrication. The ADECD cylinder head features ceramic port shields to increase insulation and exhaust energy recovery. The combustion chamber includes a ceramic firedeck and piston cap. The tribological challenge posed by top ring reversal temperatures of $550^{\circ} \mathrm{C}$ was met through the development of vapor phase lubrication using tricresyl phosphate at the ring-liner interface. A solenoid-controlled, variable valve actuation system that eliminated the conventional camshaft was demonstrated on the test bed. High pressure fuel injection via a common rail system was also developed to reduce particulate emissions.

14. SUBJECT TERMS

Diesel engine; Heavy duty trucks; Low heat rejection; Advanced technology;

Ceramics; Tribology

\begin{tabular}{|c|c|}
\hline $\begin{array}{c}\text { 17. SECURTY CLASSIFICATION } \\
\text { OF REPORT } \\
\text { Unclassified }\end{array}$ & $\begin{array}{c}\text { 18. SECURITY CLASSIFICATION } \\
\text { OF THIS PAGE } \\
\text { Unclassified }\end{array}$ \\
\hline
\end{tabular}

NSN 7540-01-280-5500

19. SECURTYY CLASSIFICATION OF ABSTRACT Unclassified

\begin{tabular}{|c|}
$\begin{array}{c}\text { 15. NUMBER OF PAGES } \\
190\end{array}$ \\
\hline $\begin{array}{c}\text { 16. PRICE CODE } \\
\text { AO9 }\end{array}$ \\
20. LIMTTATION OF ABSTRACT \\
UL
\end{tabular}

Standard Form 298 (Rev. 2-89) Prescribed by ANSI Std. Z39-18 298-102 